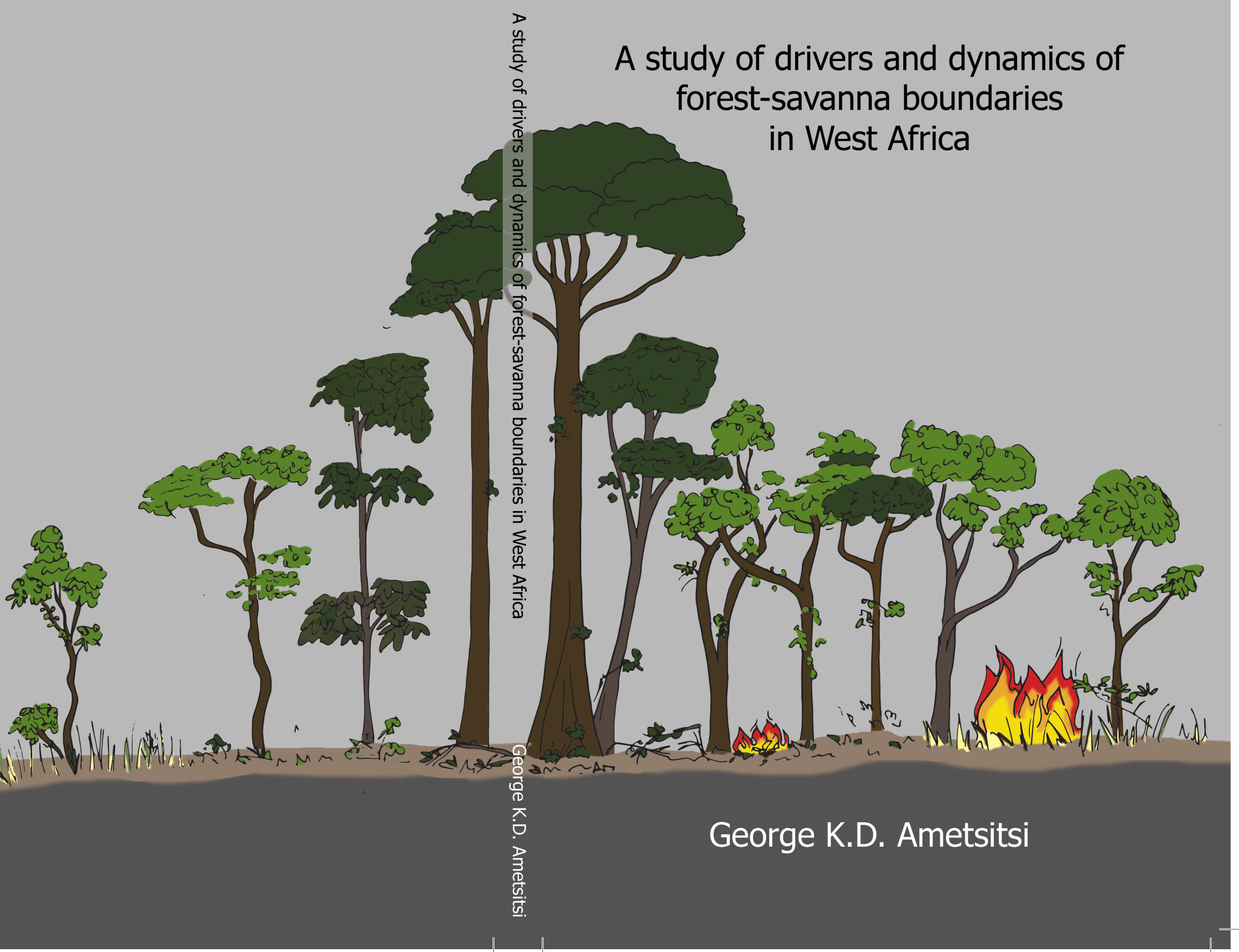




\section{Propositions}

1. Soil, climate, and fire all interact to create boundaries and transitions in the forest savanna landscape. (this thesis)

2. The classic perception of a simple forest vs. savanna dichotomy of tree species controlled by fire in the landscape cannot be sustained.

(this thesis)

3. Conservation of large tracts of land for biodiversity without making provision for the livelihoods of the fringe communities cannot be successful.

4. For countries challenged with poor governance, corruption kills more people than COVID-19.

5. To understand the PhD journey with supervisors, imagine driving your parents home after you have just passed your driving test.

6. Substituting traditional taboos of conservation with modern environmental policies without involving local communities is bound to fail.

Propositions belonging to the thesis, entitled:

A study of drivers and dynamics of forest-savanna boundaries in West Africa

George K. D. Ametsitsi

Wageningen, 26 March 2021 


\section{A study of drivers and dynamics of forest- savanna boundaries in West Africa}

George Kwaku Duku Ametsitsi 


\section{Thesis committee}

\section{Promotor}

Prof. Dr D. Kleijn

Professor of Plant Ecology and Nature Conservation

Wageningen University \& Research

\section{Co-promotors}

Dr E.M. Veenendaal

Associate Professor, Plant Ecology and Nature Conservation Group

Wageningen University \& Research

Dr P. Vergeer

Associate Professor, Plant Ecology and Nature Conservation Group

Wageningen University \& Research

\section{Other members}

Prof. Dr. P.A. Zuidema, Wageningen University \& Research

Prof. Dr. J.H.C. Cornelissen, VU University Amsterdam

Prof. Dr. R.A.G. Boot, Utrecht University

Dr M. Te Beest, Utrecht University

This research was conducted under the auspices of the Research School for Socio-Economic and Natural Sciences of the Environment (SENSE) 


\title{
A study of drivers and dynamics of forest- savanna boundaries in West Africa
}

George Kwaku Duku Ametsitsi

\author{
Thesis \\ submitted in fulfilment of the requirements for the degree of doctor \\ at Wageningen University \\ by the authority of the Rector Magnificus, \\ Prof. Dr A.P.J. Mol, \\ in the presence of the \\ Thesis Committee appointed by the Academic Board \\ to be defended in public \\ on Friday 26 March \\ at $1: 30 \mathrm{pm}$ in the Aula.
}


George Kwaku Duku Ametsitsi

A study of drivers and dynamics of forest-savanna boundaries in West Africa 217 pages.

PhD thesis, Wageningen University, Wageningen, NL (2021)

With references, with summaries in English and Dutch

ISBN: ISBN: 978-94-6395-684-0

DOI: https://doi.org/10.18174/539002 


\section{Contents}

Chapter 1: General introduction 7

Chapter 2: Extending the baseline of tropical dry forest loss in Ghana

(1984-2015) reveals drivers of major deforestation inside

a protected area

Chapter 3: Fixed or Mixed? Variation in tree functional types and vegetation structure in a forest-savanna ecotone in West Africa

Chapter 4: Sharp transitions with soft edges? Three years of field observations reveal multiple fire-mediated feedbacks in a forest-savanna ecotone in West Africa

Chapter 5: Fall leaves fall! Leaf shedding of tree species in a forest-savanna ecotone in West Africa depends on individual species, tree functional type and stand structure

Chapter 6: Variation in vegetation cover and seedling performance of tree species in a forest-savanna-ecotone

Chapter 7: General discussion

References

Summary

Samenvatting

Acknowledgements

Short biography

Selected publications 


\section{Chapter 1}

General introduction 
Chapter 1

\section{Vegetation (Variation) in Forest-Savanna Ecotone}

Forest and savanna are the predominant biomes of the tropical regions of the world and constitute about 35\% of the land surface of the earth (Grace et al. 2006). The resulting interface between these productive biomes constitutes an ecotone which is the most prevalent transition in the tropics (Oliveras \& Malhi, 2016; Torello-Raventos et al., 2013). Tropical savannas are typically dominated by fire-tolerant species that exhibit open canopy structure. Herbivory and fire are important drivers of savanna vegetation composition (Hovestadt et al., 1999; Van Langevelde et al., 2003). The crown size and form, as well as low leaf density, allow light penetrating the canopy to support grass growth underneath even though tree densities could be high. On the other hand, tropical forests characteristically have closed-canopy comprising high diversity of fire-sensitive woody species which limit frequent fire penetration due to understorey grass exclusion and fuel load reduction (Torello-Raventos et al., 2013; Ratnam et al., 2011).

Both Forest (closed-canopy) and savanna (open-canopy) could occur in close proximity under similar climatic conditions when rainfall is moderate (Oliveras \& Malhi, 2016) and constitute an area where processes may cause the transition of one biome to the other in the opposite way (Furley, 1999). Although extensive research has been carried out on forest and savanna as distinct biomes in the past, forest-savanna transitions did not receive equal attention because most specialists considered them as being either mismanaged forest areas (Clayton, 1958; Eriksson et al., 2002) or an intermediate stage in gradual forest degradation towards savanna (Ratnam et al., 2011).

Transitions from one vegetation type to the other are often considered to be the consequence of changing fire effects on the canopy cover due to differences in canopy closure with a fire-quenching threshold at around $50 \%$ projected crown cover which are considered to result in contrasting pyrogenic (open tree cover) and non-pyrogenic (closed tree cover) biomes (Hennenberg et al., 2006; Pellegrini et al., 2016; Ratnam et al., 2011; Figure 1.1). This transition results in an ecotone with species from both vegetation types which can be abrupt defining a narrow transition or forming a gentle not clearly distinguishable boundary (Nangendo, 2005), 
hereafter called soft edge. A gradual change in species composition including patches from both vegetation types in the boundary constitutes a continuum (Forman \& Godron, 1986). Transitions are thought to be sharp and modulated by fire mediated feedbacks.

Forest degradation and woody encroachment could occur concurrently in the forestsavanna transition zone due to the action of intricate anthropogenic and biophysical drivers modulating these biomes (Janssen et al., 2018). Generally, routine or persistent fire limits forest expansion into woodland even if the soil resources are suitable for forest expansion. However, successful woody encroachment of open woodland or ecosystems globally have been documented (Eldridge et al., 2011; Mitchard \& Flintrop, 2013). Woody encroachment occurs when the anthropogenic disturbances and pressure such as fire, logging and conversion of forest to arable lands are mitigated on soils that support forest growth. Encroachment is further enhanced through carbon fertilization (Lambin et al., 2001; Lloyd et al., 2008; Mitchard et al., 2009).

Dry forests and transitional forests patches are particularly valuable because they may protect diverse genetic resources and extremely important for the socioeconomics of forest fringe communities as a source of livelihood and for supplying ecosystem services (Mitchard et al., 2009; Poulter et al., 2014) such as charcoal, grazing and medicinal herbs. Recent developments in climate change mitigation have heightened the need for scrupulous management of the tropical dry forest and ecotones to assuage the effects of predicted global warming and drying scenarios for West Africa (Boko et al., 2007; Millar et al., 2007). Tropical forests contribute to climate change mitigation by removing net $\mathrm{CO}_{2}$ from the atmosphere and storing it as biomass (Bonan, 2008). In addition, forests are not only critical habitats for biodiversity but may also contain sacred groves of treasured cultural value especially in West Africa. Despite the crucial role of the forest, it is frequently susceptible to direct human disturbances and suffers severe loss even under protection (Hansen et al., 2013; Janssen et al., 2018). 
Chapter 1

\section{Determinants of vegetation structure and function}

Climate

In the literature on forest-savanna ecotone, the relative importance of climate, fire, hydrology, herbivory and soil characteristics has been subject to considerable discussion (Tinley, 1982; Hopkins, 1992; Ruggiero et al., 2002; Hirota et al., 2010; Good \& Caylor, 2011; Hoffman et al., 2012; Veenendaal et al., 2015). Favourable climate is essential for the development of closedcanopy vegetation. In mesic regions of the tropics where moisture is limited, drier conditions alone may not allow savanna species to develop to canopy closure even if fire is excluded for decades (Sankaran et al., 2005). This condition is worsened by fire which may prevent or inhibit plant growth (Bond et al., 2003; Higgins et al., 2007). The forest biome is contingent on adequate moisture availability and distribution. It has been suggested that a mean annual precipitation (MAP) above $650 \mathrm{~mm}$ is capable of sustaining canopy closure when fire is excluded for a considerable time. Potentially, closed-canopy forest may be derived from open woodlands in many parts of Africa if managed (Sankaran et al., 2005). In general rainfall and seasonality determines vegetation distribution hence closed-canopy vegetation is located in wetter regions while open canopy vegetation is selected for in the drier regions (Lloyd et al., 2008). The most interesting is the intermediate MAP (1000-2000 mm p.a.) which comprise both forest and savanna patches in mosaics (Staver et al., 2011) depending on other environmental drivers (Veenendaal et al., 1996; Ametsitsi et al., 2020).

\section{Fire dynamics}

Fire is critically associated with recruitment barriers, growth and development challenges of woody species among other environmental drivers in the savannas of the world (Bond, 2008; Staver et al., 2011). And among the multiple factors that interact to determine the distribution of savanna and forest, fire has gained prominence (Hoffmann et al., 2012a). More recently, literature has emerged that offers alternate view about fire as the predominant factor determining vegetation structure in 
the tropical regions of the world (Lehmann et al., 2011; Murphy \& Bowman, 2012; Dantas et al., 2015). In West Africa, fire is considered an important modulator of vegetation function and structure (Salzmann, 2000; Salzmann et al., 2002; White, 1983). Fire behaviour varies across the forest and savanna landscape due to topographical differences and fuel type and quality (Wells, 1965; Stott, 2000). Apart from the microclimate, high wind speed may generate catastrophic firestorms which may be unprecedented (Bradstock et al., 2010) and destructive. When woody plants are subjected to routine pyrogenic disturbance, they develop traits to adapt to the conditions. Plants may adapt to frequent fire disturbance through resource allocation to root as seedlings (Boonman et al., 2020; Issifu et al., 2019) and bark thickness for trees (Paine et al., 2010; Pausas, 2015; Pinard \& Huffman, 1997). Evidence of fire exclusion experiment and rapid woody vegetation recovery in Africa is seen in extended experiments conducted in Ghana (Swaine et al., 1992), Burkina Faso (Menaut, 1977), and Ivory Coast (Vauttoux, 1976; Louppe et al., 1995).

Soil

Although fire is very important and reduces the canopy structure of vegetation, fire effect alone is not adequate to define the vegetation types often observed. It is proposed that climate and soil factors predominantly determine the vegetation structure (Lloyd et al., 2008; Lloyd \& Veenendaal, 2016; Veenendaal et al., 2015; 2018). Edaphic properties have long been recognized as important drivers of the distribution and structure of tropical woody vegetation types (Coetzee et al., 1976; Dowling et al., 1986; Goodland \& Pollard, 1973; Trapnell et al., 1950). Good quality soil is required for species composition and structure as well as for survival and growth. Soil texture, moisture and depth of the profile determines tropical woody vegetation distribution and structure (Keay, 1960; San Jose \& Farinas, 1983; Veenendaal et al., 1996). Although close canopy vegetation or forests may exist on savanna soils (Bond, 2010; Gray \& Bond, 2015), forest soils are usually more fertile than savanna soils under similar climatic conditions (Lloyd et al., 2008; Quesada et al., 2012; Ruggiero et al., 2002). In West African forests, for example, soil nutrients have also been shown to 
Chapter 1

be important as co-determinants of forest vegetation and composition (Swaine, 1996). Generally, deeper and nutrient-rich soil profiles are associated with vegetation structural transitions in woody vegetation. This is supported by the Combined Water and Potassium (CWAK) hypothesis of Lloyd et al. (2015), which suggests that soil water availability and the nutrient potassium can mutually explain vegetation structural transitions in woody vegetation. Opposing views on fire and edaphic factors share a common convergence. However, less premium is put on fire-associated feedbacks than is generally considered to be the case (Veenendaal et al., 2018).

\section{Forest and savanna as Alternative Stable States}

At intermediate MAP (800-2500 $\mathrm{mm} \mathrm{y}-1)$ regimes in the tropics or even lower with identical environmental conditions (climate/edaphic), both closed-canopy vegetation and open woodland could co-exist (Oliveras \& Malhi, 2016). The forests and the open woodland in these mesic environments are thought to be separated by sharp boundaries instead of smooth transitions. Some researches argue that the two biomes represent alternative stable states modulated by fire-mediated feedbacks and their existence in one state depends upon perturbation (e.g. Fire and severe drought) and history of the community (Hoffmann et al., 2012a; Oliveras \& Malhi, 2016; Veenendaal et al., 2018). In the alternative stable states, return to the previous states may not be possible in the short term. Existence of forests and savannas as alternative stable states could be explained by firemediated feedbacks with the red loop in Fig 1.1.

Generally, the closed canopy ecosystem does not permit adequate light underneath to sustain growth of light-demanding grasses which is the main fuel load. Inadequate fuel load and moist microclimate created by shading suppress fire frequency and intensity (Fig 1.1). Thus, forest ecosystems are non-pyrogenic in contrast to open woodland which contains the bulk of grass biomass to sustain fire. Evidence on the ground, however, suggest that fire incursion in the closedcanopy forests which are present as mosaics in the forest-savanna transition is a regular phenomenon (Ametsitsi et al. 2020; Goetze et al., 2006). Regular fire incursion in the forests selects 
for species leading to specific floristically distinguished plant communities. Dry semi-deciduous zone (Fire zone) is an example of such evolutionary adapted community to fire in West Africa which was classified based on distinct woody species (Hall \& Swaine, 1976; Swaine, 1992). These species exhibited adaptation strategies to their dynamic environment which is supported by the long length of the palynological record of such communities (Hamilton \& Taylor 1991, Maley 1996). Even in the absence of grass biomass, senesced leaves or tree leaf litter depending on deciduousness of the trees could constitute adequate fuel load to sustain fire in the dry forest patches of the ecotones. Litter fire in a forest-savanna ecotone is a major driver of surface fire regimes and could be driven for several kilometres (Cochrane \& Laurance, 2002) by wind as observed in the lowland rain forest in Brazil.

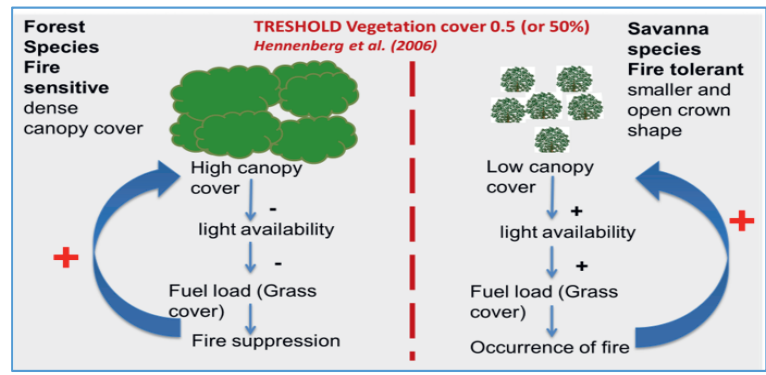

(Source: Hoffmann et al. 2012,)

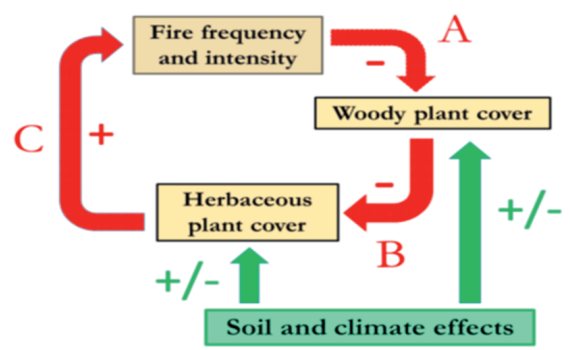

(Source: Veenendaal et al. 2018)

Figure 1.1 Conceptual framework showing a pyrogenic differentiation between forest and savanna (left) and typical roles of soil, climate and fire as factors shaping tropical vegetation structure. As depicted on the right side of the diagram, typical vegetation structure is determined by soil and climate effects however, with fire-mediated feedbacks (red arrows) possibly predominate these impacts. Forming the feedback loop are; (A) frequent and/severe fires inbibiting the establishment of new woody plant growth, (B) herbaceous plant cover predominates as a woody plant cover reduces and $(C)$ indicates an increased likelihood and/ or severity of fire as result of increased fuel load from herbaceous biomass.

The vegetation patches of the forest-savanna ecotones are not only separated into pyrogenic and non-pyrogenic systems but biomes that are not unstable and therefore rapidly 
Chapter 1

transforming from forest to savanna or vice versa when disturbed above a threshold; commonly a shift in fire regime (Oliveras \& Malhi, 2016; Pellegrini et al., 2016). However, many forest-savanna ecotones have been reported as stable even at decadal timescales (Cuni-Sanchez et al., 2016; Goetze et al., 2006; Sobey, 1978; Ametsitsi et al., 2020).

\section{Canopy effect on species recruitment}

The amount of light penetrating vegetation cover determines understorey vegetation. Vegetation cover variation does not only suppress fire and influence its behaviour but also plays an important role in seedling establishment (Bowman 2000; Cardoso et al., 2016; Gignoux et al., 2009; Hoffmann et al., 2012a) which is further selected for by factors such as irradiance, soil moisture and soil fertility (Cuni-Sanchez et al., 2016; Ruggiero et al., 2002; Saiz et al., 2012; Veenendaal et al., 1996a, 1996b). Forest and savanna species may possess varied trait attributes for survival in open pyrogenic savannas and closed-canopy forests and with fire behaviour able to determine the transition's location and dynamics (Oliveras \& Malhi, 2016).

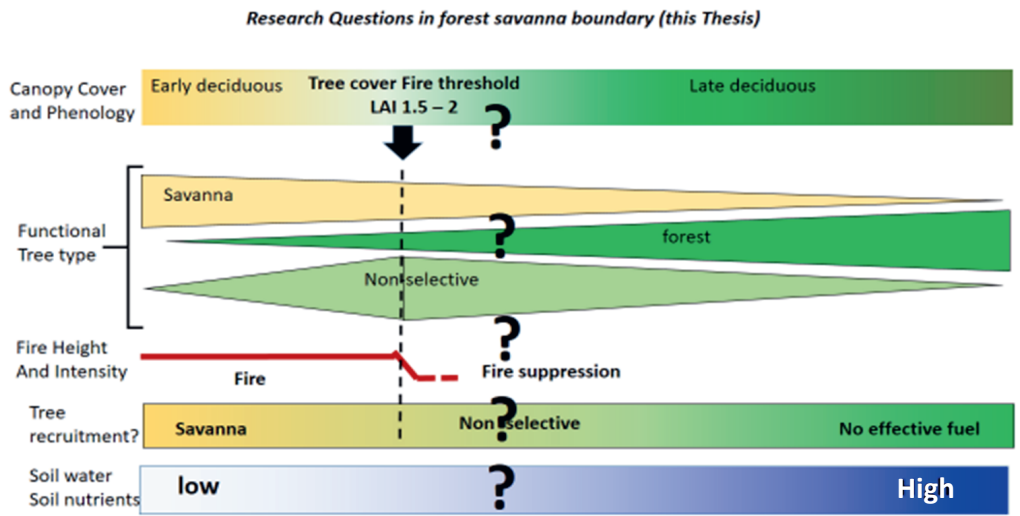

Figure 1.2. Conceptual framework to determine tree cover fire threshold, tree functional types, fire intensity and frequency, soil water resources and role of deciduous trees in the distribution of vegetation types in a forest-savanna ecotone. 
Forest advancement into savanna may be facilitated by low-light conditions which limit performance of savanna species (Armani et al., 2018; Bowman, 2000; Cardoso et al., 2016; Hoffmann et al., 2004; Ruggiero et al., 2002) but enhances forest species.

Many studies that discuss forest-savanna transitions discuss them in context of systems that operate next to each other and are divided by sharp boundaries, an idea that was first triggered by work of Hennenberg et al. (2006) that shows the quenching of fire by canopies. There is also copious literature that suggests that forests do burn which implies there should be forest fire in transitional forests (Stott 2000), however, information on fuel characteristics and types that burn in the dry forest is limited. In addition, the role of soil resources, fire and climate in influencing vegetation structure has been heavily debated in the literature and scientific symposia. While plants could adapt to water deficit in the face of climate change in the tropics resulting in environmental forcings, the extent to which anthropogenic fire could influence vegetation is largely unpredictable and depends on vegetation-fire feedbacks.

In this study, I investigate how tree functional types mix and not the dichotomy of just one versus the other and factors that drive these processes at the ecosystem level. I also investigate how soil, climate and fire all interact as drivers to create boundaries and transitions. I observed wildfire and quantified its intensity and frequency to determine its influence on vegetation structure and function and what the variations in stand and species level as well as tree deciduousness mean for the fire behaviour across the landscape. This information is of utmost importance in feeding into vegetation-climate models since the interactions between climate, vegetation and fire can strongly influence the future trajectories of vegetation in Earth system models (Lasslop et al., 2018). In addition, this study contributes knowledge to our understanding of the determinants of forestsavanna vegetation. This furthers our understanding of recruitment barriers and adaptation strategies of trees ranging from forest, non-selective and savanna species. 
Chapter 1

\section{Research objective and questions}

This thesis aims to determine how drivers of vegetation interact to create boundaries and transitions in the forest-savanna transition of West-Africa. (See figure 1.2). To achieve the objective, five main questions were addressed:

(1) How stable are the vegetation patterns in West-African forest-savanna boundaries?

(2) Do tree functional types mix in the landscape?

(3) How does fire penetrate the forest landscape in KSNR if forest burns?

(4) How do tree functional type and stand structure affect the phenology of leaf shedding?

(5) How does canopy variation select for tree species recruitment?

\section{Thesis outline}

This thesis consists of seven chapters. This first chapter provides background information on the importance of tropical savanna and forest biome and the characteristics of the forest-savanna ecotone. It reviews different perceptions on the forest-savanna transition, where tree species are grouped into pyrogenic and non-pyrogenic functional types.

In the second chapter, I assessed the conservation integrity of Kogyae Strict Nature Reserve (KSNR) as a Strict Nature Reserve to determine if vegetation patches are stable or not. Scientists often consider such nature reserves as pristine. We carried out field measurements in dry semideciduous forest and in the adjacent savanna and woodland which were analysed to determine forest cover change from 1994 to 2015.

In the third chapter, I analysed thirty-five $400-\mathrm{m}^{2}$ plots encompassing forest, savanna and intermediate vegetation types in an ecotonal area in Ghana, West Africa to investigate links between 
the vegetation composition in terms of woody PFTs and the vegetation structure in a forestsavanna mosaic. I also tested the hypothesis that savanna and transitional species can co-occur in at least some closed vegetation formations. I investigated long-term changes and fire incidence for different vegetation structural type, testing the hypothesis that many differences in vegetation structure can be simply attributed to variation in soil characteristics.

In the fourth chapter, I conducted a three-year natural fire survey in the forest-savanna ecotone of Ghana, West-Africa, aiming to understand the role of tree cover and tree species composition on fire intensity and expansion. I hypothesized that (1) canopy closure does change fire intensity but does not exclude fire from entering closed dry forest patches in savanna-forest ecotones, and (2) the intensity of fires, and by implication, fire-mediated feedbacks, change under increasing tree cover.

In the fifth chapter, I observed phenological variations of all trees above $10 \mathrm{~cm} \mathrm{DBH}$ in 35 $400 \mathrm{~m}^{2}$ plots with emphasis on deciduousness of the trees. To identify phenological characteristics across different vegetation structural types. I evaluated how phenological attributes differed between species, whether deciduousness relates to tree functional types or location of the tree, and when the trees drop their leaves. We analysed quantum of leaf litter shed in the dry season and also their synchrony with the annual anthropogenic fires in the forest-savanna ecotone of Ghana.

In the sixth chapter, I conducted a three-year field transplant experiment and assessed performance and root allocation of 864 seedlings for two congeneric species pairs of forest and savanna species in the forest-savanna ecotone of Ghana. I also investigated influences of vegetation types with varied canopy levels and its associated factors such as light, nutrient and water supplies on seedling survival, growth and traits. I tested the hypotheses that (1) forest tree species have lower survival than their savanna congeners in savanna due to relatively lower root mass fraction and root starch content needed to survive dry periods and to resprout after fire, and (2) higher 
Chapter 1

vegetation canopy being associated with a lower fuel load and higher soil nutrient status, benefits mainly forest tree seedlings as savanna species are less competitive in deep shade.

Finally, in the seventh chapter, I link the major findings of chapters 2-6 to provide answers to the main research questions by synthesising the results of the individual research chapters. Furthermore, I discuss the main scientific knowledge gaps and challenges regarding the understanding of the structural and functional variation of vegetation in forest-savanna ecotones and how the results of this thesis contribute to current knowledge on determinants of forestsavanna transition.

\section{The Study Site}

All studies presented in this thesis were conducted in the Kogyae Strict Nature Reserve (KSNR) (refer to the figure in Chapter 2) in the Ashanti Region of Ghana $\left(7^{0} 15^{\prime} 52^{\prime \prime} \mathrm{N}\right.$ and $\left.1^{\circ} 04^{\prime} 47^{\prime \prime} \mathrm{W}\right)$. The dry forest and savanna woodlands of Kogyae have received particular scientific interest recently in the study of vegetation structure, fire ecology, plant physiology and carbon dynamics in the forestsavanna transition zone (Cardoso et al., 2016; Domingues et al., 2010; Moore et al., 2017; TorelloRaventos et al., 2013; Veenendaal et al.,2015).

KSNR was established in the 1960s as a barrier reserve between the Guinea Savanna Zone in the north and the Deciduous Forest Zone in the south (Hawthorne 1995, Janssen et al. 2018). KSNR covers an area of $330 \mathrm{~km}^{2}$. The average rainfall is approximately $1.36 \mathrm{~m} \mathrm{y}-1$ and the average annual temperature is $28^{\circ} \mathrm{C}$ with little season variation (Figure 1b: Wildlife Department Accra, 1994). Rainfall distribution is seasonal with a distinct wet and dry season. Heavy rains fall between May and October with varied intensity, followed by a dry season from December to March. Longterm rainfall above the escarpment in Central Ghana has declined by $10 \%-20 \%$ since the 1970 s (Owusu \& Waylen, 2009). Presently KSNR experiences annual, mostly early wildfires, mostly the result of hunting/poaching and agriculture. Since 2004, fire has also been used as a tool to improve grazing resources for wildlife in the north-east section of the park. The structural vegetation types 
within the KSNR range from closed forests to open woodlands. Much of the forest vegetation was, however, chopped down in the late 1980s and early 1990s in the run-up to the gazetting of the strict conservation status of the park (Janssen et al., 2018).

The KNSR vegetation also has a human footprint with some record of occupation for the 19th and 20th century. Nevertheless, detectable features of past human settlements such as forest patches consisting of Terminalia schimperi (Hochst. ex Hutch. \& Dalziel) Gere \& Boatwr (syn. Anogeissus leicocarpa (DC.) Guill. \& Perr.) which typically persist for decades after village abandonment (Hopkins, 1965; Sobey, 1978) were not detected in the study area. 


\section{Chapter 2}

Extending the baseline of tropical dry forest loss in Ghana (1984-2015) reveals drivers of major deforestation inside a protected area

Thomas A.J. Janssen, George K.D. Ametsitsi, Murray Collins, Stephen Adu-Bredu, Imma

Oliveras, Edward T.A. Mitchard, Elmar M. Veenendaal

Published in Biological Conservation 218 (2018) 163-172 
Chapter 2

\section{Abstract}

Tropical dry forests experience the highest deforestation rates on Earth, with major implications for the biodiversity of these ecosystems, as well as for its human occupants. Global remote sensingbased forest cover data $(2000-2012)$ point to the rapid loss of tropical dry forest in South America and Africa, also, if not foremost, inside formally protected areas. Here, we significantly extend the baseline of tropical dry forest loss inside a protected area in Ghana using a generalizable change detection technique. The forest cover change detection is based on the normalized difference vegetation index (NDVI) derived from historical Landsat data (1984-2015). Field measurements were carried out in dry semi-deciduous forest and in the adjacent savanna and woodland. Estimates of the canopy area index and above ground woody biomass were related to NDVI derived from Landsat 8 data. The change detection indicated significant NDVI decrease in a large area initially covered by tropical dry forest, associated with deforestation. The peak in deforestation was found to have occurred between 1990 and 2002, hereafter, the conservation status of the area was improved. A combination of remote sensing data corroborated by secondary data sources provides evidence for the almost complete clearance of a tropical dry forest inside a strictly protected area, attributable to logging and land clearing for arable farming. The NDVI change detection also revealed NDVI increase in the adjacent woodlands from 2002 to 2015, demonstrating woody encroachment. Historical fire data from the MODIS burned area product indicate that the deforested area experienced a high frequency of anthropogenic burning since 2004, which may have caused further degradation and largely prevents forest regeneration. The results show the ongoing destruction of tropical ecosystems even within ostensibly protected areas and ask for the revision of protection and management strategies of such areas. 


\section{Introduction}

Deforestation and forest degradation (DD) represent a global problem (e.g. Hansen et al., 2013). West Africa is no exception where DD has occurred for millennia, principally due to logging, charcoal production and slash and burn agriculture (Hawthorne and Abu-Juam, 1995; Lupo et al., 2015). However, agricultural expansion and increasing levels of illegal logging and fire disturbance have dramatically increased DD since the end of the 19th century (Hansen and Treue, 2008; Hawthorne and Abu-Juam, 1995; Hosonuma et al., 2012; Wardell et al., 2003). Since 1990, the forest area in Ghana has decreased on average by $2 \%$ every year (FRA, 2010). As a result, timber exports have dropped markedly over the past decade: from 2008 to 2013 the total volume of Ghana's timber exports declined by $\sim 50 \%$ following decades of unsustainable exploitation (Hoare and Wellesley, 2014). The loss of natural forest in Ghana has significant socio-economic and ecological implications as these forests provide important ecosystem services and represent hotspots of biodiversity (Brooks et al., 2002; Norris et al., 2010).

In the forest savanna transition zone of West Africa, savanna and tropical dry forest occur in close proximity under similar climatic conditions. Tropical dry forests are particularly vulnerable to anthropogenic disturbances and experience high deforestation rates (Hansen et al., 2013). In contrast, woody encroachment of open ecosystems and in particular the savanna and woodlands in large areas across sub-Saharan Africa is being reported (Eldridge et al., 2011; Mitchard and Flintrop, 2013). Rising atmospheric carbon dioxide and relief from anthropogenic pressure are cited as possible drivers of such encroachment (Lambin et al., 2001; Lloyd et al., 2008; Mitchard et al., 2009; Mitchard and Flintrop, 2013). In the forest-savanna transition zone, deforestation and woody encroachment can occur simultaneously due to the action of multiple anthropogenic and biophysical drivers. Dry forest and transitional forests harbour crucial resources of genetic diversity, increasingly important for climate change adaptation in the context of the predicted warming and drying trend for West Africa (Boko et al., 2007; Millar et al., 2007). 
Chapter 2

The Forestry Department of Ghana (FDG) formally recognised the importance of tropical dry forests in 1962 and established multi-function "barrier" reserves in the transitional zone between the Guinea savanna and the fringing dry semi-deciduous forest (Hagan, 1998; Hall and Swaine, 1981; Hawthorne and Abu-Juam, 1995; Swaine, 1992). The aim was to maintain a high forest cover in order to protect natural water sources, to provide shelter to agricultural crops from dry season winds and to provide forest products for the surrounding human population (Hagan, 1998). Furthermore, the FDG aimed to preserve a dry forest belt as a fire break, to prevent the increasingly severe bushfires from northern Ghana spreading southward (Hagan, 1998). Yet due to illegal logging and the extreme El Niño drought of 1983, most of these barrier reserves were degraded by the mid-1990s and needed urgent protection (Hawthorne and Abu-Juam, 1995).

This paper focuses on one of these barrier reserves, the Kogyae Strict Nature Reserve (Figs. $1 \& 2$ ). Kogyae is the only designated strict nature reserve in Ghana, being "devoted solely to scientific research" with entry by humans for tourism or other uses prohibited (Hagan, 1998). The dry forest and savanna woodlands of Kogyae have received particular scientific interest recently, in the study of vegetation structure, fire ecology, plant physiology and carbon dynamics in the forest-savanna transition zone (Cardoso et al., 2016; Domingues et al., 2010; Moore et al., 2017; Torello-Raventos et al., 2013; Veenendaal et al., 2015). Kogyae is classified as category Ia protected area by the Inter-national Union for the Conservation of Nature (Ofori et al., 2014). The literature suggests that from 1984 to 1998 the population of communities inside and surrounding Kogyae tripled, mainly as a result of the new road access opened in 1984 (Awuku-bor, 1999; Hagan, 1998). In this period, illegal logging, agricultural expansion, charcoal production and widespread fire contributed to DD inside Kogyae (Awuku-bor, 1999; Hagan, 1998; Wildlife Department, 1994). According to a recent survey conducted by the authors among park rangers and local people, the local communities were removed from Kogyae by the Wildlife Department in 2002. While logging and farming have been limited since 2002, fires are now lit every year, both illegally 
by poachers as well as by wildlife officers to provide fresh grass for grazing wildlife (Ayivor and Ntiamoa-Baidu, 2015). The current reserve management may thus be in direct contradiction with the original aim, the conservation of tropical dry forest, for which the reserve was set up.

We assess the changes in woody cover that has occurred inside Kogyae in the past three decades using Landsat-derived NDVI in a multi-decadal change analysis. Thereby, we add quantitative spatiotemporal data to the existing, mostly anecdotal, history of Kogyae from 1986 to 2015. In addition, the climate and fire record are used to provide insights into these drivers of woody cover change. We aim to answer the following research questions:

- What woody cover changes are observed and what was the extent of DD?

- How did the drivers of woody cover change develop over time?

- How did the legal protection status of Kogyae and management efforts contribute to the conservation of dry forest?

We use insights from the case study to understand the processes driving woody cover changes in the Zones of Transition in Africa and to evaluate conservation efforts in the past decades.

\section{Materials and methods}

\section{Study area}

The Kogyae Strict Nature Reserve $\left(7^{\circ} 15^{\prime} 52^{\prime \prime} \mathrm{N}, 1^{\circ} 04^{\prime} 47^{\prime \prime} \mathrm{W}\right)$ is a $330 \mathrm{~km}^{2}$ protected area located in the north-eastern part of the Ashanti region in central Ghana. Kogyae experiences a bimodal annual rainfall distribution with high precipitation from March to July and from September to October corresponding to the passage of the Inter- Tropical Conversion Zone across the region (McSweeney et al., 2010). December and January are dry with $25.2 \mathrm{~mm}$ and $16.9 \mathrm{~mm}$ average 
Chapter 2

accumulated precipitation respectively. The pronounced dry season from December to March is caused by prevailing dry and dusty 'Harmattan’ winds from the north east (McSweeney et al., 2010). The mean annual rainfall is approximately $1350 \mathrm{~mm}$ and mean annual temperature is $28{ }^{\circ} \mathrm{C}$ with minimum variation in temperature over the year (McSweeney et al., 2010; Wildlife Department, 1994).

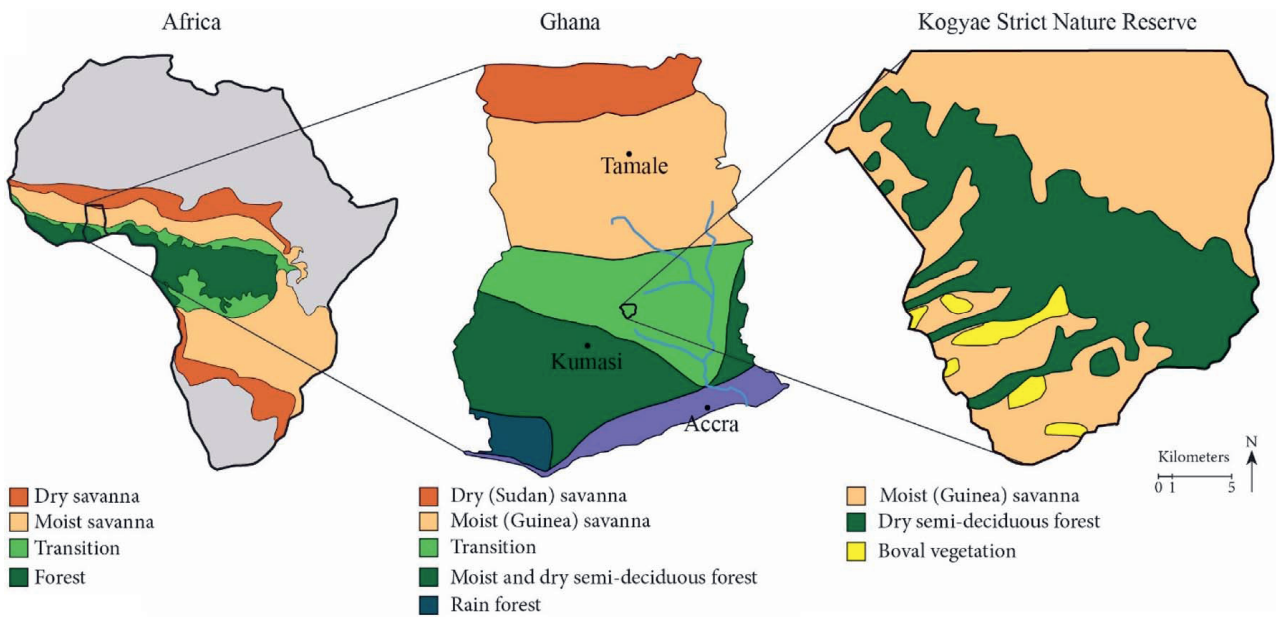

Figure 1. The location of the Kogyae Strict Nature Reserve within the different vegetation zones of Africa and Ghana. Vegetation zonation of Africa and Ghana adapted from Aubreville et al. (1958) and Yengoh et al. (2010), respectively. The vegetation zonation within Kogyae is adapted from a vegetation map in the Kogyae Management Plan (Wildlife Department, 1994), which is based on in situ observations by Schmitt and Adu-Nsiah in April-June 1993 (K. Schmitt, pers. com., 27 August 2015).

\section{Woody cover change}

\section{Field data}

Field estimates of aboveground woody biomass (AGB) and canopy area index (CAI) were used to evaluate the suitability of Landsat derived NDVI to detect changes in vegetation cover in the study area. Thirty-nine rectangular vegetation plots of $20 \times 20 \mathrm{~m}$ were established in the north-western corner of Kogyae in October 2014. The aim was to include the entire range of woody cover present in the study area, in order to evaluate the suitability of the NDVI in detecting gradual changes in 
woody cover. The field plots were located in vegetation types that are different in both their structural characteristics and floristic composition (Table S1), ranging from open, treeless grassland to tall forest with a high canopy cover and biomass (Torello-Raventos et al., 2013; Veenendaal et al., 2015). All trees with a diameter at breast height (DBH) of $>2.5 \mathrm{~cm}$ were tagged, measured and identified at species level. Tree height was estimated with a laser rangefinder (TruPulse ${ }^{\circledR}$ 200, Laser Technology Inc.). The projected crown dimension was estimated by measuring the diameter of the crown on two perpendicular axes with a measuring tape. The edge of the crown was visually determined by looking up at an angle of $180^{\circ}$. Geographic coordinates were determined at the centre of each plot using a handheld GPS device (Etrex Lengend HCx, Garmin Ltd., U.S.). For each plot the CAI ( $\mathrm{m}^{2}$ canopy area $/ \mathrm{m}^{2}$ ground area) was calculated as the sum of all crown dimensions divided by the plot area $\left(400 \mathrm{~m}^{2}\right)$. AGB was calculated using the general dry forest equation from Chave et al. (2005).
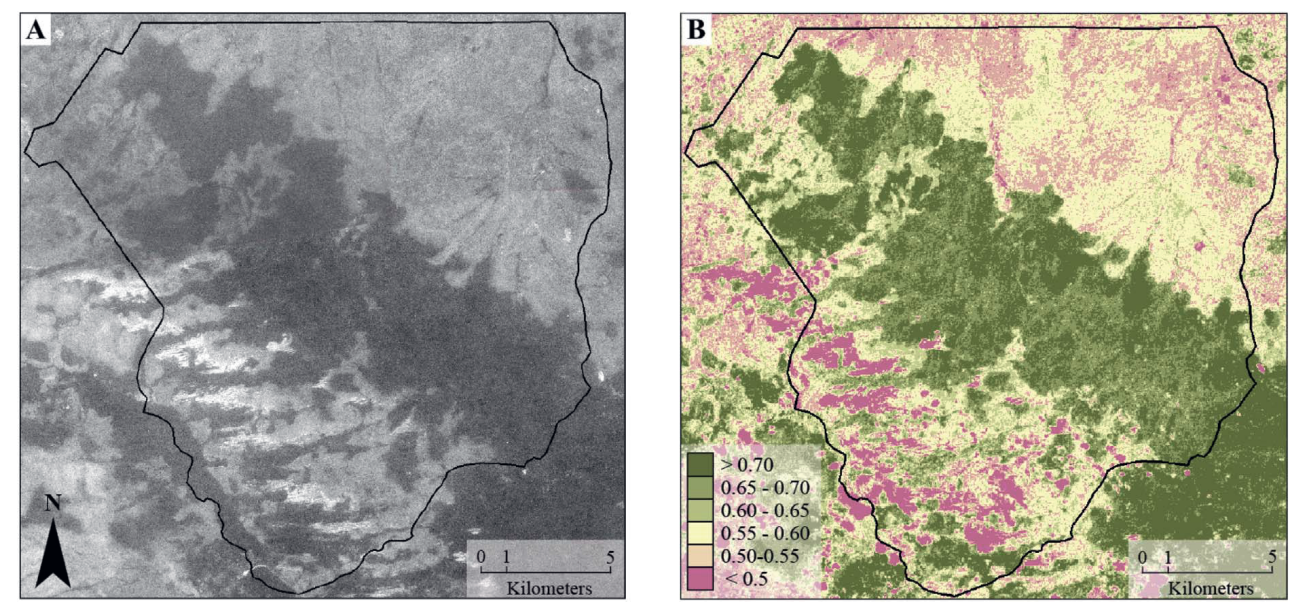

Figure 2. A Corona satellite photograph captured in January 1966 (A) and a Landsat 5 NDVI image from November 1984 (B) provide an indication of the initial vegetation cover inside Kogyae. The dry semideciduous forest in Fig. 1 is visible as darker colours in the Corona photograph and as high NDVI $>0.6)$ in the Landsat image. The bight white areas in the south west of the reserve (NDVI $<0.5)$ are sparsely vegetated rocky outcrops, known as Boval vegetation. The Guinea savanna is visible as greyish colours in the Corona photograph (NDVI 0.5-0.6). The boundary between the forest and savanna is abrupt, accentuated by annual fires that generally extinguish at the forest edge (Swaine, 1992). 
Chapter 2

Tree DBH, tree height and species specific wood density retrieved from the Global wood density database (Chave et al., 2009; Zanne et al., 2009) were used to calculate the AGB of the individual trees.

\section{Landsat based change detection}

We chose to use the Normalized Difference Vegetation Index (NDVI) derived from images acquired by three Landsat satellites to detect changes in woody vegetation cover. Landsat satellites have continuously acquired multispectral images with a $30 \mathrm{~m}$ horizontal resolution since 1972 . The NDVI was selected as it is a widely used and validated index of vegetation greenness. NDVI has been used to separate woody and grass vegetation in savannas (Archibald and Scholes, 2007) and to monitor woody vegetation changes in the Sahel (Horion et al., 2014) and in the forest savanna transition zone of Cameroon (Mitchard et al., 2009). Timing of image capture was chosen to maximize the contribution of woody vegetation to the NDVI signal and to omit the contribution of grasses. In a similar environment in Cameroon, Mitchard et al. (2009) found that the NDVI from images captured in the early dry season was most sensitive to woody vegetation greenness. We confirm this from regular in situ observations in Kogyae, as in the early dry season (midNovember) all tree species are still in full leaf while grasses have senesced. Unfortunately, cloudfree historical images from mid-November covering the study area are rare in the Landsat archive, making an annual assessment of changes in NDVI impossible. Therefore, we selected four usable (> 70\% cloud-free) images for the change analysis that would approximate three periods in the recent management history of Kogyae: the pre-disturbance (1984-1990), the disturbance (19902002) and the recovery period (2002-2015).

Remaining clouds and cloud shadows were masked from the NDVI images using the Fmask automated cloud detection algorithm version 3.3 using default settings (Zhu et al., 2015; Zhu and Woodcock, 2012). The NDVI was calculated using the Landsat 8 image and values were extracted to derive plot averaged NDVI. To evaluate the suitability of NDVI to assess changes in 
woody vegetation cover in this environment, we performed an asymptotic regression to link plotaveraged NDVI to field estimates of CAI and AGB. Plots 32 and 34 were excluded as they were dominated by a few large trees resulting in unrealistically high AGB values for this environment of $>700 \mathrm{Mg} \mathrm{ha}^{-1}$ (see Table S1).

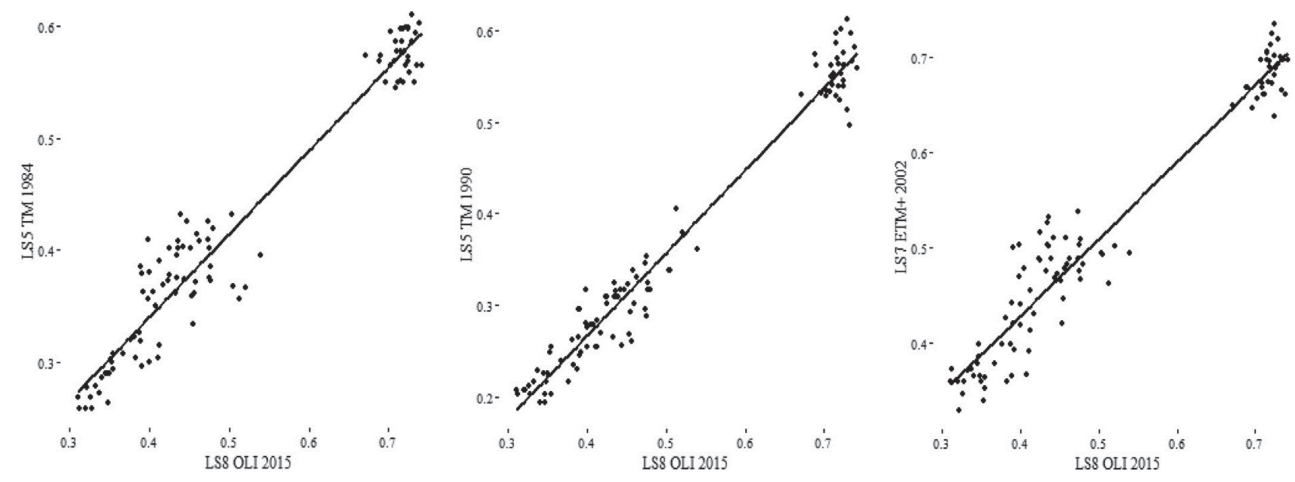

Figure 3. The cross-calibration regression of 100 pseudo-invariant targets that expectedly did not change in vegetation cover between 1984 and 2015. From left to right: the regression of November 1984 NDVI against November 2015 NDVI ( $2=0.94, \mathrm{p}<0.0001)$, November 1990 against November $2015\left(\mathrm{R}^{2}\right.$ $=0.97, \mathrm{p}<0.0001, \mathrm{n}=100)$ and November 2002 against November $2015(\mathrm{R} 2=0.94, \mathrm{p}<0.0001)$. The cross-calibration equations are provided in Table 1.

The different Landsat sensors exhibit differences in sensitivity and spectral band designation that can provide errors in the change detection. To minimize these errors, we use a cross-calibration method to calibrate the three historical NDVI images to the NDVI image of November 2015 (Mitchard et al., 2009). For the cross-calibration procedure, 100 points were selected to represent pseudo-invariant target areas in undisturbed tropical forest fragments, on roads and rocky outcrops. A linear regression was then applied to obtain the calibration equation for the 1984, 1990 and 2002 images (Fig. 3). The calibrated NDVI images were compared pairwise (i.e. 1984-1990, 1990-2002, 2002-2015) to calculate the relative change in NDVI ( $\Delta$ NDVI) in every time period, using the following equation: 
Chapter 2

$$
\Delta N D V I=\frac{N D V I_{n}-N D V I_{n-1}}{N D V I_{n}+N D V I_{n-1}}
$$

The magnitude and direction of change was established by scaling $\Delta$ NDVI in terms of standard deviations $(\mathrm{SDs})$ away from no change $(\Delta \mathrm{NDVI}=0)$. We use the average SD $(0.048)$ of change in the three examined periods obtained within the borders of the reserve. For more details about the change detection method, see Mitchard et al. (2009). To examine how $\Delta$ NDVI differed between the initial land cover types in our study area, principally savanna and dry forest, we used the earliest Landsat image available from November 1984 to derive a land cover map. We used all seven spectral bands of the image in a random forest supervised classification (Breiman, 2001) with 50 randomly sampled training samples $(100 * 100 \mathrm{~m})$. Because there is no field data available from 1984 to train the classification, we visually assigned the training samples to either forest, savanna or boval vegetation using the vegetation map and Corona satellite image in Fig. 1 and 2 , respectively, as a reference.

\section{Precipitation and fire}

Monthly accumulated precipitation from January 2000 to January 2016 was retrieved from the tropical rainfall measuring mission (TRMM) (GIOVANNI, 2015). The monthly precipitation data was area averaged for a rectangular area around Kogyae $\left(\mathrm{NE}=7^{\circ} 43^{\prime},-0^{\circ} 83^{\prime} ; \mathrm{SW}=7^{\circ} 0^{\prime},-1^{\circ}\right.$ 24'). Fire data was collected from the Moderate Re- solution Imaging Spectroradiometer (MODIS) Burned Area product (MCD45A1) which contains date of detected burning at a 500 m horizontal resolution. The data is acquired since the year 2000 by the MODIS sensor on-board the Terra and Aqua satellites. The separate in the dry season (October - March) of every year. This resulted in 14 raster datasets containing the day of detected burning, from the dry season 2001-2002 to the dry season of $2014-2015$. From these datasets the total area burned in every month of the dry season from 2000 to 2015 was calculated. 


\section{Results}

\section{Linking field data to the NDVI}

Field estimated AGB was strongly related to field estimated CAI $\left(\mathrm{R}^{2}=0.75, \mathrm{p}<0.0001, \mathrm{n}=37\right.$, Fig 4).

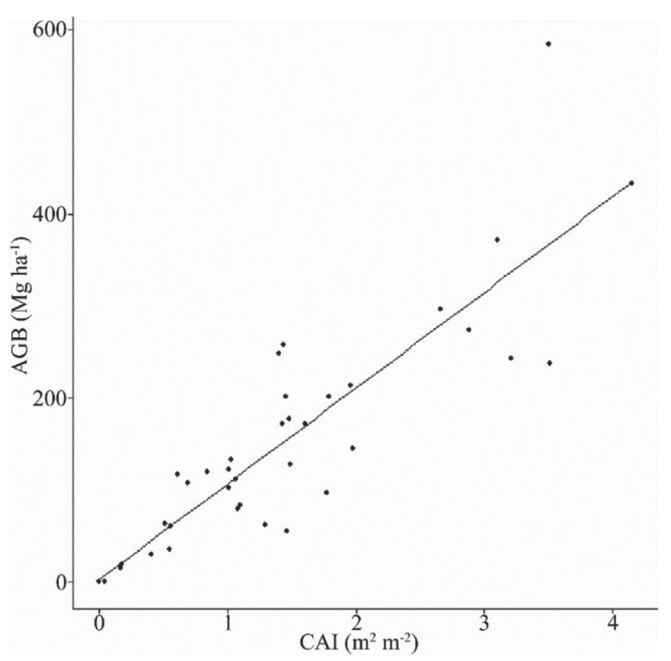

Figure 4. Field estimated AGB regressed against the field estimated CAI. The correlation is particularly strong in open ecosystems with low AGB and CAI.
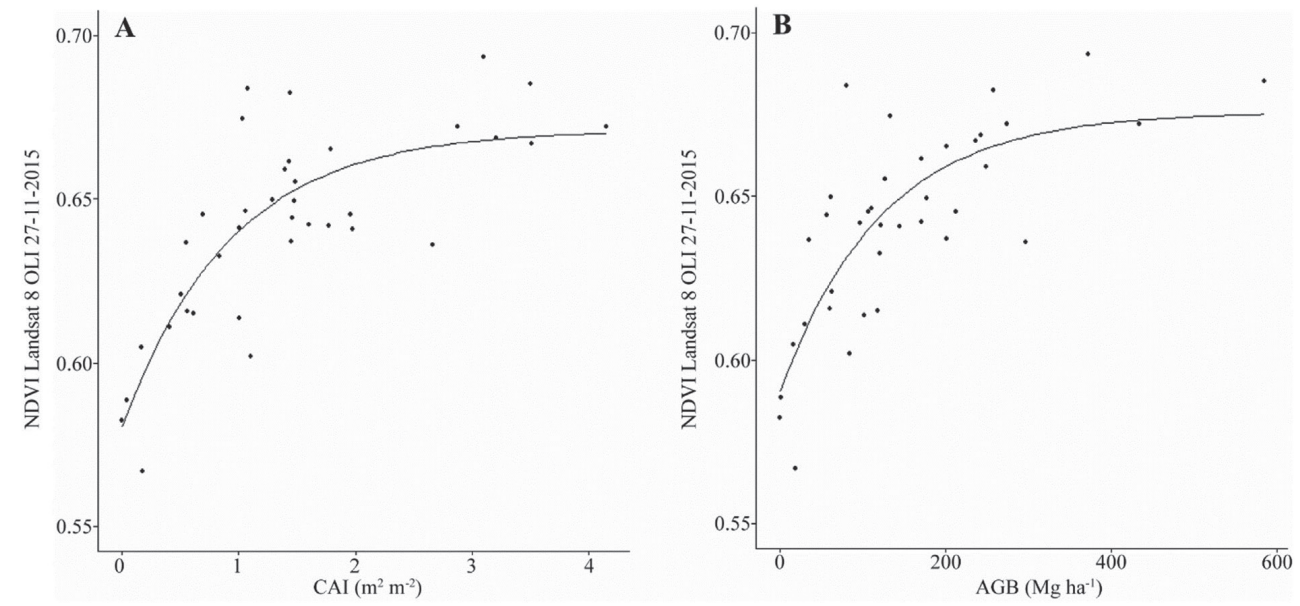

Figure 5 Landsat 8 NDVI captured on the $2^{\text {th }}$ of November 2015 regressed against field estimated CAI (A) and AGB (B). CAI and AGB showed an asymptotic relationship with NDVI with the response of NDVI to woody cover saturating around $\mathrm{CAI}=2 \mathrm{~m}^{2} \mathrm{~m}^{-2}$ and around $\mathrm{AGB}=200 \mathrm{Mg} \mathrm{ha}^{-1}$. 
Chapter 2

AGB increased linearly with CAI, roughly $100 \mathrm{Mg} \mathrm{ha}^{-1}$ with every unit of CAI. Plot averaged NDVI was related to both field estimated CAI $\left(\mathrm{R}^{2}=0.66, \mathrm{p}<0.0001, \mathrm{n}=37\right)$ and AGB $\left(\mathrm{R}^{2}=0.62, \mathrm{p}<\right.$ $0.0001, \mathrm{n}=37$, Fig 5).

\section{Changes in NDVI}

The change detection procedure showed both NDVI increase and decrease between 1984 and 2015 (Figure 6, Table A2). The detected decrease in NDVI occurred almost exclusively in areas that were covered by dry forest in 1984. Between 1984 and 1990, 10.2\% of this forest area experienced a detectable decrease in NDVI. More than half of this area (64.7\%) decreased in NDVI between 1990 and 2002. In the period 2002-2015 there was a loss of NDVI in $28.3 \%$ of the dry forest area. NDVI increase occurred mainly in the savanna, with $4.4 \%, 4.8 \%$ and $37.6 \%$ of this area showing detectable increases in NDVI in the periods 1984-1990, 1990-2002 and 2002-2015, respectively. The rate of significant NDVI loss in the area covered by dry forest increased from $1.7 \% \mathrm{yr}^{-1}{ }^{-1}$ in the first 6 years (1984-1990) to 5.4\% $\mathrm{yr}^{-1}$ in the following 12 years (1990-2002). Hereafter, from 2002 to 2015 , the rate of NDVI loss in the forest area decreased again to $2.2 \mathrm{yr}^{-1}$, cancelled out by a detectable increase of $2.4 \% \mathrm{yr}^{-1}$. Based on the observation that the decrease in NDVI occurred almost exclusively in the central dry forest belt (Fig. $6 \& 7$ ) we can conclude that this NDVI decrease is indicating DD inside Kogyae. The NDVI increase from 2002 to 2015 in the area initially covered by forest points to a possible post-disturbance recovery of the vegetation. The area covered by savanna showed a $2.9 \% \mathrm{yr}^{-1}$ increase of NDVI in the period 2002-2015. Branching patterns of positive NDVI change were visible in the NDVI change map of 2002-2015 that closely match the branching patterns of small streams that flow to the north into the Sene river (Fig. 7). This suggests that water availability is possibly driving the rate of woody encroachment in the savanna of Kogyae. 

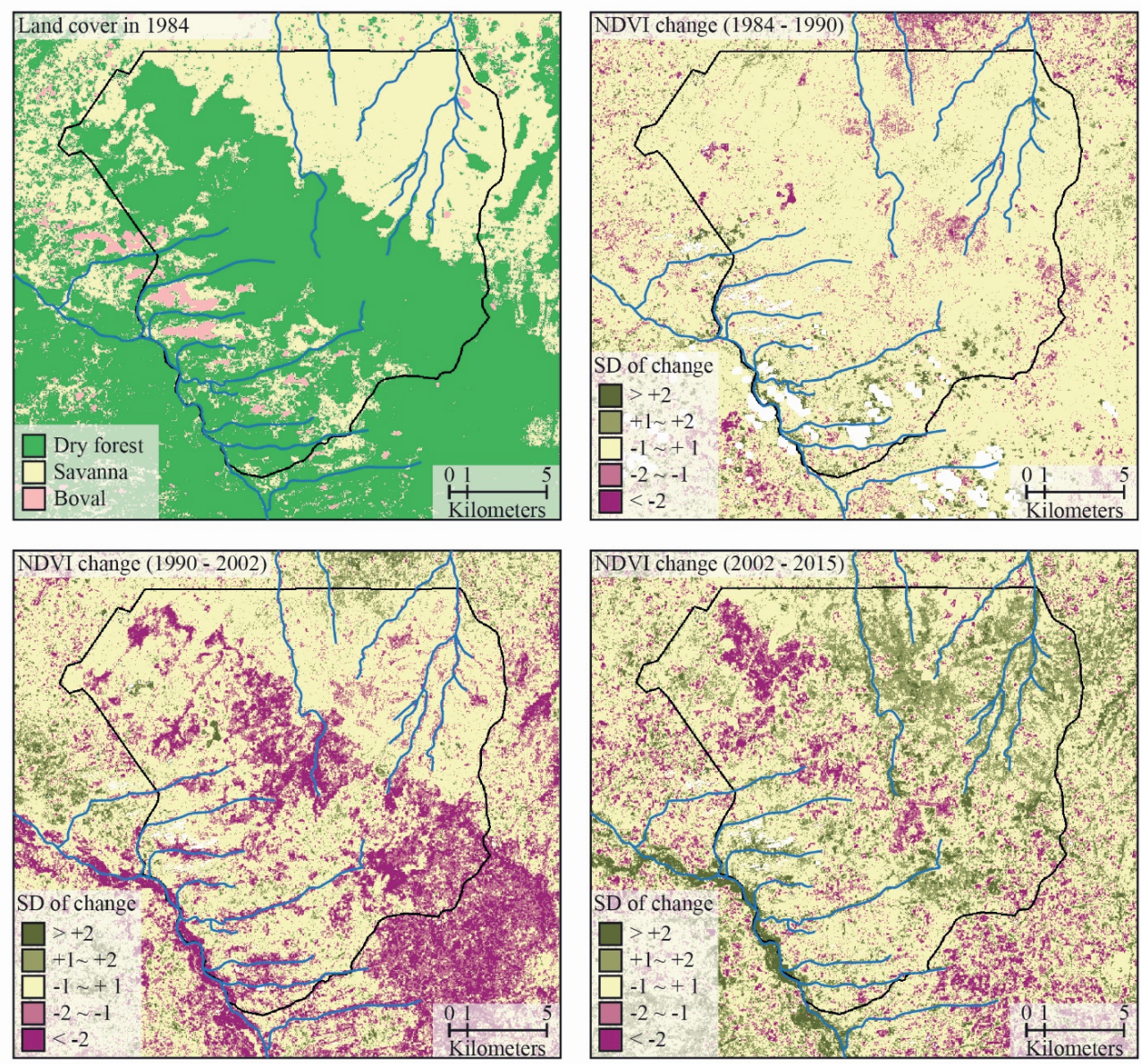

Figure 6. Map showing the 1984 land cover in Kogyae derived from the random forest classification (top left). Major rivers and streams in the study area are depicted in blue: the Afram river tributaries in the southwest and the Sene river tributaries in the north-east. Negative change in NDVI occurred mainly in the dry forest belt in the centre of the reserve, particularly in 1990-2002. Large areas of the savanna in the northeast of the reserve show a significant increase in NDVI in 2002-2015 associated with woody encroachment. The increase of NDVI in this period shows branching patterns, following the course of multiple streams that intersect the savanna. Clouds were masked and shown in white.

\section{Interactions of fire and climate}

The MODIS burned area product showed that fires were very frequent inside Kogyae (Fig. 7). In $52.3 \%$ of the reserves surface area $\left(180.7 \mathrm{~km}^{2}\right)$ a fire was recorded every 1 to 2 years, while in another $24.1 \%$ of the area $\left(83.3 \mathrm{~km}^{2}\right)$ a fire was recorded at an interval of 2 to 3 years. The remaining 
Chapter 2

$23.6 \%$ of the area $\left(81.8 \mathrm{~km}^{2}\right)$ experienced a fire return interval of 3 to 14 years. The area inside the reserve that burned annually varied significantly over the years (Fig. 8). The first four years of the record show relatively small burned areas. However, in the dry season of 2004-2005, 56.3\% of the reserve area $\left(194.6 \mathrm{~km}^{2}\right)$ burned. Thereafter, the area that burned annually remained large, with the exception of 2010-2011 $\left(51.2 \mathrm{~km}^{2}\right)$ and 2013-2014 $\left(35.2 \mathrm{~km}^{2}\right)$. There was a significant linear correlation between the extent of area burned in January and February and the accumulated precipitation in January $\left(\mathrm{R}^{2}=0.45, \mathrm{p}<0.001, \mathrm{n}=14\right)$.

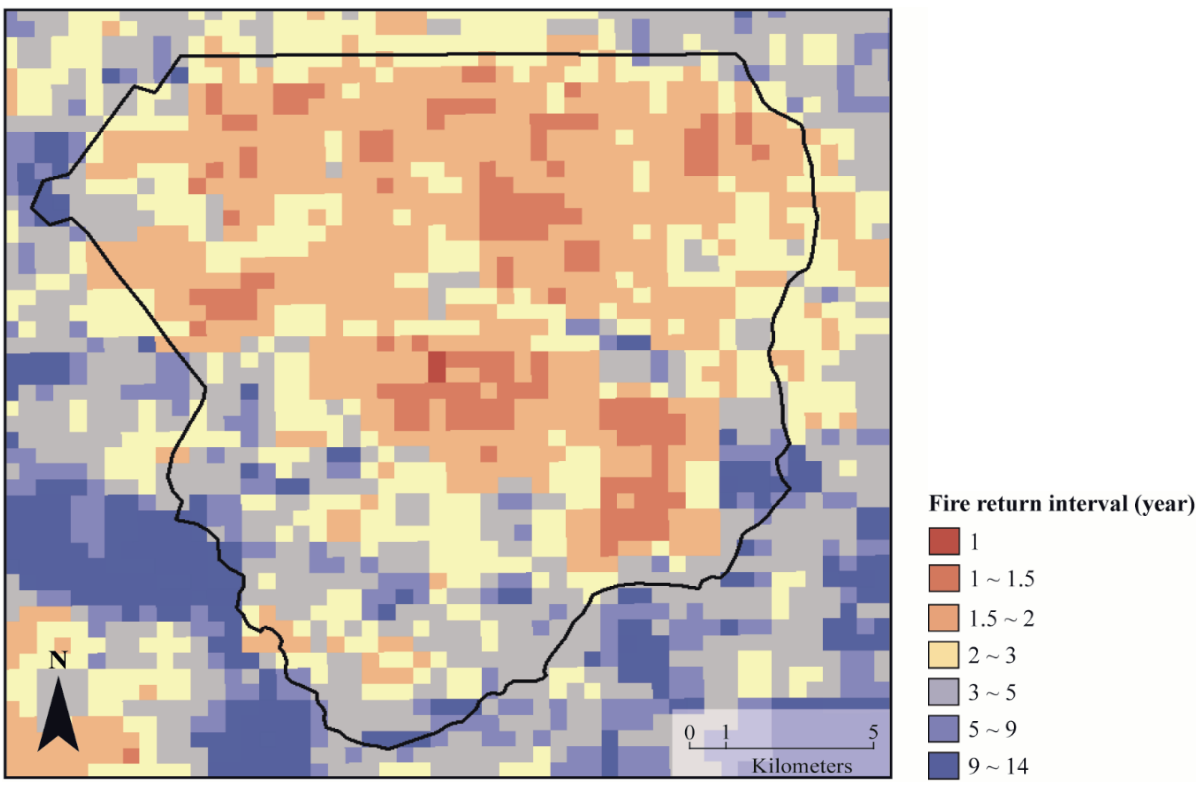

Figure 7. Fire return interval from 2000 to 2015 derived from the MODIS burned area product. The deforested area shows frequent burning as this area experiences at least one fire every two years. Also, the savanna in the north experiences a high fire frequency. Areas in the south-west are characterised by a longer fire return interval of 3 to 5 years. Note that the fire return interval inside Kogyae is significantly shorter compared to the fire return interval in the direct surroundings. 

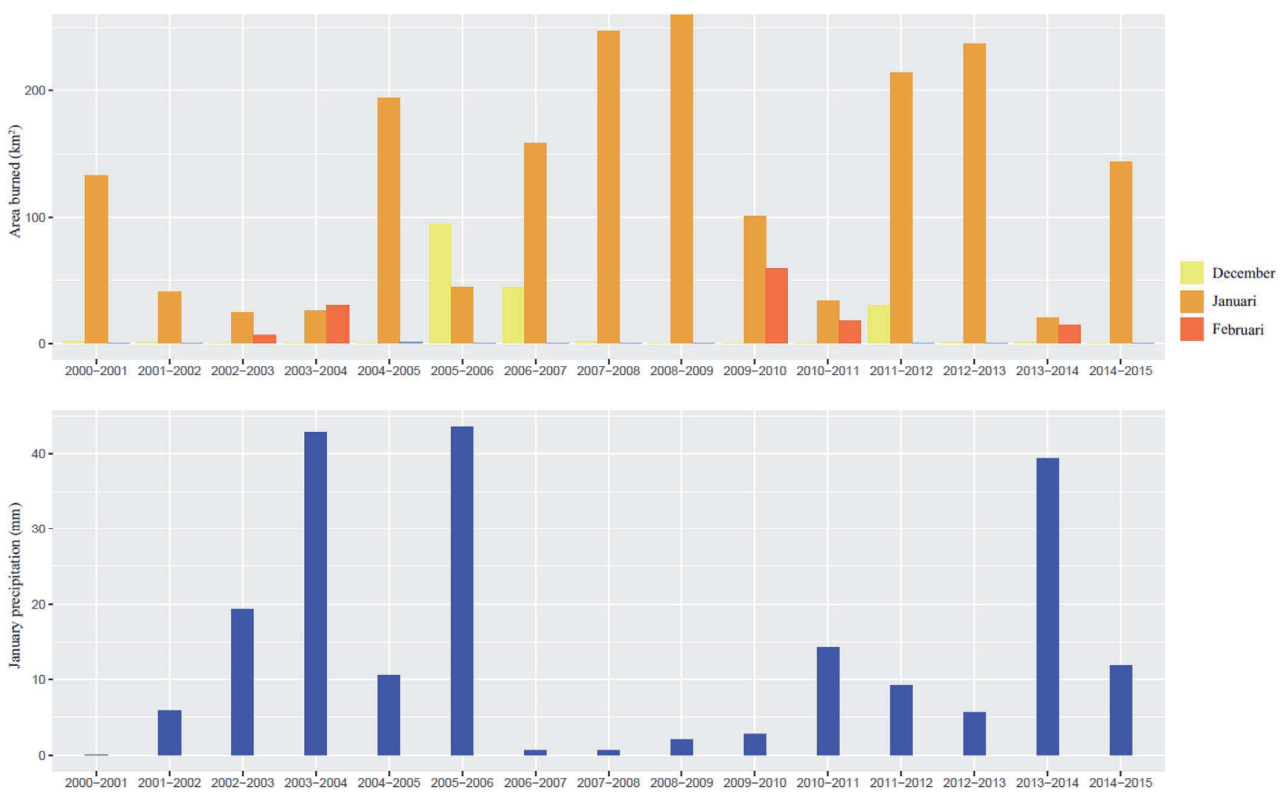

Figure 8. The extent of area burned in the three dry season months (above) and the accumulated precipitation in January (below). Associations are observable between the detected burned area and January precipitation. In 2004, 2006 and 2014 the accumulated precipitation in January peaks above 35 $\mathrm{mm}$. In these years the recorded burned area in the dry season was also relatively low. From 2007 to 2010, January was dry and these years also show a large area burned in January.

\section{Discussion}

We observed a number of changes in the study area that are important for the long-term resource exploitation and future management of the area and offer insights into long term dynamics of protected areas. The NDVI change detection procedure reveals the previously unidentified and complete clearance of a dry forest inside Ghana's IUCN Category Ia Kogyae Strict Nature Reserve between 1984 and 2015. The Landsat archive offered us the possibility to detect woody cover changes in three time periods that correspond to changes in land use, resource management and human pressure inside the reserve (Fig. 9). The estimated rate of deforestation more than doubled from $1.7 \% \mathrm{yr}^{-1}$ in the pre-disturbance period to $5.4 \% \mathrm{yr}^{-1}$ in the disturbance period (1990-2002). From 2002 to 2015, referred to as the recovery period, the deforestation rate declined again to 
$2.2 \% \mathrm{yr}^{-1}$, somewhat higher than the national deforestation rate of $2 \% \mathrm{yr}^{-1}$ in Ghana in the same period (FRA, 2010).

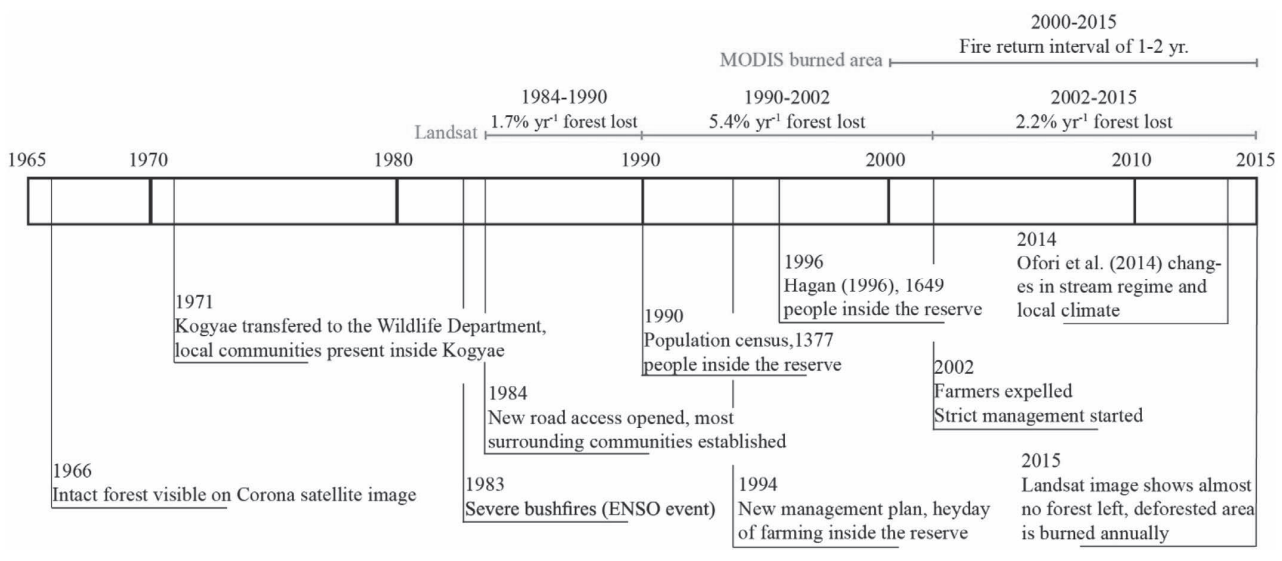

Figure 9. History of Kogyae, as described in the literature (Awuku-bor, 1999; Hagan, 1998; Ofori et al., 2014; Wildlife Department, 1994) and from the interpretation of the NDVI change detection and MODIS fire record results.

Three different procedures were performed to reduce uncertainties and prevent errors of commission in the NDVI change detection analysis. First, by selecting images captured on similar times in the different years intra-annual or seasonal variation in NDVI is largely excluded from the NDVI change detection. Secondly, the cross-calibration of the NDVI images from the different years ensures that distortions due to sensor differences are excluded while the cross-calibration procedure also reduces some of the remaining seasonal variation. Finally, by measuring NDVI change in terms of standard deviations of change within Kogyae, only areas that show a significant magnitude of change are detected. The observed changes in tree cover were found to coincide with a number of historical events in the region. (Fig. 9). The opening of road access in 1984 contributed to the influx of migrant farmers into Kogyae, engaged in arable farming (Mertens and Lambin, 2000; Wildlife Department, 1994). Low initial population density and land availability in protected areas have been found to act as pull factors to migrants in Ghana and elsewhere in Africa (Awuku- 
bor, 1999; Hartter et al., 2014; Zommers \& Macdonald, 2012). The rate of forest clearing for arable farming accelerated in the early 1990s (Fig. 9).

Two factors have been contributed to the failing of the reserve management in protecting the dry forest of Kogyae. First, a lack of definite policies and management guidelines led to a situation in which the local wildlife officers were responsible for setting out their own management priorities (Wildlife Department, 1994). Secondly, the community of settlers used to see the reserve as potential farmland that was to be released to them and therefore, they did not recognise the status of Kogyae as a protected area.

The history of Kogyae provides a textbook example of how imposing protected areas on local communities without strong enforcement rarely leads to successful conservation. The extensive deforestation observed is in line with the general trend of DD in Ghana's barrier reserves in the 1990s. Another documented example is the Tain II tributaries barrier reserve (Hawthorne and Abu-Juam, 1995; Kyereh et al., 2007). Kogyae's watershed protection function is now lost with the effects felt by local communities. Streams dry up completely during the dry season (Hagan, 1998) and the water supply from boreholes is reduced, resulting in water shortages (Ofori et al., 2014). Furthermore, dry forest tree species constitute an essential part of rural livelihoods as many species are used for charcoal and household fuel, fodder, construction wood, medicine and food (Paré, 2008). The effects of DD on biodiversity inside the reserve are expected to be substantial (Barlow et al., 2007; Green et al., 2013; Koh \& Sodhi, 2010; Norris et al., 2010).

Some of the larger mammal species previously common inside the reserve, for example Elephant (Loxodonta africana) and Black-and-white Colobus (Colobus polykomos) have become locally rare or extinct (Ayivor and Ntiamoa-Baidu, 2015). Tree species that occur in the dry semideciduous forest inside Kogyae are growing at the very limit of their ecological distribution. Economically important transitional tree species in Kogyae include Afzelia africana and Khaya senegalensis, both classified as vulnerable in The IUCN Red List of Threatened Species. Genotypes found in these populations are expected to represent valuable genetic resources, especially in the 
Chapter 2

context of climate change adaptation (Gonzalez, 2001; Millar et al., 2007). It would be a tremendous loss for the biodiversity, rural livelihoods and the forestry sector of Ghana if these genotypes would disappear completely.

A recent survey among (retired) wildlife officers and people from local communities (results not shown) confirmed that in 2002, all the farming communities residing within the reserve were expelled by the Wildlife Department. This is confirmed by the interpretation of aerial images (Google Earth ${ }^{\mathrm{TM}}$ ), as the area that was deforested within the reserve is presently not cultivated and has been clearly abandoned. The decline of forest loss observed after 2002 (Fig. 6) can therefore be attributed with confidence to a tighter control on arable farming within Kogyae by the reserve management. Yet the rate of woody cover loss in the north of the reserve remained high until 2015 (Fig. 6). This can be attributed to the damage caused by recurrent annual fires, as fire is known to accelerate forest degradation in areas where forest cover has been previously reduced and a high fire frequency is maintained (Hawthorne, 1994; Hosonuma et al., 2012; Swaine, 1992).

While fires are lit every dry season at the edges of the reserve (Ayivor and Ntiamoa-Baidu, 2015), the fire record shows that a relatively high precipitation in January $(>35 \mathrm{~mm})$ can prevent the fires from burning a large area of the reserve (Fig 8). This effect of dry season precipitation via fuel moisture on the annual variability of fire extent is well described on larger spatial scales for the African continent (Andela and van der Werf, 2014), Amazonia (Aragão et al., 2008) and equatorial Asia (van der Werf et al., 2008). The MODIS fire record suggests that the area burned inside the reserve has increased since 2004, this is confirmed by observations by the reserve management (Ayivor and Ntiamoa-Baidu, 2015). The fragmentation of dry forest, the opened canopy and the increase of savanna grasses in open areas have increased fire fuel loads with poaching and park management sustaining a high fire frequency. Logged and burned forests are found to be susceptible to renewed burning due to a substantial and dry fuel load (Kyereh et al., 2007) and a similar effect is found when analysing long term fire experiments (Veenendaal et al., 2015). Eventually, much of the original forest changed into the treeless tall grasslands and Chromolaena 
odorata thickets existing there today. The annual early burning management likely prevents or slows down the return of tropical dry forest previously present.

NDVI increase was widespread in the savanna and woodland inside Kogyae from 2002 to 2015. Our results suggest that regular fires were not able to prevent woody encroachment in the savanna as the NDVI increase occurred in the north eastern savanna zone that experienced a relatively short fire return time of 1 to 2 years in the period 2000-2015 (Fig. 7). Finding woody encroachment along streams and in the savanna adds to the increasing amount of evidence reporting woody encroachment in the woodlands and savanna of sub-Saharan Africa (Mitchard and Flintrop, 2013) and in the western Sahel (Horion et al., 2014).

Deforestation of tropical dry forests is a major global issue. From 2000 to 2012 tropical dry forests in Latin America, Africa and Eurasia experienced the highest deforestation rates of all forest ecosystems (Hansen et al., 2013). Forest clearing for agriculture is recognised as the main driver of DD in the tropics (Hosonuma et al., 2012). We show how dry forests are extremely susceptible to DD even if they are located in a protected area in the strictest sense. Formal de jure protection can be totally disconnected from de facto status, leading to creation of so-called 'paper parks' (Figueiredo and Loadman, 2007; Joppa et al., 2008). Dry forest patches are still present in Kogyae and the areas surrounding these patches are showing signs of forest recovery. However, annual fires are hindering forest recovery. This suggests that Kogyae's management should re-assess the current practice of deliberate burning. International mechanisms that will provide funding for reforestation activities in the context of climate change (REDD+), and biodiversity conservation schemes may provide an avenue for the restoration of Kogyae's forest. Most broadly, this study contributes to the ongoing debate about the effectiveness of protected areas (Di Minin and Toivonen, 2015; Joppa et al., 2008; Symes et al., 2016). We have demonstrated the application of remote sensing techniques to provide robust change detection using freely-available data, and have revealed a hitherto undocumented and near-complete loss of Ghana's most strictly protected forest. 
Chapter 2

\section{Acknowledgements}

We would like to thank the Wildlife Division of the Forestry Commission of Ghana for granting us research permission to work in the Kogyae Strict Nature Reserve (KSNR). Our appreciation also goes to the Park Manager, Mr. Dwoben Nyantakyi, and his staff at Dome Camp for providing security and technical assistance in the field, particularly Isaac Sarpong, Kwaku Yinye and Yaw Agyeman, who in addition organized various scattered settler communities in KSNR to participate in interviews to verify our findings. Finally, we would like to thank the three anonymous reviewers for their comments and suggestions. EM was funded by a research fellowship from NERC (grant ref: NE/I021217/1). TJ was partly funded by the Netherlands Earth System Science Centre (NESSC). EV and GA were funded by the EU FP7 GEOCARBON project (grant agreement no. 283080) in Ghana. 


\section{Chapter 3}

\section{Fixed or Mixed? Variation in tree functional types and vegetation structure in a forest- savanna ecotone in West Africa}

George K.D. Ametsitsi, Frank Van Langevelde Vincent Logah Thomas Janssen, Jose, MedinaVega , Hamza Issifu, Laurianne Ollivier, Koos den Hartogh, Thomas Adjei-Gyapong, Stephen Adu-Bredu, Jon Lloyd \& Elmar M. Veenendaal

Published in Journal of Tropical Ecology (2020).

https://doi.org/10.1017/S0266467420000085 
Chapter 3

\begin{abstract}
We analysed thirty-five 400-m2 plots encompassing forest, savanna and intermediate vegetation types in an ecotonal area in Ghana, West Africa. Across all plots, fire frequency was over a period of 15 years relatively uniform (once in $2-4$ years). Although woodlands were dominated by species typically associated with savanna-type formations, and with forest formations dominated by species usually associated with closed canopies, these associations were non-obligatory and with a discrete non-specialized species grouping also identified. Across all plots, crown area index, stem basal area and above-ground biomass were positively associated with higher soil exchangeable potassium and silt contents: this supporting recent suggestions of interplays between potassium and soil water storage potential as a significant influence on tropical vegetation structure. We also found an average NDVI cover increase of $\sim 0.15 \%$ year-1 (1984-2011) with plots dominated by nonspecialized species increasing more than those dominated by either forest- or savanna-affiliated species. Our results challenge the traditional view of a simple forest vs. savanna dichotomy controlled by fire, and with our newly identified third nonspecialized species grouping also potentially important in understanding ecotonal responses to climate change.
\end{abstract}




\section{Introduction}

Tropical savannas and forests are generally seen as distinct biomes composed of distinct plant functional types (PFT) and vegetation structure (Furley et al., 1992). Savannas have an open canopy with fire and herbivory considered major drivers of species composition (Hovestadt et al., 1999, Van Langevelde et al., 2003). Forests have a closed canopy where fire does not easily penetrate and with woody species present being fire sensitive (Torello-Raventos et al., 2013). Differences in canopy closure with a fire-quenching threshold at around 50\% crown cover may result in contrasting pyrogenic (open tree cover) and non-pyrogenic (closed tree cover) biomes (Hennenberg et al., 2006; Pellegrini et al. 2016; Ratnam et al., 2011). Ecotone vegetation is considered intrinsically unstable and rapidly transforming into either a stable savanna or alternate stable forest state through fire-mediated feedbacks (Hirota et al., 2011; Hoffmann et al., 2008; Oliveras \& Malhi, 2016; Pellegrini et al., 2016; Staver et al., 2011). Stands containing mixtures of forest and savanna trees then, as a consequence, are considered fire-degraded and temporary (Aubréville 1938; Ratnam et al., 2011; Stebbing 1935) but transitional vegetation comprising of a mix of forest and savanna tree species has been reported to persist over decadal timescales (CuniSanchez et al., 2016; Goetze et al., 2006). Thus closed-canopy vegetation formations containing an abundance of fire-tolerant canopy tree species may occur naturally, at least under certain conditions. Moreover, in at least one of the classic fire experiments, under a moderate (e.g. early burning) fire regime, many fire sensitive species were found to persist (Charter \& Keay, 1960). Thus, to simply distinguish between forest and savanna only and to consider transition vegetation to simply be unstable or degraded forest begs for closer scrutiny.

Climate and soil factors are key determinants of vegetation structure (Lloyd et al. 2008, Lloyd \& Veenendaal, 2016; Veenendaal et al., 2015; Veenendaal et al., 2018) Edaphic properties influence the distribution and structure of tropical woody vegetation types (Coetzee et al., 1976; Dowling et al., 1986; Goodland \& Pollard, 1973; Trapnell, et al., 1950) with soil depth and/or texture and consequently soil water storage an important driver of species composition and stand 
Chapter 3

structure (Keay, 1960; San Jose \& Farinas, 1983; Swaine 1996; Veenendaal et al., 1996b). Although in savannas, soil nutrients may be sufficient to potentially sustain forest (Bond, 2010; Gray \& Bond, 2015), forest soils are generally of a higher nutrient status than savanna soils under similar climate conditions (Lloyd et al., 2008; Quesada et al., 2012; Ruggiero et al., 2002). Of particular interest is the combined soil available water and potassium (CWAK) hypothesis (Lloyd et al., 2015) which suggests, that soil water availability and the nutrient potassium together can explain vegetation structural transitions in woody vegetation. In this paper, we closely examine variation in the structural parameters of woody vegetation in a forest-savanna boundary in Ghana, West Africa, investigating links between the vegetation composition in terms of woody PFTs and the vegetation structure in a forest-savanna mosaic. We also test the hypothesis that savanna and transitional species can co-occur in at least some closed vegetation formations. We also investigate long-term changes and fire incidence for different vegetation structural type, testing the hypothesis that many differences in vegetation structure can be simply attributed to variation in soil characteristics.

\section{Methods}

Study site

We conducted the study in the Kogyae Strict Nature Reserve (KSNR; Figure 1a) in the Ashanti Region of Ghana $\left(7^{\circ} 15^{\prime} 52^{\prime \prime} \mathrm{N}\right.$ and $\left.1^{\circ} 04^{\prime} 47^{\prime \prime} \mathrm{W}\right)$. KSNR was established in the 1960 s as a barrier reserve between the Guinea Savanna Zone in the north and the Deciduous Forest Zone in the south (Hawthorne, 1995; Janssen et al., 2018). KNSR covers an area of $330 \mathrm{~km}^{2}$. Average rainfall is approximately $1.36 \mathrm{~m} \mathrm{y}-1$ and the average annual temperature is $28^{\circ} \mathrm{C}$ with little season variation (Figure 1b: Wildlife Department Accra, 1994). Rainfall distribution is seasonal with a distinct wet and dry season. Heavy rains fall between May and October with varied intensity, followed by a dry season from December to March. Long-term rainfall above the escarpment in Central Ghana has declined by 10-20\% compared to the period 1950- 1970 (Owusu \& Waylen, 2009). Presently KSNR regionally experiences annual, mostly early wildfires, mostly the result of hunting/poaching 
and agriculture. Since 2004, fire has also been used as a tool to improve grazing resources for wildlife in the north-east section of the park. The structural vegetation types within the KSNR range from closed forests to open woodlands. Much of the forest vegetation was, however, chopped-down in the late 1980s and early 1990s in the run-up to the gazetting of the strict conservation status of the park (Janssen et al., 2018). The KNSR vegetation also has a human footprint with there being some record of occupation for the 19th and 20th century. For example, pottery can be found (Wildlife Department Accra, 1994) and transitional woodland patterns have sometimes been linked to past agricultural activity. Nevertheless, detectable features of past human settlements such as forest patches consisting of Terminalia schimperi (Hochst. ex Hutch. \& Dalziel) Gere \& Boatwr (syn. Anogeissus leicocarpa (DC.) Guill. \& Perr.) which typically persist for decades after village abandonment (Hopkins 1965, Sobey 1978) were not detected in the study area.

A total of 35 plots of $20 \times 20 \mathrm{~m}$ were established in the north-east corner of the park (Figure 1a). This plot size was considered to be small enough to allow for a homogeneous vegetation structure but still large enough to obtain a representative sample of the dominant tree species composition (with there usually being more than 15 trees with a diameter at breast height (dbh) of $2.5 \mathrm{~cm}$ or more in each plot). All plots were located in an area where no recent human disturbances such as logging were detectable. The plots were distributed in patches of varying tree cover across the naturally occurring vegetation mosaic and first classified a priori by eye as savannalike (woody vegetation with incomplete canopy closure and a herb layer of C4 grasses), forest-like (woody vegetation with complete canopy closure and a sparse herb layer of mainly C3 forbs and C3 grasses), and 'intermediate'. Fifteen plots were established in the savanna-like vegetation, 10 plots in the forest-like vegetation, and 10 plots in semi-closed 'intermediate' vegetation. All plots were located a maximum distance of $3.0 \mathrm{~km}$ from each other to allow for likely similar historical fire patterns. Also, plots were only established in flat areas of the landscape $(0-3 \%$ slope estimated by eye) to avoid surface hydrological processes and the influence of catena 
Chapter 3

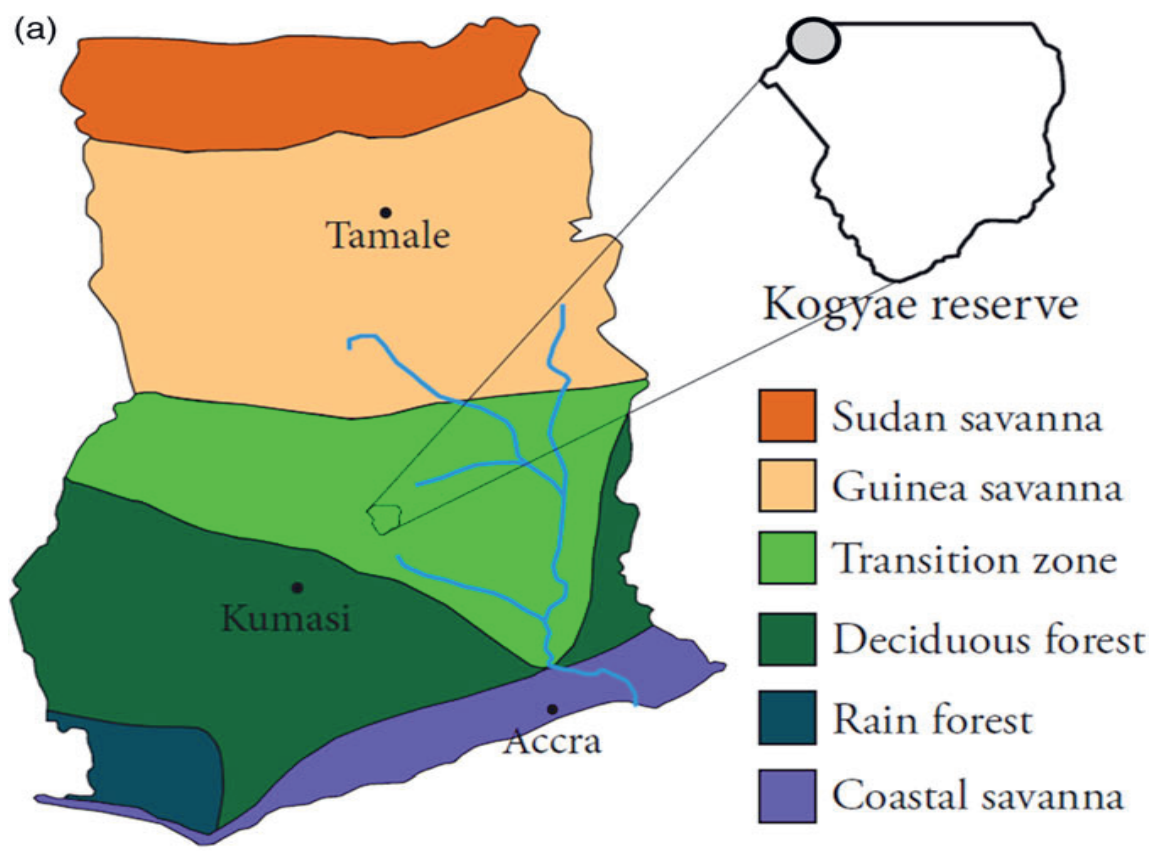

$100 \mathrm{~km}$

(b)

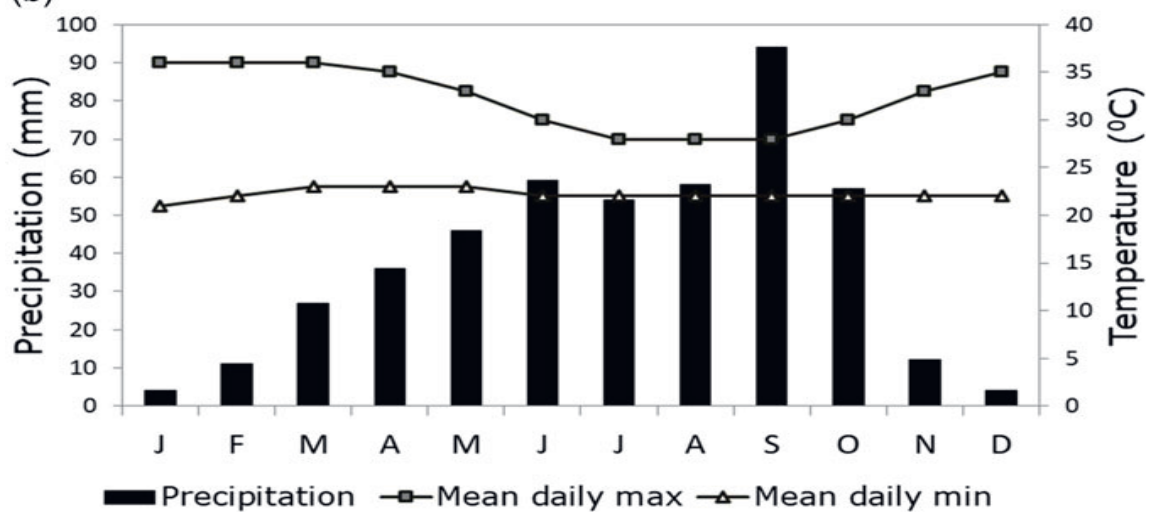

Figure 1. Map of Ghana showing the different vegetation zones and location of the Kogyae Strict Nature Reserve. Vegetation zonation adapted from Yengoh et al. (2010). The grey circle indicates the location of the study site (a). Yearly rainfall and temperature distribution for the Kogyae Strict Nature Reserve (b) (McSweeney et al., 2010; Wildlife Department Accra, 1994). 


\section{Vegetation parameters}

In each plot, diameter and height were measured of trees with a diameter $\geq 2.5 \mathrm{~cm}$ at breast height (dbh). Trees were identified at species level. The crown area of each tree was calculated from crown diameter measured on two perpendicular axes. Total canopy area was calculated by summing up crown areas. Basal area was calculated as the sum of basal area of all individual trees in a plot. Canopy area index (CAI) was determined by dividing total crown area by the area of the plot. Height of all trees $>10 \mathrm{~cm}$ dbh was measured with a laser rangefinder (TruPulse ${ }^{\circledR}$ 200, Laser Technology Inc.). Hemispheric photographs, to determine woody leaf area index (LAI), were taken using a Nikon E4500 camera with fisheye lens, mounted at $1 \mathrm{~m}$ height. Photographs were underexposed by two stops to enhance contrast (Woodgate et al., 2012; Zhang et al., 2005). LAI was determined using Gap Light Analyser imaging software with contrast settings determined by three independent observers (Frazer et al., 1999; Promis et al., 2011).

Tree classification, biomass calculation and structural vegetation plot clustering

Based on information on species habitat and/or distribution as taken from Keay (1989), Hawthorne (1995), and Hawthorne \& Jongkind (2006) all species in the study were classified a priori as savanna-affiliated ( S), forest-affiliated trees ( F) or nonspecialised (N) - the latter species having been reported as regularly occurring in both forest and savanna. Estimates of above-ground woody biomass (AGB) for each plot were calculated using a generic allometric equation for tropical trees (Chave et al., 2014). To investigate similarity in PFT composition, plots were clustered on the basis of the contribution of the PFTs to the total crown area in the plot using all trees $\geq 2.5 \mathrm{~cm}$ dbh, using SPSS version 23.0 (complete linkage and single Euclidian distance to emphasise plot differences). For the second classification, CAI, AGB, average canopy height $(\mathrm{H})$, the 0.95 quantile of average canopy height, $\mathrm{H}^{*}$ : calculated as $\mathrm{H}^{*}=\mathrm{H}+1.645 \sigma$ where $\sigma=$ the plot standard deviation of tree height (Hyndman \& Fan 1996) for trees $\geq 10 \mathrm{~cm}$ dbh. This clustering allows for a classification in structural vegetation types (VST) as defined by Torello-Raventos et al. (2013): 
Chapter 3

\section{Soil chemical and physical analyses}

In September 2014 composite soil samples were taken in the middle of the growing season at depth intervals of $0-10,10-20,20-40,40-60,60-80$ and $80-100 \mathrm{~cm}$ with a cylindrical soil auger at the centre of a plot and in the four quadrants. Samples were air dried before laboratory analysis. Total $\mathrm{N}$ and total P were determined according to Novozamsky et al. (1983). Available P (P-Olsen) was determined according to Olsen (1954). The cation exchange capacity (CEC) and exchangeable K, $\mathrm{Ca}$ and $\mathrm{Mg}$ were determined after extraction with unbuffered $0.01 \mathrm{M} \mathrm{BaCl} 2$ (Gillman, 1979). Percentage organic matter $(\mathrm{OM})$ was determined by loss on ignition. Soil $\mathrm{pH}$ was determined in $\mathrm{H} 2 \mathrm{O}(1: 2.5)$. All soil nutrient data are expressed on a volume basis as nutrients available in $1 \mathrm{~m} 3$ using bulk density measurements taken at 20 -cm intervals from the surface to $100 \mathrm{~cm}$ depth using soil pits.

Soil moisture content (MC) was determined by weighing soil samples (taken in September 2014 and additionally in the dry season in January 2015) in the field with a digital balance of precision $\pm 0.01 \mathrm{~g}$ in situ. The water mass was determined after drying at $80^{\circ} \mathrm{C}$ to constant weight. Percentage soil moisture content was expressed in volume by multiplying the gravimetric water content with bulk density.

Particle size analysis for composite samples representing from the top $20 \mathrm{~cm}$ was as per the Boyoucos method (Gee \& Bauder, 1986). Soil depth (d) in each plot was determined by digging a $1.5 \times 2.0-\mathrm{m}$ soil pit to the ferricrete layer or, on occasion, sandstone layer. In six representative plots, a complete soil description and classification was undertaken with layers of different appearance, thickness and properties arising from various soil-forming processes being recorded. The resulting information was used in conjunction with the laboratory analyses to classify soil types according to the World Resource Base soil classification scheme (IUSS Working Group WRB, 2006) with pit descriptions deposited in the world soil information database. For the remaining 29 
plots, soils were classified by eye by a local pedologist using information acquired from six pits that had been analysed in detail.

Fire occurrence and vegetation cover change

The occurrence of fire was estimated by the fire return time (period 2000-2014) on the basis of the MODIS Burned Area Product (MCD45A1; Roy et al., 2008). As this product has a spatial resolution of $500 \times 500 \mathrm{~m}$ and fire may still be patchy within a landscape, whether a specific plot actually would have burned in a given year cannot be determined precisely. We therefore define a fire occurrence as one in the vicinity of the plot (but not whether the plot has actually burned) and quantified as the fire return time of the pixel in which the plot was located. To evaluate any link between fire history and vegetation change, vegetation cover was determined by calculation of the averaged Normalised Vegetation Index (NDVI) change over the period 1984-2015 in four steps. We first used NDVI derived from Landsat TM (21 November 1984 and 22 November 1990), Landsat ETM+ (15 November 2002) and Landsat OLI (27 November 2015) at a resolution of 30 $\times 30 \mathrm{~m}$. The NDVI from 1984, 1990 and 2002 was then cross-calibrated to the NDVI of 2015 correcting for sensor differences (Mitchard et al., 2009). NDVI trends over the period were subsequently determined for each plot using linear regression across the four data points for NDVI over time and determining the slope of the regression line.

\section{Statistical analyses}

Statistical analyses were undertaken with SPSS version 23 unless stated otherwise. Comparisons of structural properties between plots were done with a single ANOVA and Post- Hoc Tukey test. Data were sometimes log-transformed to ensure normality of the residuals and homogeneity of variances. If this proved insufficient non-parametric tests were applied. To test for differences in tree heights of the tallest trees a general linear model assuming normal error distribution (GLM) was used. GLMs were also used to test whether there were differences in soil nutrients, soil depth and other environmental resources between the PFTs or VSTs. Each GLM was followed by a 
Chapter 3

Tukey post hoc test to determine the differences between the PFT or VST groupings. For the analysis of NDVI cover change trends we used a GLM with PFT or VST groupings as a factor and CAI as a covariate to compensate for the fact that CAI shows a saturating relationship with increasing CAI (Janssen et al., 2018).

Vegetation structural properties were first correlated with soil physical and chemical properties using Kendall's non-parametric rank correlation test. Ordinary Least Squares (OLS) models were used to quantify relationships between $\mathrm{BA}, \mathrm{CAI}$ and $\mathrm{AGB}$ and the measured soil parameters, selecting the minimum adequate model based as that with the lowest Bayes information criterion (BIC) which has a stricter penalty associated with additional terms as compared to the Akaike information criterion (AIC) thus reducing any chance of overfitting (Schwarz 1978). These analyses were undertaken using the $\mathrm{R}$ statistical platform using the dredge function within the MuMIn package (Barton, 2013) with the simplest model within two units of the lowest BIC model (Aho et al., 2014) chosen.

\section{Results}

Classifying vegetation with plant functional or structural properties As detailed in Appendix 1, 56 tree species were found across the 35 study plots of which 19 were classified as savanna-affiliated (S), 26 as forest-affiliated (F) and 11 as non-specialised $(\mathrm{N})$ Classification of plots on the basis of PFT cover contribution resulted in three clusters which, on the basis of their species composition as weighted by canopy cover, were classified as either savanna $(89 \% \pm 3.6 \%$ (mean \pm SE) ST dominance), transitional $(60 \% \pm 5.4 \% \mathrm{~N}$ dominance) or forest $(74 \% \pm 5.5 \% \mathrm{~F}$ dominance; Figure 2a, Appendix 2). Frequently occurring forest (F) tree species included, Ceiba pentandra, Didymosalpinx abbeokutae, Manilkara obovata and Sterculia tragacantha. Dominant savanna (S) trees included Terminalia glaucescens and Pterocarpus erinacens. Typically, ubiquitous non-selective $(\mathrm{N})$ trees include Bridelia micrantha, Lannea nigritana, Margaritaria discoidea and Pouteria alnifolia. 
Fixed or mixed

(a)

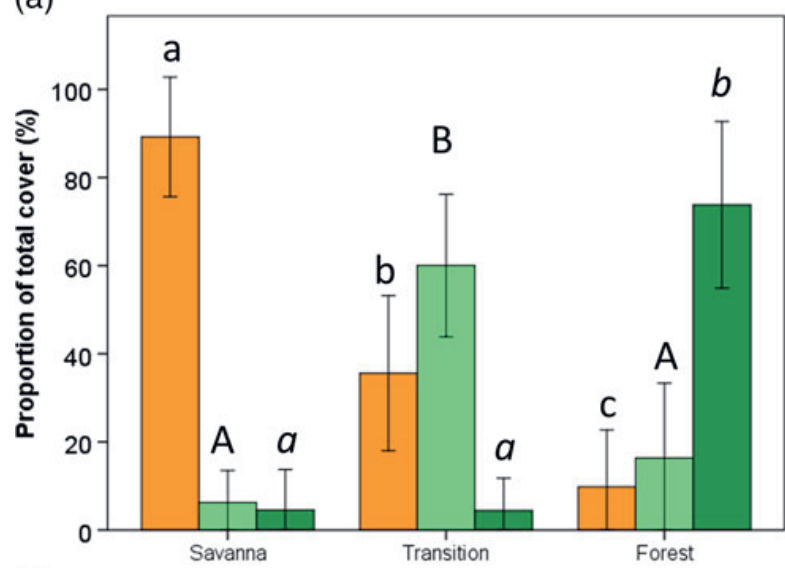

(b)

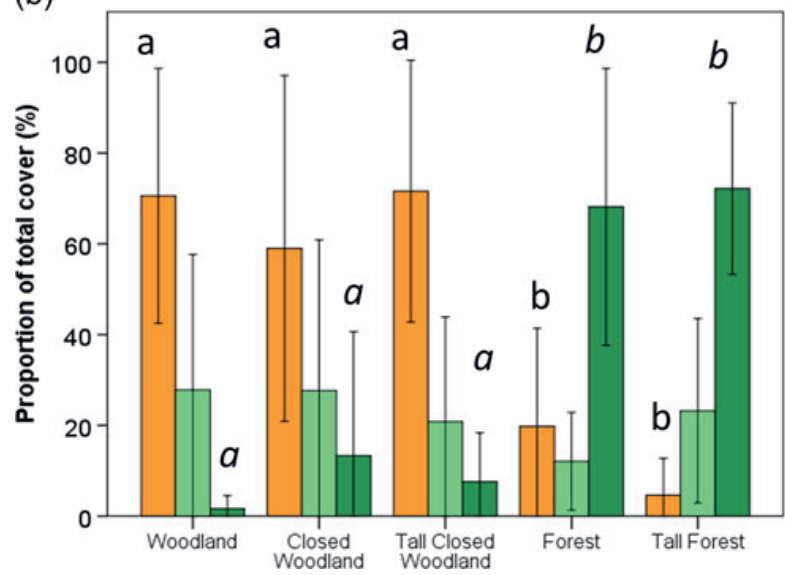

Figure 2. Percentage composition of forest, savanna and non-specialized tree species by crown area in plots at the Kogyae Strict Nature Reserve, Ghana, grouped on the basis of plant functional types (a) and grouped on the basis of the vegetation structural characteristics (b). Orange bars represent savanna trees, light green bars non-specialized trees and dark green bars forest trees. Different letters (small caps, capital, italics) indicate significant differences of the tree types between the classes (one-way ANOVA post hoc Tukey test; $\mathrm{P}<0.05$ ). Error bars denote \pm 1 SD.

Alternatively, classifying on the basis of stand structural parameters resulted in five clusters viz. woodland, closed woodland, tall closed woodland, forest and tall forest (Figure 2b, 3). Woodland (including closed and tall closed) was on average dominated by S-species (59\%-75\%), while F-species dominated the forest and tall forest classifications (on average 68\%-72\%), also 
Chapter 3

being much rarer in other VSTs $(\max 15 \%)$ and almost absent in woodlands. N-species were on average more equally distributed among VSTs (12\%-28\%; Figure $2 \mathrm{~b})$.

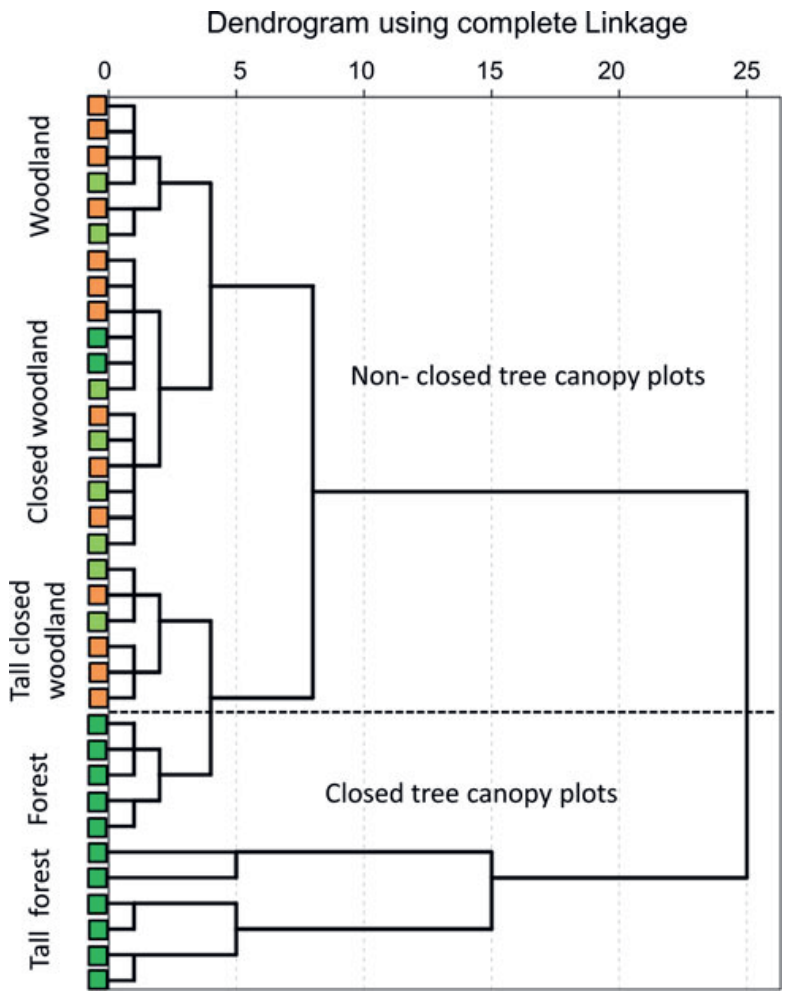

Figure 3. Clustering of the plots at the Kogyae Strict Nature Reserve, Ghana, into vegetation structural types. Typology follows Torello-Raventos et al. (2013) (all trees $\geq 10 \mathrm{~cm} \mathrm{dbh).} \mathrm{Squares}$ on the $\mathrm{y}$ axis identify the plant functional type classification of the same plots (orange $=$ savanna tree dominated, light green $=$ non-specialized tree dominated, dark green $=$ forest tree dominated) (see also Appendix 2).

Variation in dominance of PFTs within individual structural groupings was however large. For example, the woodland grouping contained both S- and N-dominated stands within the closed woodlands grouping encompassing stands dominated by all three PFT (Figure 3). In closedcanopy-forest and tall-forest plots the species PFT classification was always F-affiliated. 
Forest species in woodland and closed woodlands were typically of smaller-than average stature than is typical for this PFT (although sometimes up to ca. $25 \mathrm{~m}$ tall), with the most common F-species in woodland being Sterculia tragacantha Lindl., Vitex grandiflora Gurke and Kigelia africana (Lam.) Benth. S-trees were found only in low numbers in forest and tall forest, but within tall closed woodland and (tall) forest patches, several tall-statured S-affiliated specimens such as Terminalia schimperi and Khaya senegalensis Desr. (height up to $30 \mathrm{~m}$ ) were found. N-species were found in all five VSTs, with this group including taller species such as Afzelia africana $\mathrm{Sm}$. and Lannea nigritana (Scot-Elliot) Keay. Comparing the PFT classification with the VST classification, S-dominated plots were generally classified as woodlands up to tall closed woodlands, N-dominated plots as woodlands to tall closed woodlands, and F-dominated plots as closed woodlands, forest or tall forest. Smaller trees and shrubs (viz. dbh $2.5-5 \mathrm{~cm}$ ) were absent in woodland but constituted $5 \%$ of all trees in VST in the other woodland classes and 15\% in the forest classes (data not shown).

\section{Variation in quantitative vegetation structural properties}

Variation in structural properties for the five VST categories is shown in Figure 4. Average canopy height and 95\% quantile height were lowest for woodlands and closed woodland with both these VSTs being significantly shorter than tall closed woodland and forest (Figure 4a). Leaf area index varied from $1.3 \mathrm{~m}^{2} \mathrm{~m}^{-2}$ to $2.2 \mathrm{~m}^{2} \mathrm{~m}^{-2}$ in tall forests with complete canopy closure - taken here as occurring at a LAI of 1.7 to $1.8 \mathrm{~m}^{2} \mathrm{~m}^{-2}$ equating to a projected crown cover of $60 \%$ - observed for the forest and tall forest plots (Figure 4b). CAI varied between $0.8 \mathrm{~m}^{2} \mathrm{~m}^{-2}$ in woodlands to $3.7 \mathrm{~m}^{2}$ $\mathrm{m}^{-2}$ in tall forest (Figure 4b). AGB increased from around $100 \mathrm{Mg} \mathrm{ha}^{-1}$ in woodlands to over 200 $\mathrm{Mg} \mathrm{ha}{ }^{-1}$ in forest with a large increase to near $600 \mathrm{Mg} \mathrm{ha}^{-1}$ for tall forests (Figure 4c). Average maximum height achieved by individual trees, being the tallest tree recorded for each PFT, in each plot is shown in Figure 4d. 
(a)

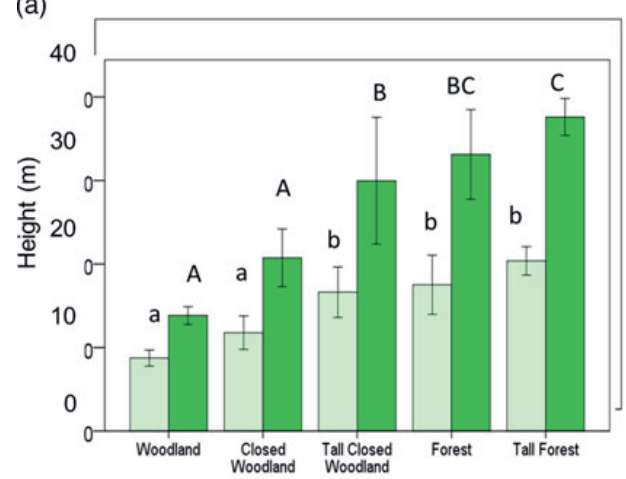

(b)

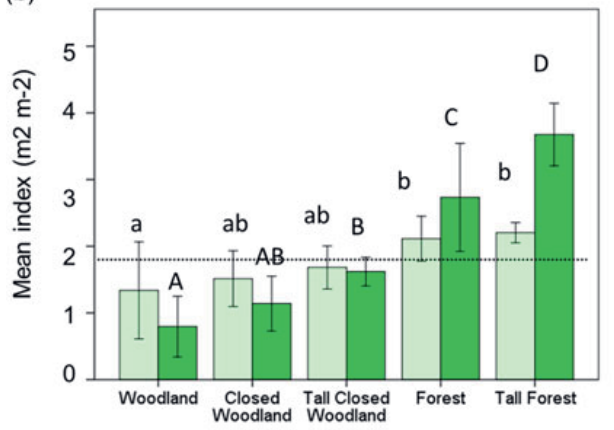

(c)

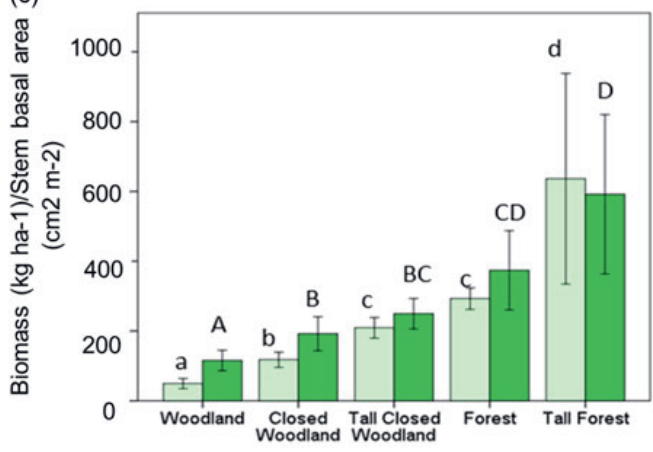

(d)

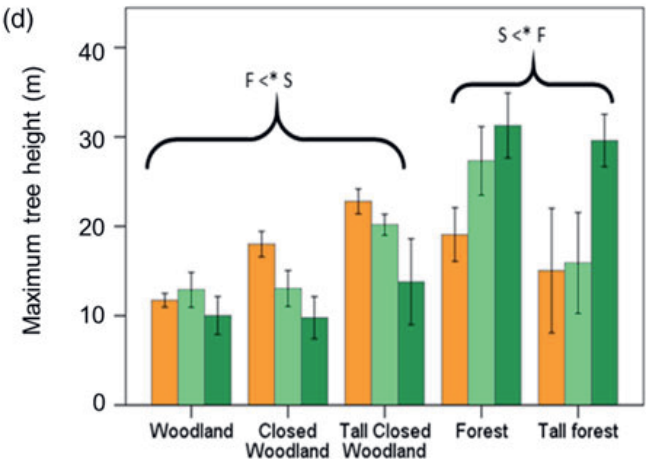

Figure 4. Variation of structural traits across the vegetation structural types of the plots at the Kogyae Strict Nature Reserve, Ghana. Average canopy height (light green bars); 95\% quantile height (dark green bars) (a); leaf area index (light green bars) crown area index (dark green bars) (b), the dotted line indicates a threshold level where the canopy is considered closed. Above-ground biomass (light green bars) and stem basal area (dark green bars) (c). Different letters in a, b and c indicate significant differences between the classes (one-way ANOVA post hoc Tukey test. $\mathrm{P}<$ 0.05) (after log-transforming data for $\mathrm{ABG}$ and $\mathrm{BA}$ ). Maximum tree height per plant functional type (d) (orange bars savanna trees, light green bars non-specialized trees and dark green bars forest trees). Brackets in (d) indicate that savanna trees (S) are significantly taller in woodlands (all types) compared with forest trees $(\mathrm{F})$ and forest trees are significantly taller in forest types. Nonspecialized trees are intermediate in all cases. Error bars denote \pm 1 SD.

Average maximum height differed significantly across the different VSTs with a significant interaction between PFT and VST. (GLM; P< 0.001): F-species were significantly shorter (P < 0.05) than S-species in woodlands (including the closed and tall closed woodlands), but S-species 
were significantly shorter than F-species in the forest and tall-forest plots. On the other hand, maximum tree height for $\mathrm{N}$-species did not vary significantly across VSTs (Figure 4d).

\section{Fire occurrence near plots and vegetation cover change}

Fires were assessed over the period 2000-2015, with most fires occurring in the period after 2005 (with as a result thus in recent years a higher frequency). For the whole period average fire frequency in the vicinity of the plots was $0.35 \pm 0.08 \mathrm{y}^{-1}$ (mean \pm SE) for woodlands, $0.30 \pm 0.05$

$\mathrm{y}^{-1}$ for closed woodland and tall closed woodland plots, $0.29 \pm 0.03 \mathrm{y}^{-1}$ for forest plots and $0.26 \pm$ $0.03 \mathrm{y}^{-1}$ for tall forest plots with only woodlands being significantly different from tall forest plots (one way ANOVA; $\mathrm{F}=2.98, \mathrm{P}<0.35$ with Tukey post hoc test).

Including CAI as (non-significant) covariate, the long-term vegetation cover trend, measured through NDVI change between 1984 and 2015, was significantly different between VSTs (data analysed with a single ANOVA; $\mathrm{F}_{4,30}=4.68, \mathrm{P}<0.005$ ). All VSTs showed an increase in NDVI over the period 1984 -2005 (Figure 5a) with the highest rate of increase in woodland being $0.23 \% \mathrm{y}^{-1}$. Closed woodlands showed an average increase of $0.11 \% \mathrm{y}^{-1}$, with the slowest rate of increase being for the tall forest plots $\left(0.08 \% \mathrm{y}^{-1}\right)$. Cover increase of PFT classified vegetation types was also significantly different between plots (CAI again included as a covariate but now significant; $\mathrm{F}_{(1,31)}=5.06, \mathrm{P}<0.032 ;$ PFT $\left.\mathrm{F}_{(1,32)}=1.44 \mathrm{P}<0.001\right)$ and showed a significantly larger increase of $0.22 \% \pm 0.02 \% \mathrm{y}^{-1}$ (marginal mean $\pm \mathrm{SE}$ ) in $\mathrm{N}$-dominated plots than for S-dominated and $\mathrm{F}$ dominated plots for which the rates of increase were $0.11 \% \pm 0.02 \% \mathrm{yr}^{-1}$ and $0.13 \% \pm 0.02 \% \mathrm{y}^{-1}$ respectively (Figure 5b). 
Chapter 3
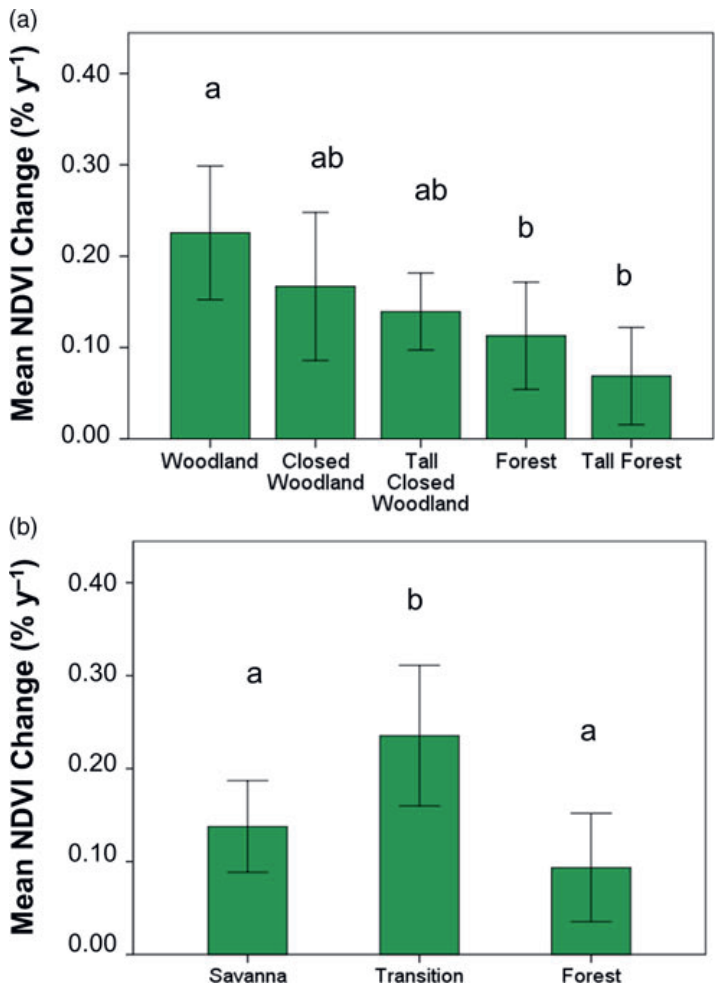

Figure 5. Mean NDVI change in the different vegetation structural types (a) and Plant functional type dominated (b) plots in the Kogyae Strict Nature Reserve, Ghana, over the period 1984-2015. Letters indicate significant differences between the types. (a) One-way ANOVA post hoc Tukey test; P > 005. Error bars denote \pm 1 SD. (b) GLM with CAI as covariate. Means are marginal means with a test of contrasts $P>005$. Error bars denote \pm 1 SE.

\section{Soil physical and chemical parameters and vegetation structural classification}

All soils were of a high sand content (Appendix 3) with woodlands and closed woodlands generally found on Lixisols, and forests mostly on Arenosols. Maximum soil depth ranged from $1.0 \mathrm{~m}$ and $2.6 \mathrm{~m}$ and, although varying significantly between VSTs (GLM analysis $\left(\mathrm{F}_{4,30}=2.93 \mathrm{P}<0.04\right)$, with differences not significant in a post-hoc test, but significant $(\mathrm{P}<0.013)$ with soil depths for forest and tall forest grouped VSTs (average $2.08 \pm 0.26 \mathrm{~m}$ ) versus woodlands and closed woodlands grouped VSTs (average $1.71 \pm 0.43 \mathrm{~m}$.). Soil physical and chemical data integrated across the upper 1-m profile for each plot are shown in Table 1. No significant differences were found in particle 
size between the different VSTs in the first $20 \mathrm{~cm}$ of the soil. Across all plots, increased silt fractions occurred at the expense of lower sand fractions, and with the clay fractions (always less than 0.05 g g-1) also being slightly greater in siltier soils (Appendix 4). Soil $\mathrm{pH}$ (H20) values ranged from 6.1 to 6.4 and did not differ across VSTs (One-way ANOVA, $\mathrm{P}<0.179)$. Soil nutrients were variable and did not differ systematically according to VST. Although wet-season volumetric soil moisture content $(\theta \mathrm{V})$ did not differ significantly between VSTs $\left(\mathrm{GLM}, \mathrm{F}_{4,30}=6.77, \mathrm{P}<0.099\right)$ when sampled in the dry season, soils under forest VSTs had more depleted soil moisture $(\theta \mathrm{V} \sim 0.018)$ as compared to the woodland VSTs $(\theta \mathrm{V} \sim 0.031)$ with these differences being significant at $\mathrm{P}<$ 0.001 .

Table 1. Soil parameters in the vegetation structural type plots at Kogyae, Ghana. Soil Moisture Organic matter, $\mathrm{pH}(\mathrm{H} 2 \mathrm{O})$ and soil nutrients are averaged over $1 \mathrm{~m}$ depth. Particle size analysis was done over the top $20 \mathrm{~cm}$. All values are calculated per volume unless indicated otherwise. Parameters for which significant differences were found are in bold. Superscripts indicate differences at $\mathrm{P}<0.05$; Single ANOVA with post hoc Tukey test.

\begin{tabular}{|c|c|c|c|c|c|c|}
\hline $\begin{array}{l}\text { Vegetation structural } \\
\text { type }\end{array}$ & $\begin{array}{l}\text { Woodland } \\
(n=12)\end{array}$ & $\begin{array}{l}\text { Closed woodland } \\
\qquad(n=6)\end{array}$ & $\begin{array}{c}\text { Tall closed } \\
\text { woodland }(n=6)\end{array}$ & $\begin{array}{l}\text { Forest } \\
(n=5)\end{array}$ & $\begin{array}{l}\text { Tall forest } \\
\qquad(n=6)\end{array}$ & Average all plots \\
\hline Soil parameter & Mean \pm SD & Mean \pm SD & Mean \pm SD & Mean \pm SD & Mean \pm SD & Mean \pm SD \\
\hline $\begin{array}{l}\text { Soil moisture } \\
\text { wet season ( } \% \text { vol) }\end{array}$ & $18.9 \pm 0.81$ & $20.8 \pm 2.35$ & $19.9 \pm 2.26$ & $18.7 \pm 1.54$ & $18.2 \pm 2.36$ & $19.5 \pm 2.19$ \\
\hline $\begin{array}{l}\text { Soil moisture } \\
\text { dry season ( } \% \text { vol) }\end{array}$ & $3.04^{\mathrm{a}} \pm 0.84$ & $3.23^{a} \pm 0.63$ & $3.03^{\mathrm{a}} \pm 0.90$ & $1.76^{b} \pm 0.33$ & $1.80^{b} \pm 0.52$ & $2.71 \pm 0.93$ \\
\hline Sand (\%) (top $20 \mathrm{~cm}$ ) & $87.0 \pm 1.78$ & $85.6 \pm 2.47$ & $84.3 \pm 2.29$ & $83.10 \pm 4.72$ & $84.4 \pm 2.93$ & $85.1 \pm 2.93$ \\
\hline Clay (\%) (top $20 \mathrm{~cm}$ ) & $1.50 \pm 0.52$ & $2.25 \pm 1.13$ & $2.89 \pm 1.11$ & 2.241 .60 & $1.14 \pm 0.82$ & $2.04 \pm 1.17$ \\
\hline Silt (\%) (top $20 \mathrm{~cm})^{1}$ & $11.5 \pm 1.49$ & $12.2 \pm 1.89$ & $12.9 \pm 1.28$ & $14.7 \pm 3.30$ & $14.5 \pm 2.23$ & $12.9 \pm 2.27$ \\
\hline $\mathrm{pH}\left(\mathrm{H}_{2} \mathrm{O}\right)$ & $6.26 \pm 0.24$ & $6.03 \pm 0.26$ & $6.15 \pm 0.22$ & $6.23 \pm 0.35$ & $6.37 \pm 0.37$ & $6.18 \pm 0.30$ \\
\hline $\mathrm{N}$ tot $\left(\mathrm{mg} \mathrm{dm}^{-3}\right)$ & $474 \pm 84$ & $535 \pm 197$ & $485 \pm 137$ & $419 \pm 137$ & $425 \pm 39$ & $480 \pm 149$ \\
\hline$P$ tot $\left(\mathrm{mg} \mathrm{dm}^{-3}\right)$ & $125 \pm 98$ & $106 \pm 49$ & $130 \pm 60$ & $57 \pm 10$ & $8 \pm 13$ & $98 \pm 60$ \\
\hline $\mathrm{CEC}\left(\mathrm{cmol} \mathrm{dm} \mathrm{m}^{-3}\right)$ & $5.22 \pm 3.39$ & $6.27 \pm 3.80$ & $6.88 \pm 4.84$ & $2.48 \pm 2.19$ & $7.58 \pm 3.99$ & $5.88 \pm 3.90$ \\
\hline $\mathrm{Na}\left(\mathrm{cmol} \mathrm{dm}^{-3}\right)$ & $0.70 \pm 0.79$ & $0.80 \pm 0.53$ & $0.51 \pm 0.31$ & $0.41 \pm 0.81$ & $0.75 \pm 0.66$ & $0.67 \pm 0.60$ \\
\hline $\mathrm{K}\left(\mathrm{cmol} \mathrm{dm}^{-3}\right)$ & $0.26 \pm 0.23$ & $0.24 \pm 0.23$ & $0.25 \pm 0.23$ & $0.34 \pm 0.30$ & $0.98 \pm 1.51$ & $0.38 \pm 0.68$ \\
\hline $\mathrm{Mg}\left(\mathrm{cmol} \mathrm{dm}^{-3}\right)$ & $0.67 \pm 0.87$ & $2.23 \pm 2.46$ & $2.21 \pm 3.17$ & $1.73 \pm 2.69$ & $1.10 \pm 0.77$ & $1.69 \pm 2.21$ \\
\hline $\mathrm{Ca}\left(\mathrm{cmol} \mathrm{dm} \mathrm{dm}^{-3}\right)$ & $4.67 \pm 2.57$ & $4.83 \pm 4.06$ & $4.86 \pm 4.12$ & $1.43 \pm 1.04$ & $3.68 \pm 3.74$ & $4.13 \pm 3.52$ \\
\hline
\end{tabular}


Chapter 3

\section{Soil physical and chemical parameters and vegetation structural variation}

Using non-parametric Kendall's $\tau$ to probe associations between the vegetation structural properties of canopy height, crown area index (CAI), leaf area index (LAI), above-ground woody biomass (AGB) and basal area (BA) with environmental and edaphic conditions (Table 2), significant bivariate correlations were found for all four canopy structure metrics and with the frequency of fire occurrence in the vicinity of the study plots $(\mathrm{P}<0.05)$, and with correlations of both LAI and AGB with soil depth $(\mathrm{P}<0.01$ on both cases). Soil silt content was also positively correlated with all of canopy height $(\mathrm{P}<0.05)$, CAI $(\mathrm{P}<0.01)$ and AGB $(\mathrm{P}<0.01)$. There were also negative correlations between all four structural metrics with organic matter content $(\mathrm{P}<0.01)$ and dry-season soil moisture content and negative correlations for some or all of the canopy structural metrics with total $\mathrm{N}$, extractable $\mathrm{P}$ and total $\mathrm{P}$. Organic matter content correlated positively with fire frequency in the vicinity of a plot $(\mathrm{P}<0.01)$ as well as soil water content in the dry season $(\mathrm{P}<0.01)$, also showing positive relationships with total nitrogen $(\mathrm{P}<0.05)$ and both total and exchangeable phosphorus $(\mathrm{P}<0.01)$. Soil depth and exchangeable potassium $(\mathrm{Kex})$ were also positively correlated $(\mathrm{P}<0.01)$.

\section{Soil factors as predictors of vegetation structure}

Ignoring VFT or PFT classification and simply testing plot-level soil parameters directly against the associated CAI, BA or AGB (with the latter two measures being log-transformed due to their heteroscedasticity: Figure 4) both silt fraction $\phi$ silt and log exchangeable potassium [Kex] emerged as the best predictors in all three cases (Table 3) and with a positive interaction between $\phi$ silt and $\log [$ Kex $]$ for both BA $\left(\mathrm{R}^{2}=0.37\right)$ and AGB $\left(\mathrm{R}^{2}=0.41\right)$, but not for CAI $\left(\mathrm{R}^{2}=0.31\right)$ also found. The nature of the predicted responses is shown in the form of a 'heat plot' in Fig. 6 with the observed values also shown. All three metrics of canopy structure showed similar responses with maximum values found when high $[\mathrm{Kex}]$ and high $\phi$ silt occur simultaneously. The same data is 
also shown in the more conventional form of plots of predicted vs. observed values in Fig. SI.X with symbols coloured according to report fire frequency as well.

Table 2. Correlations between vegetation structural parameters and environmental conditions and resources for the plots in Kogyae Strict Nature Reserve, Ghana. Numbers represent Kendall's $\tau$ coefficient $(\mathrm{n}=35 ; *, \mathrm{P}<0.05 ; * *, \mathrm{P}<0.01)$ Can Hgt $=$ Canopy height; CAI $=$ Crown area index; LAI $=$ Leaf area index; $\mathrm{AGB}=$ aboveground biomass; Fire $=$ Fire occurrence in the vicinity of the plot; MC WS $=$ Moisture content Wet season profile; MC DS Moisture content dry season profile; S depth = Soil profile depth; $\%$ Sand top $20 \mathrm{~cm}$; \% Clay top $20 \mathrm{~cm}$; \% Silt top $20 \mathrm{~cm}$; OM = organic matter; P Olson extr.; N total; P total; $\mathrm{EC}=$ Cation exchange capacity; $\mathrm{Na}=\mathrm{Na}$ extractable; $\mathrm{K}=\mathrm{K}$ extractable; $\mathrm{Mg}=\mathrm{Mg}$ extractable and $\mathrm{Ca}=$ Ca extractable. Parameters for which significant differences were found are in bold

\begin{tabular}{|c|c|c|c|c|c|c|c|c|c|c|c|c|c|}
\hline & Can Hgt & CAl & LAI & AGB & BA & MC_Wet & MC_Dry & S_Depth & $\%$ sand & $\%$ silt & Fire & pH_ $\mathrm{H}_{2} \mathrm{O}$ & OM \\
\hline Can Hght & 1.000 & $0.602^{*+}$ & $0.321^{* *}$ & $0.723^{*}$ & $0.586^{*}$ & -0.062 & $-0.433^{*}$ & 0.140 & -0.021 & $0.286^{*}$ & $-0.320^{\star}$ & 0.049 & $-0.342^{* *}$ \\
\hline CAI & & 1.000 & $0.553^{* *}$ & $0.657^{* *} 0$ & $0.685^{*}$ & -0.119 & $-0.553^{*}$ & 0.228 & $-0.246^{\star} \quad-0.056$ & $0.406^{* \prime}$ & $-.0434^{* *}$ & 0.113 & $-0.429^{* *}$ \\
\hline LAI & & & 1.000 & $0.404^{* *} 0$ & $0.462^{*}$ & -0.091 & $-0.543^{*}$ & 0.094 & -0.198 & 0.223 & $-0.597^{*}$ & 0.189 & $-0.421^{*}$ \\
\hline AGB & & & & 1.000 & $0.776^{*}$ & -0.106 & $-0.418^{*}$ & 0.197 & -0.026 & $0.339^{* *}$ & $-0.313^{*}$ & 0.126 & $-0.382 *$ \\
\hline BA & & & & & 1.000 & -0.116 & $-0.399^{*}$ & 0.157 & -0.060 & $0.356^{* \prime}$ & $-0.380^{*}$ & 0.099 & $-0.409^{* *}$ \\
\hline MC_Wet & & & & & & 1.000 & 0.116 & -0.211 & -0.189 & 0.066 & 0.024 & -0.146 & $0.240^{*}$ \\
\hline MC_Dry & & & & & & & 1.000 & -0.187 & 0.118 & $-0.282^{\star}$ & $0.408^{*}$ & $-0.284^{*}$ & $0.445^{* *}$ \\
\hline S_Depth & & & & & & & & 1.000 & $0.327^{*}$ & 0.058 & -0.031 & 0.204 & $-0.309^{* *}$ \\
\hline$\%$ sand & & & & & & & & & $0.551^{*}$ & $-0.745^{*}$ & 0.076 & -0.057 & -0.101 \\
\hline$\%$ clay & & & & & & & & & 1.000 & $.289^{*}$ & 0.090 & -0.101 & $0.397^{* *}$ \\
\hline$\%$ silt & & & & & & & & & & 1.000 & -0.132 & 0.099 & -0.083 \\
\hline Fire & & & & & & & & & & & 1.000 & -0.114 & $0.356^{* *}$ \\
\hline pH_H2O & & & & & & & & & & & & 1.000 & $-0.234^{\star}$ \\
\hline \multirow[t]{2}{*}{$\mathrm{OM}$} & & & & & & & & & & & & & 1.000 \\
\hline & P_Olser & & $\mathrm{N}$-tot & P_tot & & CEC & $\mathrm{Na}$ & $\mathrm{K}$ & $\mathrm{Mg}$ & $\mathrm{Ca}$ & & & \\
\hline Can Hght & $-0.336^{\circ}$ & & -0.170 & -0.197 & & 0.056 & -0.126 & 0.157 & 0.029 & -0.174 & & & \\
\hline CAI & -0.217 & & $-0.271^{\star}$ & $-0.254^{\star}$ & & 0.015 & -0.197 & 0.133 & 0.032 & -0.180 & & & \\
\hline LAI & -0.172 & & $-0.286^{\star}$ & $-0.270^{*}$ & & -0.047 & -0.121 & 0.131 & 0.135 & -0.125 & & & \\
\hline AGB & -0.277 & & -0.176 & $-0.261^{\star}$ & & 0.029 & -0.116 & 0.207 & 0.113 & -0.180 & & & \\
\hline $\mathrm{BA}$ & $-0.318^{\circ}$ & & -0.153 & $-0.274^{\star}$ & & -0.035 & -0.069 & 0.177 & 0.170 & -0.126 & & & \\
\hline MC_Wet & 0.069 & & 0.129 & 0.220 & & -0.055 & 0.163 & 0.062 & 0.217 & 0.025 & & & \\
\hline MC_Dry & 0.153 & & $0.328^{* *}$ & $0.284^{*}$ & & 0.062 & 0.193 & -0.136 & -0.022 & 0.136 & & & \\
\hline S_Depth & 0.065 & & -0.051 & $-0.262^{\star}$ & & 0.136 & 0.075 & $0.330^{* *}$ & 0.000 & -0.160 & & & \\
\hline$\%$ sand & 0.078 & & 0.098 & -0.068 & & 0.044 & 0.068 & 0.000 & 0.017 & 0.088 & & & \\
\hline$\%$ clay & 0.121 & & 0.114 & 0.322 & & -0.087 & 0.002 & -0.026 & 0.032 & -0.101 & & & \\
\hline$\%$ silt & -0.147 & & -0.201 & -0.083 & & -0.008 & -0.123 & 0.012 & -0.062 & -0.150 & & & \\
\hline Fire & 0.183 & & 0.119 & $0.278^{*}$ & & 0.050 & -0.054 & -0.140 & $-0.386^{* *}$ & 0.063 & & & \\
\hline pH_H $\mathrm{H}_{2} \mathrm{O}$ & 0.079 & & -0.049 & -0.187 & & 0.224 & 0.045 & $0.314^{* *}$ & 0.012 & 0.062 & & & \\
\hline OM & $0.311^{\circ}$ & & $0.304^{*}$ & 0.624 & & 0.126 & -0.045 & $-0.267^{\star}$ & -0.126 & 0.200 & & & \\
\hline P_olsen & 1.000 & & $0.281^{\star}$ & $0.338^{4}$ & & 0.069 & 0.032 & 0.106 & -0.076 & 0.022 & & & \\
\hline $\mathrm{N}$-tot & & & 1.000 & 0.176 & & -0.032 & $0.267^{\star}$ & 0.045 & 0.213 & 0.230 & & & \\
\hline P_tot & & & & 1.000 & & 0.200 & -0.139 & -0.220 & $-0.267^{\star}$ & 0.106 & & & \\
\hline CEC & & & & & & 1.000 & -0.032 & 0.042 & $-0.274^{\star}$ & 0.133 & & & \\
\hline $\mathrm{Na}$ & & & & & & & 1.000 & $0.482^{* *}$ & $0402^{* *}$ & 0.049 & & & \\
\hline $\mathrm{K}$ & & & & & & & & 1.000 & $0.314^{* *}$ & -0.106 & & & \\
\hline $\mathrm{Mg}$ & & & & & & & & & 1.000 & 0.055 & & & \\
\hline $\mathrm{Ca}$ & & & & & & & & & & 1.000 & & & \\
\hline
\end{tabular}


Chapter 3

Table 3. Estimates for ordinary least square models relating variation for selected structural variables (basal area and canopy area index) to selected soil variables of the plots in Kogyae Strict Nature Reserve, Ghana. Models were selected on the basis of their Bayes Information Criterion (BIC). Symbols and units: $\phi$ silt $=$ silt fraction $($ dimensionless $) ;[$ Kex $]=$ soil exchangeable potassium $(\mathrm{cmolm}-3)$. Also given is the coefficient of determination adjusted according to the statistic based on the number of independent variables in the model. In all cases the independent variables have been centred on their mean.

\begin{tabular}{|c|c|c|c|c|c|c|c|c|c|}
\hline & \multicolumn{3}{|c|}{$\begin{array}{l}\text { Canopy area index } \\
\qquad\left(\mathrm{m}^{2} \mathrm{~m}^{-2}\right)\end{array}$} & \multicolumn{3}{|c|}{$\begin{array}{c}\log (\text { basal area }) \\
\left(\mathrm{m}^{2} \mathrm{ha}^{-1}\right)\end{array}$} & \multicolumn{3}{|c|}{$\begin{array}{l}\log \text { (above ground biomass) } \\
\left(\mathrm{Mg} \mathrm{DW} \mathrm{ha}^{-1}\right)\end{array}$} \\
\hline & Estimate & SE & $\mathrm{P}$ & Estimate & SE & P & Estimate & SE & P \\
\hline Intercept & 1.77 & 0.16 & 0.030 & 3.14 & 0.08 & $<0.001$ & 5.00 & 0.10 & $<0.001$ \\
\hline $\operatorname{asin}\left(\phi_{\text {silt }}\right)$ & 24.49 & 6.97 & 0.001 & 10.00 & 3.62 & 0.010 & 11.96 & 4.81 & 0.019 \\
\hline $\log \left[K_{\text {ex }}\right]$ & $0.24 \beta$ & 0.145 & 0.102 & 0.155 & 0.076 & 0.148 & 0.176 & 0.100 & 0.086 \\
\hline $\operatorname{asin}\left(\phi_{\text {silt }}\right) \times \log \left[K_{\text {exd }}\right]$ & - & - & - & 6.95 & 3.40 & 0.050 & 11.00 & 4.52 & 0.021 \\
\hline$R^{2}{ }_{\text {adj }}$ & 0.31 & & & 0.37 & & & 0.41 & & \\
\hline
\end{tabular}

\section{Discussion}

\section{Vegetation composition versus structure}

Our main objective here has been to establish the link between plant functional type trees (savanna, transitional and forest species) and vegetation structure in vegetation patches in a forest-savanna mosaic in Ghana (Figure 4). Although our plots were smaller than most, the structural parameters quantified in our $400-\mathrm{m}^{2}$ plot encompassed variation generally observed in forest-savanna transitions (Mitchard et al., 2011; Veenendaal et al., 2015). There were some high biomass plots of above $600 \mathrm{Mg} \mathrm{ha}^{-1}$ in tall forest patches, such variation may be expected in plots of smaller scale as used in our study (Mitchard et al., 2011; Veenendaal et al., 2015). At this spatial scale of investigation, plot classification according to plant functional types (PFTs) showed a clear separation between S-species-dominated plots, N-species-dominated plots and F-speciesdominated plots (Figure 2). This is not surprising as trees often demonstrate clustered distributions at relatively small $\left(400 \mathrm{~m}^{2}\right)$ spatial scales, especially when all tree size classes are included (Couteron \& Kokou, 1997). The distribution of PFTs across the various vegetation structural types (VST) did, however, show a mixing of species. 
Fixed or mixed
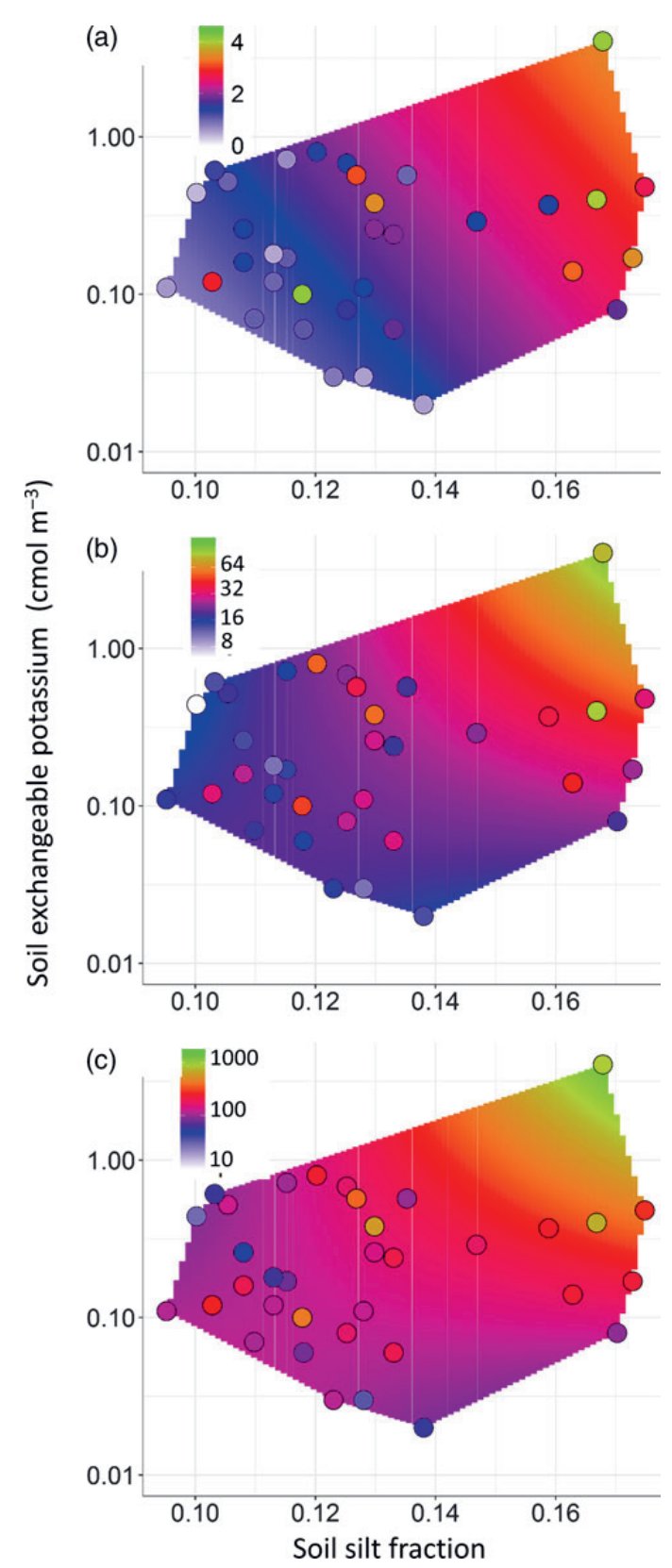

Figure 6. Modelled responses to variations in soil silt fraction, $\phi$ silt, and exchangeable potassium concentration, [Kex]. (a) canopy area index $(\mathrm{m} 2 \mathrm{~m}-2)$, (b) stand basal area $(\mathrm{m} 2 \mathrm{~m}-1)$, (c) above-ground biomass (Mg DW ha-1) for plots at the Kogyae Strict Nature Reserve, Ghana. Observations are shown as circles underlain by a 'heat map' of the modelled response across the dataset [Kex]; $\phi$ silt domain as represented by a convex ull (Rodriguez Casal \& Pateiro L'opez, 2010). 
Chapter 3

Generally, S-trees were mostly limited to woodland (including closed and tall closed) VSTs, with F-trees predominantly occurring in forest VSTs; but with N-trees were found in all VSTs as might be expected from their a priori assigned ubiquitous position (Figure 2). Nevertheless, F-trees occurred in significant numbers in (tall) closed woodlands and S-trees in forest plots. Thus, at our spatial scale of investigation forest and savanna PFTs are thus not exclusively separated. Some mixing of S- and F-species has been recognised before in West African transitional vegetation (Asare, 1962; Charter \& Keay, 1960; Hopkins 1965; Schrodt et al., 2015; Torello-Taventos et al., 2013) and in both over- and understorey (Armani et al., 2018), although this has, at least in some cases, been interpreted as a forest degradation response (Ratnam et al., 2011).

The structural classification employed here has allowed comparisons of how key vegetation characteristics such as cover and biomass vary between the VSTs, also allowing us to quantify how the different PFTs may contribute to the various different structures of the stands. For example, in the more open woodland plots dominated by S- and N-species, forest trees are almost entirely lacking. F-species increase in dominance as canopy closure occurs (Figure 2b and 3) This is likely due to the selective pressure of fire for recruitment of forest tree seedlings with canopy closure (Armani et al., 2018; Boonman et al., 2019; Cardoso et al., 2016; Issifu et al., 2019).

In the forest plots, presumably better growth conditions have allowed F-trees on average to achieve greater heights than S-trees (Figure 4) although individual savanna trees, particularly Terminalia schimperi and Khaya senegalensis were observed to sometimes attain a forest tree stature with heights of up to $30 \mathrm{~m}$. These predominantly savanna species are often mentioned as pioneer species preceding forest expansion into savanna (Hennenberg et al., 2005; Nansen et al., 2001). Tall S trees may also persist in forests long after forest expansion has taken place (Mitchard et al., 2011) explaining part of the mixing of $\mathrm{F}$ - and $\mathrm{S}$-tree species in the larger size classes.

Across all plots in the study area, we found a small increase in tree cover over time to have occurred with an average NDVI increment of $0.15 \% \mathrm{y}^{-1}$ (Figure 5), this being equivalent to a LAI increment of ca. $0.01 \mathrm{y}^{-1}$ or 0.3 units over the 30 -y period (Janssen et al., 2018). Such slow rates of 
increase are difficult to detect at short timescales but provide an indication that canopy closure is increasing. The lowest rate of increase in NDVI was for the tall forest plots, but as the relationship between tree cover (e.g. CAI) and NDVI and vegetation cover saturates at CAI $>2.5$ Janssen et al., 2018; Mitchard et al., 2009) canopy cover increase based on NDVI increment may have been underestimated for the forest formations. Interestingly stands dominated by $\mathrm{N}$-tree species showed the highest NDVI increase. Though undoubtedly a heterogenous group, N-species likely have particular traits of a greater plasticity than is the case of $\mathrm{F}$ - or $\mathrm{N}$ - species, enabling them to persist in variable environments such as forest-savanna ecotones where, for West Africa at least they are commonly observed (Hennenberg et al., 2005; Nansen et al., 2001). In this context it is interesting to speculate on how ongoing increases in $\left[\mathrm{CO}_{2}\right]$ may be playing a role in driving the observed slow canopy cover increase. A continuing global increase in $\left[\mathrm{CO}_{2}\right]$ may be playing a role in driving the observed slow canopy cover increase. In tropical trees intrinsic water use efficiency increases have been demonstrated to occur at a rate of $10 \%$ or more per 50 y (van der Sleen et al., 2015) potentially compensating for the observed reduction of annual rainfall (Owusu \& Waylen, 2009) in the study area. A high fire incidence in our study area does not seem to have prevented a gradual woody cover increase, although it may well have just slowed it down: as, for example, our average NDVI increase is at $0.15 \% \mathrm{y}^{-1}$ much slower than the ca. $1 \% \mathrm{y}^{-1}$ reported for a forest-savanna transition in Central Africa (1985 - 2006) where fire incidence had decreased by 30\% (Mitchard et al., 2011). Nevertheless, we do also note that the Cameroon transition also has higher precipitation and greater exchangeable soil K concentrations (Veenendaal et al., 2015). Fire may also influence species selection through recruitment (Armani et al., 2018; Cardoso et al., 2016; Issifu et al., 2019; Swaine 1992).

\section{Drivers of observed woody cover patterns - fire}

According to the Alternative Stable State paradigm, a large emphasis is put on the role of fire in causing unstable transitional vegetation forms which rapidly tend towards either forest or savanna 
Chapter 3

(Hirota et al., 2011; Lehman et al., 2011; Lehmann et al., 2014). But interestingly, from this study and others, what actually seems to be happening is a longer-term persistence or slow change (at least at decadal timescales) of intermediate vegetation types in many places (Cuni-Sanchez et al., 2016; Goetze et al., 2006;). Notwithstanding this, in vegetation types where edaphic conditions are not sufficient to permit canopy closure, there is a strong correlation with fire frequency (Table 2), which is, itself, likely to have influenced canopy cover (for a quantitative analysis of this process see Veenendaal et al., 2018). Nevertheless, using the mean fire frequency estimates available here, less than $25 \%$ of the data set variation in CAI could be explained by variation in fire frequency (OLS: $\mathrm{R} 2=0.21, \mathrm{P}<0.005)$, this being much less than the variation accountable for by the soil properties of Table 3. More detailed observations of fire behaviour in different vegetation structural types in our study area are needed to better understand the relationship between closing cover, fire effects and recruitment opportunities of savanna, forest and non-specialist PFTs in forest-savanna ecotones, especially as regards their interactions with soil physical and chemical properties. Drivers of observed woody cover patterns - soils Soil physical and chemical characteristics have already been documented to influence vegetation structure as well as species composition in the study region (Asare, 1962; Markham \& Babbedge, 1979; Swaine et al., 1977). Although there were significant correlations between vegetation structural parameters and soil nutrients, once grouped together we found no large differences between VSTs in nutrient status in our site (Table 1). Nevertheless, organic matter was higher underneath the more open vegetation types, possibly related to accumulation of oxidation resistant carbon of pyrogenic origin or directly related to soil characteristics not measured (Saiz et al., 2012). Although there is some evidence for soil nutrients being co-determinant of the positioning of the forest boundary globally (Veenendaal et al., 2015), the variation in our nutrient measurements between our VST structural groupings did not show significant differences. Nevertheless, when variation in CAI, BA and AGB were considered across the dataset as whole, significant relationships involving $[\mathrm{K}]$ ex and silt fraction were observed (Table 3). These associations are consistent with the Combined Water and Potassium (CWAK) hypothesis 
of Lloyd et al. (2015) as originally developed in South America. That hypothesis supposes that where water content of the rooting zone is also important. The latter should be dependent on both rooting depth and soil texture, and according to the models of Table 3 for the very sandy soils of the study area here it seems that relatively minor changes in silt content may be of critical importance. A rough estimate of the likely magnitude of any silt effect can be obtained using the moisture pedo-transfer function of Oliveira et al. (2002) which, developed in the semi-arid region of northeast Brazil, is one of the few available that calculates plant available water (PAW) as a function of all of silt, clay and sand fractions (Tomasella \& Hodnett, 2004). The Oliveira et al. (2002) equation also requires an estimate of soil bulk density $\rho$ and, taking our study average of $\rho$ $=1.51 \mathrm{Mg} \mathrm{m}-3$, then with the silt/sand/clay associations of Appendix 4 we obtain for $\phi$ silt $=0.10$ g g-1 an associated PAW of ca. $0.035 \mathrm{~m} 3 \mathrm{~m}-3$. But for $\phi$ silt $=0.15 \mathrm{~g}$ g-1 the same equation gives $\mathrm{PAW} \cong 0.048 \mathrm{~m} 3 \mathrm{~m}-3$. Thus, for the coarsely textured soils encountered here an increase in silt fraction of 5\% (in absolute terms) might reasonably be expected to result in an increase in PAW of over 30\% (in relative terms). Or put another way, integrated over a 2 -m depth profile then a soil with a silt fraction of $0.15 \mathrm{~g} \mathrm{~g}-1$ can potentially store nearly $1.0 \mathrm{~m}$ of $\mathrm{H} 20$, but with a silt fraction of 0.10 then the equivalent amount is only about $0.7 \mathrm{~m} \mathrm{H} \mathrm{20:} \mathrm{this} \mathrm{difference} \mathrm{of} \mathrm{about} 0.3 \mathrm{~m} \mathrm{H} 20$ equating to about 1-mo wet-season rainfall (Figure 1b).

In addition to this soil texture effect, impenetrable layers such as fericretes may obstruct the downward drainage of groundwater (Batjes, 1996). In our study area such impermeable layers generally occurred, but for forest soils these were found on average almost $40 \mathrm{~cm}$ deeper than woodland plots. A deeper soil profile for forest soils should thus allow for a larger volume of stored water, this then amplifying the silt potassium is a critical nutrient for plant function and growth, especially in water-limited environments effect on PAW per unit volume as discussed above. Together these effects could shorten the period of complete depletion of soil water in the upper profile in the dry season by almost 1 mo (Huttel, 1975; Veenendaal et al., 1996b). Soil depth variation such as found by us is already well known to strongly influence tropical vegetation 
Chapter 3

structure (Hiernaux et al., 2009; Keay, 1960; Lloyd et al., 2015; Markham \& Babbedge, 1979; Moore \& Attwell, 1999; San José \& Farinas, 1983) with Hartemink \& Huting (2008) also noting that small variations in silt content are strongly associated with relatively large changes in the physical and chemical properties of South African Arenosols. Large-scale global analyses considering soils only in terms of their surface-layer sand and carbon contents (Lehman et al., 2014) must by necessity ignore such subtle but important variation in soil properties which are no doubt important in influencing tropical vegetation structure across a range of scales.

\section{Conclusion}

We aimed to look at variation in vegetation structure and plant functional type composition within a forest-savanna transition zone as related to fire frequency and soil physical and chemical properties. We found evidence for soil-available-water related parameters, silt content, soil depth and exchangeable potassium to all be playing a role in patch distribution and PFT composition. On the other hand, we did not find support for a bimodal system of fire-prone vegetation consisting of fire tolerant savanna tree species and fire-suppressed vegetation consisting of fire sensitive forest tree species as proposed in ASS theory. Rather our ecotonal mosaic consisted of a range of plots of varying canopy cover and with these plots also varying in their relative abundances of savanna, non-specialist and forest species.

\section{Acknowledgements}

This paper is dedicated to the memory of Mr. Ntim Gyakari who assisted with his extensive botanical knowledge. We thank the Wildlife Division of the Forestry Commission of Ghana for permission to work in the Kogyae Strict Nature Reserve. Our appreciation also goes to the Park Manager, Mr. Dwoben Nyantakyi, and his staff at Dome Camp, particularly Isaac Sarpong, Kwaku Yinye and Yaw Agyeman. Elmar Veenendaal and George Ametsitsi were partially funded by the EU KP7 GEOCARBON project (contract number 283080). Jon Lloyd and Vincent Logah received support through Royal Society - DFID (Africa capacity building initiative programme) and with Jon Lloyd also being supported by a Royal Society Wolfson fellowship 
Fixed or mixed

\section{Appendices}

\section{Appendix 1.}

List of tree species in the study plots in the Kogyae Strict Nature Reserve and their division in

Plant functional type $(\mathrm{F}=$ forest tree; $\mathrm{S}=$ savanna tree; $\mathrm{N}=$ non-specialized tree) See main text for further explanation

\begin{tabular}{|c|c|}
\hline SPECIES & $\begin{array}{c}\text { Plant functional } \\
\text { type (PFT) }\end{array}$ \\
\hline Afzelia africana Pers. & $\mathrm{N}$ \\
\hline Albizia adianthifolia (Schum.) W.Wight & $\mathrm{F}$ \\
\hline Albizia coriaria Oliv. & $S$ \\
\hline Berlinia grandiffora (Vahl) Hutch. \& Dalżel & $\mathrm{N}$ \\
\hline Bombax buonopozense P.Beauv. & $\mathrm{F}$ \\
\hline Borassus aethiopum Mart. & s \\
\hline Bridelia micrantha (Hochst) Baill. & N \\
\hline Ceiba pentandra (L.) Gaertn. & $\mathrm{F}$ \\
\hline Cola caricifolia (G.Don) K.Schum. & $\mathrm{F}$ \\
\hline Cola gigantea A.Chev. & $\mathrm{F}$ \\
\hline Cola lateritia K.Schum. & $\mathrm{F}$ \\
\hline Cussonia arborea Hochst. ex A.Rich & $S$ \\
\hline Dacryodes klaineana (Pierre) H.J.Lam & $\mathrm{F}$ \\
\hline Daniellia oliveri (Rolfe) Hutch. \& Dalziel & $s$ \\
\hline Detarium senegalense J.F.Gmel. & N \\
\hline Dialium guineense Willd. & $\mathrm{F}$ \\
\hline Diospyros mespiliformis Hochst. ex A.DC. & $\mathrm{N}$ \\
\hline Didymosalpinx abbeokutae (Hiern) Keay & $\mathrm{F}$ \\
\hline Elaeis guineensis Jacq. & $\mathrm{F}$ \\
\hline Erythrophleum suaveolens (Guill. \& Perr.) Brenan & $\mathrm{F}$ \\
\hline Ficus sp & N \\
\hline Gardenia erubescens Stapf \& Hutch. & S \\
\hline Grewia sp & $\mathrm{F}$ \\
\hline Quassia undulata (Guill. \& Perr.) D.Dietr. & $\mathrm{F}$ \\
\hline Holarhena floribunda (G.Don) T.Durand \& Schinz & $\mathrm{F}$ \\
\hline Hymenocardia acida Tul. & $S$ \\
\hline
\end{tabular}

\begin{tabular}{|c|c|}
\hline SPECIES & $\begin{array}{l}\text { Plant functional } \\
\text { type (PFT) }\end{array}$ \\
\hline Khaya senegalensis (Desv.) A.Juss. & s \\
\hline Kigelia africana (Lam.) Benth. & $\mathrm{F}$ \\
\hline Lannea acida A.Rich. & $s$ \\
\hline Lannea nigritana (Scott-Elliot) Keay & N \\
\hline Lecaniodiscus cupanioides Planch, ex Benth. & $\mathrm{F}$ \\
\hline Lepisanthes senegalensis (Poir.) Leenh. & s \\
\hline Lonchocarpus sericeus (Poir.) DC. & $\mathrm{F}$ \\
\hline Lophira lanceolata Tiegh. ex Keay & s \\
\hline $\begin{array}{l}\text { Manilkara obovata (Sabine \& G.Don) } \\
\text { J.H.Hemsl. }\end{array}$ & $\mathrm{F}$ \\
\hline Maranthes polyandra (Benth.) Prance & $s$ \\
\hline Margaritaria discoidea (Baill.) G.LWebster & $\mathrm{N}$ \\
\hline Milicia excelsa (Welw.) C.C.Berg & $\mathrm{F}$ \\
\hline Monodora angolensis Welw. & $\mathrm{F}$ \\
\hline Sarcocephalus latifolius (Sm.) E.A.Bruce & s \\
\hline Bauhinia thonningii Schum. & $s$ \\
\hline Pouteria alnifolia (Baker) Roberty & $\mathrm{N}$ \\
\hline Pseudocedrela kotschyi (Schweinf.) Harms & s \\
\hline Pterocarpus erinaceus Poir. & s \\
\hline Ricinodendron heudelotii (Baill.) Heckel & $\mathrm{F}$ \\
\hline Spathodea campanulato P.Beauv. & $\mathrm{F}$ \\
\hline Sterculia tragacantha Lindl. & $\mathrm{F}$ \\
\hline Syzygium abbreviatum Merr. & N \\
\hline Terminalia glaucescens Planch. ex Benth. & s \\
\hline $\begin{array}{l}\text { Terminalia schimperi" (Hochst. ex Hutch \& Dalziel) } \\
\text { Gere \& Boatwr. }\end{array}$ & s \\
\hline Trichilia nubescens Oliv & $\mathrm{F}$ \\
\hline Uvaria chamae P.Beauv. & $\mathrm{N}$ \\
\hline Vitellaria paradoxa C.F.Gaertn. & s \\
\hline Vitex grandiffolia Gürke & $\mathrm{F}$ \\
\hline Zanthoxylum zanthoxylaides (Lam.) Zepern. \& Timler & $S$ \\
\hline
\end{tabular}


Chapter 3

\section{Appendix 2}

Clustering of the sampled plots into Plant functional types dominated plot types based on cover (all trees $\geq 2.5 \mathrm{~cm}$ dbh). Number on the y axis refers to the plot numbers.

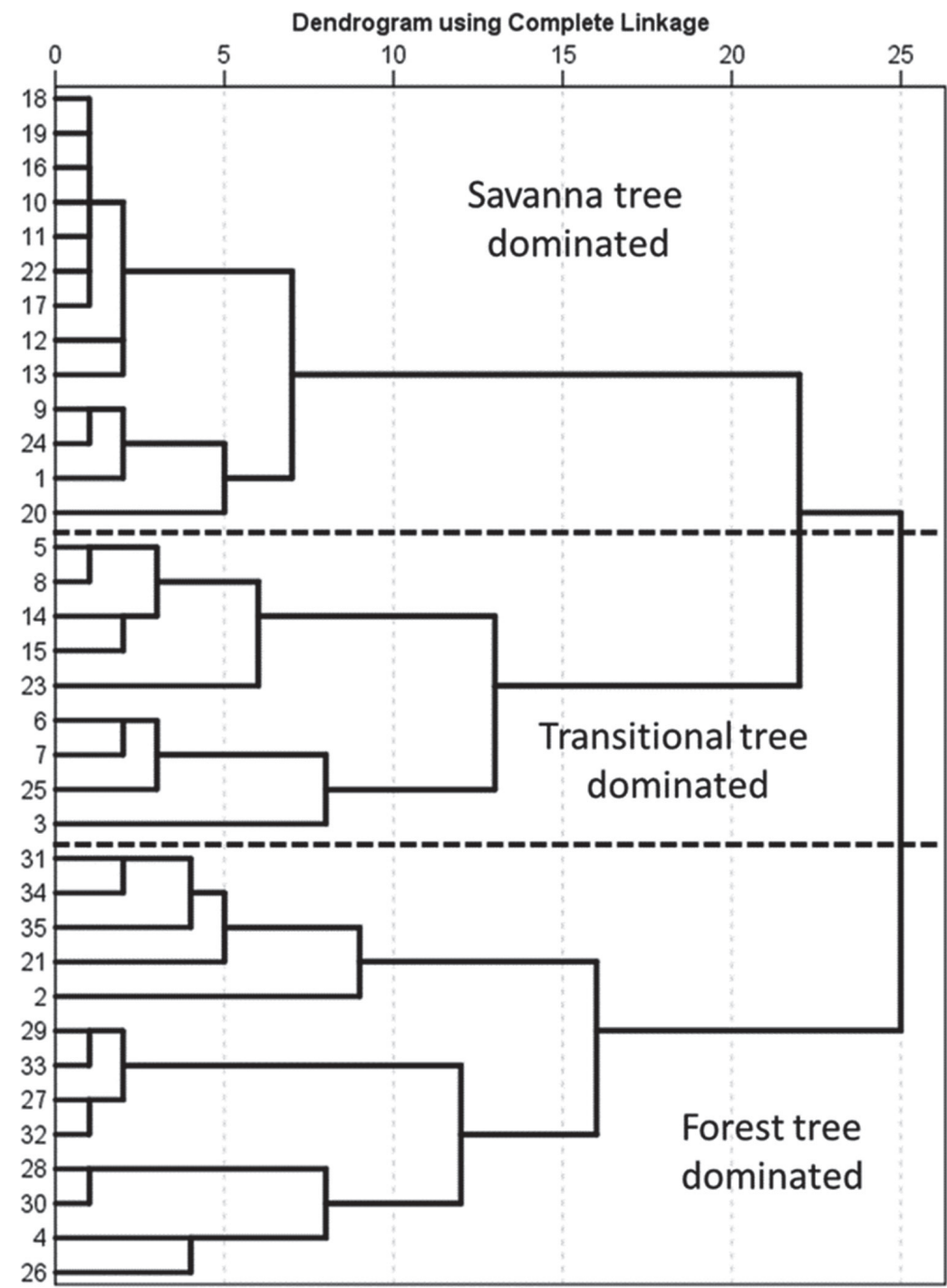


Fixed or mixed

\section{Appendix 3.}

Classification of vegetation patches in the study area and soil classification

\begin{tabular}{|c|c|c|c|c|}
\hline $\begin{array}{l}\text { Plot } \\
\text { Number }\end{array}$ & $\begin{array}{l}\text { Plant } \\
\text { functional } \\
\text { type } \\
\text { dominance }\end{array}$ & $\begin{array}{l}\text { Classification } \\
\text { Based on } \\
\text { structure }\end{array}$ & $\begin{array}{l}\text { Soil type } \\
\text { top } 20 \\
\mathrm{~cm}\end{array}$ & $\begin{array}{l}\text { Soil Type } \\
\text { WBR } \\
\text { classification }\end{array}$ \\
\hline 1 & Savanna & $\begin{array}{l}\text { Closed } \\
\text { woodland }\end{array}$ & Sand & $\begin{array}{l}\text { Abruptic } \\
\text { Lixisol }\end{array}$ \\
\hline 2 & Savanna & Forest & Sand & $\begin{array}{l}\text { Abruptic } \\
\text { Lixisol }\end{array}$ \\
\hline 3 & Transition & $\begin{array}{l}\text { Tall closed } \\
\text { woodland }\end{array}$ & $\begin{array}{l}\text { Loamy } \\
\text { sand }\end{array}$ & $\begin{array}{l}\text { Abruptic } \\
\text { Lixisol }\end{array}$ \\
\hline 4 & Forest & $\begin{array}{l}\text { Closed } \\
\text { woodland }\end{array}$ & $\begin{array}{l}\text { Loamy } \\
\text { sand }\end{array}$ & $\begin{array}{l}\text { Abruptic } \\
\text { Lixisol }\end{array}$ \\
\hline 5 & Transition & $\begin{array}{l}\text { Tall closed } \\
\text { woodland }\end{array}$ & $\begin{array}{l}\text { Loamy } \\
\text { sand }\end{array}$ & $\begin{array}{l}\text { Abruptic } \\
\text { Lixisol }\end{array}$ \\
\hline 6 & Transition & $\begin{array}{l}\text { Closed } \\
\text { woodland }\end{array}$ & $\begin{array}{l}\text { Loamy } \\
\text { sand }\end{array}$ & $\begin{array}{l}\text { Abruptic } \\
\text { Lixisol }\end{array}$ \\
\hline 7 & Transition & $\begin{array}{l}\text { Closed } \\
\text { woodland }\end{array}$ & $\begin{array}{l}\text { Loamy } \\
\text { sand }\end{array}$ & $\begin{array}{l}\text { Abruptic } \\
\text { Lixisol }\end{array}$ \\
\hline 8 & Transition & Woodland & Sand & $\begin{array}{l}\text { Abruptic } \\
\text { Lixisol }\end{array}$ \\
\hline 9 & Savanna & $\begin{array}{l}\text { Closed } \\
\text { woodland }\end{array}$ & $\begin{array}{l}\text { Loamy } \\
\text { sand }\end{array}$ & $\begin{array}{l}\text { Chromic } \\
\text { Lixisol }\end{array}$ \\
\hline 10 & Savanna & Woodland & Sand & $\begin{array}{l}\text { Chromic } \\
\text { Lixisol }\end{array}$ \\
\hline 11 & Savanna & $\begin{array}{l}\text { Closed } \\
\text { woodland }\end{array}$ & Sand & $\begin{array}{l}\text { Chromic } \\
\text { Lixisol }\end{array}$ \\
\hline 12 & Savanna & Woodland & $\begin{array}{l}\text { Loamy } \\
\text { sand }\end{array}$ & $\begin{array}{l}\text { Chromic } \\
\text { Lixisol }\end{array}$ \\
\hline 13 & Savanna & $\begin{array}{l}\text { Closed } \\
\text { woodland }\end{array}$ & $\begin{array}{l}\text { Loamy } \\
\text { sand }\end{array}$ & $\begin{array}{l}\text { Chromic } \\
\text { Lixisol }\end{array}$ \\
\hline 14 & Transition & Woodland & $\begin{array}{l}\text { Loamy } \\
\text { sand }\end{array}$ & $\begin{array}{l}\text { Pisoplinthic } \\
\text { Lixisol }\end{array}$ \\
\hline 15 & Transition & Woodland & Sand & $\begin{array}{l}\text { Pisoplinthic } \\
\text { Lixisol }\end{array}$ \\
\hline 16 & Savanna & $\begin{array}{l}\text { Tall closed } \\
\text { woodland }\end{array}$ & $\begin{array}{l}\text { Loamy } \\
\text { sand }\end{array}$ & $\begin{array}{l}\text { Chromic } \\
\text { Lixisol }\end{array}$ \\
\hline 17 & Savanna & Woodland & Sand & $\begin{array}{l}\text { Chromic } \\
\text { Lixisol }\end{array}$ \\
\hline 18 & Savanna & $\begin{array}{l}\text { Tall closed } \\
\text { woodland }\end{array}$ & Sand & $\begin{array}{l}\text { Chromic } \\
\text { Lixisol }\end{array}$ \\
\hline 19 & Savanna & $\begin{array}{l}\text { Closed } \\
\text { woodland }\end{array}$ & $\begin{array}{l}\text { Loamy } \\
\text { sand }\end{array}$ & $\begin{array}{l}\text { Chromic } \\
\text { Lixisol }\end{array}$ \\
\hline 20 & Savanna & $\begin{array}{l}\text { Tall closed } \\
\text { woodland }\end{array}$ & $\begin{array}{l}\text { Loamy } \\
\text { sand }\end{array}$ & $\begin{array}{l}\text { Chromic } \\
\text { Lixisol }\end{array}$ \\
\hline 21 & Forest & $\begin{array}{l}\text { Closed } \\
\text { woodland }\end{array}$ & $\begin{array}{l}\text { Loamy } \\
\text { sand }\end{array}$ & $\begin{array}{l}\text { Chromic } \\
\text { Lixisol }\end{array}$ \\
\hline 22 & Savanna & $\begin{array}{l}\text { Closed } \\
\text { woodland }\end{array}$ & Sand & $\begin{array}{l}\text { Chromic } \\
\text { Lixisol }\end{array}$ \\
\hline 23 & Transition & $\begin{array}{l}\text { Closed } \\
\text { woodland }\end{array}$ & Sand & $\begin{array}{l}\text { Pisoplinthic } \\
\text { Lixisol }\end{array}$ \\
\hline
\end{tabular}

\begin{tabular}{|c|c|c|c|c|}
\hline $\begin{array}{l}\text { Plot } \\
\text { Number }\end{array}$ & $\begin{array}{l}\text { Plant } \\
\text { functional } \\
\text { type } \\
\text { dominance }\end{array}$ & $\begin{array}{l}\text { Classification } \\
\text { Based on } \\
\text { structure }\end{array}$ & $\begin{array}{l}\text { Soil type } \\
\text { top } 20 \\
\mathrm{~cm}\end{array}$ & $\begin{array}{l}\text { Soil Type } \\
\text { WBR } \\
\text { classification }\end{array}$ \\
\hline 24 & Savanna & $\begin{array}{l}\text { Tall closed } \\
\text { woodland }\end{array}$ & $\begin{array}{l}\text { Loamy } \\
\text { sand }\end{array}$ & $\begin{array}{l}\text { Chromic } \\
\text { Lixisol }\end{array}$ \\
\hline 25 & Transition & $\begin{array}{l}\text { Closed } \\
\text { woodland }\end{array}$ & Sand & $\begin{array}{l}\text { Chromic } \\
\text { Lixisol }\end{array}$ \\
\hline 26 & Forest & Tall forest & $\begin{array}{l}\text { Loamy } \\
\text { sand }\end{array}$ & Arenosol \\
\hline 27 & Forest & Tall forest & Sand & Arenosol \\
\hline 28 & Forest & Tall forest & Sand & Arenosol \\
\hline 29 & Forest & Forest & $\begin{array}{l}\text { Loamy } \\
\text { sand }\end{array}$ & Arenosol \\
\hline 30 & Forest & Tall forest & Sand & Arenosol \\
\hline 31 & Forest & Forest & Sand & Arenosol \\
\hline 32 & Forest & Tall forest & $\begin{array}{l}\text { Loamy } \\
\text { sand }\end{array}$ & Arenosol \\
\hline 33 & Forest & Forest & $\begin{array}{l}\text { Loamy } \\
\text { sand }\end{array}$ & Arenosol \\
\hline 34 & Forest & Tall forest & $\begin{array}{l}\text { Loamy } \\
\text { sand }\end{array}$ & Arenosol \\
\hline 35 & Forest & Forest & $\begin{array}{l}\text { Loamy } \\
\text { sand }\end{array}$ & Arenosol \\
\hline
\end{tabular}


Chapter 3

\section{Appendix 4}

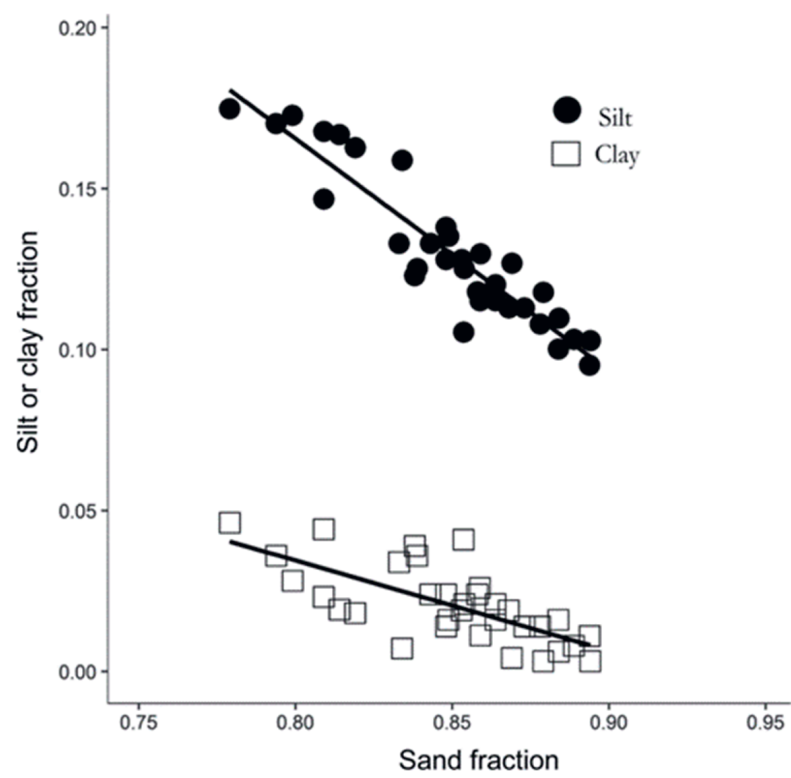

The relationship between sand, silt and clay fractions across the study sites. For silt fraction vs. sand fraction, the OLS regression equation is $\mathrm{y}=0.394-0.387 \mathrm{x}(\mathrm{r} 2=0.86)$ and for the clay fraction vs. the sand fraction the equation is $\mathrm{y}=0.173-0.150 \mathrm{x}(\mathrm{r} 2=0.48)$.

\section{Appendix 5}
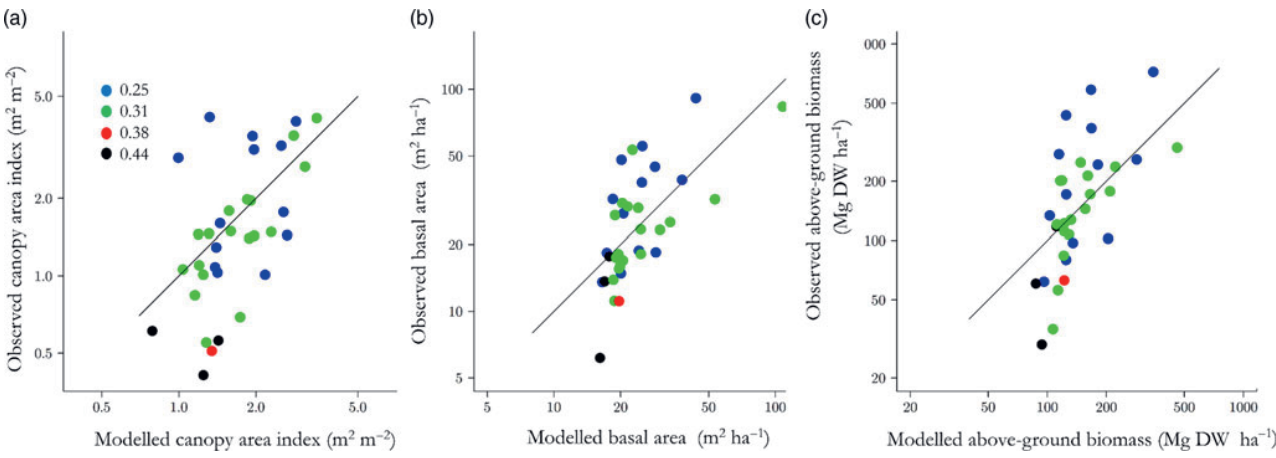

Predictive ability of the models of Table 3. (a) Canopy area index, (b) stand basal area ( $\mathrm{m} 2 \mathrm{ha}-1)$, (c) above-ground biomass. Symbols are colour coded according to MODIS Burned Area Product derived fire frequency (a-1) for the period 2000-2014 as detailed in panel (a). 


\section{Chapter 4}

Sharp transitions with soft edges? Three years of field observations reveal multiple fire-mediated feedbacks in a forest-savanna ecotone in West

Africa

George K.D. Ametsitsi, Frank Van Langevelde, Thomas A.J. Janssen, Jose A. Medina-Vega, Hamza Issifu, Laurianne Ollivier, Stephen Adu-Bredu, Vincent Logah, Philippine Vergeer, Jon Lloyd \& Elmar M. Veenendaal 
Chapter 4

\section{Abstract}

Aiming to understand the role of tree cover and tree species composition on fire intensity and expansion, we monitored natural fire frequency and intensity across a range of vegetation types in an ecotonal area in Ghana, West Africa. For woodlands, below a woody vegetation leaf area index ( $\left.L_{\mathbb{W}}\right)$ threshold of 1.5 to $2.0, \mathrm{C}_{4}$ grass herbaceous biomass accumulated resulting in a fuel load of ca. $6.0 \mathrm{t} \mathrm{ha}^{-1}$ (moisture content $<30 \%$ ). In forests $\left(L_{\mathbb{W}}>2\right.$ ), standing herbaceous fuel loads were typically much lower, averaging around $2.5 \mathrm{t} \mathrm{ha}^{-1}$, and with higher moisture content. On the other hand, dry leaf litter densities increased from $0.5 \mathrm{tha}^{-1}$ in woodlands to more than $1.5 \mathrm{t} \mathrm{ha}^{-1}$ in forests. This difference in fuel load source and moisture content resulted in two distinct types of fire which co-occur on the landscape scale. First, we identified high intensity fires in the more open woodland $\left(L_{\mathbb{W}}<1.5\right)$ sustained by a high standing herbaceous layer fuel load. These fires attained heights of up to $2 \mathrm{~m}$ and with ambient temperatures as high as $300{ }^{\circ} \mathrm{C}$ being measured. Second, there are lower intensity more benign leaf litter fires which typically occur in forests with $L_{\mathbb{W}}>2$. These more benign fires, which do not attain heights greater than $0.5 \mathrm{~m}$ and generated ambient temperatures typically around $100{ }^{\circ} \mathrm{C}$, are typically associated with "non-specialised" tree species which are not clearly associated with either open savanna or denser forest-like vegetation types. We hypothesize a mechanism for the maintenance of such species with their early deciduous nature of a critical importance. This observed duality of fire types as observed in the current study leads to what we term "soft fire transitions". This is in contrast to a simple savanna $v$ s. forest, fire $v$ s. nofire dichotomy that results in a "hard fire transition", such as currently prevails in the literature.

Keywords: canopy cover, forest-savanna ecotone, vegetation structure, litter, standing fuelload, fire. 


\section{Introduction}

Fire-mediated feedbacks are considered the most important mechanism underlying the coexistence of forest and savanna as Alternate Stable States (ASS) in Forest-Savanna (FS) ecotones (e.g., Hirota et al., 2011; Staver et al., 2011). The proposed mechanism relies on the notion that fires can be supressed when a tree canopy cover is dense enough to outcompete grasses, the latter constituting the principal fuel source enabling the penetration of fires. Indeed, tree canopy cover thresholds associated with fire penetration vs. suppression (Hennenberg et al., 2006; Hoffman et al., 2012) effectively separating the two biomes have been reported - or at least hypothesised - to exist in many places and with the existence of such 'thresholds' having usually been taken as evidence supported in the ASS theory (e.g. in Africa:, Charles-Dominique et al., 2018; Cardoso et al., 2018; Australia \& Oceanea: Warman \& Moles, 2009; Ibanez et al., 2013; South America: Hoffman et al., 2012; Dantas et al., 201;: but see also Lloyd \& Veenendaal, 2016 for an alternative interpretation). Consistent with this 'threshold' notion, a minimum grass fuel load of around $3.0 \mathrm{t}$ DW ha ${ }^{-1}$ has been suggested as being required to prevent "bush encroachment" vi: the expansion of trees and shrubs into savanna grassland pastoral systems (Trollope, 1980). The threshold notion has taken hold, particularly in modelling studies, and have led some to conclude that underneath forest canopy, there is insufficient biomass to provide the fuel load to sustain fire and that therefore, closed-canopy forest formations in the FS ecotone are necessarily non-pyrogenic (Beckage et al., 2009; Lasslop et al., 2016; Van Nes et al., 2018).

The perception that the understorey of ecotonal forests is essentially fire-free is not shared by many dry tropical forest ecologists (see e.g., Murphy \& Lugo, 1986; Stott et al., 1990). For example, in West Africa, fire is considered a regular phenomenon in dry forest to the extent that unique "fire forest" formations have been floristically distinguished through the abundance of specific fire-resistant tree species (Hall \& Swaine, 1976; Swaine 1992). Such trees are presumably evolutionarily adapted to such dynamic fire prone environments, which is supported by evidence of the long length of the palynological record of these forest communities (Hamilton \& Taylor, 
Chapter 4

1991; Maley, 1996). Fire occurrences in the West African FS ecotone are often frequent (e.g. every two years) and dry forest formations are present as patches (Ametsitsi et al., 2020; Goetze et al., 2006). The distribution of these dry forest formations has been linked to topography in the landscape, soil water availability and other soil factors (Ametsitsi et al., 2020; Markham \& Babeddge, 1979; Swaine et al., 1976). Despite the apparent dynamic nature of the forest-savanna ecotone (Oliveras \& Malhi, 2016) they are also often reported to be remarkably stable at decadal timescales (Cuni-Sanchez et al., 2016; Goetze et al., 2006; Sobey, 1978; Ametsitsi et al., 2020).

In FS ecotones, a distinct group usually referred to as "savanna tree species", dominate the open vegetation formations such as woodland, while another distinct group of "forest tree species" is usually associated with more closed forest-type formations (Dantas et al., 2013; Hoffmann et al., 2012a; Torello-Raventos, et al., 2013). Associated with this forest/savanna species dichotomy are strong differences in fire-associated traits between the two species groupings with, for example, forest trees attaining a greater maximum height while having thinner bark compared to savanna trees (Dantas et al., 2013; Pinard \& Huffman, 1997). However, there is also a number of "nonselective tree species" that manage to successfully maintain populations in both pyrogenic and nonpyrogenic environments, having seemingly intermediate values of e.g. maximum height and bark thickness (Ametsitsi et al., 2020; Armani et al., 2018; Ratnam et al., 2019). Furthermore, the regeneration niche of these non-selective species appears strongly associated with the degree of canopy closure (Boonman et al., 2019; Cardoso et al., 2016; Issifu et al., 2019). The fact that the driest part of tropical forests is not as fire-free as sometimes reported and that non-selective species and communities exist, suggests that also fire characteristics may change across the FS boundary. In this study we therefore aim to quantify fire behaviour across a gradient of canopy closure in a FS boundary in Ghana, West Africa. We hypothesize that: 1. increasing canopy closure changes fire behaviour but does not exclude fire from entering closed dry forest patches in savanna-forest ecotones, 2. Fire intensity and tree species community are correlated in the different vegetation types, with high intensity fires in savanna tree dominated vegetation, low intensity fires in forest 
tree dominated vegetation and intermediate intensity fires in non-selective dominated vegetation. In our discussion we review contrasting findings in the literature on the sharpness of forest-savanna boundaries and propose a way forward for further research.

\section{Methods}

\section{Study site}

Observations were made over the dry seasons of 2012-2013, 2013-2014 and 2014-2015 in the Kogyae Strict Nature Reserve (KSNR) in the Ashanti Region of Ghana (7015'52'N and $\left.1^{\circ} 04^{\prime} 47^{\prime \prime W}\right)$. Covering an area of $330 \mathrm{~km}^{2}$, the KSNR lies in the transition zone between the Guinea Savanna Zone in the north of Ghana and the Deciduous Forest Zone in the South Janssen et al., 2018). Average annual rainfall is $1.36 \mathrm{~m} \mathrm{yr}^{-1}$, with a distinct dry season from December to March. The average annual temperature is $28^{\circ} \mathrm{C}$ with little seasonal variation in temperature. The KSNR experiences annual, relatively early wildfires, mostly as a result of hunting/poaching and agriculture (Janssen et al., 2018). Since 2004, fire has also been used as a tool to manage grazing resources for wildlife. As we were not allowed to start experimental fires ourselves, we relied for our fire observations on these annual "naturally occurring" landscape fires. We were alerted of approaching fires via an early warning system from wildlife department staff present at the research site. The structural vegetation types within the KSNR range from closed forests to open woodlands, a considerable area of dry forest inside the reserve has been cut down in the 1980's and early 1990's in the run-up to the gazetting of the strict conservation status of the park (Janssen et al., 2018; Ametsitsi et al., 2020).

\section{Vegetation measurements}

In 2013 a total of 29 plots of $20 \mathrm{~m} \times 20 \mathrm{~m}$ were established in the North East corner of the park, which were extended to a total of 35 plots in 2014. The plot size was chosen to be small enough to allow for a homogeneous vegetation structure but large enough to obtain a representative sample 
Chapter 4

of the stand-level tree species composition. All plots were randomly located in vegetation types initially identified by eye as: savanna-like vegetation, forest-like vegetation and semi-closed 'intermediate' vegetation. All plots were located at a maximum distance of $7.0 \mathrm{~km}$ from each other to allow for wildfires entering the research area to reach all plots at the same time.

\section{Vegetation structural parameters used and plant functional type composition}

Based on plot-level measurements of: diameter at breast height $(D)$, crown area index $\left(C_{\mathrm{W}}\right)$, leaf area index $\left(L_{w}\right)$ and 0.95 quantile height $\left(H^{*}\right)$, each of the 35 plots was classified into vegetation structural types (VST) vi氵: "woodland" (6 plots) "closed woodland" (18 plots) or "forest" (11 plots) as described in detail in Ametsitsi et al. (2020). In brief, $D$ and $H$ were measured for all trees with $D \geq 2.5 \mathrm{~cm}$ and with $C_{\mathbb{W}}$ estimated for all trees with $\mathrm{DBH}>10 \mathrm{~cm}$. Woody vegetation leaf area index $\left(L_{w}\right)$ was determined at its seasonal maximum in the late wet season (October) and minimum in the middle of the dry season (January) from hemispheric photographs taken during diffuse light conditions (Frazer et al., 1999; Promis et al., 2011) as is also decribed in detail in Ametsitsi et al. (2020).

As is also explained in more detail in Ametsitsi et al. (2020), each tree species observed was classified into one of three plant functional types (PFT) viz "savanna-affiliated" (S) "forestaffiliated" $(F)$ or "non-specialised" $(N)$ - the latter species regularly occurring in both forest and savanna. This classification was performed on the basis of both ecological information from Keay (1989), Hawthorne (1995), and Hawthorne \& Jongkind (2006) as well as on the basis of the relative contribution of each of the PFTs assessed using estimates of $C_{\mathrm{W}}$. In this case also including the smaller trees $C_{\mathbb{W}}(2.5<D<10 \mathrm{~cm})$, thereby providing an alternative means by which the 35 plots were classified as either savanna $(89 \pm 3.6 \%$ (mean \pm SE) $S$ dominance), transitional (60 $\pm 5.4 \%$ $\mathrm{N}$ dominance) or forest $(74 \% \pm 5.5 \% \mathrm{~N}$ dominance). Detailed information on the clustering procedures used and about the relationships between the VFT vs. PFT classifications are available in Ametsitsi et al. (2020). The classification of the plots is provided here in Appendix 1, which also 
introduces a combined class allowing us to statistically assess the role of tree functional type dominance in the canopy in relation to fire behaviour.

\section{Fire behaviour related parameters}

The fires studied here were not controlled by us but were human-lit (by e.g. farmers, poachers or the Wildlife Department) inside or on the edges of the reserve, usually around three weeks after the last rains. The Wildlife Department informed us when fires were nearing the study area, which allowed us to a determine a number of pre-fire parameters. Standing fuel-load before the fires was determined by harvesting three randomly selected replicates of $1 \mathrm{~m}^{2}$ quadrats in each plot. At each sampling time, all standing biomass was clipped, collected and oven dried at $80{ }^{\circ} \mathrm{C}$ to constant weight to determine dry weight. In 2013, the day before fire entered the plots, fresh sub-samples of different fuel types (herbs, grasses and the invasive shrub Cbromoleana odorata (L.) R.M.King \& H.Rob.) were also clipped, collected and weighed in the field, to determine fuel moisture content at the onset of an early season fire of these different fuel types. Special attention was paid to $C$. odorata, as this species has been considered to fulfil a reinforcing role in fire behaviour (Macdonald \& Frame, 1988; Swaine, 1992). The relative abundance (\% cover) of different standing fuel types was estimated by eye for all plots in 2015. Consumption of standing fuel load was measured in 2013 and 2015 by clipping, collecting, oven drying and weighing of the remaining fuel load (3 replicates $1 \mathrm{~m}^{2}$ ) in burned areas after the fire had passed. Pre-fire tree leaf litter was separately collected in 2015 from the same clipped quadrats and subsequently oven dried and weighed to determine leaf litter dry weight.

Climatic conditions in the field (wind speed, air temperature and relative humidity) were measured at the start of each fire using a Kestrel 4500 Pocket Weather tracker in 2013 and 2014 and from a weather station at $3 \mathrm{~km}$ distance from the plots (Skye Instruments LLandindrod Wels) in 2015. In 2013, direct velocity measurements from the moving fire front were obtained over 
Chapter 4

distances of $50 \mathrm{~m}$ in woodland/closed woodland vegetation by means of a Global Positioning System.

In all three years we estimated the percentage area burnt per plot by eye as soon as the fire had passed. Direct fire measurements of fire height (all three years) and ambient temperature in the vicinity of the fire (2014 and 2015 only) were determined with simple pyrometers (as in e.g. Stott 2000) specifically adapted for this study (see Appendix 2). This low-cost approach allowed for three pyrometers per plot. Fire height was determined by means of cotton threats attached to the pyrometer at $0.3 \mathrm{~m}$ intervals up to $3.0 \mathrm{~m}$ height. The highest cotton threat that was scorched was taken as a measure of maximum fire height. If fire had passed a pyrometer but no cotton thread had burned the flame height was arbitrarily set at $0.15 \mathrm{~m}$.

Ambient air temperatures in 2014 and 2015 (not to be confused with the concept of flame temperature in fire science) were estimated using temperature-sensitive industrial paints (OMEGALAQ ${ }^{\circledR}$ Liquid Temperature Lacquers https://www.omega.com). The paint was applied to galvanized steel bars affixed horizontally at $0 \mathrm{~m}$ (2015 only), $0.3 \mathrm{~m}$ and $0.6 \mathrm{~m}$ above-ground (2014 and 2015), with sixteen temperature indicator paints $(107,149,204,253,302,343,399,454$, $510,566,621,649,704,760,816$ and $927^{\circ} \mathrm{C}$ ) applied to each bar. These paints change colour when their temperature indicator value is reached. After each fire, we recorded whether the fire had passed the pyrometer and which indicator paints had changed colour, as an indication of the ambient temperature during the fire. If a fire had passed the pyrometer but none of the paints had changed colour, the ambient temperature was arbitrarily set at $71^{\circ} \mathrm{C}$ (the average between the minimum indicator value of $107^{\circ} \mathrm{C}$ and average air temperature $35^{\circ} \mathrm{C}$ ). The ambient air temperature values from the pyrometers were averaged per plot for each fire event.

\section{Statistical analyses}

Statistical analyses were undertaken with SPSS version 25. Comparisons of structural properties between plots were done with a single ANOVA and a Tuckey HSD Post-Hoc test. If necessary, 
data were log-transformed to ensure normality and homogeneity of variances as indicated in the Results section. If the log-data transformation proved insufficient, Kruskal Wallis nonparametric $\chi^{2}$ tests were used with pairwise comparisons between groups.

\section{Results}

\section{Tree cover variation}

Tree crown cover, expressed as canopy area index $(C w)$, wet season leaf area index ( $L_{w}$ October) and dry season $L_{\mathbb{W}}$ (January), varied similarly between the three vegetation structural types (VST's) (Figure 1a).

All three measures of tree crown cover were significantly different between VST's ( $C w: \mathrm{F}_{2,31}$ $\left.=48.0, \mathrm{P}<0.001 ; L_{\mathbb{W}}(\mathrm{Oct}): \mathrm{F}_{2,32}=8.7, \mathrm{P}<0.001 ; L_{\mathbb{W}}(\mathrm{Jan}): \mathrm{F}_{2,32}=37.0, \mathrm{P}<0.001\right)$ with woodlands (Cw $0.80 \pm 0.5 \mathrm{~m}^{2} \mathrm{~m}^{-2} ; L_{\mathbb{W}}$ (Oct) $1.3 \pm 0.7 \mathrm{~m}^{2} \mathrm{~m}^{-2} ; L_{\mathbb{W}}$ (Jan) $0.51 \pm 0.2 \mathrm{~m}^{2} \mathrm{~m}^{-2}$; mean $\pm \mathrm{SD}$ ) and closed woodlands $\left(C w 1.3 \pm 0.4 \mathrm{~m}^{2} \mathrm{~m}^{-2} ; L_{\mathbb{W}}(\right.$ Oct $) 1.6 \pm 1.3 \mathrm{~m}^{2} \mathrm{~m}^{-2} ; L_{\mathbb{W}}$ (Jan) $\left.0.52 \pm 0.3 \mathrm{~m}^{2} \mathrm{~m}^{-2}\right)$ similar and forests significantly different $\left(C w 3.3 \pm 0.8 \mathrm{~m}^{2} \mathrm{~m}^{-2}\right.$; $L_{\mathbb{W}}$ (Oct) $2.2 \pm 0.3 \mathrm{~m}^{2} \mathrm{~m}^{-2} L_{\mathbb{W}}$ (Jan) $1.4 \pm 0.3 \mathrm{~m}^{2} \mathrm{~m}^{-2}$; Figure 1a). We find that wet season $L_{\mathbb{W}}$ saturates with increasing $C w$ when $C w>$ $2.0 \mathrm{~m}^{2} \mathrm{~m}^{-2}$ (Appendix 3), suggesting that at after this point a higher crown cover is offset by increasing crown openness in these vegetation types and therefore less leaf area per unit of crown area.

Also, when comparing tree functional types, we find that tree crown cover is significantly different between the savanna plots and the forest plots $\left(C w \mathrm{~F}_{2,31} 21.8 \mathrm{P}<0.0001: L_{\mathbb{W}}\right.$ (Oct.) $\mathrm{F}_{2,32}$ 15.2 $\left.\mathrm{P}<0.0001 ; L_{\mathbb{W}}(\mathrm{Jan}) \mathrm{F}_{2,32} 38.8 \mathrm{P}<0.0001\right)$. The savanna and transition plots have a significantly lower $C w\left(C w s a v a n n a 1.0 \pm 0.5 \mathrm{~m}^{2} \mathrm{~m}^{-2}\right.$ and $C w$ transition $\left.1.4 \pm 0.4 \mathrm{~m}^{2} \mathrm{~m}^{-2}\right)$ compared to the forest plots $\left(C w 2.9 \pm 1.1 \mathrm{~m}^{2} \mathrm{~m}^{-2}\right)$. However, wet season $L_{\mathbb{w}}$ showed a different picture, with the transition and forest plots having a similar higher wet season $L_{\mathbb{W}}$ (transition $1.8 \pm 0.4 \mathrm{~m}^{2} \mathrm{~m}^{-2}$ and forest $2.1 \pm$ $\left.0.3 \mathrm{~m}^{2} \mathrm{~m}^{-2}\right)$ and the savanna plots a significantly lower wet season $L_{\mathbb{W}}\left(1.3 \pm 0.4 \mathrm{~m}^{2} \mathrm{~m}^{-2}\right)$. While $L_{\mathbb{W}}$ declined in all three tree functional types from the wet to the dry season, the $L_{\mathbb{W}}$ in the transitional 
Chapter 4

plots changed from being more similar to the forest plots in the wet season to becoming more similar to the savanna plots in the dry season (Figure $1 \mathrm{~b}$ ). $L_{\mathbb{W}}$ in the savanna and transition plots were both relatively low in the dry season (savanna $L_{\mathbb{W}}$ (Jan) $0.47 \pm 0.1 \mathrm{~m}^{2} \mathrm{~m}^{-2}$; transition $L_{\mathbb{W}}$ (Jan) $0.48 \pm 0.1 \mathrm{~m}^{2} \mathrm{~m}^{-2}$ ) while the forest plots showed significantly higher dry season $L_{\mathbb{W}}$ (Jan) $1.3 \pm 0.4$ $\mathrm{m}^{2} \mathrm{~m}^{-2}$ ) (Figure 1b). The average reduction in $L_{\mathbb{W}}$ between the late wet season (October) and the middle of the dry season (January) was for the savanna ( $60 \pm 15 \%$ reduction) and transition (70 \pm 9\%) plots significantly larger than in forest plots $\left(40 \pm 15 \%, \mathrm{~F}_{2,32} 14.1 \mathrm{P}<0.001\right)$.
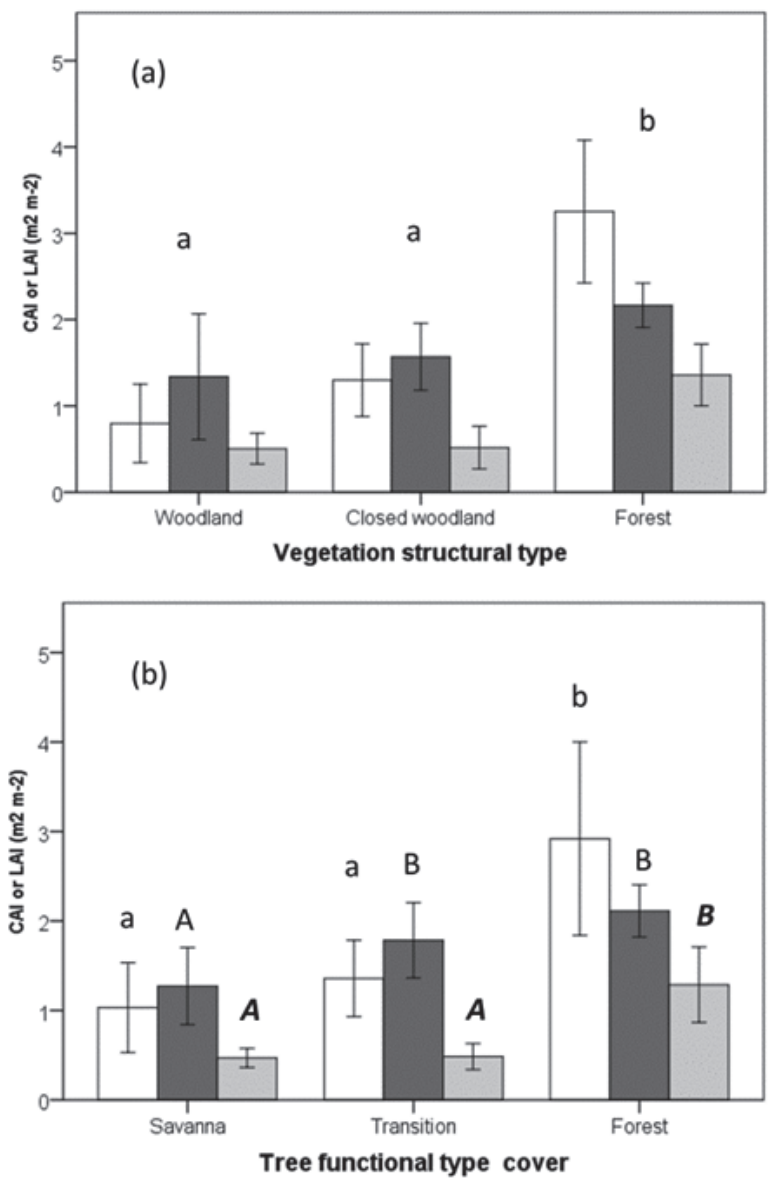

Figure 1. Crown cover measurements of vegetation structural (a) and Plant functional (b) plot types. White bars are Crown Area Index (CAI); Dark grey bars are October Leaf area index (LAI; 
Light grey bars are January Leaf area index (LA). Error bars denote standard errors. Letters on each bar denote significant differences (Tuckey $\mathrm{P}<0.05$ ).

\section{Climate and onset of fires in the study area}

Monthly rainfall was similar during the three years of observation and typical of this region with rains ending at the end of November or the beginning of December (Figure 2). In 2013, fire entered the plots on the morning of the $19^{\text {th }}$ of January. Wind speeds on that day were on average $0.0 \mathrm{~m} \mathrm{~s}$ ${ }^{1}$ in the morning and $0.7 \mathrm{~m} \mathrm{~s}^{-1}$ in the afternoon with temperatures of $33{ }^{\circ} \mathrm{C}$ and $36.8^{\circ} \mathrm{C}$ and relative humidity of $44 \%$ and $21.6 \%$ in the morning and afternoon, respectively. The fire front moved with an estimated speed of $0.007 \mathrm{~m} \mathrm{~s}^{-1}$ in the morning and $0.024 \mathrm{~m} \mathrm{~s}^{-1}$ in the afternoon. In 2014, fire reached all plots in the afternoon of February $2^{\text {nd }}$. When the fire reached the plots, we measured an average wind speed of $1.1 \mathrm{~m} \mathrm{~s}^{-1}$, an air temperature of $33.5^{\circ} \mathrm{C}$ and a relative humidity of $11.8 \%$. Finally, in 2015 a fire reached the plots on February $4^{\text {th }}$ while we measured in the morning a wind speed of $2.3 \mathrm{~m} \mathrm{~s}^{-1}$, an air temperature of $29.4^{\circ} \mathrm{C}$ and a relative humidity of $81 \%$ and in the afternoon a wind speed of $2.3 \mathrm{~m} \mathrm{~s}^{-1}$, an air temperature of $34.9^{\circ} \mathrm{C}$ and a relative humidity of $44 \%$ (see also Appendix 4 for general conditions during the periods of fire observation).

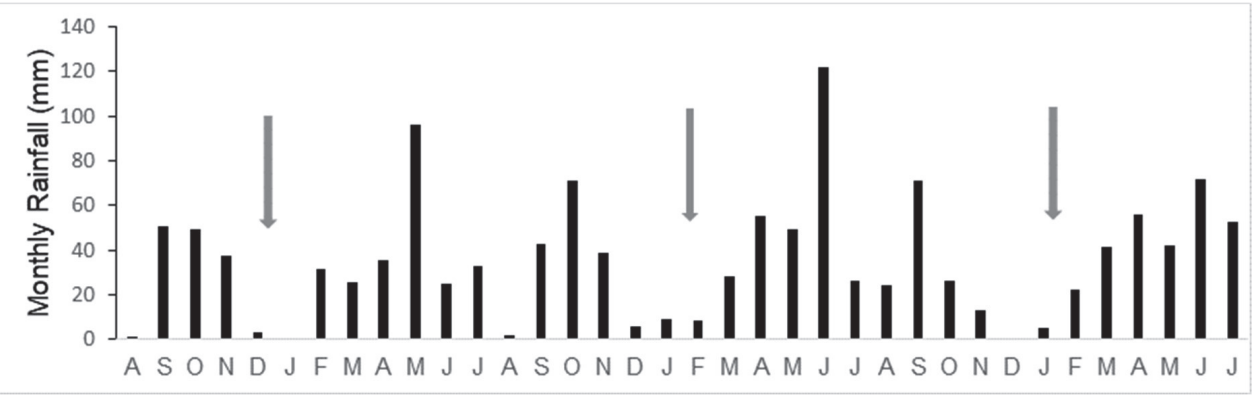

Figure 2. Monthly rainfall data Ejura weather station August 2012 - July 2015). Arrows indicate approximate date of fire events.

\section{Fuel load characteristics}

We found that standing fuel load declined with increasing tree canopy cover in all three measuring years (Figure 3). Suppression of fuel load by tree crown cover was particularly evident after the 
Chapter 4

canopy reaching a closure around $C w>1.7$ (equivalent to the $L_{\mathbb{W}}$ of similar value, Appendix 3), with standing fuel load values on average below $2.0 \mathrm{t} \mathrm{ha}^{-1}$. Differences in standing fuel load between VSTs were statistically significant (Figure 4a, ANOVA on log-transformed data: $F_{2,31}=10.7$, $\mathrm{P}<0.001$ ), with standing fuel load for woodlands, being on average $6.4 \mathrm{t} \mathrm{ha}^{-1}$ (range $1.6-10.9 \mathrm{t}$ ha ${ }^{1}$ ) and closed woodlands $3.6 \mathrm{tha}^{-1}$ (range $0.7-9.2 \mathrm{t} \mathrm{ha}^{-1}$ ) being significantly higher compared to the forest plots with $1.3 \mathrm{t} \mathrm{ha}^{-1}$ (range $0.9-2.1 \mathrm{t} \mathrm{ha}^{-1}$ ). When comparing the three different functional tree types, we also find significant differences in standing fuel load between the plots (Figure 4b, ANOVA on log-transformed data $\left.\mathrm{F}_{2,31}=16.6 \mathrm{P}<0.001\right)$. The standing fuel load in the savanna plot was on average $6.8 \mathrm{t} \mathrm{ha}^{-1}$ (range $1.7-10.9 \mathrm{t} \mathrm{ha}^{-1}$ ), being significantly higher compared to the $2.6 \mathrm{tha}^{-1}$ (range $0.7-7.3 \mathrm{t} \mathrm{ha}^{-1}$ ) in the transition plots and $1.4 \mathrm{t} \mathrm{ha}^{-1}\left(\right.$ range $0.7-3.3 \mathrm{t} \mathrm{ha} \mathrm{a}^{-1}$ ) in the forest plots.

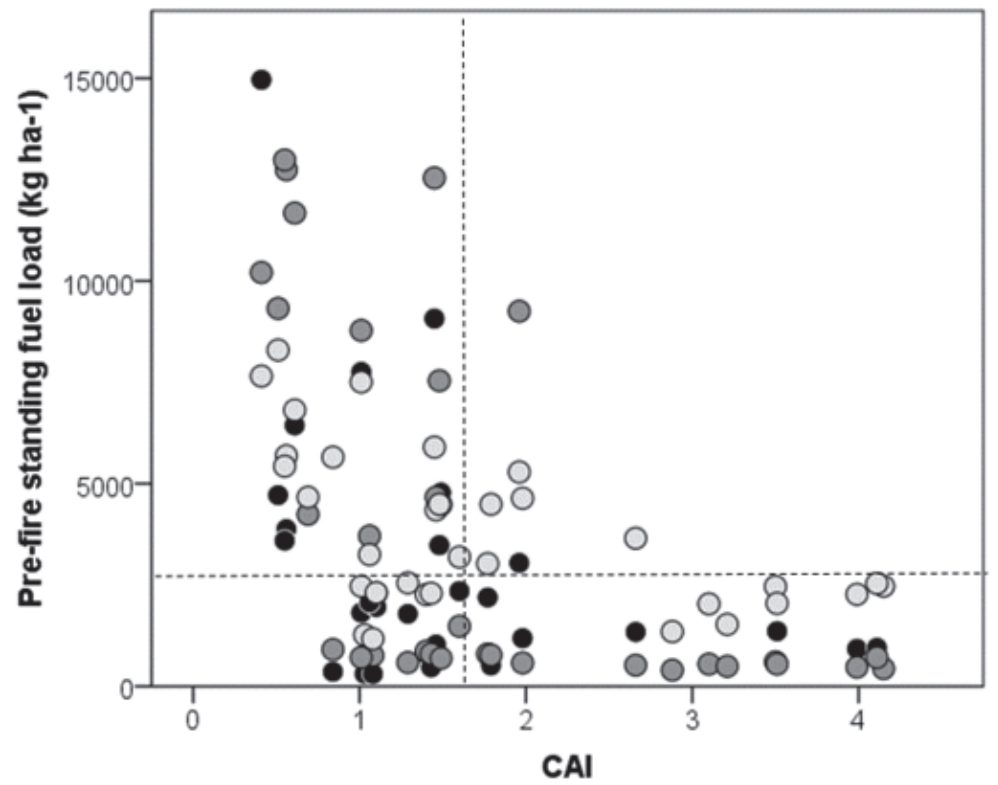

Figure 3. Canopy area index and standing fuel load. Variation by year. 2013 (Black circles) 2014 (Dark grey circles) 2015 (light grey circles. Vertical dashed line - Threshold proposed by Hennenberg et al. (2006) for fire suppression. Horizontal dashed line Threshold proposed by Trollope (1980) for the control of fire tolerant woody vegetation (further explanation see main text). 
We found that the moisture content of the standing fuel load, which were sampled from one forest, four woodland and four closed woodland plots on the day before the fire in 2013, was significantly different between grasses and other herbs (Figure 4c, One-way ANOVA $F_{3,12}=15.37$, $\mathrm{P}<0.0001)$. Grasses showed with an average of $25 \pm 13.4 \%$ (mean \pm s.d.) a significantly lower moisture content compared to C. odorata $(46 \% \pm 5.5 \%)$ and the remaining herbs $(49.5 \pm 14.8 \%)$. Projected cover of standing fuel load estimated in 2013 varied significantly between vegetation structural classes (Kruskal Wallis, $\mathrm{X}^{2}$ 14.639. $\mathrm{P}<0.001$, not shown), with total fuel load cover declining from an average $40 \%$ (range $17 \%$ - 53\%) in woodlands to $31 \%$ (range $14 \%-55 \%$ ) in closed woodlands and 15\% (range 12\% -19\%) in forest. The distribution of standing fuel load cover over the different fuel types (grasses, herbs and $C$. odorata) varied significantly among the VST's (Figure 4d) with a high grass cover (Kruskal Wallis, $\mathrm{X}^{2}$ 14.639. $\mathrm{P}<0.001$ ) in woodlands (mean $37 \%$; range $20-53 \%$ ) and closed woodlands (Mean 20\%; Range 12\% - 29\%) and virtually no grass cover in the forest plots (mean 5\%; range 1\% - 9\%). Furthermore, we observed that the grasses in woodlands were predominantly $\mathrm{C}_{4}$ species while in the forest plots the grasses were almost exclusively of $\mathrm{C}_{3}$ signature (mainly Oplismenus spec.). Herbs contributed much less to the total standing fuel load cover but still varied significantly (Kruskal Wallis, $\mathrm{X}^{2} 12.170, \mathrm{P}=0.002$ ), between woodlands (mean $2 \%$; range $0-7 \%$ ), closed woodlands (mean 3\%; range $0 \%-18 \%$ ) and forest plots (mean $10 \%$; range 5\% - 18\%). C. odorata varied non-significantly (Kruskal Wallis, $\mathrm{X}^{2} 4.313$, $\mathrm{P}<0.12$ ) between woodlands (mean 3\%; range $0-3 \%$ ) and closed woodlands (mean 6\%; Range $0 \%-40 \%$ ) while C. odorata was virtually absent from the forest plots (mean $0.4 \%$; range $0 \%-$ $3 \%$. 

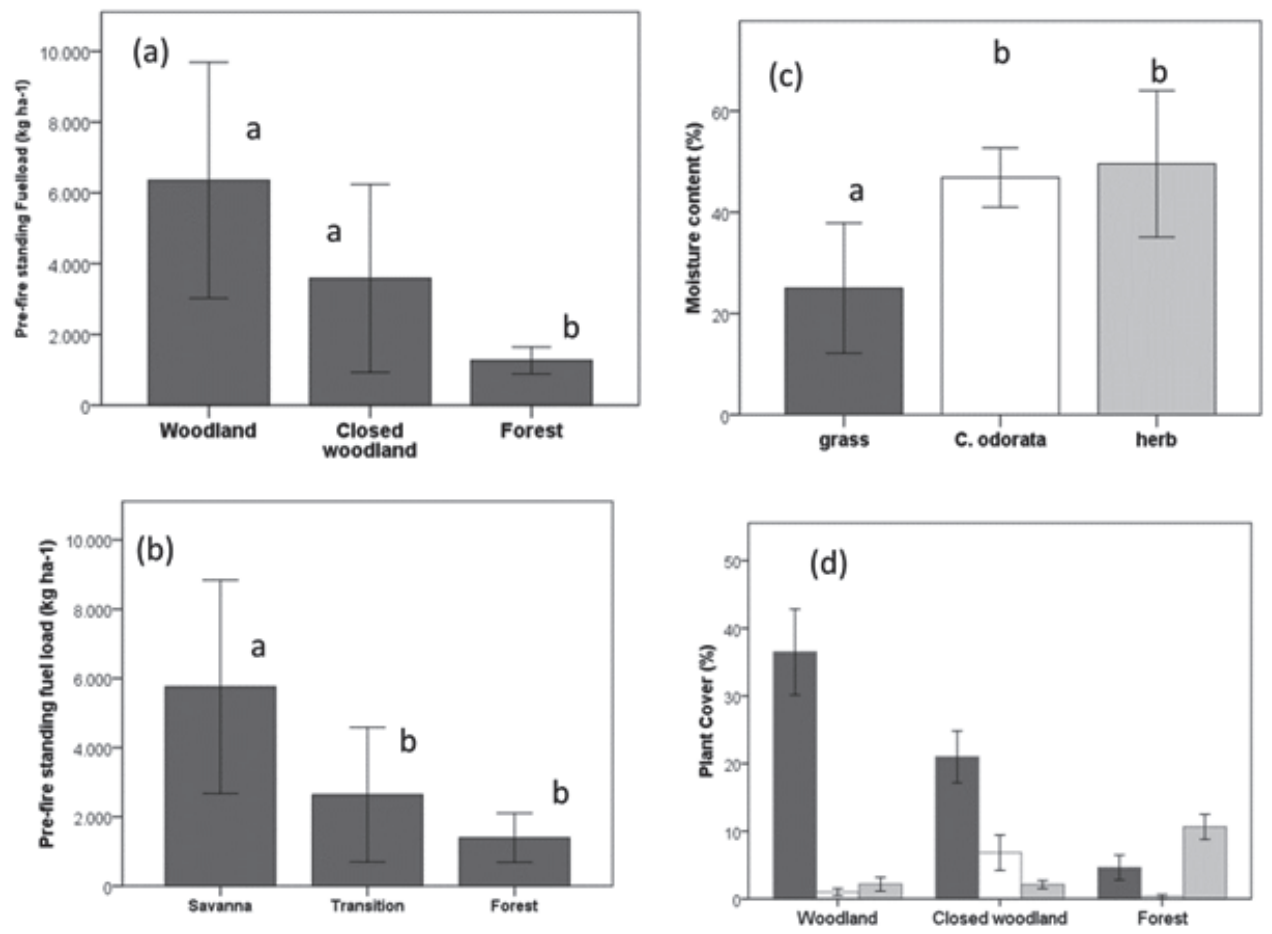

Figure 4. Fuel Characteristics of standing fuel load. Variation of fuel load by Vegetation structural type (a) and by plant functional type (b) (three years average in $\mathrm{kg} \mathrm{ha}^{-1}$ ). Pre-fire moisture content (measured a day before the fire in 2013 in \%) and abundance (\% cover) of standing fuel types in 2015 (c) (Letters indicate significant differences Tuckey $<0.05$. Biomass data log-transformed)

Tree leaf litter biomass (determined in 2015 only) varied significantly (One-way ANOVA $\mathrm{F}_{2,31}=4.7, \mathrm{P}=0.016$ ) between the VST's, with $0.6 \pm 0.3 \mathrm{t} \mathrm{ha}^{-1}$ (mean \pm s.d.) in woodlands, $1.2 \pm$ $0.7 \mathrm{t} \mathrm{ha}^{-1}$ in closed woodlands and $1.8 \pm 0.7 \mathrm{t} \mathrm{ha}^{-1}$ in the forest plots (Figure 5). A similar significant trend of increasing leaf litter biomass with increasing tree crown cover was visible when looking at the tree functional types (One-way ANOVA $F_{2,31}=5.4 \mathrm{P}>0.01$ ); with an average leaf litter biomass of $0.8 \pm 0.6 \mathrm{tha}^{-1}$ in the savanna plots, $1.3 \pm 0.8 \mathrm{tha}^{-1}$ in the transition plots and $\left.1.7 \pm 0.7 \mathrm{t} \mathrm{ha}^{-1}\right)$ in the forest plots (not shown). Pre-fire leaf litter moisture content did not significantly vary between vegetation structural types, with $9 \%$ in the woodland, $9 \%$ in the closed woodland and $11 \%$ in the forest plots (One-way ANOVA F2,32 = 2.347 P = 0.514). 


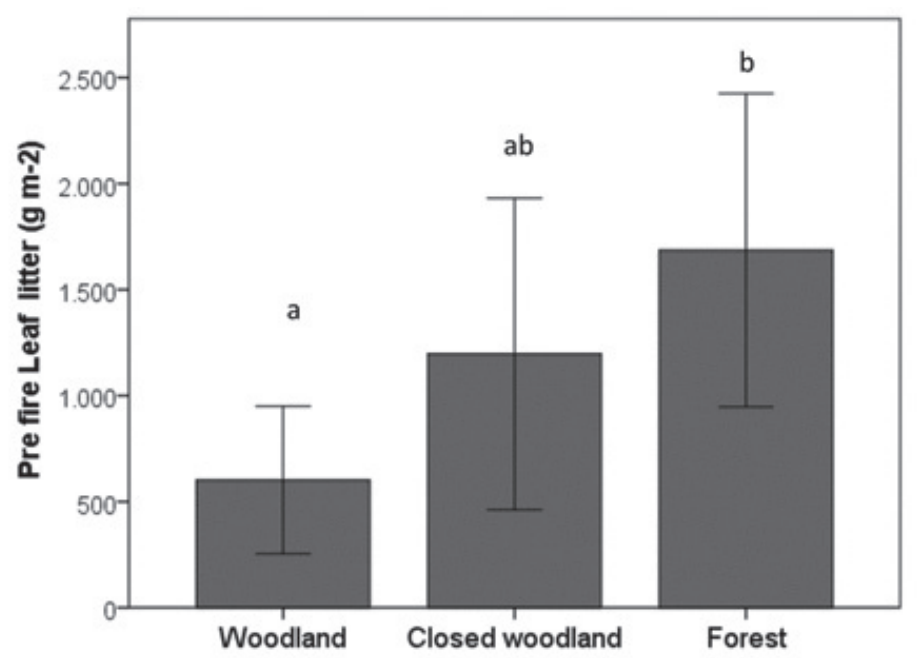

Figure 5. Pre-fire litter fuel by Vegetation structural type Letters indicate significant differences (Tukey $\mathrm{p}<0.05)$. The pattern for plant functional types is similar and not shown.

\section{Area burned fire type and fuel consumption}

We observed that if a fire reached a plot, it usually burned most or the whole area of the plot. For example, in 2013 all plot surfaces burned 70 - 100\% with the exception of two closed woodland plots ( 0 and 10\%). In 2014, all of the 35 plots burned. In the woodland plots, $100 \%$ of the plot area burned, while in closed woodland and forest plots some area remained unburned, with the average plot area burned in closed woodlands being $90 \%$ (range $52-100 \%$ ) and $84 \%$ in forests (range $40-100 \%$ ). In 2015, fire burned 20 out of 35 plots. If fire reached a plot, the average plot area burned was again $100 \%$ in woodland plots, $78 \%$ in closed woodland plots and $84 \%$ in forest plots. The average of individual observations combining plot burning data for all years if fire reached a plot gave a marginally significant difference in percentages plot area burned between the different VST's (Kruskal Wallis, $\mathrm{X}^{2} 5.250 \mathrm{P}=0.072$ ) with similar percentages of $100 \%, 90 \%$ and $83 \%$ of the plot area burned for woodland, closed woodland and forest respectively.

Visual observations suggested that at least two different types of fire occurred in the study area; a high intensity standing fuel load fire type that is fuelled by dried grasses and herbs with high 
Chapter 4

flames (up to $3 \mathrm{~m}$ ) and on the other hand a low intensity leaf litter fire type with low flames (often below $30 \mathrm{~cm}$ ) that consumed all the leaf litter. While the former is associated to the more open woodland vegetation, the latter was common in the more closed vegetation (see photographs Appendix 5).

Consumption of the standing fuel load, estimated in 2013 and 2015, did not vary significantly between VST's (One-way ANOVA F2,36 $=0.790, \mathrm{p}=0.461$ ) with average fuel load consumption rates varying from $77 \pm 17.4 \%$ (mean \pm s.d.) in woodlands to $78 \pm 20.5 \%$ in closed woodlands and $70 \pm 16.3 \%$ in forests. Leaf litter consumption (only measured in 2015), was 100\% in 12 out of 20 plots that burned. In other plots it was not determined due to fire-induced leaf fall in some trees.

\section{Fire height and ambient temperatures during fire in relation to tree cover and composition}

Fire height, averaged over all individual observations from 2013 to 2015, differed significantly between the different PFT plots (Kruskal Wallis, $\mathrm{X}^{2} 26.212 \mathrm{P}=0.001$ ). In the savanna plots, we measured a median fire height of $80 \mathrm{~cm}(\mathrm{n}=30$, range $15-270 \mathrm{~cm})$, while in the transitional and forest plots median fire height was lower with $15 \mathrm{~cm}(\mathrm{n}=13,15-230 \mathrm{~cm})$ and $25 \mathrm{~cm}(\mathrm{n}=30$, range $15-70 \mathrm{~cm}$ ), respectively (Figure $6 \mathrm{~b}$ ). Pairwise comparing the different PFTs showed that plots dominated by savanna associated species significantly differed from plots dominated by transitional and forest species (Figure $6 \mathrm{~b}$ ).

Similarly, fire height also differed significantly among the different VST's (Kruskal Wallis, $\left.\mathrm{X}^{2}=14.598, \mathrm{P}=0.01\right)$, with in the woodland plots a median fire height of $130 \mathrm{~cm}(\mathrm{n}=15$, range $15-230 \mathrm{~cm})$, in the closed woodland plots a median height of $50 \mathrm{~cm}(\mathrm{n}=43$, range $15-270 \mathrm{~cm})$ and in the forest plots a median height of $30 \mathrm{~cm}(\mathrm{n}=20$ range $15-70 \mathrm{~cm}$, Figure $6 \mathrm{~b})$. Pairwise comparing different PFT's indicated that the median fire height in the woodland plots was significantly differed from the median fire height in the closed woodland and forest plots (Figure $6 \mathrm{~b})$. 

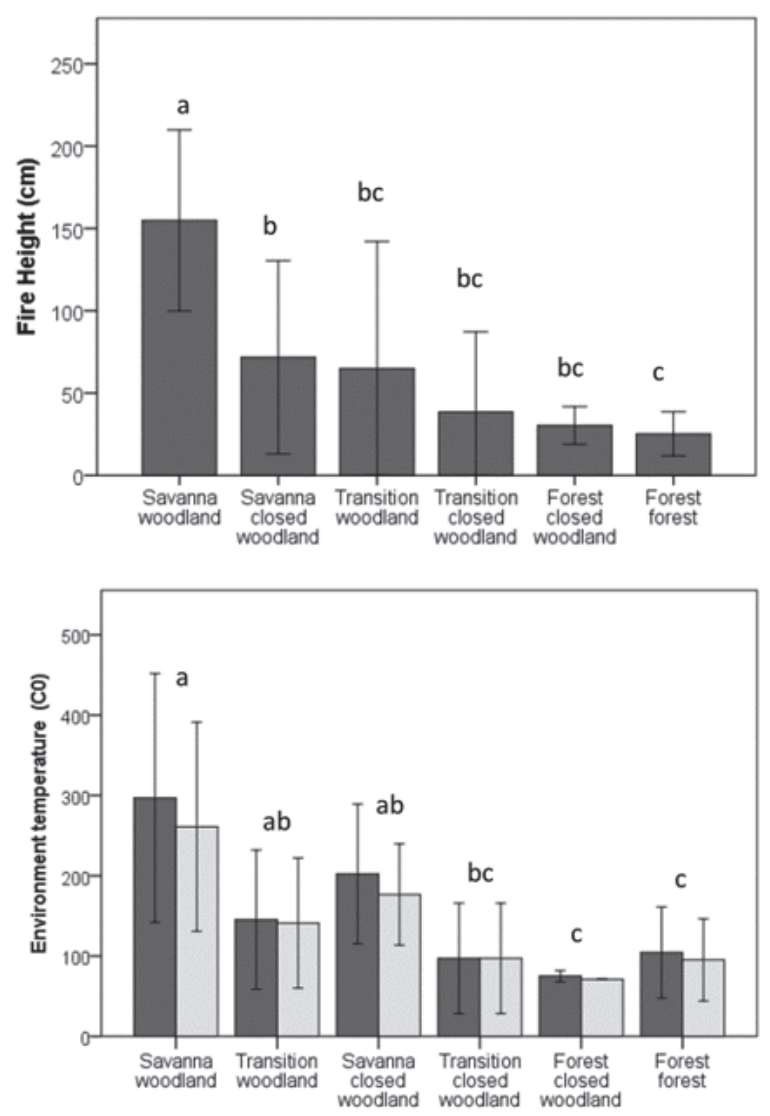

Figure 6. Fire characteristics for the combination class of tree functional type and vegetation structural type. (a) Fire height (Means \pm 1 s.d.) (b) Maximum environment temperature at 30 and $60 \mathrm{~cm}$ height. Letters indicate statistical differences at $\mathrm{P}<0.05$ (GLM with adjusted Tukey test for 7 estimates on log-transformed data. Significant differences 30 and $60 \mathrm{~cm}$ data varied in a similar way for both heights)

Ambient temperatures recorded at a height of $30 \mathrm{~cm}$ above the surface if a fire passed showed significantly different values for the different PFT's (Kruskal Wallis, $\mathrm{X}^{2} 17.144, \mathrm{P}<0.001$ ). The highest temperatures were observed in the savanna plots $\left(n=22\right.$, median $204{ }^{\circ} \mathrm{C}$, range $71-$ $491^{\circ} \mathrm{C}$ ), followed by the transitional plots and the forest plots ( $\mathrm{n}=11$ and 21 , respectively, median $71^{\circ} \mathrm{C}$ (range $71-253^{\circ} \mathrm{C}$ ) (Figure $7 \mathrm{~b}$ ). Ambient temperatures during fire recorded at $60 \mathrm{~cm}$ above the surface were also significantly different between the different PFT's (Kruskal Wallis, X² 19.391, $\mathrm{p}<0.001)$. At $60 \mathrm{~cm}$, the highest temperatures were again observed in the savanna plots $(\mathrm{n}=22$, 
Chapter 4

median $204{ }^{\circ} \mathrm{C}$ (range $71-404{ }^{\circ} \mathrm{C}$ ) followed by the transitional plots $\left(\mathrm{n}=11\right.$, median $71{ }^{\circ} \mathrm{C}$ (range $\left.71-253{ }^{\circ} \mathrm{C}\right)$ and the forest plots $\left(\mathrm{n}=21\right.$ median $71{ }^{\circ} \mathrm{C}$, range $\left.71-218{ }^{\circ} \mathrm{C}\right)($ Figure $7 \mathrm{~b})$.

Ambient temperatures at $30 \mathrm{~cm}$ above the surface during fire differed also significantly between the different VST's (Kruskal Wallis, $\mathrm{X}^{2}$ 6.836, $\mathrm{P}<0.033$, Figure 7 a). The highest temperatures were observed in the woodland plots $\left(\mathrm{n}=20\right.$ median $204^{\circ} \mathrm{C}\left(\right.$ range $\left.70-491{ }^{\circ} \mathrm{C}\right)$ followed by the closed woodland plots $\left(\mathrm{n}=25\right.$ median $149^{\circ} \mathrm{C}$, range $\left.71-336^{\circ} \mathrm{C}\right)$ and the forest plots $\left(\mathrm{n}=9\right.$, median $=71^{\circ} \mathrm{C}$, range $\left.71-253^{\circ} \mathrm{C}\right)$. At $60 \mathrm{~cm}$ above the surface, the highest ambient temperatures were again observed in the woodland plots $\left(\mathrm{n}=20\right.$, median $=204^{\circ} \mathrm{C}$, range $71-404$ ${ }^{\circ} \mathrm{C}$ ), followed by the closed woodland plots $\left(\mathrm{n}=25\right.$, median $141^{\circ} \mathrm{C}$, range $71-269^{\circ} \mathrm{C}$ ) and the forest plots $\left(\mathrm{n}=9\right.$ median $71{ }^{\circ} \mathrm{C}$, range $71-218^{\circ} \mathrm{C}$ (Figure 7 a).

Ambient fire temperature measurements at the soil surface in the 20 plots that burned in 2015 were also significantly different between the vegetation types (nonparametric test Kruskal Wallis, $\left.\mathrm{X}^{2} 11.123, \mathrm{P}=0.005\right)$. The highest temperatures were observed in the three burned woodland plots (mean $528^{\circ} \mathrm{C}$, range $491-565^{\circ} \mathrm{C}$ ) while in the seven closed woodland plots that burned, the mean ambient temperature at the surface was $379^{\circ} \mathrm{C}$ (range $97^{\circ} \mathrm{C}-491{ }^{\circ} \mathrm{C}$ ). In the ten forest plots that burned in 2015 , the mean ambient fire temperature at the surface was $172{ }^{\circ} \mathrm{C}$ (range $83-565^{\circ} \mathrm{C}$ ). These temperature values were often the result of single sensitive paint colour changes that was caused by woody debris burning in contact with that specific paint, while no other liquified.

In the analysis of fire characteristics of combined VST's and PFT's, we find that for the closed woodland VST, both fire height (Kruskal Wallis $=28,375 \mathrm{P}=0.0001$ ) and the ambient temperature at $30 \mathrm{~cm}$ (Kruskal Wallis, $\left.\mathrm{X}^{2} 19,241 \mathrm{P}=0.005\right)$ and $60 \mathrm{~cm}$ (Kruskal Wallis $\mathrm{X}^{2}=$ 20,797, $\mathrm{P}=0.001)$ above the surface are significantly higher when savanna associated species dominated the canopy compared to when non-specialised or forest PFT's dominated the canopy (Appendix 1). 
(a)

Rainfall (mm)
Phenology

(b)

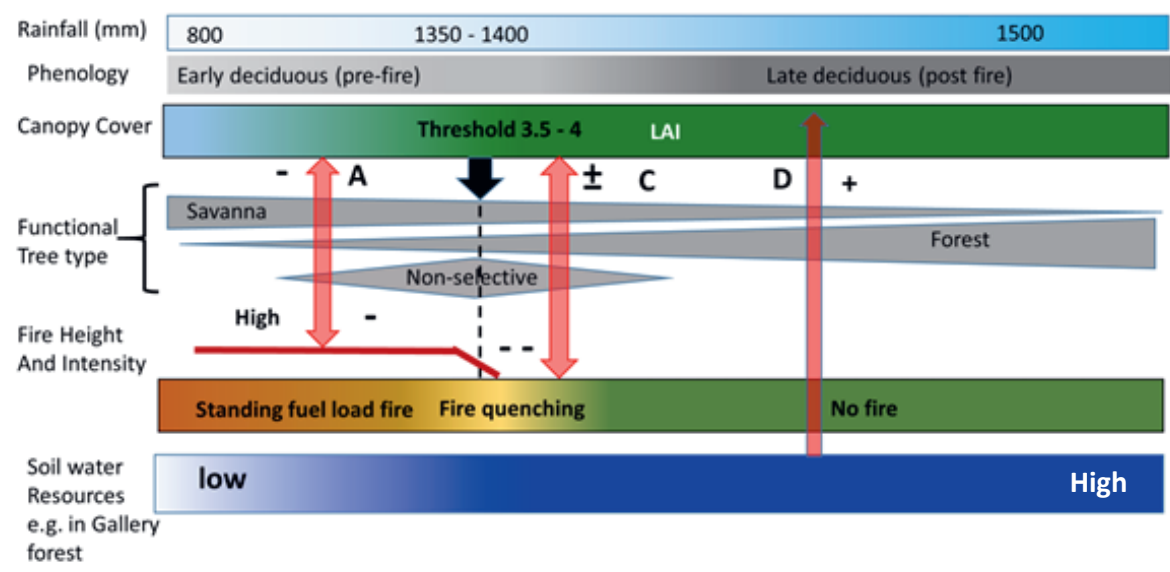

Figure 7. Conceptual diagram of tree cover - fire feedbacks (a) Situation observed in the Kogyae study site (Based on this study, Ametsitsi et al., 2020, Hennenberg et al., 2006) and (b) Feedbacks expected, if additional soil water resources are available. $1350 \mathrm{~mm}$ to $1400 \mathrm{~mm}=$ approximate position of the transition where parameters were measured.

Pairwise comparisons showed a large change in these fire intensity parameters between savanna species dominated closed woodland plots (S-closed woodlands) and non-specialised species dominated closed woodland plots (N-dominated closed woodlands). These two combined 
Chapter 4

categories also differed significantly (ANOVA $\left.F_{1,14}=4.409, \mathrm{p}=0.054\right)$ in wet season $L_{\mathbb{W}}$, with wet season $L_{\mathbb{W}}$ in the non-specialised dominated closed woodland plots being higher $\left(L_{\mathbb{W}}\right.$ oct $=1.77+/$ $0.25)$ compared to the savanna species dominated closed woodland plots $\left(L_{\mathbb{W}}\right.$ oct $\left.=1.39+/-0.39\right)$. This suggests that the more supressed fire intensity in the non-specialised species dominated closed woodland plots compared to the savanna species dominated closed woodland plots is related to a more closed canopy in the wet season.

Over the three years of observations, we did not observe any mortality in the larger trees $(>10 \mathrm{~cm} \mathrm{DBH})$ and only a few trees of the lower size class $(>2.5 \mathrm{~cm} \mathrm{DBH} 2.5<\mathrm{DBH}<10 \mathrm{~cm})$ showed top kill, which also only occurred woodlands and closed woodlands. We did observe sprout kill in low shrubs and seedlings $<2.5 \mathrm{~cm}$ but found these shrubs and seedlings also to be resprouting in the following wet season.

\section{Discussion}

In this study we aimed to describe the nature of fire mediated feedbacks under increasing tree cover and the nature and degree to which fire can percolate the vegetation under increasing tree cover. For this purpose, we measured vegetation and fire characteristics during three consecutive fire seasons in a forest-savanna ecotone in Ghana. The fires were typically found to start in the middle and towards the end of January, which represents the early to mid-season fire period in West Africa (Owusu-Afriyie, 2008; Janssen et al., 2018). As a rule of thumb, the first fires in West Africa start approximately four weeks after the last rainfall event, which is when the grass layer is dry and combustible enough to start a self-sustaining fire, with a moisture content of grasses necessary to sustain fire being in the order of below 30\% (see e.g. Finney et al., 2013) as was observed by us in 2013. Once a fire has started it can subsequently dry and burn wetter material in the fire.

The weather conditions in terms of wind speed were typical for the season with low wind speeds at night and in the mornings and moderate $\left(1-2.5 \mathrm{~m} \mathrm{~s}^{-1}\right)$ wind speeds at midday associated with general Harmattan conditions. As fires move slowly in the night and early morning under low 
wind speeds (as we measured in 2013), we expect our plots to have burned mostly during the day. Generally, the fires we observed and described here can be considered more moderate in character and impact compared to late season fires with drier fuel loads (see e.g. Veenendaal et al., 2018) that do occur in the reserve (Janssen et al., 2018) but we did not observe in our study area.

Fuel load in our study area was with an average range of less than $2.0 \mathrm{t} \mathrm{ha}^{-1}$ under canopy in forest to $>6.0 \mathrm{th}^{-1}$ in woodlands similar to what is observed in other forest-savanna transitions in West- and Central Africa (Hennenberg et al., 2006; Cardoso et al., 2018). Also, we observed a higher moisture content in herbs suggesting that the changing composition of the standing fuel load at higher $L_{\mathbb{W}}$ (increase of herbs) contributes to a reduced fire intensity ( see e.g. Cardoso et al., 2018). We did not observe any enhanced fire effects in plots where the invasive shrub/herb $C$. odorata was more abundant, which might also be a result of the relatively high fuel load moisture content that we observed in this study. Generally, our forest and closed woodland structural type plots had larger amounts of dry leaf litter mass compared to woodland plots; also reported by others (e.g. Hennenberg et al., 2006).

In contrast to some studies that found virtually no percolation of fire under tree canopy (Cardoso et al. 2018, Hoffman et al. 2012), in our study area fire was able to percolate all vegetation structural types: woodlands, closed woodlands and forests, burning most if not all of the plot surface area but slightly less so in the closed woodland and forest plots. Given the size of our plots $(20 \times 20 \mathrm{~m})$ and the location of these plots in larger patches of $50 \times 50 \mathrm{~m}$ or more, our fire percolation was at least similar to the largest fire percolation (50 m.) reported in Hennenberg et al., (2006). In 2014 all plots were reached by fire; however, a part of the study area did not burn in 2015. In areas reached by fire, the average plot area that was left unburned was small $\left(<15 \mathrm{~m}^{2}\right)$ but these unburned patches could still represent temporary safe sites for fire-sensitive plant species. Furthermore, the presence of unburned patches can partly explain the disjunct patterns of savanna and forest species in the overstorey and understorey vegetation that is observed in Kogyae (Armani 
Chapter 4

et al., 2018) as well as the existence of small numbers of forest trees within savanna (Ametsitsi et al., 2020).

As reported elsewhere (e.g. Cardoso et al., 2018; Charles-Dominique et al., 2018 (in this study herbivory also plays a role); Hoffman et al., 2012), we also found that tree canopy cover has a supressing effect on fire intensity and spread. Besides standing fuel biomass reduction, we already noted the generally higher moisture content of herbs dominating the understory vegetation. These results confirm earlier findings that understorey vegetation is less flammable under moister conditions (Kaufman \& Uhl, 1990; Cardoso et al., 2018) and this represents an additional negative feedback on fire besides the supressing effect of standing fuel load reduction. Notwithstanding this, fires still penetrated under the tree canopy, fuelled by the presence of dry leaf litter. This litter type of fire has been reported to occur in forests globally (Cochrane \& Schulze, 1998, 1999, Cochrane et al., 1999; Swaine, 1992; Mutch, 1970; Stott, 2000 for examples from South America, Africa, Asia and Australia) and hinges on the litter layer being dry enough (Ray et al., 2010). Considering that flame height of litter fires is often below $30 \mathrm{~cm}$ (Figure 6a), with our method ambient temperature hardly detectable (hence median in forest often below $71{ }^{\circ} \mathrm{C}$ ) these fires appear rather benign in intensity (scorch height also being a "good" predictor of fire intensity (Williams \& Moore, 1998).

We find that the threshold level at which the fire regime shifts from standing fuel load fires to dry litter fires lies at a wet season $L_{\mathbb{W}}$ of $1.7-2.0$. Our results indicate that the high $L_{\mathbb{W}}$ (average $>1.8$ ) in closed woodlands strongly reduces the standing fuel biomass of grasses during the wet season, while a substantial early dry season $L_{\mathbb{W}}$ reduction $(60 \%)$ as a result of leaf shedding, drives the build-up of a dry litter layer in these closed woodland plots. Although benign in nature, litter fires have been identified as an important contributor to tree seedling mortality and provide a tree functional type recruitment bottleneck that may also provide an important feedback, through a change in tree species composition, on the tree canopy (e.g. Cochrane \& Schulze, 1999; Cardoso et al., 2016; Issifu et al., 2019). These interactions between benign litter fires and tree species 
composition in forest-savanna ecotones provide a mechanistic explanation of why intermediate or non-selective tree communities between savanna and forests exist (e.g. Hall \& Swaine, 1976; Swaine, 1992; Dexter et al., 2018; Ametsitsi et al., 2020; Ratnam et al., 2019).

\section{Sharp ecotones with soft edges?}

Many studies report or argue in favour of specific thresholds for sharp transitions between forest and savanna, mediated by the presence or absence of fires (Cardoso et al., 2018; Hoffman et al., 2012; Ibanez et al., 2013; Staal \& Flores, 2016), while some note sharp edges with a degree of transition (Charles-Dominique et al., 2018). Our study was executed in a landscape where sharp boundaries are less clear and sharp edges in the form of e.g. gallery forest formations (see for many examples e.g. Cole, 1986) were purposely avoided (Ametsitsi et al., 2020; Janssen et al., 2018). The threshold for fire quenching observed in recent studies differs per study within some areas for $L_{\mathbb{w}}$ values near to the forest edge of $\geq 3$ (Cardoso et al., 2018; Hoffman et al., 2012) to around 1.5 (Hennenberg et al., 2006, conversion from projected tree cover to $L_{\mathbb{W}}$ cover taken from TorelloRaventos et al., 2013) to as low as 0.5 if herbivory is present (Charles-Dominique et al., 2018). We have conceptualised such apparent contrasting findings in an attempt to reconcile these observations (Figure 8).

In our study, standing fuel load fires were substantially reduced around $L_{\mathbb{W}} 1.5-2$ (Figure 7a). Below this threshold, standing fuel load mediated fires have a significant effect on the tree canopy as quantified in e.g. Veenendaal et al. (2018). A closing canopy (closed woodlands) reduces fire intensity and non-selective species become more common under lower fire intensity (this study and Ametsitsi et al., 2020). In woodlands that experience high intensity fires, the canopy is dominated by savanna tree species. As the canopy closes to above the $L_{\mathbb{W}}$ threshold when standing fuel load is supressed (2.0), we find mostly forest species in these communities. However, dry leaf litter fires continue to percolate beneath the closed canopy. Litter fires are of lower intensity and flame height compared to the standing fuel load type fires and have therefore a limited effect on 
Chapter 4

tree canopy cover, but act as filter for the tree species recruitment (Cardoso et al., 2016; Issifu et al., 2019). For this reason, the direct impact of litter fires on canopy cover (depicted as feedback B in Figure 7a) is not so strong, although litter fires influence species composition.

Limited rainfall and soil water retention leads to soil water shortages in the dry season (Hall \& Swaine 1976; Veenendaal et al., 1996b; Ametsitsi et al., 2020), which stimulates early dry season leaf shedding (this study). Dry leaf litter build-up in the early dry season provides fuel to litter fires and drives a positive feedback between benign fires and the presence of early deciduous tree species in dry forest (Feedback B). When sufficient trees become semi-deciduous and leaf shedding is delayed beyond when the grass layer is ready to burn, the feedback B disappears. We did not observe this in our study area but in West Africa a sharp decline of fire occurrences has been documented (both in ground records and satellite data) between dry deciduous forest and moist semi-deciduous forest types at higher rainfall (1500 mm) (Owusu-Afriyie, 2008).

In Figure $7 \mathrm{~b}$ we speculate about the effect of a higher soil water availability due to a higher groundwater table (e.g. as found in Gallery forest in forest-savanna ecotones). Now, additional groundwater supply does not only increase tree canopy cover but also delays the timing of leaf shedding. Furthermore, increased plant available water in forest enhances the differences in moisture level between the fuel biomass in the savanna and in the forest understory due to effects of an enhanced microclimate (Biddulph \& Kellman, 1998; Cardoso et al., 2018; Marsh, 1978; Justiniano \& Fredericksen, 2000). In this case, savanna standing fuel load fires become seasonally disjunct from leaf fall with standing fuel biomass in the forest also too moist so that leaf litter fires are less likely to happen. The dry grass biomass standing fuel load fires then continues to act as a sharpening switch causing a sharp transition as e.g. demonstrated in Lloyd \& Veenendaal (2016). Litter fires are in our view likely a characteristic of more fire-adapted forest and transitional tree communities described in the dry forests of Africa and elsewhere (Hall \& Swaine 1976, Ratnam et al. 2019) and we propose that through early dry season leaf shedding the existence of soft transitions such as reported here can be reconciled with sharp transitions observed elsewhere. 


\section{Concluding remarks}

In this study we set out to examine fire-tree canopy cover feedbacks in a West African forestsavanna ecotone. (1) We found the clear negative feedback of canopy closure on standing fuel load with C4 grass fuel load strongly reduced at wet season $L_{\mathbb{W}}$ of around 1.5-1.2. We presented evidence that the fire regime switches from standing fuel load fire to tree leaf litter fire when canopy closure approaches a wet season $L_{\mathbb{W}}$ of around 1.7-2.0. We argue that benign ground fires are driving the species composition of specific tree communities in which these fires act as filter on tree species recruitment and are the cause of fire-resistant transitional tree species communities that may be largely absent if additional water supply is present.

\section{Acknowledgements}

We thank the Wildlife Division of the Forestry Commission of Ghana for permission to work in the Kogyae Strict Nature Reserve. Our appreciation also goes to the Park Manager, Mr. Dwoben Nyantakyi, and his staff at Dome Camp, particularly Isaac Sarpong, Kwaku Yinye and Yaw Agyeman. Elmar Veenendaal and George Ametsitsi were partially funded by the EU KP7 GEOCARBON project (contract number 283080). Jon Lloyd and Vincent Logah received support through Royal Society - DFID (Africa capacity building initiative programme) and with Jon Lloyd also being supported by a Royal Society Wolfson fellowship. 
Chapter 4

Appendix 1. Classification of vegetation patches in the study area (source: Ametsitsi et al. 2020)

\begin{tabular}{|c|c|c|c|}
\hline $\begin{array}{c}\text { Plot } \\
\text { Number }\end{array}$ & $\begin{array}{l}\text { Plant functional } \\
\text { type dominance }\end{array}$ & $\begin{array}{l}\text { Classification Based } \\
\text { on structure }\end{array}$ & $\begin{array}{c}\text { Combined Classification } \\
\text { Pre-fix indicates dominating PI } \\
\text { functional type } \\
\end{array}$ \\
\hline 1 & Savanna & Closed woodland & $\mathrm{S}^{*}{ }_{\text {CClosed Woodland }}$ \\
\hline 2 & Forest & Forest & F_Forest \\
\hline 3 & Transition & Closed woodland & N_Closed woodland \\
\hline 4 & Forest & Closed woodland & F_Closed woodland \\
\hline 5 & Transition & Closed woodland & N_Closed woodland \\
\hline 6 & Transition & Closed woodland & N_Closed woodland \\
\hline 7 & Transition & Closed woodland & N_Closed woodland \\
\hline 8 & Transition & Woodland & N_Closed woodland \\
\hline 9 & Savanna & Closed woodland & S_Closed woodland \\
\hline 10 & Savanna & Woodland & S_woodland \\
\hline 11 & Savanna & Closed woodland & S_Closed woodland \\
\hline 12 & Savanna & Woodland & S_woodland \\
\hline 13 & Savanna & Closed woodland & S_Closed woodland \\
\hline 14 & Transition & Woodland & N_woodland \\
\hline 15 & Transition & Woodland & N_woodland \\
\hline 16 & Savanna & Closed woodland & S_Closed woodland \\
\hline 17 & Savanna & Woodland & S_woodland \\
\hline 18 & Savanna & Closed woodland & S_Closed woodland \\
\hline 19 & Savanna & Closed woodland & S_Closed woodland \\
\hline 20 & Savanna & Closed woodland & S_Closed woodland \\
\hline 21 & Forest & Closed woodland & F_Closed woodland \\
\hline 22 & Savanna & Closed woodland & S_Closed woodland \\
\hline 23 & Transition & Closed woodland & N_Closed woodland \\
\hline 24 & Savanna & Closed woodland & S_Closed woodland \\
\hline 25 & Transition & Closed woodland & N_Closed woodland \\
\hline 26 & Forest & Forest & F_Forest \\
\hline 27 & Forest & Forest & F_Forest \\
\hline 28 & Forest & Forest & F_Forest \\
\hline 29 & Forest & Forest & F_Forest \\
\hline 30 & Forest & Forest & F_Forest \\
\hline 31 & Forest & Forest & F_Forest \\
\hline 32 & Forest & Forest & F_Forest \\
\hline 33 & Forest & Forest & F_Forest \\
\hline 34 & Forest & Forest & F_Forest \\
\hline 35 & Forest & Forest & F Forest \\
\hline
\end{tabular}


Appendix 2. Graphical representation of the poles used to measure environment temperature and fire height. Pyrometers were constructed using 16 temperature-sensitive paints (OMEGALAQ ${ }^{\circledR}$ Liquid Temperature Lacquers) applied to galvanized metal rows of $25 \mathrm{~cm}$ long and $1 \mathrm{~cm}$ diameter staked at 30 and $60 \mathrm{~cm}$ above ground. Each colour marks one temperature, from a minimum $107^{\circ} \mathrm{C}$ to a maximum $927^{\circ} \mathrm{C}$. Pieces of cotton were attached along the pole every $30 \mathrm{~cm}$ to a maximum of $300 \mathrm{~cm}$ to estimate maximum flame height.

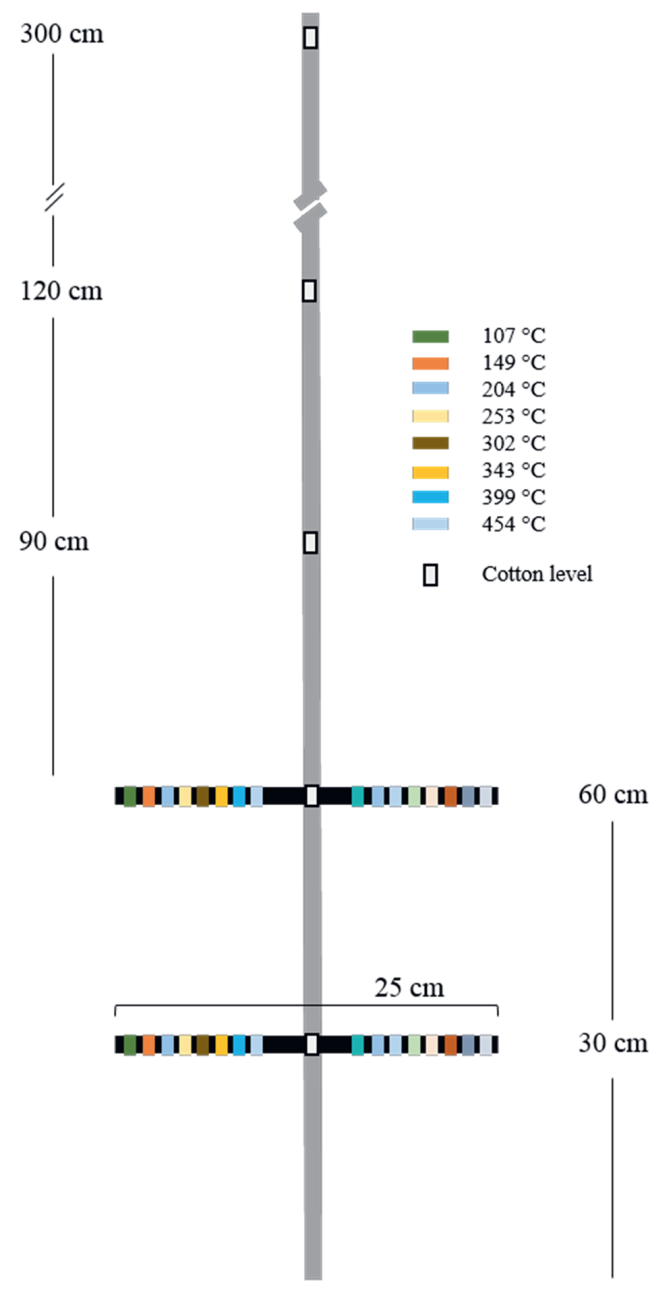


Appendix 3. The relationship between crown area index (CAI) and leaf area index in October $(\mathrm{LAI}(\mathrm{Oct}))$ a Michaelis Menten Equation $(\mathrm{LAI}=2.8 * \mathrm{CAI}) /(0.9+\mathrm{CAI})$ has been fitted for ease of view.

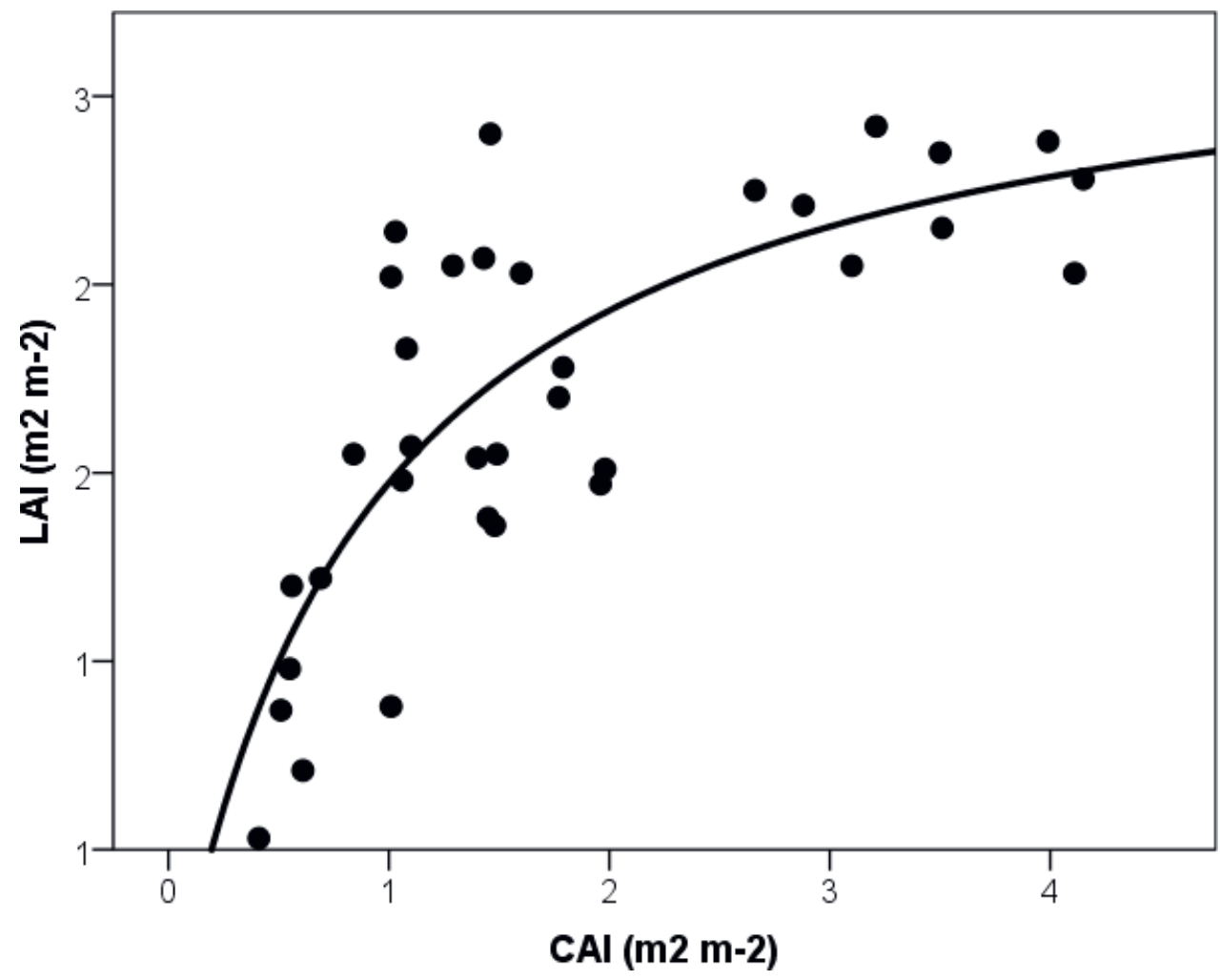


Appendix 4. Weather conditions in KNSR during the period of the fire events. Data from The Ejura weather station.
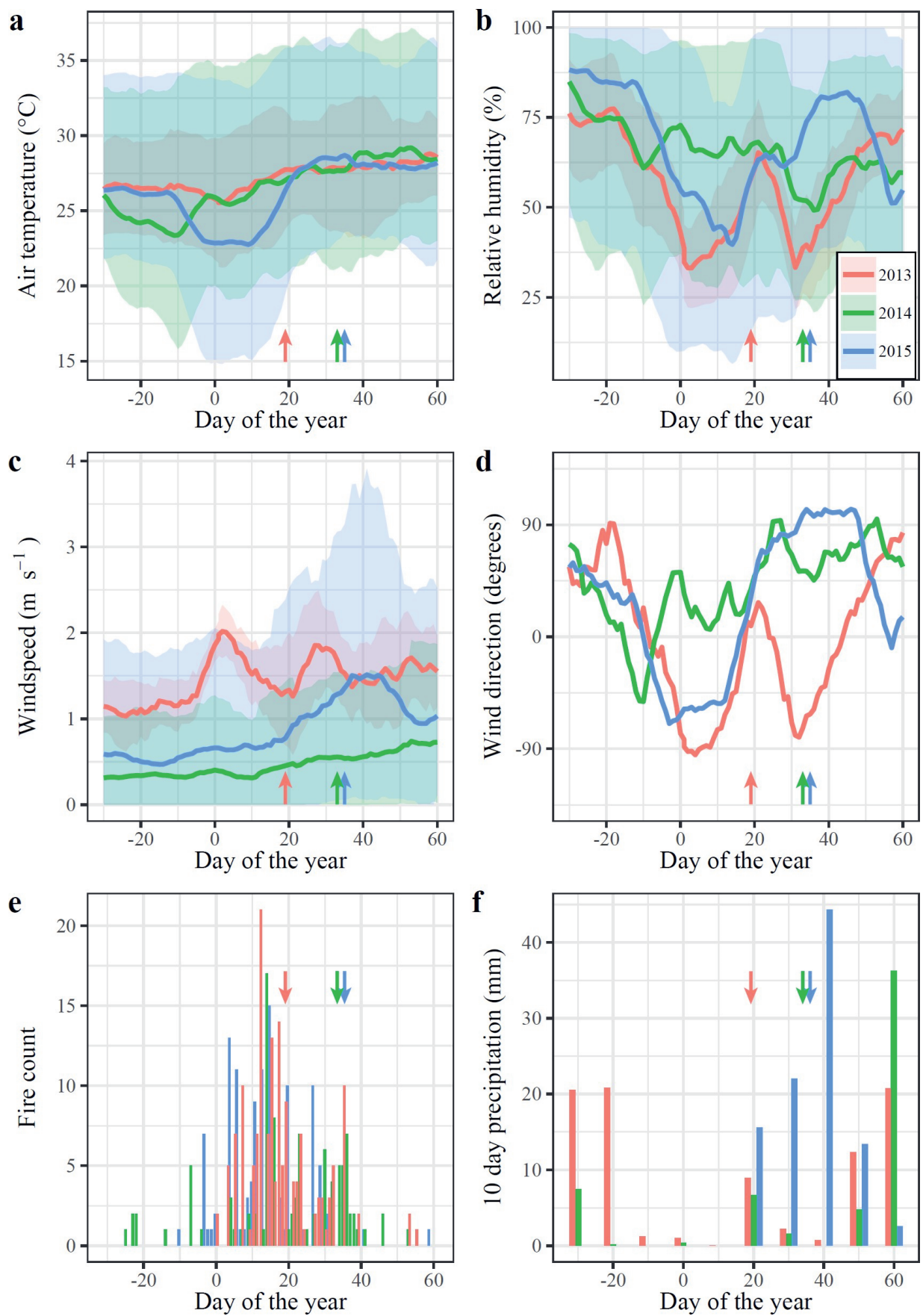
Chapter 4

Appendix 5. Picture of a typical standing fuel load fire (a) and of a leaf litter fire (b) (Pictures: Laurianne Ollivier 2014).
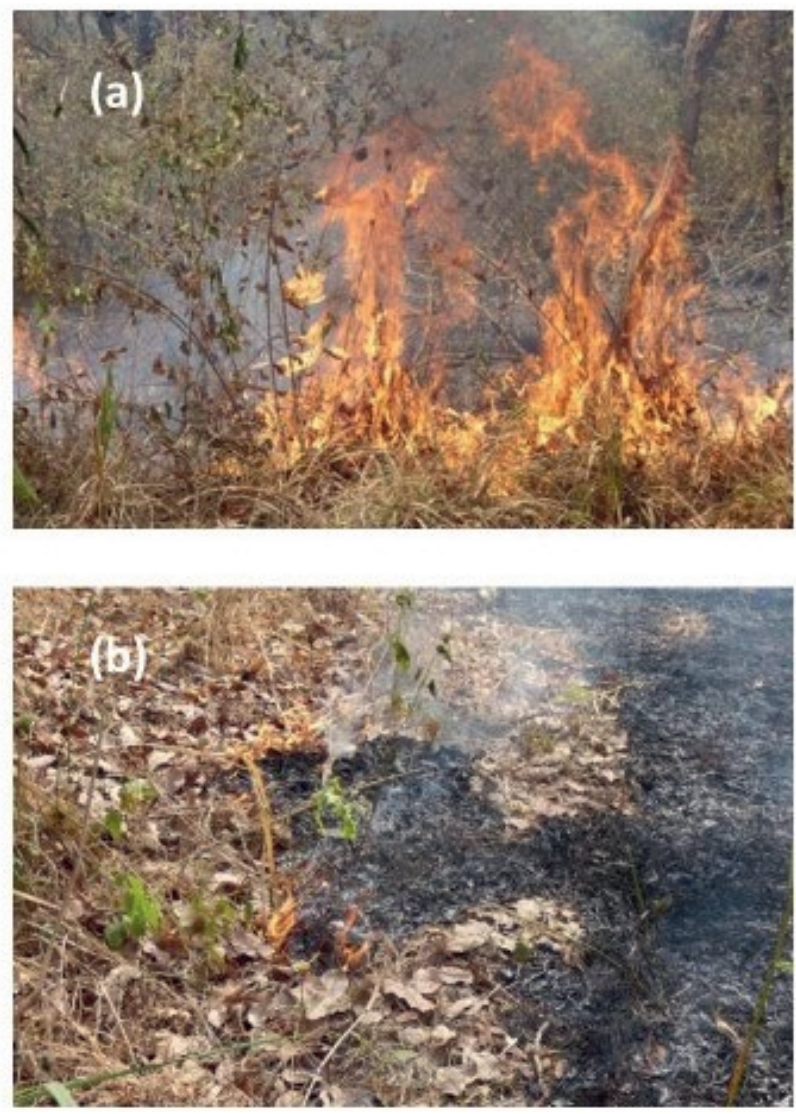


\section{Chapter 5}

Fall leaves fall!* Leaf shedding of tree species in a forest-savanna ecotone in West Africa depends on individual species, tree functional type and stand structure

George K.D. Ametsitsi, Thomas Janssen, Frank Van Langevelde, Hamza Issifu, Lucy Amissah,

Stephen Adu-Bredu, Vincent Logah, Philippine Vergeer, Jon Lloyd \& Elmar M. Veenendaal

Fall, leaves, fall; die, flowers, away;

Lengthen night and shorten day;

Every leaf speaks bliss to me

Fluttering from the autumn tree.

Emily Brontë 
Chapter 5

\begin{abstract}
Leaf fall may play a role in the penetration of litter fires in forest-savanna transitions. We monitored leaf fall across a range of vegetation types in an ecotonal area in Ghana, West Africa. We used leaf area index (LAI) to monitor changes at the stand level combined with estimates on leaf retention in individual trees. We used estimates of leaf retention on individual trees to assess variability among species and tree functional types (savanna, neutral and forest tree functional type, TFT). We assessed whether vegetation structure (woodlands, closed woodlands, forests) had an influence on the leaf retention of TFT's vegetation structure. Highest end of rainy season LAI was found in October/November in forest species dominated plots, with intermediate LAI in plots dominated by the neutral TFT and the lowest LAI in plots dominated by savanna TFT. This difference was maintained even as the dry season progressed with the LAI in forest dominated species being in decline as soon as the rains ended in November.
\end{abstract}

Keywords: canopy cover, forest-savanna ecotone, vegetation structure, litter, standing fuel load, fire. 


\section{Introduction}

Savanna fires are often reported to stop at the forest-savanna border and not penetrate forest. The mechanism for this is a dense enough tree canopy cover to suppress grass biomass, the latter constituting the principal fuel source enabling the penetration of fires (e.g. Charles-Dominique et al., 2018; Cardoso et al., 2018; Hennenberg et al., 2006; Warman \& Moles, 2009; Ibanez et al., 2013; Hoffmann et al., 2012b; Dantas et al., 2013). However, fire events are also widely reported in dry forest. Fires in forests are common in some places including West Africa and Asia, where fires are not only being fuelled by a grass biomass but also by leaf litter produced by tree cover (Ametsitsi et al., 2020; This thesis; Ratnam et al., 2019; Stott, 1986, 2000; Stott et al., 2000). In West Africa, "fire forests" consist of specific tropical "fire" forest communities (Hall \& Swaine, 1976; Swaine, 1992).

The distribution of forest communities across climatic landscapes in West Africa is associated with changes in leaf production and leaf phenology with wetter forest showing less seasonality in leaf shedding (Fauset et al., 2012; Swaine, 1992; Aguirre-Gutiérez, et al., 2019). Leaf traits are directly linked to phenology both within and across the savanna boundary and with tree functional type. Savanna trees are more deciduous than forest trees and with considerable variation among forest trees (Schrodt et al., 2015). If vegetation has access to water resources, for example in gallery forests, leaf phenology changes, with more semi-deciduous or (semi-) evergreen species becoming more abundant (De Bie et al., 1998). Thus, adjunct to leaf cover (suppression of grass biomass), leaf phenology (supply of tree leaf litter fuel) may also play a role in litter-fuelled fire penetration and may be associated with soil water supply, tree species and tree functional type.

In the forest-savanna (FS) boundary of Kogyae in Central Ghana, we have previously reported on the link between vegetation structure and water retention and available Potassium (Ametsitsi et al., 2020) and the existence of benign litter fires under closed tree canopies. Also, some evidence was provided for differences in leaf phenology between forest patches differing in (structure and tree type composition). In this study, we explore if leaf phenology differences can 
Chapter 5

be attributed to specific tree species, tree functional type or stand structural types and to what extent this phenological behaviour may influence the tree phenology and as a consequence the production of tree leaf litter at the start of the dry season.

We hypothesise that; (1) savanna-associated tree species have a more deciduous, and earlier leaf fall phenological behaviour compared to forest tree species with tree species occurring in both forest, savanna or forest-intermediate, thus, phenological behaviour being more a tree functional type trait than a species-specific trait. (2) The timing of leaf fall of tree species in open tree stands (woodland) is earlier than in denser tree stands (forest) irrespective of tree functional type.

\section{Methods}

\section{Study site}

Observations were made over the period October 2014 to February 2015 in the Kogyae Strict Nature Reserve (KSNR) in the Ashanti Region of Ghana ( $7^{0} 15^{\prime} 52^{\prime \prime N}$ and $\left.1^{\circ} 04^{\prime} 47^{\prime \prime W}\right)$. With a size of $330 \mathrm{~km}^{2}$, KSNR lies in the transition zone between the Guinea Savanna Zone in the north and the Deciduous Forest Zone in the South (Janssen et al., 2018). Average rainfall is approximately $1.36 \mathrm{~m} \mathrm{yr}^{-1}$. Rainfall distribution is seasonal with a distinct wet and dry season. Heavy rains fall between May and October, followed by a dry season from December to March. The annual average temperature is $28^{\circ} \mathrm{C}$ with little seasonal variation. The structural vegetation types within the KSNR range from closed forests to open woodlands (Ametsitsi et al., 2020).

\section{Vegetation measurements and plot classification}

Thirty-five plots of $20 \mathrm{~m} \times 20 \mathrm{~m}$ were established in the North-East corner of the park. The plot size was selected small enough to allow for a homogeneous vegetation structure but large enough to obtain a representative sample of the stand-level tree species composition. All plots were located in vegetation types initially identified by eye and divided over savanna-like vegetation, forest-like vegetation and semi-closed 'intermediate' vegetation. All plots were located a maximum distance 
of $7.0 \mathrm{~km}$ from each other. Based on the plot-level measurements, diameter at breast height $(D)$, crown area index $\left(C_{\mathbb{W}}\right)$, leaf area Index $\left(L_{\mathbb{w}}\right)$ and 0.95 quantile height $\left(H^{*}\right)$, each of the 35 plots had previously been classified as one of three vegetation structural types (VST) vi₹: "woodland" (6 plots) "closed woodland" (18 plots) or "forest" (11 plots) as described in detail by Janssen et al. (2018) and Ametsitsi et al. (2020). In brief, $D$ and $H$ were measured for all trees with $D \geq 2.5 \mathrm{~cm}$ and with $C_{\mathbb{W}}$ estimated for all trees with $\mathrm{DBH}>10 \mathrm{~cm}$, with values taken in 2014 . Woody vegetation leaf area index (LAI) was determined from hemispheric photographs taken during diffuse light conditions (Frazer et al., 1999; Promis et al., 2011). Observations on leaf retention (the $\%$ of leaves left on an individual tree compared to the October density of leaves $(100 \%)$ done by eye supported by canopy pictures (Ametsitsi et al., 2020). All trees $>10 \mathrm{~cm} \mathrm{DBH}$ were monitored.

As is also explained in detail in Ametsitsi et al. (2020), each tree species observed as part of this study was classified into one of three plant functional types (PFT) viz "savanna-affiliated" $(S)$ "forest-affiliated" $(F)$ or "non-specialised" or "neutral" $(N)$ - the latter species regularly occurring in both forest and savanna. This classification was done on the basis of ecological information from Keay (1989), Hawthorne (1995), and Hawthorne \& Jongkind (2006) and on the basis of the relative contribution of each of the PFTs assessed using estimates of the $C_{\mathbb{W}}$ of trees with $D>10$ $\mathrm{cm}$ as well as smaller trees $(\mathrm{D}>2.5 \mathrm{~cm})$ this provided an alternative means by which the 35 plots could be classified as either savanna $(89 \pm 3.6 \%$ (mean \pm SE) $S$ dominance), transitional (60 \pm $5.4 \% \mathrm{~N}$ dominance) or forest $(74 \% \pm 5.5 \% \mathrm{~N}$ dominance). Detailed information on the clustering procedures used and details of the relationships between the VFT vs. PFT classifications are available in Ametsitsi et al. (2020).

\section{Statistical analyses}

Statistical analyses were undertaken with SPSS version 25. Comparisons of leaf cover and leaf retention between plots were done with a single ANOVA and Post-Hoc Tukey test. If necessary, data were log-transformed to ensure normality and homogeneity of variances as indicated in the 
Chapter 5

results section. If the log-data transformation proved insufficient, Kruskal Wallis non-parametric $-\chi^{2}$ tests were used. The comparisons of leaf retention between individual trees was analysed with a linear mixed effect model with tree functional type $(\mathrm{S}, \mathrm{N}, \mathrm{F})$, species and plot structural type (Woodland, closed woodland and forest) as fixed factors and tree size (DBH) as a random factor.

\section{Results}

\section{Climate}

The rainy season ended mid-November with the last rainfall $\left(7 \mathrm{~mm} \mathrm{Wk}^{-1}\right)$ in the third week of November, followed by a dry period up to mid-January (Figure 1). In the third week of January there was a short rainfall period $(18 \mathrm{~mm})$ and significant rains fell from the first week of February $(22 \mathrm{~mm})$ to the second week of February $(43 \mathrm{~mm})$ thereafter declining again. Air temperatures were stable during the first part of the dry season (average $27^{\circ} \mathrm{C}$ ) with a somewhat colder spell in the beginning of January $\left(23{ }^{\circ} \mathrm{C}\right.$ average) and particularly colder nights and drier air (VPD of -4.5 $\mathrm{KPa}$ ). Dry air conditions remained except during periods of rainfall.

\section{Variation in leaf area index}

Savanna tree functional type-dominated plots had in the latter part of the rainy season (October, November), a LAI of $1.28 \pm 0.32 \mathrm{~m}^{2} \mathrm{~m}^{-2}$ to $1.29 \pm 0.39 \mathrm{~m}^{2} \mathrm{~m}^{-2}$ (Figure 2a). LAI declined in December to $0.95 \pm 0.29 \mathrm{~m}^{2} \mathrm{~m}^{-2}$ reaching the lowest values in January and February of $0.48 \pm 0.11$ $\mathrm{m}^{2} \mathrm{~m}^{-2}$ and $0.44 \pm 0.21 \mathrm{~m}^{2} \mathrm{~m}^{-2}$ increasing in March after the February rains to $0.92 \pm 0.37 \mathrm{~m}^{2} \mathrm{~m}^{-2}$. Transition plots dominated by "non-selective" functional tree types showed similar variation in LAI with maximum end of rainy season values in October and November reaching $1.65 \pm 0.28$ $\mathrm{m}^{2} \mathrm{~m}^{-2}$ to $1.76 \pm 0.45 \mathrm{~m}^{2} \mathrm{~m}^{-2}$ respectively. In this forest type, LAI declined in December to $1.27 \pm$ $0.37 \mathrm{~m}^{2} \mathrm{~m}^{-2}$ reaching the lowest values again in January and February of $0.48 \pm 0.15 \mathrm{~m}^{2} \mathrm{~m}^{-2}$ and $0.63 \pm 0.31 \mathrm{~m}^{2} \mathrm{~m}^{-2}$ increasing in March after the February rains to $1.08 \pm 0.35 \mathrm{~m}^{2} \mathrm{~m}^{-2}$. Forest tree functional type-dominated plots showed the highest values of LAI with maximum end of rainy 
season values in October and November reaching $2.15 \pm 0.24 \mathrm{~m}^{2} \mathrm{~m}^{-2}$ to $2.33 \pm 0.19 \mathrm{~m}^{2} \mathrm{~m}^{-2}$ respectively declining to LAI $1.84 \pm 0.34$ in December reaching the lowest values again in January and February of $1.36 \pm 0.36$ and $1.37 \pm 0.51$ increasing in March after the February rains to 1.60 \pm 0.35 . During the Months of October and November, the three plot types were always statistically significantly different $\left(\mathrm{F}_{2,32}\right.$ Oct. 29.887, $\mathrm{P}<0.0001,\left(\mathrm{~F}_{2,32}\right.$ Nov. 28.606, $\mathrm{P}<0.0001$; differences between groups with Tukey's test $\mathrm{P}<0.05$ indicated in figure $2 \mathrm{a}$ ). While from January onwards savanna and transitional plots were not significantly different from each other but forest plots were $\left(\mathrm{F}_{2,32}\right.$ values for January, February and March being 56.757, 22.923 and 12.429 respectively with $\mathrm{P}$ always $<0.0001)$. Forest plots thus maintained the highest LAI throughout. Maximum LAI decline in January (LAI November - LAI January) was significantly different (Tukey post hoc test $\mathrm{P}<0.05)$ between savanna plots $\left(0.82 \pm 0.38 \mathrm{~m}^{2} \mathrm{~m}^{-2}\right)$ and transition plots $\left(1.27 \pm 0.33 \mathrm{~m}^{2} \mathrm{~m}^{-2}\right)\left(\mathrm{F}_{2,32}\right.$ 4.21, $\mathrm{P}<0.025)$ with forest plots showing an intermediate and not significantly different decline from the other two types $\left(0.98 \pm 0.33 \mathrm{~m}^{2} \mathrm{~m}^{-2}\right)$.

LAI variation was closely associated with soil moisture decline in the plots (Figure $2 \mathrm{~b}$ ) with soil moisture not significantly different between plots in October $\left(\mathrm{F}_{2,32} 2.357 \mathrm{P}<0.111\right)$ varying from $18.8 \%$ in savanna tree dominated plots to $17.7 \%$ in forest tree dominated plots. From November onwards, soil moisture was always somewhat (but always statistically significantly) lower in plots dominated by forest trees and with the highest LAI compared to other tree type dominated plots. The lowest LAI values were reached in January with moisture content significantly different between plot types $\left(\mathrm{F}_{2,32}=22.807, \mathrm{P}<0.001\right)$ and with the strongest depletion in the plot type with the highest LAI (average values for savanna, transition and forest plots being 3.45 $\pm 0.68 \%$, $2.74 \pm 0.57$ and $1.82 \pm 0.57$ respectively).

When quantifying LAI in plots classified on the basis of stand structure, similar seasonal patterns were found as before with forests maintaining higher LAI values than closed woodlands or woodlands (Figure S1) but differences in LAI between November and January were now not found to be statistically significantly different between the three categories (woodlands, closed 
Chapter 5

woodlands and forests). Soil moisture patterns were similar as before with the forest plots depleting surface soil water more than the other plot types (not further shown).
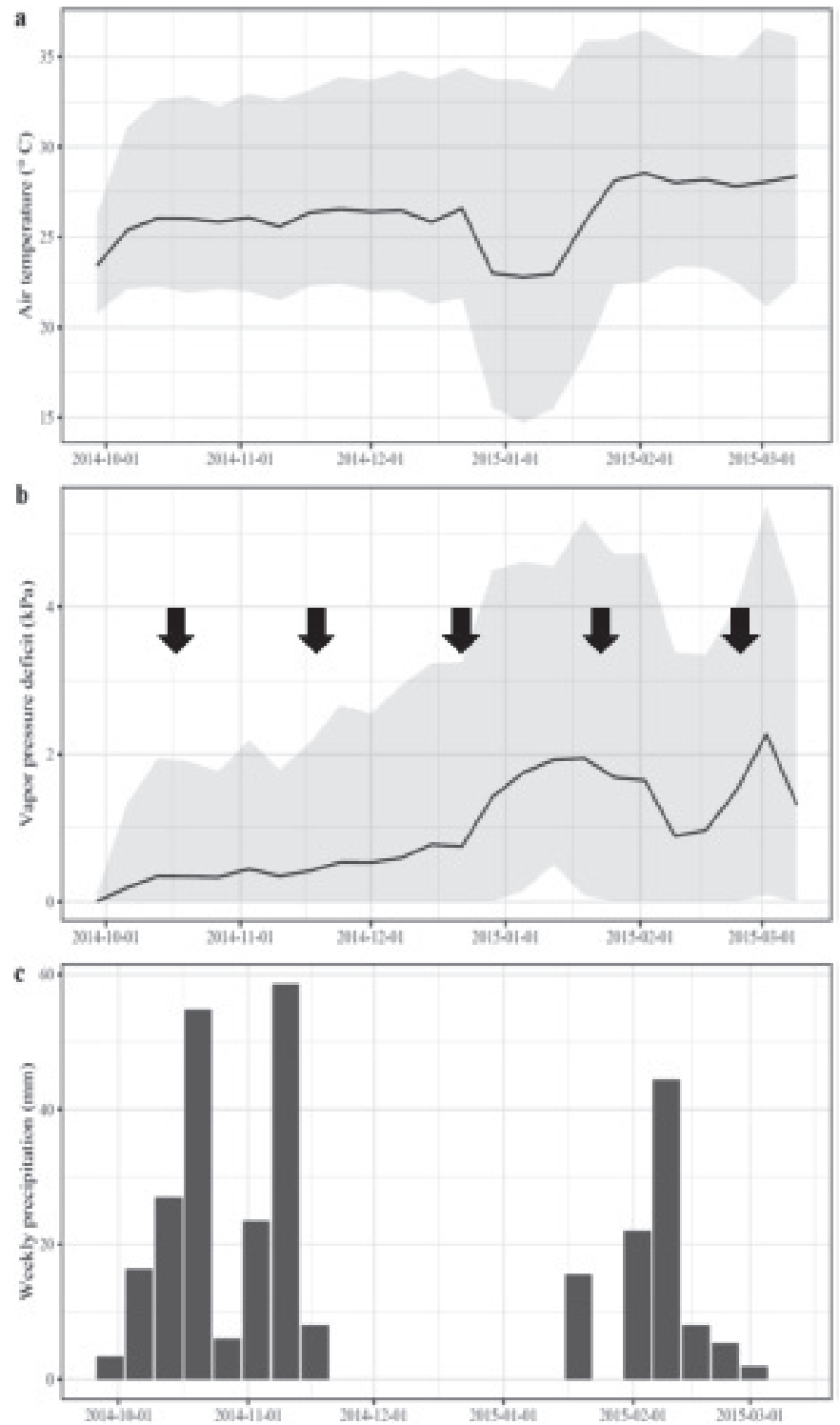

Figure 1. Average daily air temperature (a), vapor pressure deficit (b) and weekly rainfall (c) in the Kogyae Strict nature Reserve study site for the period October 2014 - March 2015. Arrows in b indicate the phenological observation dates. 

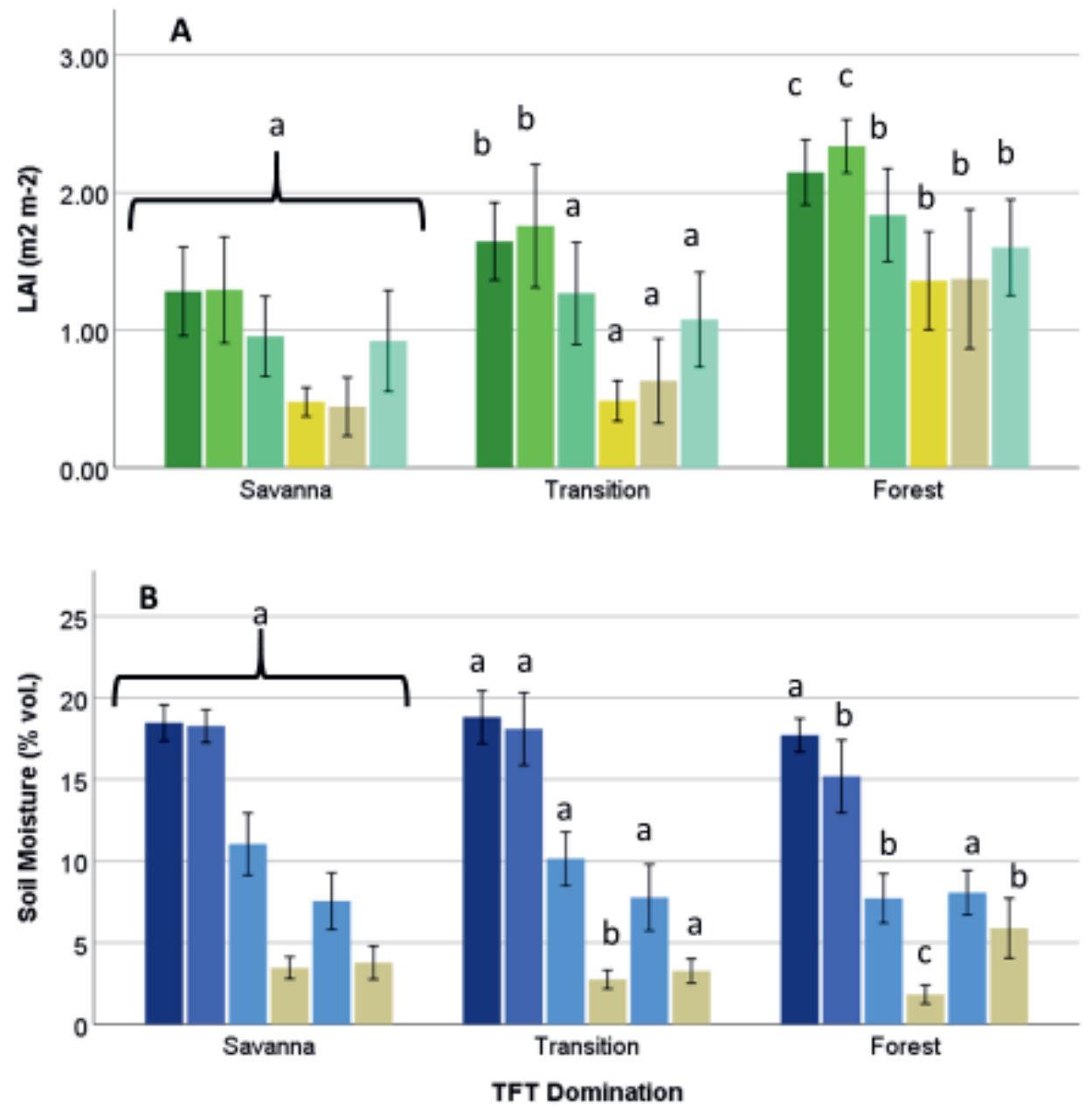

Figure 2. Variation in leaf area index $\left(\mathrm{LAI}, \mathrm{m}^{2} \mathrm{~m}^{-2}\right.$ ) (a) and soil moisture over $1 \mathrm{~m}$. depth (b) (\% vol. average $1 \mathrm{~m}$. depth) in plots characterised by a dominance of $\mathrm{S}$ species (Savanna), N species (Transitional) and F species (Forest). Bars indicate values for October, November, December, January, February and March respectively. Letters indicate differences between plot types for each month (savanna always a) with Tukey's post-hoc test $\mathrm{p}<0.05$ ). 
Chapter 5

\section{Percentage leaf retention in different plant functional type dominated plots}

As observed for LAI, percentage retained leaves showed a similar pattern of decline as the dry season progressed (Figure 3). Forest plots retained a higher proportion of leaves as the dry season progressed, with lowest retention in transition plots dominated by non-selective species with savanna tree dominated plots being intermediate. In December, leaf retention in forest patches was still $77 \pm 13 \%$ while this was in savanna plots $66 \pm 12 \%$ and transition plots $62 \pm 6 \%$ with transition plots significantly different from forest plots (Tukey post-hoc test $\mathrm{P}<0.05$ ) and savanna plots intermediate. By January, leaf retention was in forest plots still $52 \pm 22 \%$ while in savanna plots $36 \pm 21 \%$ and transition plots $26 \pm 13 \%$ with Transition plots again significantly different from forest plots (Tuckey post hoc test $\mathrm{P}<0.05$ ) and savanna plots being intermediate.

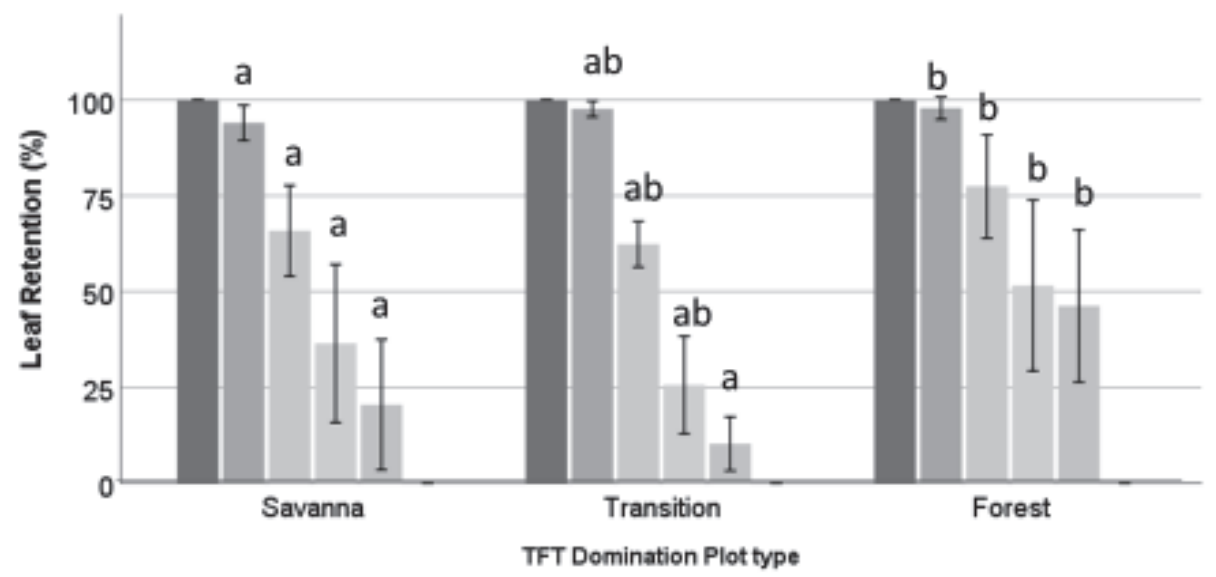

Figure 3. Variation in leaf retention (\% of leaves retained compared to October) in plots characterised by a dominance of $\mathrm{S}$ species (Savanna), N species (Transitional) and F species (Forest). (\% percentage weighed for crown area of individual trees). The first (deepest green) bar indicates October values. Subsequent bars indicate values for November, December, January and February respectively. Letters indicate differences between plot types for each month (savanna always a) with Tukey's post-hoc test $\mathrm{p}<0.05$ ). 


\section{Leaf level retention of individual species and tree functional types}

While overall patterns were linked to tree functional type dominated plots, individual tree species also varied widely even within TFT. This is illustrated for nine common tree species in Figure 4. Of the species shown here, two tree species Lepisanthes senegalensis (S) and Manilkara obovata (F) largely retained leaves throughout the season. Four species, Terminalia glaucescens $(\mathrm{S})$, Bridelia micranta $(\mathrm{N})$, Margarita discoides $(\mathrm{N})$, and Pouteria alternifolia $(\mathrm{F})$ retained around $50 \%$ of their leaves by mid-

January with B. micranta having lost all its leaves by mid-February. The third example includes species such as Pterocarpus erinaceaus (S), Lannea nigritana $(\mathrm{N})$, and Ceiba pentandra $(\mathrm{F})$ which retained no leaves by mid -January. Tree species also differed in average tree size (Table S1 and S2). Mixed linear model analysis on leaf retention in TFT, vegetation structure and species, with tree size $(\mathrm{DBH})$ as a random factor to correct for tree size effects (Table 1) showed that by November, species significantly determined leaf retention and that these differences were significant up to February. TFT effects were significant in December and January but no longer in February. Vegetation structural type had a marginally significant effect $(\mathrm{P}<0.088)$ on leaf retention in February, with a significant interaction between species and plot structural type. 
Chapter 5

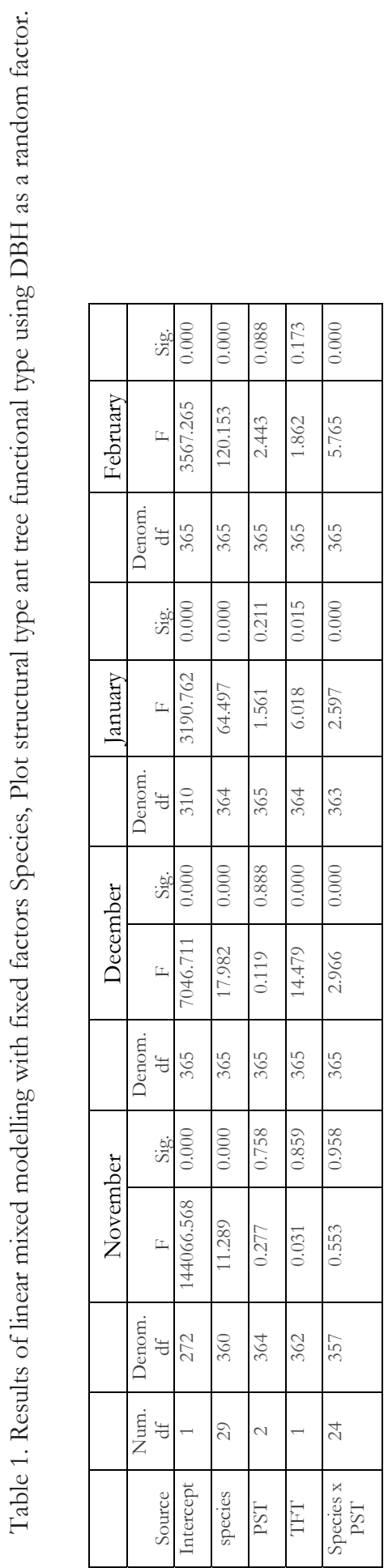




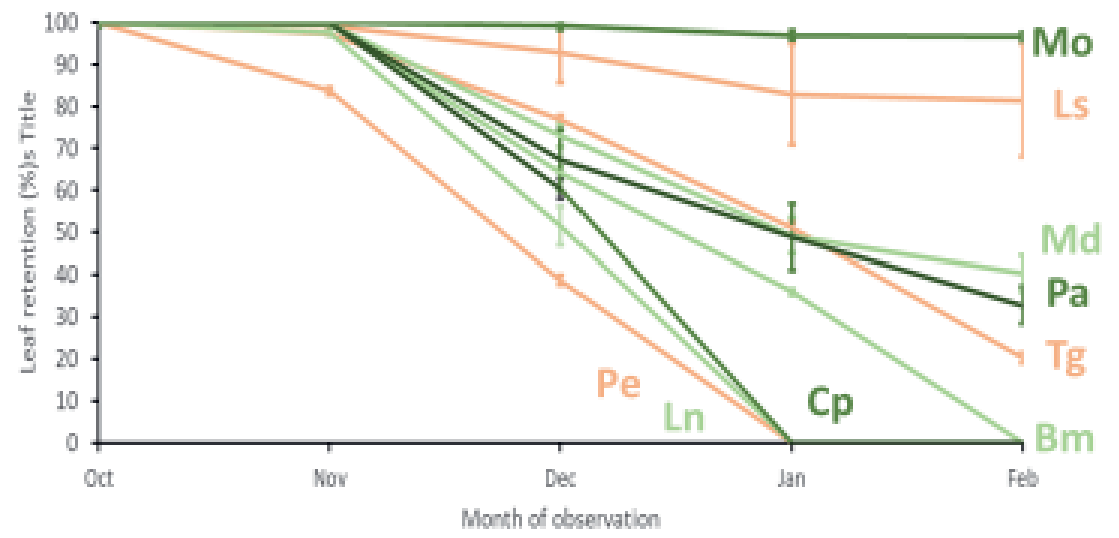

Figure 4. Decline in leaf retention (\% of leaves retained compared to October) in selected tree species differing in phenology pattern. Error bars indicate $+/-1$ s.d. Savanna species (brown lines) Ls $=$ Lepisanthes senegalensis $(\mathrm{n}=7), \mathrm{Pe}=$ Pterocarpus erinaceus $(\mathrm{n}=57), \operatorname{Tg}=$ Terminalia glaucescens $(\mathrm{n}=60)$. Non-selective species (light-green lines) $\mathrm{Bm}=$ Bridelia micranta $(\mathrm{n}=13) \mathrm{Ln}=$ Lannea nigritana $(\mathrm{n}=19), \quad \mathrm{Md}=$ Margarita discoides $(\mathrm{n}=49)$. Forest species (dark green lines) CP $=$ Ceiba pentandra $(\mathrm{n}=13)$ Mo $=$ Manilkara obovata $(\mathrm{n}=19)$. Pouteria alternifolia $(\mathrm{n}=18)$.

\section{Discussion}

We undertook this study to better understand the leaf phenological behaviour of vegetation patches in the Forest-Savanna Boundary. Leaf retention at the start of the wet season is of interest for two reasons. First, delayed leaf fall may indicate water availability which drives tree leaf phenology and allows for denser stands of trees (De Bie et al., 1998; Ametsitsi et al., 2020; Cardoso et al., 2018). Second, the timing of leaf fall in relation to fire events in the FS border also influences fire penetration in dry forest and may influence forest structure (Ametsitsi et al., 2020; Stott, 1986; Stott, 2000; Stott et al. 1990; Swaine, 1992). At the stand level, we found clear differences in Leaf area index (LAI). LAI declined rapidly after the rains stopped but LAI in forest tree-dominated plots always remained higher than in savanna or neutral tree-dominated transitional vegetation. In water-limited tropical systems, larger LAI values are often observed in woody vegetation with access to additional water resources (Charles-Dominique et al., 2018; Cardoso et al., 2018; 
Chapter 5

Hoffmann et al., 2012a; Ametsitsi et al., 2020). Soil water in the first meter was, as the dry season progressed, however most strongly depleted in forest patches. It is not unusual to find greater soil water depletion in the dry season under denser tree stands in water-limited tropical systems, possibly related to denser rooting near the surface (Veenendaal et al., 2008; Bougma et al., 2020) also giving credibility to the potentially important role of soil water retention in systems where water is limiting tree stands (Lloyd et al., 2015; Ametsitsi et al., 2020). While Forests had the highest LAI, the greatest decline in LAI and thus the greatest absolute leaf fall was observed in transition stands mainly consisting of $\mathrm{N}$ trees. Taking a community based specific leaf area estimate for Specific Leaf Area of approx. $100 \mathrm{~g} \mathrm{~m}^{-2}$ (Schrodt et al., 2015), this results in a contribution to leaf litter fuel of 0.8 (Savanna and Forest) to 1.3 (Transition) tonnes $\mathrm{ha}^{-1}$ to the leaf litter that can be consumed in litter driven fires. This is $30-50 \%$ of the total litter fuel present at the time fires penetrate the study area which however remains highest in forest vegetation (This thesis, chapter 3).

\section{Leaf Retention}

When scaling up leaf retention in individual trees to canopy level we found very similar patterns as observed with LAI measurements providing some fidelity to the accurateness of these estimates that in themselves were based on by eye observation. This allowed for further disentangling the role of different TFT's in the leaf phenology. Looking at TFT behaviour, the greatest decline in leaf retention in neutral $N$ species with the highest level in leaf retention in Forest species (again supported by the observation that the greatest decline in leaf fall is in the transition vegetation). However, different species contribute in different degrees to this result and TFT's are not scattered randomly in the landscape nor are they all the same size (Ametsitsi et al., 2020). In fact, a large variation in tree size can be observed. Therefore, we undertook an analysis of the leaf retention, as far as possible disentangling importance of vegetation structure and individual species and TFT. This analysis showed a strong significance for TFT and species during the first part of the drying 
cycle but not for vegetation structural type. This suggests that e.g. forest trees generally maintain their leaves longer but irrespectively of the stand they are in with the opposite effect for savanna and neutral $N$ species. Also, it shows that indeed not all species will have the same phenological behaviour. Vegetation structure appears to become more influential later as the dry season progresses with species effect still significant mid-February but with no longer a significant effect of TFT possibly as leaf retention also reduces in some species of forest trees, but instead a significant interaction between species and plot. Suggesting that now vegetation structure has an influence on retention behaviour of species.

\section{Concluding remarks}

We set out to investigate whether species, vegetation type or tree functional type influence the retention of leaves on trees at the beginning of the dry season. We found strong evidence that particularly species and tree functional type effects are important for leaf retention in the first half of a dry season with transition and savanna type similar but transition vegetation as a result of greater leaf cover the strongest contribution to leaf litter at the start of the dry season. Overall, the phenology patterns observed seem to support the possibility of litter fires across a closing cover of trees and help to explain the existence of litter fires under these conditions.

\section{Acknowledgements}

We thank the Wildlife Division of the Forestry Commission of Ghana for permission to work in the Kogyae Strict Nature Reserve. Our appreciation also goes to the Park Manager, Mr. Dwoben Nyantakyi, and his staff at Dome Camp, particularly Isaac Sarpong, Kwaku Yinye and Yaw Agyeman. Elmar Veenendaal and George Ametsitsi were partially funded by the EU KP7 GEOCARBON project (contract number 283080). Jon Lloyd and Vincent Logah received support through Royal Society - DFID (Africa capacity building initiative programme) and with Jon Lloyd also being supported by a Royal Society Wolfson fellowship. 
Chapter 5

\section{Supporting figures and tables}

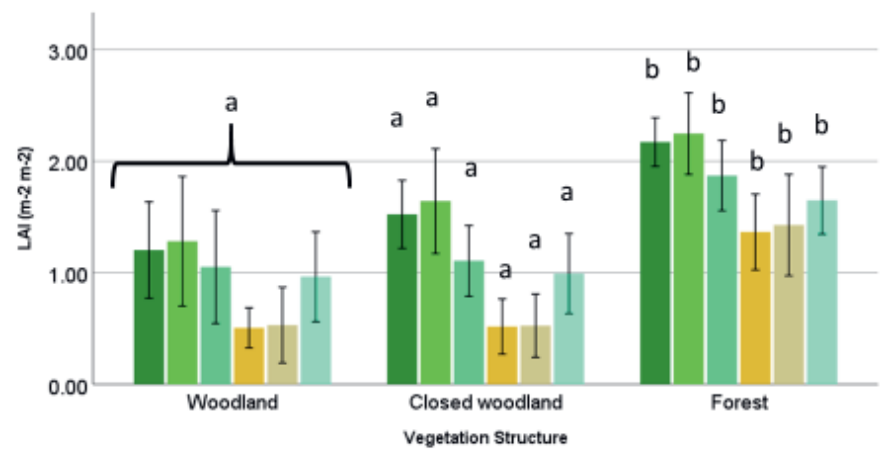

Figure S1. Variation in leaf area index $\left(\mathrm{LAI}, \mathrm{m}^{2} \mathrm{~m}^{-2}\right)$ in plots characterised by vegetation structure woodland, closed woodland and forest). Bars indicate values for October, November, December, January, February and March respectively. Letters indicate differences between plot types for each month (savanna always a) with Tukey's post-hoc test $\mathrm{p}<0.05)$.

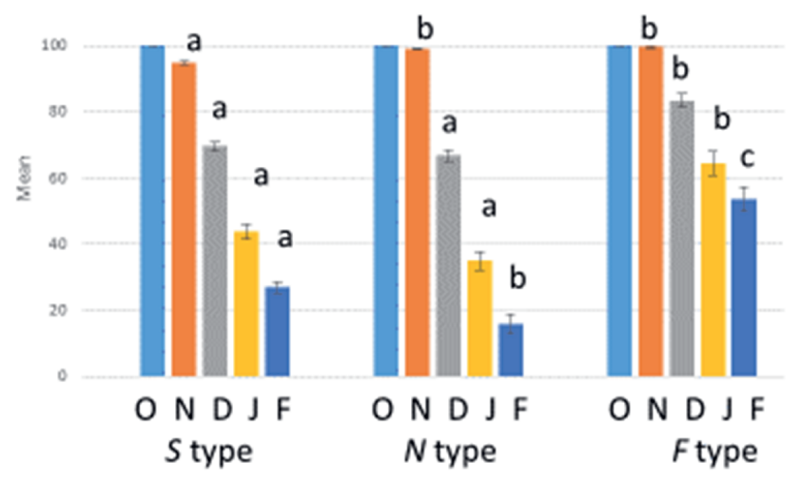

Figure S2. Patterns of leaf retention (\%) of plant functional types irrespective of stand they were in. (S $=$ savanna $N=$ Neutral $F=$ Forest type; Letters under the bar refer to the month of observation. Letters indicate differences between plot types for each month (savanna always a) with Tukey's post-hoc test $\mathrm{p}<0.05)$. 
Table S1. Tree functional type (TFT; $F=$ forest, $N=$ non-selective, $S=$ savanna), Average Diameter at breast height $(\mathrm{DBH})$ and Height of of tree species used in figure 4 main text.

\begin{tabular}{|c|c|c|c|c|c|c|}
\hline Species & TFT & $\mathrm{N}$ & & $\mathrm{DBH}(\mathrm{cm})$ & Basal area $\left(\mathrm{cm}^{2}\right)$ & Height $(\mathrm{m})$ \\
\hline Ceiba pentandra & $F$ & 13 & Mean & 49.5 & 2558.9 & 23.7 \\
\hline Ceiba pentandra & $F$ & & Std. dev & 29.6 & 2829.7 & 7.5 \\
\hline Manilkara obovate & $\mathrm{F}$ & 19 & Mean & 49.7 & 2412.9 & 20.8 \\
\hline Manilkara obovate & $\mathrm{F}$ & & Std. dev. & 25.3 & 2337.7 & 8.3 \\
\hline Pouteria alternifolia & $\mathrm{F}$ & 18 & Mean & 24.8 & 585.8 & 12.2 \\
\hline Pouteria alternifolia & $\mathrm{F}$ & & Std. dev. & 11.9 & 527.4 & 4.1 \\
\hline Bridelia Micrantha & $\mathrm{N}$ & 13 & Mean & 14.8 & 182.4 & 6.7 \\
\hline Bridelia Micrantha & $\mathrm{N}$ & & Std. dev. & 3.6 & 86.4 & 2.2 \\
\hline Lannea nigritana & $\mathrm{N}$ & 19 & Mean & 39.9 & 1389.2 & 17.4 \\
\hline Lannea nigritana & $\mathrm{N}$ & & Std. dev. & 13.7 & 871.1 & 3.5 \\
\hline Margarintaria discoida & $\mathrm{N}$ & 49 & Mean & 22.4 & 421.5 & 10.3 \\
\hline Margarintaria discoida & $\mathrm{N}$ & & Std. dev. & 5.9 & 215.7 & 3.2 \\
\hline Lepisanthes senegalensis & S & 7 & Mean & 17.8 & 269.4 & 9.7 \\
\hline Lepisanthes senegalensis & $\mathrm{S}$ & & Std. dev. & 5.6 & 159.9 & 2.4 \\
\hline Plterocarpus erinaceaus & $\mathrm{S}$ & 57 & Mean & 31.8 & 905.7 & 14.9 \\
\hline Plterocarpus erinaceaus & $\mathrm{S}$ & & Std. dev. & 12.1 & 685.8 & 4.7 \\
\hline Terminalia glaucescens & $\mathrm{S}$ & 60 & Mean & 19.6 & 337.9 & 10.8 \\
\hline Terminalia glaucescens & $\mathrm{S}$ & & Std. dev. & 6.7 & 256.7 & 4.4 \\
\hline
\end{tabular}

Table S2. Size parameters: Diameter at Breast height (DBH), Tree height, and Crown area for different tree functional types; Averages per class.

\begin{tabular}{|l|l|r|r|r|r|}
\hline & TFT & & \multicolumn{1}{c|}{ Mean } & Minimum & Maximum \\
\hline DBH $^{*}(\mathrm{~cm})$ & S & 232 & 23.49 & $10.0^{*}$ & 93.90 \\
\hline & N & 104 & 26.61 & $10.0^{*}$ & 85.31 \\
\hline & F & 106 & 39.55 & $10.0^{*}$ & 127.96 \\
\hline & & & & & \\
\hline Height* $(\mathrm{m})$ & S & 232 & 11.75 & 2.48 & 29.64 \\
\hline & $\mathrm{N}$ & 104 & 12.14 & 3.38 & 33.88 \\
\hline & $\mathrm{F}$ & 106 & 18.16 & 6.00 & 42.52 \\
\hline & & & & & \\
\hline Crown area* $(\mathrm{m} 2)$ & $\mathrm{S}$ & 232 & 33.48 & 0.20 & 401.15 \\
\hline & $\mathrm{N}$ & 104 & 53.72 & 1.33 & 764.54 \\
\hline & $\mathrm{F}$ & 106 & 100.19 & 0.71 & 481.11 \\
\hline & & & & & \\
\hline
\end{tabular}

*Minimum DBH selected. 


\section{Chapter 6}

\section{Variation in vegetation cover and seedling performance of tree species in a forest-savanna- ecotone}

Hamza Issifu, George K. D. Ametsitsi, Lana J. de Vries, Gloria D. Djagbletey, Stephen AduBredu, Philippine Vergeer, Frank van Langevelde, Elmar Veenendaal

Published in Journal of Tropical Ecology, 35, 74-82 (2019) 
Chapter 6

\section{Abstract}

Differential tree seedling recruitment across forest-savanna ecotones is poorly understood but hypothesized to be influenced by vegetation cover and associated factors. In a 3-y-long field transplant experiment in the forest-savanna ecotone of Ghana, we assessed performance and root allocation of 864 seedlings for two forest (Khaya ivorensis and Terminalia superba) and two savanna (Khaya senegalensis and Terminalia macroptera) species in savanna woodland, closed-woodland and forest. Herbaceous vegetation biomass was significantly higher in savanna woodland $(1.0 \pm 0.4 \mathrm{~kg}$ $\mathrm{m}^{-2}$ vs $0.2 \pm 0.1 \mathrm{~kg} \mathrm{~m}^{-2}$ in forest) and hence expected fire intensities, while some soil properties were improved in forest. Regardless, seedling survival declined significantly in the first-year dryseason for all species with huge declines for the forest species (50\% vs $6 \%$ for Khaya and $16 \%$ vs $2 \%$ for Terminalia) by year 2 . After 3 y, only savanna species survived in savanna woodland. However, best performance for savanna Khaya was in forest, but in savanna woodland for savanna Terminalia which also had the highest biomass fraction $\left(0.8 \pm 0.1 \mathrm{~g} \mathrm{~g}^{-1}\right.$ vs $0.6 \pm 0.1 \mathrm{~g} \mathrm{~g}^{-1}$ and 0.4 $\left.\pm 0.1 \mathrm{~g} \mathrm{~g}^{-1}\right)$ and starch concentration $(27 \% \pm 10 \%$ vs $15 \% \pm 7 \%$ and $10 \% \pm 4 \%)$ in roots relative to savanna and forest Khaya respectively. Our results demonstrate that tree cover variation has species-specific effects on tree seedling recruitment which is related to root storage functions.

Keywords: Biomass allocation; canopy cover; drought survival; fuel load; root starch; seedling traits; soil properties; tropical trees 


\section{Introduction}

Forest-savanna ecotones characterized by a mosaic of forest patches within savanna environments represent a common feature of the landscape of West Africa (Hennenberg et al., 2005; McCook 1994). Across the tropics, observations of forest encroachment in savannas are on the rise (Bowman et al., 2001; Mitchard et al., 2009; Schwartz et al., 1996; Veenendaal et al. 2015), generally occurring at decadal timescales with rapid changes in vegetation cover and species composition (Cuni-Sanchez et al., 2016; Jeffery et al., 2014). Such vegetation transitions have important implications for ecosystem services and local livelihoods due to changes in composition, productivity, diversity and abundance of species (Mitchard et al., 2009; Poulter et al., 2014).

The process of forest advancement into savannas is still little understood, and the relative influences of fire (Higgins et al., 2007; Hoffmann et al., 2012a), edaphic and climatic factors (Bowman et al., 2015; Lloyd et al., 2015; Veenendaal et al., 2015, 2018) on the formation of closedcanopy vegetation have been highlighted in several studies. It is also recognized that vegetation (canopy) cover has important influences on fire behaviour and intensity, light and edaphic factors. As a result, tree seedling establishment success can be mediated by the extent of vegetation cover via fire suppression (Bowman, 2000; Cardoso et al., 2016; Gignoux et al., 2009; Hoffmann et al., 2012a) or through amelioration of factors such as irradiance, soil moisture and soil fertility (CuniSanchez et al., 2016; Ruggiero et al., 2002; Saiz et al., 2012; Veenendaal et al., 1996a, 1996c).

Forest species generally may lack the suite of traits that make savanna species successful in open pyrogenic savannas, while savanna species may be less successful in closed-canopy forests for the same reason and forest advancement in savanna may be facilitated in sites with higher woody canopy cover where low-light conditions constrain performance of savanna species (Armani et al., 2018; Bowman 2000; Cardoso et al., 2016; Hoffmann et al., 2004; Ruggiero et al., 2002). However, there is little empirical data on whether canopy closure facilitates the establishment of forest species and to what extent this limits survival and growth performance of savanna species across forestsavanna ecotones. 
Chapter 6

In this study, we investigated influences of vegetation type (with a focus on canopy cover levels being the main distinguishing factor) and its associated factors on seedling survival, growth and traits (i.e. root mass fraction and root starch concentration) in a field transplant experiment that lasted three growing seasons and two dry/fire seasons. We used two congeneric species pairs of forest and savanna species that are common to the forest-savanna ecotone or to nearby semideciduous forest in West Africa to test the following hypotheses: (1) The forest tree species have lower survival than their savanna congeners in savanna due to relatively lower root mass fraction and root starch content needed to survive dry periods and to resprout after fire. (2) Higher vegetation (canopy) cover, being associated with a lower fuel load and higher soil nutrient status, benefits mainly forest tree seedlings as savanna species are less competitive in deep shade.

\section{Materials and methods}

\section{Study site}

The field transplant experiment was carried out in Kogyae Strict Nature Reserve (KSNR) located in the forest-savanna transition zone of Ghana $\left(7^{\circ} 1901.66100 \mathrm{~N}, 1^{\circ} 0505.86300 \mathrm{~W}\right)$. Climatically, the area has a bimodal rainfall pattern with major peaks occurring in May-June and September-

October (Figure 1), with a mean annual rainfall of 1200-1300 mm. Four vegetation types are distinguished in the area: transitional forest, savanna, riparian woodland and boval vegetation (vegetation on flat iron pans) (Wildlife Department, 1994), but plot selection for this study was done following the structural classification of Torello-Raventos et al. (2013) in woodland, closed woodland and forest vegetation patches. In the study site, tree cover has been stable or slowly increasing over the last $30 \mathrm{y}$ (Janssen et al., 2018).

\section{Species selection}

We selected four tree species from two families and two genera. Each species pair in a genus comprised one forest and one savanna species (Table 1). Seeds of Khaya ivorensis and Terminalia superba were collected from a moist semi-deciduous forest (Bobiri Forest reserve, $6.678^{\circ} \mathrm{N}$, 
$1.32^{\circ} \mathrm{W}$ ), while those of Khaya senegalensis and Terminalia macroptera were collected within Kogyae Strict Nature Reserve itself. Seedlings were raised from seeds at the Forestry Research Institute of Ghana nursery in April 2012. At 3 months old, seedlings were transported to the Kogyae Strict Nature reserve and allowed 7 days to recover from any transportation shock before transplanting.

Table 1. Classification and biophysical limits of tree species used in the study. All species thrive within the Kogyae Strict Nature Reserve or in nearby semi-deciduous forest in Ghana. Sources of information: Hawthorne (1995),

http://www.worldagroforestry.org/sites/treedbs/treedatabases.asp.

\begin{tabular}{|c|c|c|c|c|c|}
\hline Species & Family & $\begin{array}{c}\text { Functional } \\
\text { type }\end{array}$ & Guild & Distribution & $\begin{array}{c}\text { Rainfall } \\
\text { range } \\
(\mathrm{mm})\end{array}$ \\
\hline $\begin{array}{l}\text { Khaya ivorensis (Desr.) } \\
\text { A.Juss }\end{array}$ & Meliaceae & Forest & $\begin{array}{l}\text { Non-pioneer } \\
\text { light demander }\end{array}$ & $\begin{array}{l}\text { Moist-dry } \\
\text { forest }\end{array}$ & $1600-2500$ \\
\hline $\begin{array}{l}\text { Khaya senegalensis } \\
\text { (Desr) A.Juss }\end{array}$ & Meliaceae & Savanna & $\begin{array}{l}\text { Moderately } \\
\text { shade tolerant }\end{array}$ & $\begin{array}{l}\text { Gallery } \\
\text { forest }\end{array}$ & $400-1750$ \\
\hline $\begin{array}{l}\text { Terminalia superba } \\
\text { (Engl.\&Diels) }\end{array}$ & Combretaceae & Forest & Pioneer & $\begin{array}{l}\text { Moist-dry } \\
\text { forest }\end{array}$ & $1000-1800$ \\
\hline $\begin{array}{l}\text { Terminalia macroptera } \\
\text { (Guill. \& Perr.) }\end{array}$ & Combretaceae & Savanna & Open savanna & $\begin{array}{l}\text { Moist open } \\
\text { woodland }\end{array}$ & $700-1500$ \\
\hline
\end{tabular}

\section{Transplantation experiment}

Thirty-six $10 \times 10$-m plots were randomly established under the three vegetation types differing in canopy closure; 12 each for cover classes typical for woodland, closed woodland and forest canopies (following Torello-Raventos et al., 2013) in three sites (blocks) that were about $750 \mathrm{~m}$ apart. In each plot, six seedlings each of the four species (Table 1) were assigned and planted in random positions in rows (1.4 $\mathrm{m}$ within and between rows of seedlings). A total of 864 seedlings were planted (i.e. 6 seedlings $\times 4$ plots $\times 3$ cover classes $\times 3$ blocks $\times 4$ species). Seedlings were transplanted in September 2012 at the beginning of the second rainy season (Figure 1). No additional watering was done and no fire protection was given during the experimental period. 
Chapter 6

Canopy cover of plots in the various vegetation patches was assessed using leaf area index (LAI) and canopy openness in October before the end of the rainy season (peak leaf cover). Additionally, we assessed absence/presence of $\mathrm{C}_{4}$ grasses in the herb layer.

LAI and canopy openness were obtained by analysing hemispheric photos, taken at $1 \mathrm{~m}$ above the ground in each plot with a fish-eye lens mounted on a Nikon E4500 camera. Images were then analysed with Gap Light Analyser software (Veenendaal et al., 2015). Mean percentage canopy openness and (LAI) ranged between 18.5-25\% (1.7-2.0) for forest plots, $32-45 \%(0.7-1.0)$ for closed woodland plots and $60-73 \%(0.1-0.25)$ for (savanna) woodland plots. The herb layer in plots with highest LAI (forest plots) consisted mainly of $\mathrm{C}_{3}$ species, while canopy cover was mainly provided by forest trees. In the closed woodlands tree cover was provided by a mix of different species with tree crowns not touching and $\mathrm{C}_{4}$ grasses were present, while cover in woodlands was provided by savanna trees (Torello-Raventos et al., 2013).

Data on seedling height and survival were taken for three seasons. Before the first dry season, three censuses were conducted at 1, 2 and 3 mo after transplantation, the third month being at the onset of the first dry season (December 2012) (Figure 1). Subsequent censuses were conducted only at the end of the consecutive growth seasons (December) of 2013 and 2014. The first dry season and its associated fires occurred 5 mo into the experiment (19 January and subsequent days in 2013). The plots also burnt in the second year (around 4 February 2014).

The experiment ended in December 2014 at the end of the third wet season (Figure 1). Fire intensity was not measured separately in this experiment, but after each fire event we observed that the forest plots generally had been lightly touched by fire, whereas all plots in closed-woodland and woodland cover types burnt more heavily in both dry-season fires that occurred within the period of this study. All surviving seedlings at the end of the experiment were carefully excavated. Seedling height, total plant dry weight and root mass fraction were determined. Immediately after harvest, samples were microwaved, in preparation for determination of root starch content, following a carbohydrate extraction protocol of Duranceau et al. (1999) adapted from Dubois et al. (1956). 
Root starch content was analysed for all species (except Terminalia superba, for which we had no adequate samples available).

\section{Environmental factors}

Soil moisture content of the top layer $(0-60 \mathrm{~mm})$ was determined with a theta probe (Delta-T Devices, Cambridge, UK). Five moisture measurements were made across all four plots of each vegetation type within a block (as all four plots laid fairly close to one another). This was done at the centre and at the outer corners of the plots. Measurements were done twice, at $7 \mathrm{wk}$ (November 2012) and $13 \mathrm{wk}$ (December 2012). We took five soil samples per vegetation type per block using a cylindrical auger at the centre and at the mid-distance to the four corners of the outer plots. Sampling was done at three depths $(0-10 \mathrm{~cm}, 10-20 \mathrm{~cm}$ and $20-30 \mathrm{~cm})$ and composites were formed from the replicates for each depth category and put in zip-lock plastic bags and later analysed for soil organic matter content (loss-on-ignition method; Ball, 1964) and some biogeochemical properties. CEC, Mg, Ca, K analyses (Gilman 1979) were done using an Atomic Absorption spectrometer (VARIAN AA240FS, Varian Inc.). Total N and P were analysed according to Novozamsky et al. (1983) using the Segmented Flow Analyser (SKALAR SAN ${ }^{++}$ System) and P-Olsen was determined according to Olsen et al. (1954).

Data on fuel load and fuel composition as a proxy for fire intensity were taken from three random $1-\mathrm{m}^{2}$ quadrats per plot and averaged for each plot per vegetation type. In each plot, cover abundances of grasses and herbs were estimated. Also, dry weights of total herbaceous vegetation (i.e. including herbs and grasses and litter were determined from sub-samples by cutting vegetation and collecting litter and weighing them after oven drying. Daily rainfall data from August 2012 to December 2015 recorded in Ejura, the nearest meteorological station $(25 \mathrm{~km}$ away from experimental site), were obtained from the Ghana Meteorological Agency. There were gaps in the data for some months (October 2012, November 2013 and June 2015). Mean monthly rainfall for months with missing data were estimated using records from the last 15 days of the month before 
Chapter 6

and the first 15 days of the month after the reference month. For example, mean rainfall for October 2012 was estimated as mean of rainfall values from 16 September to 15 November 2012.

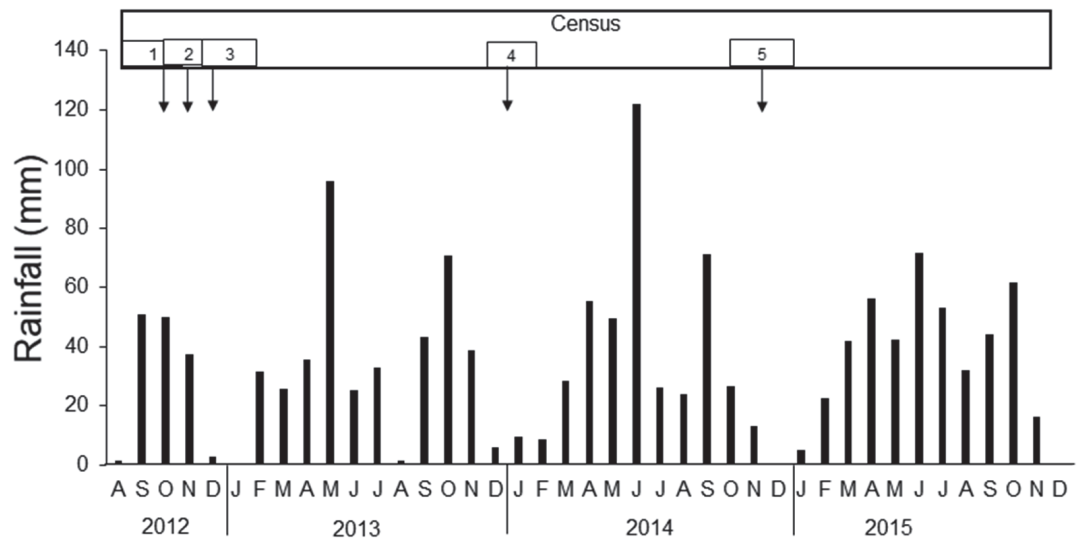

Figure 1. Mean monthly precipitation for Ejura, Ghana (nearest meteorological station to Kogyae Strict Nature Reserve-KSNR) for the experimental period and beyond. Timing of all five censuses conducted are shown.

\section{Statistical analyses}

We used linear mixed-effects models (Zuur et al., 2009) to test for differences in soil moisture content of the topsoil layer among vegetation types and measurement weeks (as fixed factors), including the interaction term of two fixed factors and a random block effect. Similarly, we tested fixed effects of vegetation type including a random block effect on organic matter content, litter mass, herbaceous vegetation biomass and cover abundances of herbaceous vegetation using linear mixed-effects models. Block was included as random factor in these analyses. Soil organic matter content was analysed for each soil depth separately. Also, cover abundance of grass and herbs were analysed separately. We checked for normality and homoscedasticity and applied natural log (ln), square root and arcsine transformations (Sokal \& Rohlf, 1995) on herbaceous vegetation biomass, litter mass and cover abundance proportions of grasses and herbs respectively. A multivariate analysis of variance (MANOVA) was used to test, for each soil layer, differences in soil chemical properties among vegetation types. 
Survival data from each census (conducted at months 1, 2, 3, 15 and 27) were analysed separately to compare survival among species and vegetation types in generalized linear models (GLM) using binomial distribution with logit link function. Sidak correction was used for multiple comparisons.

Seedling heights recorded in years 1, 2 and 3, were tested for differences among years and vegetation types separately for each species in linear mixed-effects models. A random block effect was included in the models and Sidak correction was used for multiple comparisons. Also, for each species, a Kruskal-Wallis test (Sokal \& Rohlf, 1995) was used to determine if seedling height differed among years 1, 2 and 3. For T. superba, a Mann-Whitney U-test was used to compare height of years 1 and 2 as insufficient samples were available in year 3.

Data on total seedling dry weight, root mass fraction (RMF) and root starch concentration were analysed in separate linear mixed-effects models for each species to determine fixed effects of vegetation type. All analyses were done on SPSS version 23.0.

\section{Results}

\section{Soil properties}

Soil moisture content $(\mathrm{SMC})$ of the topsoil layer $(0-60 \mathrm{~mm})$ after 7 wk differed significantly $\left(\mathrm{F}_{2,84}\right.$ $=8.4, \mathrm{P}<0.001)$ among vegetation types, higher in forest and closed-woodland $(6.11 \% \pm 1.71 \%$ and $6.25 \% \pm 1.89 \%$ respectively) than savanna woodland at $4.25 \% \pm 2.07 \%$. We found that SMC had dropped to an average of $2.7 \%$ at $13 \mathrm{wk}$ into the experiment (i.e. at the start of the dry season) $\left(\mathrm{F}_{1,84}=66.6, \mathrm{P}<0.001\right)$. During the experimental period, all vegetation types showed a similar decline in moisture content and at the end of the experiment SMC was still lower in savanna woodland and closed woodland $(1.95 \% \pm 1.53 \%$ and $2.69 \% \pm 1.89 \%$ respectively) than forest at $4.74 \% \pm 2.2 \%$.

Soil organic matter in the top $10 \mathrm{~cm}$ was significantly higher in the forest compared with savanna woodland and closed-woodland sites $\left(\mathrm{F}_{2,6}=19.6, \mathrm{P}=0.002\right)$. Interestingly, no significant differences between vegetation types were found for soil layers below $10 \mathrm{~cm}$ (Table 2). Significant 
Chapter 6

differences between different vegetation types were also found for soil $\mathrm{pH}$, total nitrogen and CEC $\left(\mathrm{F}_{2,9}=5.85, \mathrm{P}=0.039 ; \mathrm{F}_{2,9}=17.4, \mathrm{P}=0.003 ; \mathrm{F}_{2,9}=16.7, \mathrm{P}=0.004\right.$ respectively $)$, but again only in the upper $10 \mathrm{~cm}$ soil layer. Soil $\mathrm{pH}$ was lowest in forest and highest in woodland. Total nitrogen was higher in forest than in savanna woodland and closed-woodland. CEC was lowest in closedwoodland and similar between savanna woodland and forest. No significant vegetation type effect was found for levels of $\mathrm{Ca}, \mathrm{Mg}, \mathrm{K}$, total P and P-Olsen (Table 2).

\section{Herbaceous vegetation and litter}

Total biomass of herbaceous vegetation (including grasses and herbs) differed among vegetation types $\left(F_{2,31}=29.8, P<0.001\right)$. Biomass of herbaceous vegetation was $0.23 \pm 0.12 \mathrm{~kg} \mathrm{~m}^{-2}$ in forest, lower than biomass in closed-woodland and savanna woodland which had similar biomass of 0.84 $\pm 0.25 \mathrm{~kg} \mathrm{~m}^{-2}$ and $0.99 \pm 0.35 \mathrm{~kg} \mathrm{~m}^{-2}$ respectively. Similarly, litter mass differed significantly $\left(\mathrm{F}_{2,31}\right.$ $=23.3, \mathrm{P}<0.001)$ among vegetation types being higher in forest $\left(0.21 \pm 0.11 \mathrm{~kg} \mathrm{~m}^{-2}\right)$ than closedwoodland $\left(0.06 \pm 0.05 \mathrm{~kg} \mathrm{~m}^{-2}\right)$ and savanna woodland $\left(0.03 \pm 0.05 \mathrm{~kg} \mathrm{~m}^{-2}\right)$. Overall, grasses were more abundant $\left(\mathrm{F}_{2,31}=111, \mathrm{P}<0.001\right)$ in savanna woodland $(51.5 \% \pm 8.8 \%)$ and closed-woodland $(50.8 \% \pm 8.7 \%)$ than forest at $15.4 \% \pm 3.1 \%$. Percentage cover of herbs was low overall (average of $3 \%)$ and did not differ significantly $\left(\mathrm{F}_{2,33}=1.68, \mathrm{P}=0.2\right)$ among vegetation types. 


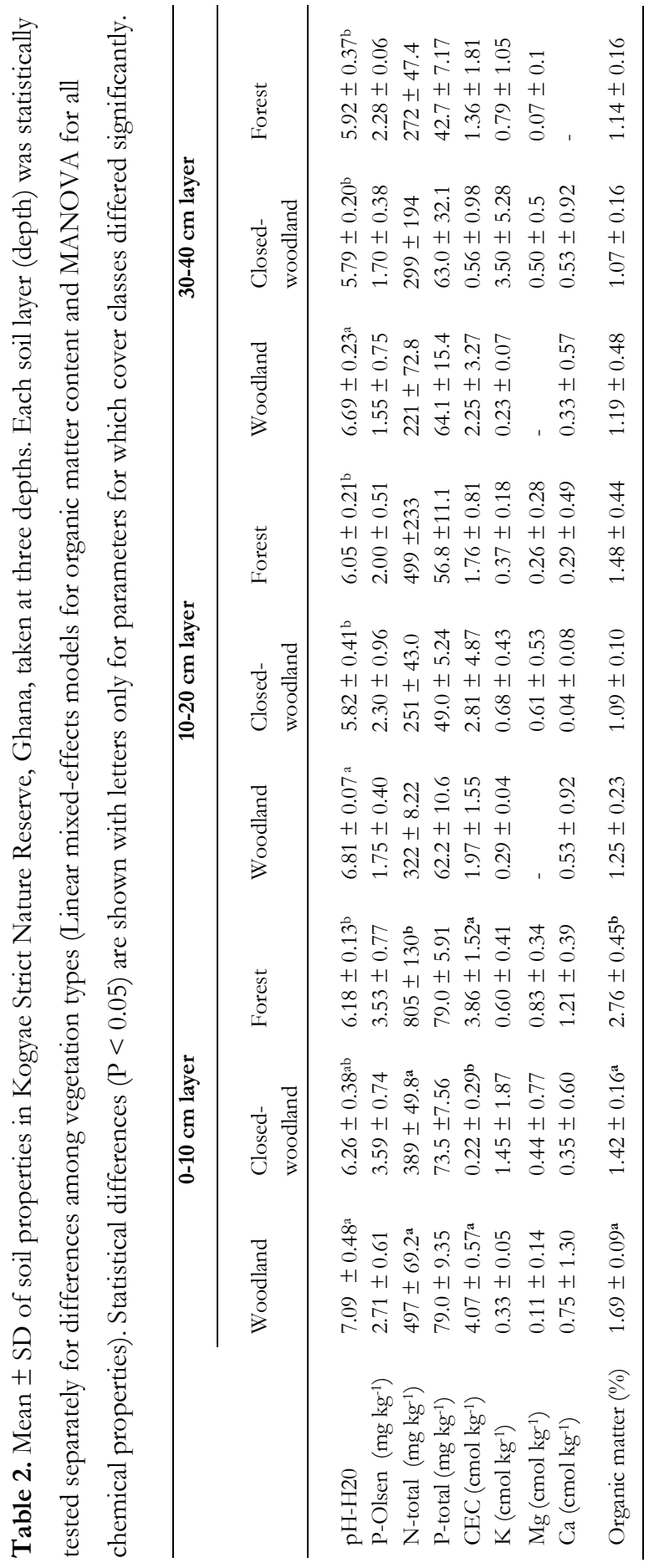


Chapter 6

\section{Seedling survival}

A few weeks (4-8 wk) into the experiment, both Terminalia species showed lower survival, relative to the Khaya species, in forest plots (Figure 2). Survival differences for T. superba versus K. ivorensis $(\mathrm{P}=0.02)$ and T. macroptera versus $K$. senegalensis $(\mathrm{P}<0.001)$ were revealed through pairwise comparisons (with Sidak correction). Generally, seedling survival remained high, particularly for the Khaya species and regardless of vegetation cover until 3 months (i.e. onset of the first dry season). By this census, survival had considerably declined for all species (Figure 2). We found a significant species $\times$ vegetation cover interaction effect (Table 3), but differences among species were mainly between and not within vegetation cover type.

At 15 months, and after the first dry-season fire, significant survival differences were found among species (Table 3). Overall, 50\% of all savanna Khaya was still alive versus $6 \%$ for its forest congener. We found a similar pattern in genus Terminalia with $16 \%$ survival for the savanna type versus $2 \%$ for its forest congener. Pairwise comparisons showed that survival of the savanna Khaya was significantly higher than all other species in all vegetation types. Savanna Terminalia also had a significantly higher survival than both forest species in savanna woodland. Between the two forest species, survival in savanna woodland and closed-woodland was higher for forest Khaya than forest Terminalia. In the final census (27 months on) after the second dry-season fire and third wet season (Figure 2), 12\% of the total number of planted seedlings were still alive. There was a significant interaction effect of vegetation type and species (Table 3). None of the forest species was alive in savanna woodland where $20 \%$ survival for the savanna Khaya and $13 \%$ for savanna Terminalia were observed. Remarkably, higher survival was observed in forest $(55 \%)$ and closed-woodland $(33 \%)$ for the savanna Khaya as compared with $8 \%$ and $4 \%$ in the respective vegetation types for forest Khaya. The savanna Terminalia survived in very low numbers in closed-woodland (4\%) and forest $(1 \%)$. There were no seedlings of the forest Terminalia surviving in savanna woodland and only $1 \%$ survived in forest (Figure 2 ). 


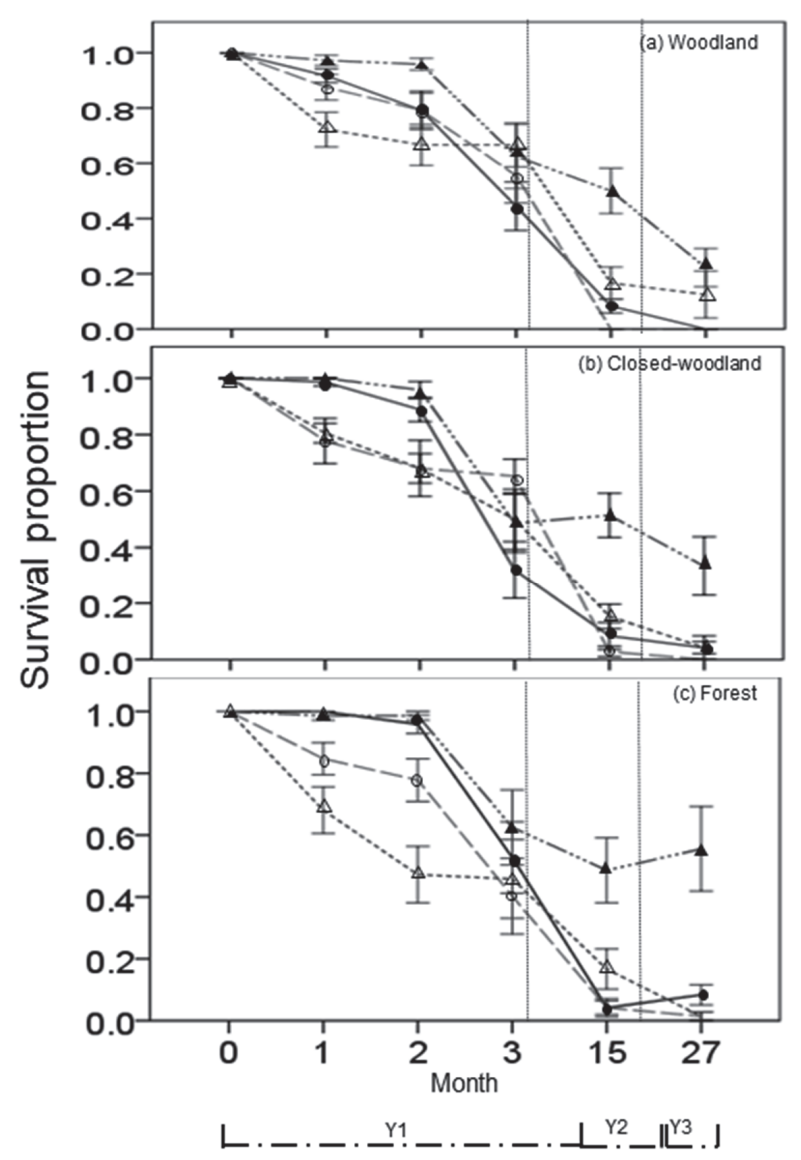

Figure 2. Proportion of surviving seedlings of Khaya senegalensis (filled-triangle), Khaya ivorensis (filled-circle), Terminalia macroptera (open triangle), Terminalia superba (open circle) at woodland cover (a), closed-woodland cover (b) and forest cover (c) in Kogyae Strict Nature Reserve, Ghana. Month corresponds to the month of transplantation, with month of transplanting $=0$. Grey vertical lines indicate times when the dry season fires occurred. Error bars show \pm 1 standard error of the mean. 
Chapter 6

Table 3. Binomial analysis (with logit link) of seedling survival of four tree species in three vegetation types in Kogyae Strict Nature Reserve, Ghana. Analyses were done separately for each census (month) and all factors included in the separate models are presented. Significant effects are indicated with asterisks and non-significant effects by "ns".

\begin{tabular}{lllll}
\hline $\begin{array}{l}\text { Time } \\
(\mathbf{m o})\end{array}$ & Main effects and interactions & df & $\begin{array}{l}\text { Wald Chi- } \\
\text { Square }\end{array}$ \\
\hline 1 & Vegetation type & 2 & 0.0001 & $1.0 \mathrm{~ns}$ \\
& Species & 3 & 5.42 & $0.144 \mathrm{~ns}$ \\
& Vegetation type x Species & 6 & 9.38 & $0.159 \mathrm{~ns}$ \\
2 & Vegetation type & 2 & 3.29 & $0.192 \mathrm{~ns}$ \\
& Species & 3 & 68.6 & $<0.001^{*}$ \\
& Vegetation type x Species & 6 & 19.0 & $0.004^{*}$ \\
3 & Vegetation type & 2 & 4.67 & $0.097 \mathrm{~ns}$ \\
& Species & 3 & 10.7 & $0.013^{*}$ \\
& Vegetation type x Species & 6 & 21.5 & $0.001^{*}$ \\
15 & Vegetation type & 2 & 0.0003 & $1.0 \mathrm{~ns}$ \\
& Species & 3 & 97.4 & $<0.001^{*}$ \\
& Vegetation type x Species & 6 & 0.88 & $0.99 \mathrm{~ns}$ \\
& Vegetation type & 2 & 0.000012 & $1.0 \mathrm{~ns}$ \\
& Species & 3 & 34.4 & $<0.001^{*}$ \\
& Vegetation type x Species & 6 & 13.5 & $0.036^{*}$ \\
\hline & & & &
\end{tabular}

\section{Seedling growth}

Seedling height was significantly lower in year 2 for all species relative to year 1 heights evidencing shoot loss (Table 4, Figure 3). We found that for the forest species in both genera, seedling height did not differ among vegetation cover types, but for both savanna species, differences between vegetation types were significant $\left(\mathrm{F}_{2,107}=5.32, \mathrm{P}=0.006\right.$ for Khaya and $\mathrm{F}_{2,33}=3.27, \mathrm{P}<0.001$ for 
Terminalia). Savanna Khaya was taller in forest and closed-woodland than woodland while savanna Terminalia was taller in savanna woodland than closed-woodland and forest (Figure 3).

At the end of the third wet season, plant height was higher than recorded for year 2 for all species except forest Terminalia for which there were insufficient seedlings for comparison suggesting recovery from year 2 drought/fire. Also compared to year 1, both savanna species in year 3 were significantly taller, but forest Khaya in year 3 did not differ from year 1 height (Table 4), suggesting a higher cumulative shoot recovery of the savanna than forest species in this study.

Overall, plant dry weight of the savanna Khaya was $3.4 \pm 1.9 \mathrm{~g}$ and did not differ significantly $\left(F_{2,80}=0.20, P=0.82\right)$ among vegetation types as was the case for its forest congener $\left(F_{1,5}=0.22, P=0.67\right)$ (Figure 4a). Seedlings of the savanna Terminalia did grow significantly larger in savanna woodland $\left(16.0 \pm 12.9 \mathrm{~g} ; \mathrm{F}_{2,15}=17.4, \mathrm{P}<0.001\right)$ compared to closed-woodland and forest where seedlings weighed on average $1.9 \pm 0.5 \mathrm{~g}$. Unfortunately, for the forest Terminalia, biomass could not be analysed because not enough seedlings survived at final harvest (Figure 4a).

\section{Biomass proportion and starch concentration in roots}

We found that root mass fraction significantly differed $\left(\mathrm{F}_{2,77}=4.88, \mathrm{P}=0.01\right)$ among vegetation types for savanna Khaya, which was higher in savanna woodland at $0.71 \pm 0.10 \mathrm{~g} \mathrm{~g}^{-1}$ and lowest in the forest at $0.61 \pm 0.11 \mathrm{~g} \mathrm{~g}-1$ (Figure $4 \mathrm{~b}$ ). Root mass fraction of the forest Khaya did not differ significantly $\left(\mathrm{F}_{1,5}=2.01, \mathrm{P}=0.22\right)$ between closed-woodland and forest where it survived till the end (Figure 4b). Also, for the savanna Terminalia, root mass fraction did not differ significantly $\left(\mathrm{F}_{1,10}=1.14, \mathrm{P}=0.31\right)$ between savanna woodland and closed-woodlands where it survived till the end. Overall root mass fraction (regardless of vegetation type) differed significantly $\left(\mathrm{F}_{3,95}=14.6\right.$, $\mathrm{P}<0.001$ ) among species being highest in savanna Terminalia (mean $=0.79 \pm 0.09 \mathrm{~g} \mathrm{~g}^{-1}$ ) and lowest in forest Khaya (mean $=0.44 \pm 0.07 \mathrm{~g} \mathrm{~g}^{-1}$ ). Root mass fraction of savanna Khaya was intermediate $\left(\right.$ mean $\left.=0.64 \pm 0.13 \mathrm{~g} \mathrm{~g}^{-1}\right)$ between the two other species. 
Chapter 6

We found that root starch concentration differed significantly $\left(\mathrm{F}_{2,27}=19.1, \mathrm{P}<0.001\right)$ among species and also among vegetation types $\left(\mathrm{F}_{2,27}=3.48, \mathrm{P}=0.045\right)$. Pairwise comparisons revealed highest root starch concentration for seedlings in savanna woodland $(21.6 \% \pm 10.7 \%)$ and lowest in closed-woodland $(13.8 \% \pm 9.8 \%)$. Among species, savanna Terminalia stored the most starch in their roots $(27.1 \% \pm 9.6 \%)$ whereas forest Khaya stored the least $(9.6 \% \pm 3.9 \%)$ while savanna Khaya had intermediate root starch storage $(14.9 \% \pm 6.8 \%)$.

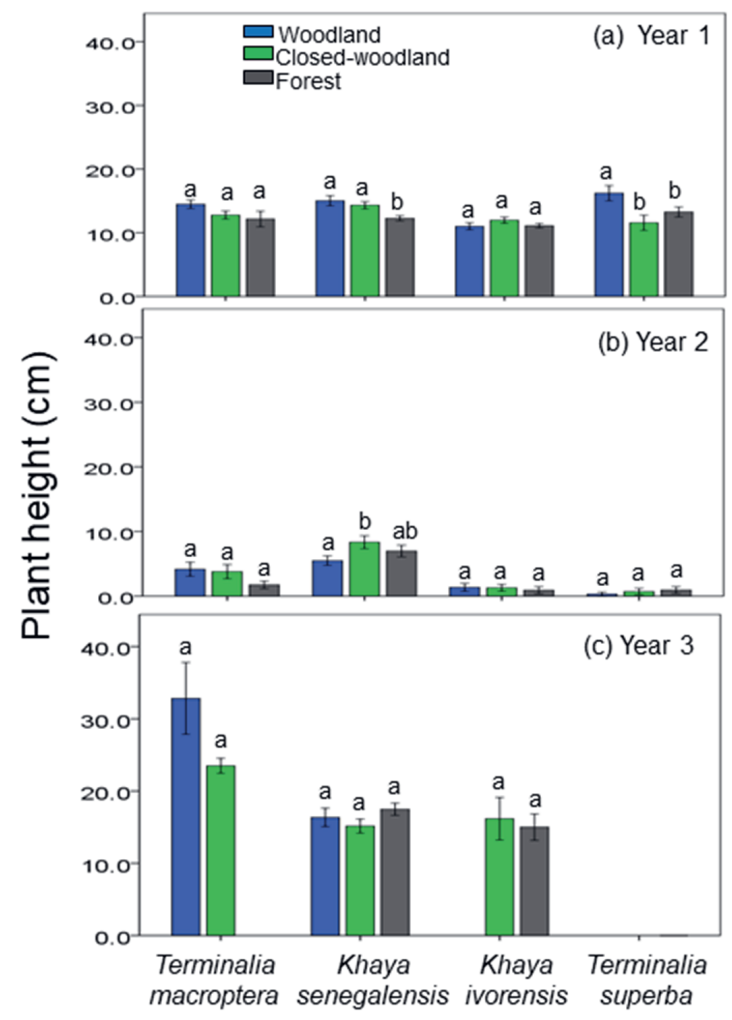

Figure 3. Mean seedling height of each species at three vegetation types for the three growing seasons in Kogyae Strict Nature Reserve, Ghana. In year 3, Terminalia superba was excluded due to too few numbers to allow for analysis. Also, there were insufficient samples of Khaya ivorensis and Terminalia macroptera for woodland and forest respectively. Statistical comparisons (with Sidak 
adjustment) are done among vegetation types for each species. Different letters indicate significant differences $(\mathrm{P}<0.05)$. Error bars are $\pm 1 \mathrm{SE}$ of mean.

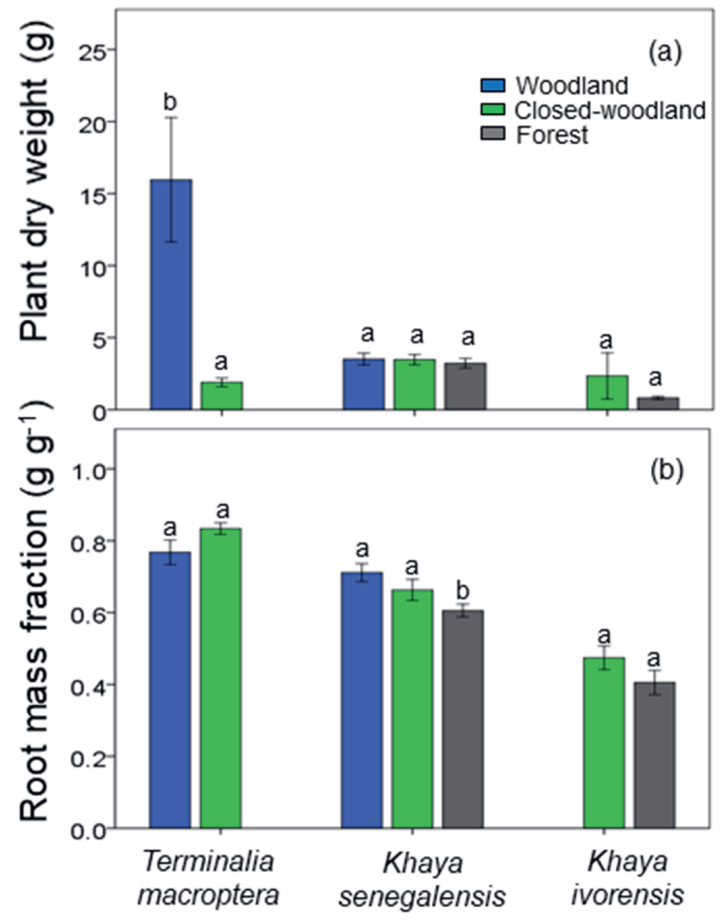

Figure 4. Mean seedling dry weight and root mass fraction for three species in three vegetation types in Kogyae Strict Nature Reserve, Ghana. Statistical comparison is among vegetation types, but not among species. Data not presented for Terminalia superba due to insufficient samples. Also, samples were insufficient for Khaya ivorensis and Terminalia macroptera in woodland and forest respectively. Different letters indicate significant differences $(\mathrm{P}<0.05)$. Error bars are $\pm 1 \mathrm{SE}$ of mean. 
Chapter 6

Table 4. Pairwise comparisons (from Kruskal-Wallis test) of tree seedling height recorded in years 1, 2 and 3 at Kogyae Strict Nature Reserve, Ghana. Analyses were done for each species separately. For Terminalia superba, only years 1 and 2 are compared using Mann-Whitney-U test. Years for which median seedling height differed significantly $(\mathrm{P}<0.05)$ are indicated with asterisk.

\begin{tabular}{lllll}
\hline Species & $\begin{array}{l}\text { Years compared } \\
\text { pairwise }\end{array}$ & Test statistic & $\begin{array}{l}\text { Standard } \\
\text { error }\end{array}$ & P-value \\
\hline Khaya senegalensis & $2-1^{*}$ & 91.5 & 13.8 & $<0.001$ \\
& $2-3^{*}$ & -139 & 15.3 & $<0.001$ \\
& $1-3^{*}$ & -47.3 & 17.3 & 0.019 \\
\cline { 2 - 5 } & $2-1^{*}$ & 136 & 9.70 & $<0.001$ \\
& $2-3^{*}$ & -177 & 30.4 & $<0.001$ \\
& $1-3$ & -40.7 & 30.9 & 0.563 \\
\cline { 2 - 5 } Terminalia macroptera & $2-1^{*}$ & 109 & 10.4 & $<0.001$ \\
& $2-3^{*}$ & -181 & 24.3 & $<0.001$ \\
& $1-3^{*}$ & -71.4 & 25.3 & 0.014 \\
\cline { 2 - 5 } & $2-1^{*}$ & 809 & 596 & $<0.001$ \\
\hline
\end{tabular}

\section{Discussion}

Forest and savanna species occur predominantly in their respective non-pyrogenic and pyrogenic environments. Yet, widespread observations have been made of forest species encroaching savannas in many places across the globe (Bowman et al., 2001; Mitchard et al., 2009). Higher vegetation cover is hypothesized to increase establishment of forest species, but tests in forestsavanna ecotones produced mixed results (Bowman et al., 2001; Cardoso et al., 2016; Gignoux et al., 2009; Hoffmann et al., 2004).

Generally, higher canopy cover suppresses pyrogenic fuel loads (Hennenberg et al., 2006) and aids tree seedling survival as fire in open savanna vegetation induces high seedling mortality (Cardoso et al., 2016; Gignoux et al., 2009; Hoffmann et al., 2004). Here, we assessed survival and growth of seedlings of two congeneric pairs of forest and savanna trees over a period of $3 \mathrm{y}$ (two 
dry/fire seasons) allowing for assessments at different moments in time and beyond one season in both forest and savanna environments. We assessed flammable material as an indication of fire intensity, soil characteristics as well as biomass fraction and starch concentration in roots in relation to different vegetation types (differing in extent of canopy closure).

The forest plots typically had higher soil moisture, organic matter and $\mathrm{N}$ content compared with the savanna woodland plots, which is in line with other studies (Fensham et al., 2003; Kellman 1985; Markham \& Babbedge, 1979) and which may be caused by the presence of increased cover and litter input by trees (Fensham et al., 2003; Kellman, 1985). Higher N content could also be the result of fixation by trees and the nitrification of $\mathrm{N}$ (leftover after uptake by vegetation) could explain the lower $\mathrm{pH}$ found in forest plots (Ste-Marie \& Pare, 1999). These differences between forest and savanna woodlands were found in top $(10 \mathrm{~cm})$ soil only. Additionally, several other soil parameters measured such as $\mathrm{P}, \mathrm{K}, \mathrm{Mg}, \mathrm{Ca}$ and $\mathrm{CEC}$ were similar in both environments. Thus, no firm conclusions can perhaps be drawn on whether soils differ markedly between forest and savanna patches in this ecotone. Nonetheless, higher topsoil moisture content, organic matter and $\mathrm{N}$ may affect tree seedling growth and survival.

Savanna woodland plots were characterized by higher biomass of herbaceous vegetation, while litter load was somewhat higher in closed-canopy forest cover (but only $\sim 0.2 \mathrm{~kg} \mathrm{~m}^{-2}$ ). This is the result of the higher canopy cover in forest excluding grasses, consistent with findings in other studies (Hennenberg et al., 2006; Hoffmann et al., 2012b). Faster and more intense fires have been observed for savanna than forests (Hennenberg et al., 2006; Hoffmann et al., 2012b) as a consequence of this difference in type and biomass of herbaceous vegetation.

\section{Seedling survival}

Survival in the first few weeks for both species in the genus Terminalia was lower in forest (at LAI of $\sim 1.7-2.0$ ) than in savanna, while species in genus Khaya were not affected. Clearly, both Terminalia species prefer higher light levels, at least in the first weeks after germination. The forest 
Chapter 6

Khaya is a non-pioneer light demander (Hawthorne, 1995) while its savanna congener is known to tolerate moderate shade (Kwesiga \& Grace, 1986). Three months into the first dry season, these apparent species differences were no longer observed and mortality had reached about half for nearly all individuals. Prior to this census (census 3) rainfall had declined from $37 \mathrm{~mm}$ in November to $3 \mathrm{~mm}$ in December (Figure 1).

Thus, the high mortality of the initial establishment phase may suggest a similar response to dry season drought for all species and regardless of vegetation cover. It was in the second dry season that the reported differences between forest and savanna species (Hoffmann et al., 2004) became evident in both genera tested in this study. At this stage, seedlings had gone through the first dry and fire seasons and subsequent recovery. And thus fire- and drought survival traits became more important explaining the greater survival of the savanna species.

At the end, the savanna Khaya had the most survivors in all vegetation types because it is both drought/fire tolerant and also moderately shade tolerant. None of the two forest species survived in woodlands where the highest biomass of flammable material was recorded. Except for the forest Khaya that had few surviving seedlings in closed-woodland, the forest species generally survived in forest, although in very low numbers. This suggests that the long dry seasons and associated fire events in this ecotone limits their colonization possibilities (Cardoso et al., 2016). Survival in savanna Khaya was similar to that of savanna Terminalia in savanna woodland, but markedly contrasting in closed-canopy forest and closed woodland with intermediate canopy cover (although to a lesser extent), with canopy closure favouring savanna Khaya and more open environments favouring savanna Terminalia. Again, this is consistent with the natural distributions of the two species.

\section{Seedling growth, biomass proportions and starch concentration in roots}

Within the first growing season, seedlings tended to grow taller (significantly for two species) in woodlands than forest. Perhaps this represents an increased growth response to the increasing light 
availability (Veenendaal et al., 1996c) associated with increasing canopy openness from forest to savanna. By the second year, seedling height had greatly reduced for all species indicating shoot loss resulting from drought and/or fire of the first dry season. The difference in height between years 2 and 1 which was greater for the two forest species than their savanna congeners may be an indication of a greater adverse effect of the dry season on the forest species. At the end of year 3 , seedlings were a lot taller (relative to year 1 heights) for both savanna species. By contrast, y 3 seedlings of the surviving forest tree K. ivorensis (mortality of forest Terminalia was $99 \%$ at this stage) were not taller than they were in year 1 suggesting a higher cumulative recovery and resprouting capacity for the savanna species than their forest congeners. This is consistent with our prediction and also reported in several other studies (Fensham et al., 2003; Gignoux et al., 2016; Okali \& Dodoo, 1973).

Vegetation cover type did not have profound effects on shoot loss and subsequent regrowth over the 3-y period except on savanna Khaya in year 2. This is inconsistent with our expectation because flammable material differed among vegetation types and should have influenced extent of stem die-back (top-kill) (Higgins et al., 2007). Perhaps this finding suggests that drought effect on stem die-back was stronger than the ameliorating influence of canopy cover. The fact that seedlings in closed-canopy forest also experience drought stress (Veenendaal et al., 1996a) lends support to this assertion. This may explain why patterns of forest development as well as mature trees of Khaya senegalensis appear to closely follow branching patterns of streams. It may also explain the overall rather slow development of forest vegetation on savanna patches in Kogyae Strict Nature Reserve and elsewhere in the transition (Armani et al., 2018; Janssen et al., 2018).

At the end of the experiment, the savanna species outperformed the forest species in terms of attained biomass at harvest, allocation to roots and root starch concentration. This was consistent with our expectation as species from drier pyrogenic environments have been reported to have higher root mass fraction and carbohydrate reserves for overcoming drought and fire (Cardoso et al., 2016; Hoffmann et al., 2004; O’Brien et al., 2014; Tomlinson et al., 2012). 
Chapter 6

Overall, our results suggest that the possibilities for establishment of moist semi-deciduous forest species in the forest-savanna ecotone are particularly limited by the dry season and its associated pyrogenic environment. More interestingly, we demonstrate that savanna species also differ in their tolerance to canopy cover and open pyrogenic environments specifically related to root storage functions, thus contributing to a better understanding of differences in tree seedling recruitment between species across the forest-savanna ecotones.

\section{Acknowledgements}

Financial support was provided by NUFFIC and Wageningen University for various stages of data gathering. We are grateful to the Ghana Wildlife Division (GWD) of the Forestry Commission for granting us permission to conduct this research in Kogyae Strict Nature Reserve (KSNR). We thank staff of GWD at Dome Camp of KSNR for their assistance during fieldwork. Nuni Ferawati and José A. Medina-Vega assisted with field data collection of the second year. We thank David Kleijn and two anonymous reviewers for giving critical feedback that greatly improved this paper. We are grateful to Frans Moller and Jan van Walsem for providing assistance with laboratory analysis of plant and soil samples. 


\section{Chapter 7}

General Discussion 
Chapter 7

\section{Introduction}

Forest-savanna transitions are generally discussed as consisting of different systems that operate next to each other with separate vegetation formations and distinct woody species (Cochrane \& Schulze, 1999; Furley, 1999; Furley \& Ratter, 1988; Lehmann et al., 2011; Murdoch et al., 1976; Ratter \& Dargie, 1992; Saiz et al., 2012; Thompson et al., 1992). They are also often separated into distinct pyrogenic and non-pyrogenic systems. A threshold tree cover that prevents the buildup of fuel for grass fires and thus causing a sharp separation between the two systems has gained wide acceptance through the work of e.g. Hennenberg et al. (2006) who showed the quenching of fire by tree canopies in forest-savanna mosaics in the Ivory Coast. However, there is also ample literature (Cochrane et al., 1999; Swaine et al., 1990) that suggest that fire is a widespread phenomenon in drier forests and forest-savanna mosaics. While this demonstrably has consequences on tree species composition in vegetation transitions (Cuni-Sanchez et al., 2016; Goetze et al., 2006; Swaine, 1992), there are at present still few studies that specifically focus on the interplay between fire, tree cover and tree species in areas where the savanna meets the forest. This study has therefore been inspired by the need for better understanding of the effects of vegetation cover change, soil heterogeneity and impending climate change on tree species selection and also the role of fire in FS transitions. Knowledge of determinants of the forest-savanna vegetation and the ecology of the trees in this area may aid reforestation and management in this environment.

\section{Forest-savanna transition landscape of the tropics}

The humid savanna and the dry forest of the tropical landscapes of the world vary significantly in structure and in function but do occur in proximity under similar climatic conditions (Furley, 1999). These unique biomes are sometimes considered degraded vegetation types or wrongly classified (Aubréville, 1959; Ratnam et al., 2011; Stebbing, 1935) and until recently, they were considered poor in terms of biodiversity (Furley, 1999). Historically, botanists have had difficulty in describing 
transitional vegetation in West Africa and considered the closed vegetations of the FS boundary that do not exclusively consist of "tall forest trees" to be "primitif", "disturbed" or "degraded" with a notion which considered much of the savanna as being fire-derived from dry forest (Aubréville, 1959; Bégué, 1937; Stebbing, 1935).

In addition to the role of fire, FS boundaries are likely strongly affected by various other factors such as soil resources and (micro-)climate. Indeed, the role of soil resources versus fire and climate on vegetation structure has recently been debated in literature and scientific symposia (Chave et al., 2009; De Amorim et al., 2005; San Jose, 1983; Veenendaal et al., 2015; Lloyd \& Veenendaal, 2016). Modelling studies show that, for many parts of the tropical world where both forest and savanna co-occur, transitional vegetation is sparse because savanna areas, potentially suitable for forest in terms of climate and soil resources, are maintained by fires (Bond, 2010; Hirota et al., 2011; Hoffmann et al., 2012a). Proponents of fire as the main modulator of vegetation structure and function restrict edaphic factor limitations to situations such as shallow or sandy soils and routine flooding specifically, which they argue is not widespread. They suggest fire to be responsible for the treeless tropical landscape that is commonly observed. Recent studies, however, indicate that, despite the strong effect of fire on vegetation structure, soil properties are a main determinant of vegetation structure especially in water deficit areas (Lloyd et al., 2015; Veenendaal et al., 2015). Fire feedbacks may act as a catalyst but may be less important than initially thought. Moreover, fire effects are more prominent and sustaining in open vegetation characterised by nutrient-poor soils and fire frequency and intensity may increase on nutrient-rich soils whose vegetation is severely degraded (Cochrane \& Schulze, 1999; Kyereh et al., 2007). This stresses the need of not only including fire, but also soil resources when studying drivers and dynamics of FS boundaries. In this thesis, I have comprehensively studied these drivers.

In this thesis, I conducted three-year field experiments, did observations and made use of remote sensing analyses with the aim to determine how drivers of vegetation interact to create boundaries and transitions in the forest-savanna transition of West-Africa. The dissertation 
Chapter 7

provides insights into how soil, climate and fire interact as drivers to create boundaries and transitions. Understanding of drivers that shape boundaries and transitions is of great value as it will contribute knowledge to current status of vegetation formations and its vegetation structure that exists within the area, how it is distributed and the mechanisms and policies that need to be applied to maintain it and its dynamic nature.

To achieve the objective, five main questions (Figure 7.1; see also introduction) were addressed:

(1) How stable are the vegetation patterns in West-African forest-savanna boundaries?

(2) Do tree functional types mix in the landscape?

(3) How does fire penetrate the forest landscape in Kogyae strict nature reserve if forest burns?

(4) How do tree functional type and stand structure affects the phenology of leaf shedding?

(5) How does canopy variation selects for tree species recruitment?

In this synthesis chapter, I review and integrate the findings that I presented in the previous research chapters in the light of present literature on forest-savanna transition and explore the implications on forest-savanna dynamics.

The overall findings of the $\mathrm{PhD}$ study are summarised in Figure 7.1 and discussed in greater detail below. 


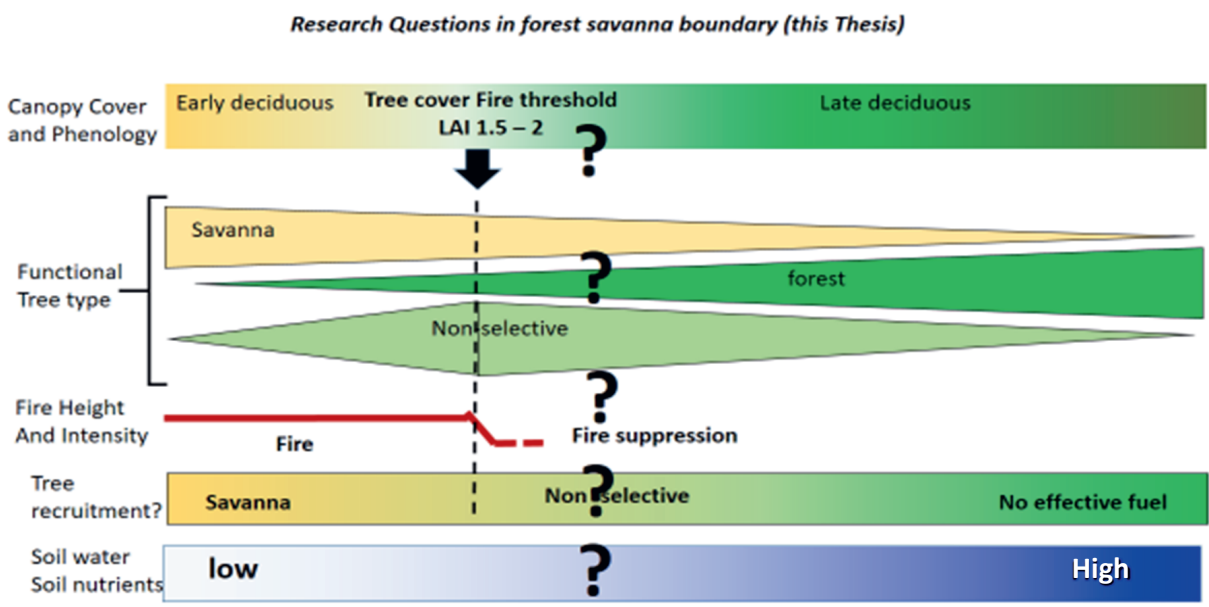

Figure 7.1. Conceptual framework to determine tree cover fire threshold, tree functional types, fire intensity and frequency, soil water resources and role of deciduous trees in the distribution of vegetation types in a forest-savanna ecotone (see also introduction).

\section{General observations on the history and ecology of Kogyae strict nature reserve (Q1)}

The Kogyae strict nature reserve (KSNR) is a large reserve within the forest-savanna transition zone of Ghana. Although the reserve was demarcated as a strict nature reserve and therefore considered under the International Union for Conservation of Nature (IUCN), there were no clearly defined policies to be strictly complied by to control human use especially until 1994 leading to managerial challenges. On many occasions in the past, management priorities were determined according to the convictions of the officer-in-charge. Policies implemented were scrupulously determined by the limited budget allocation and inadequate equipment supply (Ghana Wildlife Department, 1994). KSNR management was further confronted by a persistent demand for additional land by fringe communities. Former landowners seem not to recognise the restrictive entry status of the park partly because they were not adequately consulted and compensated for land acquisition. They, therefore, expect the land to be returned to them hereafter (Awuku-bor, 
Chapter 7

1999; Ghana Wildlife Department, 1994; Hagan, 1998). Institutional failures or inefficiencies in the conservation of natural resources may result from a lack of collaboration and strict policy application (Infield, 2001). Until 1994 wildlife policy of Ghana came into effect, the government was not obliged to collaborate or negotiate conditions with fringe communities when managing forest reserves. Continuous encroachment into the park by fringe communities with detrimental fire use practices is most likely to convert significant portions of closed-canopy vegetation to woodland unless management derives innovative ways to implement and enforce strict compliance.

Historical developments and various land uses influence the ecosystem functioning subsequently affecting the vegetation type found in a forest-savanna transition (Cochrane et al., 1999; Hansen et al., 2013). In West-Africa, most of the dry forest has been destroyed by land-use change (commercial logging and agriculture) (Swaine, 1992). As a result, only a small portion of the original forest remains in the reserves today. Assisted by remote sensing techniques, we traced recent developments of KSNR to understand longer time scale changes in the vegetation. As indicated previously, KSNR is a protected area under category Ia of IUCN, defined as strictly protected for biodiversity and also possibly geological/ geomorphological features, where human visitation, use and impacts are controlled and limited to ensure the protection of the conservation values. It is therefore expected to be managed under strict regulations as classified.

Surprisingly, we found that a significant portion of the once existent dry tropical forest of the park had been removed in commercial logging operations apart from arable farming just before gazetting, causing collateral damages to the ecosystem. Degradation of important dry forest reserves in Ghana in the 1990s was widespread (Hawthorne \& Abu-Juam, 1995; Kyereh et al., 2007). Tropical dry forest destruction amidst climate change is an international issue. Perturbation through logging has led to a long-term absence of forest cover in some parts of KSNR. The degraded patches have been converted to woodland mosaics and colonized by the exotic plant species Chromolaena odorata and savanna grasses. Our NDVI analysis conducted also revealed that despite the impact of frequent fires, some parts particularly on the north-eastern savanna zone of 
the park have over time remained stable or are increasing the density of the vegetation. It is in this part of the KSNR that I examined vegetation dynamics and fire characteristics within the reserve.

Canopy opening and tree cover reduction as a consequence of logging created a suitable environment for grasses and Chromolaena odorata with significant ecological consequence on the environment. Grasses constitute the bulk of biomass that fuels grassy fires and their continuous existence make the degraded patches more susceptible to seasonal fires (Kyereh et al., 2007). Chromolaena odorata on the other hand influences fire dynamics by reducing fire frequency and intensity by its high moisture content in early fires. However in drier environments when the moisture content is low, it augments flammability capable of transforming grass fires into highintensity canopy fires (Brooks et al., 2004; te Beest et al., 2012) due to flammable chemical constituents inherent in the shrub (Aigbedion-Atalor et al., 2019). However, in KSNR, Chromolaena odorata did not influence fire behaviour of plots dominated by it possibly due to its high moisture content in early fires as I will further elaborate in chapter 4. When established, Chromolaena odorata eliminates indigenous grasses and herbs through competition for light and soil resources (Honu \& Dang, 2000; Liao et al., 2019; te Beest et al., 2013). Thus, the diversity and floristic compositions of native species as well as their richness and abundance in degraded areas can be reduced by the invasion of Chromolaena odorata because it has canopy effects on survival and growth of tree seedlings underneath (de Rouw, 1991; Honu \& Dang, 2000; Liao et al., 2019; te Beest et al., 2013). Seedling regeneration and establishment under Chromolaena odorata is therefore constrained (Ranwala \& Thushari, 2012).

The wildlife department now undertakes annual burning practices at the onset of the dry season to stimulate fresh grass growth for herbivores. This possibly retards or slows down forest development and possibly delays the restoration of the destroyed tropical dry forest (Janssen et al., 2018). From all indications, frequent burning impedes recruitment and establishment of forest tree seedlings in the forest-savanna transition (Cardoso et al., 2016a; Gignoux et al., 2009). Apart from anthropogenic disturbances, herbivore browsing could be detrimental to woody plants as often 
Chapter 7

reported in the savanna vegetation (Hovestadt et al., 1999; Van Langevelde et al., 2003). This however does not seem to play a role in KSNR as we did not observe heavy grazing and herbivores were only present in low density (Ayivor \& Ntiamoa-Baidu, 2015a), even though Mammals including buffaloes and civet cats are protected by KSNR (Ghana Wildlife Department, 1994).

\section{The Link Between Vegetation Structure and Plant Functional Type Variation (Q2)}

In chapter 3 of this thesis, I examined variation in the structural parameters of woody vegetation and investigated the link between plant functional type trees (savanna, transitional and forest species) and vegetation structure of a forest-savanna boundary in Ghana, West Africa. In a forestsavanna ecotone where climatic variables are similar, soil and fire are likely to be the main determinants of the vegetation structure and function (Staver et al., 2017). Therefore, I expected variation in vegetation structure across the forest-savanna transition landscape on possibly heterogeneous soils. I adopted a structural classification method to classify vegetation according to Torello-Raventos et al., (2013) to be able to compare variation in major vegetation structural attributes such as cover and biomass between vegetation structural types (VSTs) and to be able to determine in absolute terms proportional contribution of plant functional types (PFTs) to numerous structures of tree stands.

Although classification according to PFTs at a scale showed discrete grouping of savanna (S) species-dominated plots, non-selective $(\mathrm{N})$-species-dominated plots and forest $(\mathrm{F})$ speciesdominated plots, the distribution of PFTs across the numerous VST exhibited mixing of species. The closed canopy plots were conventionally dominated by forest affiliated species while woodland plots were dominated by savanna affiliated species. Species found in our woodland are likely shadeintolerant but fire-resistant with conspicuous fire scars on their thick barks and have characteristic traits such as investment into roots of their seedlings to enable re-sprouting in the fire-prone vegetation type (Gashaw et al., 2002; Jhariya et al., 2014; Nangendo, 2005). N-species also referred to as ubiquitous species are dry forest trees with a degree of fire tolerance both in the seedling and 
the mature stage. They are wide-ranging which become more abundant as the canopy closes. The location of the species is perhaps determined by their ability to adapt to environmental stressors such as fire, shade and moisture limitation. While the F-species can occur in all vegetation types, they only dominate in closed vegetation probably because they are fire sensitive and shade tolerant.

Our finding that, savanna and transitional functional type species could co-occur and possibly form a closed canopy vegetation is an important observation. Non-selective species occupy a unique ecological spectrum. They constitute an intermediate vegetation type that bridges the forest-savanna vegetation gradient and select for species with intermediate traits for fire, shade tolerance and differential moisture regime (this thesis). Species mixing in West African transitional vegetation has been documented before (Asare, 1962; Schrodt et al., 2015; Torello-Raventos et al., 2013) and also in East-Africa (Nangendo, 2005).

In this latter field study conducted on species classification and distribution in a forestsavanna mosaic in Uganda, Nangendo (2005) concluded that species composition overlapped even though vegetation classes were distinct. Like $\mathrm{N}$-species identified in Ghana, wide-ranging species which expressed their optimal on a vegetation gradient were identified. Some forest species recruit their seedlings under different vegetation types where ameliorative conditions may prevail. Recently in Ghana, (Armani et al., 2018) reported recruitment of seedlings of understorey species of forest and savanna under different undergrowth of trees. Thus, a certain degree of functional tree species mixing exists at seedling level (Nangendo, 2005) at the understorey level (Armani et al., 2018) and at the stand level (this thesis). By implication, stands containing mixtures of forest and savanna trees are not fire-degraded and temporary as suggested by researchers (e.g. Aubréville, 1938; Ratnam et al., 2011; Stebbing, 1935) but reflect the richness of plant adaptation in this dynamic system (Issifu et al., 2019) where forest and savanna trees coexist.

I also found that despite the presence of annual fires which could have retarded growth, slow woody cover increment is occurring. This increment as indicated by NDVI, was highest in $\mathrm{N}$-species dominated plots. Forest and savanna transition vegetation observed over decadal time 
Chapter 7

scale seems to be stable or changing slowly as reported by other researchers (Cuni-Sanchez et al., 2016; Goetze et al., 2006) or faster under more favourable soil conditions and climate (Mitchard et al., 2009).

Soil physical and chemical characteristics have been documented to influence vegetation structure as well as species composition in the study region (Asare, 1962; Markham \& Babbedge, 1979; Swaine et al., 1976). Soil nutrients e.g. cations are considered important in vegetation formation ( Veenendaal et al., 2015). My study demonstrated the importance of soil as a potential cause of variation in vegetation structure i.e. crown area index, stem basal area and above-ground biomass. I indeed found that $30-40 \%$ of the vegetation structure can be explained by soil exchangeable potassium and silt contents. Both factors have recently also been demonstrated to be main modulators of vegetation structure and function in Tropical South America (Lloyd et al., 2015) and are linked to soil water retention as well as osmotic regulation in plants, suggesting access to sufficient water as a main driver of tree density in KSNR.

In the absence of fire, pioneer forest seedlings may however still successfully recruit into the woodland patches of the reserve as long as it has adequate soil resources and depth to sustain a dry forest. Fire exclusion may lead to a much denser tree cover (Veenendaal et al., 2018). The degree to which tree seedlings may escape the fire trap is indirectly linked to the availability of resources (Hoffmann et al., 2012a).

Closed-canopy vegetation may require much more soil water for evapotranspiration. Usually, greater soil water depletion in the dry season under denser tree stands in water-limited tropical systems occurs, possibly related to denser rooting of the woody vegetation (Bougma et al. 2020, Murphy and Lugo 1986, Veenendaal et al. 1996, 2008). However, deeper soil profile for forest soils may allow for a larger volume of stored water to compensate for loss. In KNSR deeper soils found in the forest patches may have the potentials to store more water to assuage the impact of the dry season on closed-canopy vegetation. This may partly explain the existence of dry forest patches in the ecotone. 


\section{Characteristics of forest-savanna transition fires $(\mathrm{Q} 3)$}

Fire like soil resources is an important determinant of vegetation structure and function and they co-determine the vegetation structure in the forest-savanna transition where annual fires could be routine (Lloyd et al., 2015; Lloyd \& Veenendaal, 2016; Staal \& Flores, 2015; Veenendaal et al., 2015). Fire is thought to maintain savanna areas that could have been suitable for forest although climate and soil resources may be suitable(Bond, 2010; Hirota et al., 2011; Hoffmann et al., 2012a; Staver et al., 2011). Annual man-made fire, however, is a common phenomenon in the forestsavanna transitions and within the study area, fire incursion into the forests is regularly observed (Cardoso et al., 2016a; Hall \& Swaine, 1976; Swaine, 1992). In this study, I examined fire-tree cover feedbacks in West-African forest-savanna ecotone to quantify fire behaviour across a gradient of canopy closure in the forest-savanna boundary at Kogyae.

I found that in KSNR, canopy closure of the vegetation does change fire intensity and behaviour but does not exclude fire from entering closed dry-forest patches. While open vegetation enables grass growth to sustain regular fire, closed canopy vegetation suppresses growth of lightdemanding grasses in the understory through light competition which eliminates grass fires. Differences in standing fuel load and litterfall preceding the dry season is significant. I also distinguished at least two types of fires: (1) a high-intensity fire fueled by grasses (fire height up to $2 \mathrm{~m}$; ambient temperature up to $300{ }^{\circ} \mathrm{C}$ ) and (2) a benign leaf litter fire at LAI $>2$ (fire height below $50 \mathrm{~cm}$; ambient temperature below $105^{\circ} \mathrm{C}$ (the lowest paint indicator). Contrary to commonly held opinion that fire does not penetrate closed-canopy vegetation, fire burnt most if not all of the surface irrespective of vegetation formation but slightly less so in closed woodlands and forests associated with litter fires than in woodland which had standing fuel in abundance. The two fire types could be distinguished mainly by their frequency of occurrence and intensity.

These findings have important ecological implications. I think that these benign ground fires under closed canopy could select for specific tree communities where these fires may act as filters for species recruitment (see further Q5) and eliminate overly fire-sensitive species. This may 
Chapter 7

be the explanation for intermediate vegetation type dominated by non-selective species bridging the pyrogenic characteristics of the two vegetation types. Non-selective species were commonly found maintaining populations in intermediate vegetation and as a link between woodland and closed-canopy vegetation (Ametsitsi et al., 2020; Armani et al., 2018; Ratnam et al., 2019). These non-selective species were defined as species that not clearly associate with either open savanna or denser forest-like vegetation types so taper-off in the open savanna and also in the densest forest associated with low-intensity fires. These species may differ in functional traits from forest and savanna species. I will discuss this later in Q5.

Fire penetrating under tree canopy due to the presence of dry litter (although commonly documented but overlooked by researchers) is a phenomenon which has been reported from forests globally (Cochrane et al., 1999; Cochrane \& Schulze, 1998, 1999; Mutch, 1970; Ratnam et al., 2011; Stott, 1986; Swaine, 1992). Litter fires are influenced by litter layer being dry enough (Ray et al., 2010) and the drier climate (Swaine, 1992). And in West-Africa, "fire forest" formations have been floristically distinguished through the abundance of specific tree species (Hall \& Swaine, 1976; Swaine, 1992) which presumably have adapted to litter fire incursion with time.

My findings contrasted with numerous studies which report sharp transitions between forest and savanna due to the presence of fires (Cardoso et al., 2019; Hoffmann et al., 2012a; Ibanez et al., 2013) or sharp edges while noting some degree of transition(Charles-Dominique et al., 2018a). In this study, I showed that indeed litter fires are common in other forest-savanna transitions and form a continuity of flammability between woodland and the closed canopy forest patches which favour non-selective species. By implication, fire is a routine phenomenon in the tropical dry forest due to preceding rainfall (drought), dry season length seasonality of fire events and degree of drought. 


\section{The impact of tree leaf retention on low-intensity fires in the forest-savanna transition} (Q4)

In recognition that leaf litter may play a pivotal role in the penetration of litter fires in the dry forest patches of the forest-savanna transitions (Chapter 4), I investigated the extent to which tree species, tree functional type or vegetation structure influence the retention or shedding of tree leaves during the dry season. This investigation was conducted by a combination of field observation and structural measurements. I focused on the status of leaf retention across the forestsavanna landscape, that is vegetation cover differing in the degree of leaf cover (LAI) at the time of early fires (late January) in mid-dry season.

In the tropical forests, there is an intrinsic link between terrestrial hydrological conditions and vegetation greenness (Xie et al., 2019). Sustained availability of water leads to increased LAI, higher leaf retention (Gond et al., 2013) which influences timing and duration of leaf loss as far as phenology is concerned.

On a larger scale, soil water availability is a driver of forest structure, species diversity and distribution and controls canopy dynamics (Borchert, 1994; Eamus \& Prior, 2001). Thus in WestAfrica, rainfall and soil water retention together determine seasonal soil water shortage (Hall \& Swaine, 1976; Veenendaal et al., 1996; de Bie et al., 1998) and depending on rainfall seasonality and duration of the dry period, leaf shedding may be stimulated. Leaf shedding is an evolutionary response to biotic and abiotic environments and a trade-off between avoidance and resistance to water stress (Parolin et al., 2010; Singh \& Kushwaha, 2016). That is some tree species retain their leaves while others shed theirs completely or partially at different scales and timing which is thought to be influenced by the species, plant functional type or vegetation structure and hydrological constraints. Larger LAI values in water-limited tropical systems are inherently linked to groundwater resources access (Ametsitsi et al., 2020; Cardoso et al., 2018; Charles-Dominique et al., 2018b). Thus, the degree of leaf retention and LAI are both governed by water supply and should be considered together. Also, we should keep in mind that in dry tropical forest trees there 
Chapter 7

is still a great variation in deciduousness (Borchert et al., 2002; Singh \& Kushwaha, 2005) and adaptation strategies may thus vary considerably.

We observed in KSNR that deciduous tree species started shedding leaves two weeks into the dry season depending on the extent or severity of dry season while others spread them throughout the season and in some cases, retain some leaves. Amongst all plant functional types, LAI declined after the rains stopped but not all species showed the same phenological behaviour. Generally, Savanna trees were more deciduous than forest trees and with considerable variation among forest trees as observed elsewhere across the forest-savanna boundary (Schrodt et al., 2015).

Tree species and tree functional type were particularly important for leaf retention in the first half of a dry season. In forest tree-dominated plots, leaf retention always remained higher and significantly different from savanna or non-selective tree-dominated transitional vegetation from January. Vegetation structural type (equivalent to e.g. density of trees in the landscape) became important for leaf retention later in the dry season. While the deciduousness of savanna trees was evident, the greatest absolute leaf fall in December and January was observed in transition stands that mainly consisted of non-selective tree species and were significantly different from forest plots (with the highest retention).

The higher leaf retention in the forest plots and its associated transpiration may have led to a stronger depletion of near-surface soil moisture in the forest plots in the dry season (Chapter 3). This underlines the importance of competition for water observed in drier closed forests and may have consequences for seedling recruitment (Veenendaal et al., 1996) due to competition for belowground resources with bigger trees, especially in less fertile and drier soils (Coomes \& Grubb, 1996). In the forest, trees may have access to extra water in the dry season because they tap into progressively deeper sources to exploit water to sustain the required physiological processes which enables them to survive while depleting the upper profile of water (e.g. Stratton et al., 2000; Veenendaal et al., 2008). In the forest-savanna boundary, the depletion of near-surface soil water 
by the forest plots may thus be an environmental filter that selects for specific forest species that are better adapted to such an environment (see e.g. Cardoso et al., 2016).

The timing and synchrony of fire and leaf fall may influence fire penetrating the dry forest and consequently forest structure and function. Anthropogenic fires in West-Africa commence approximately four weeks after the last rainfall when the grasses have become dry enough. While the woodland portions then become readily flammable, the herbs dominating the under-canopy vegetation generally have higher water content and are therefore less flammable (Cardoso et al., 2018; Kauffman \& Uhl, 1990; this study). Adequate dry litter in the forest, however, enhances fire penetrating the dry forest. The dry forest may not burn if there is extra groundwater supply that keeps the undergrowth moist and deciduous trees retain their leaves longer (Cardoso et al., 2018). Thus additional groundwater supply may not only increases tree cover, but also the timing of deciduousness and increase differences in the moisture level of the fuel biomass in the savanna and the forest understorey (Biddulph \& Kellman, 1998; Cardoso et al., 2018; Justiniano \& Fredericksen, 2000; Marsh, 1978). This may create a sharpening switch (sensu Lloyd \& Veenendaal, 2016) and sharp boundaries between pyrogenic and non-pyrogenic systems (see Chapter 4). On the contrary, prolonged drought, e.g. during El Niño years (e.g. Veenendaal et al., 1996), may cause long periods with very limited water supply which in turn may trigger deciduous trees to shed more leaves and stimulate forest litter fires. This will intensify forest fires during such periods.

My work shows however that in normal years the forest and closed woodland vegetations are still capable to produce enough leaf litter to sustain ground fires, even early in the rainfall season (Chapter 4). This provides mechanistic explanation for the occurrence of dry deciduous fire forests in this region (Swaine 1992). It is of interest to note that specifically non-selective species may contribute to this phenomenon as they occur in denser tree stands but with a to savanna trees comparable degree of deciduousness at stand level. 
Chapter 7

\section{Canopy cover effects on recruitment (Q5)}

In chapter 3, I showed that woody canopy cover affects fire behaviour. Some plant functional types were more likely to be associated with changes in woody canopy cover with non-selective species in the intermediary. Similarly, the degree of canopy closure plays an important role in the recruitment of seedlings of savanna, forest and intermediate or "non-selective" tree species e.g.(Cardoso et al., 2016a; Gignoux et al., 2009).

To help explain the distributions of tree functional types in a forest-savanna ecotone typical of West-Africa, we investigated how variation in the tree canopy cover influences recruitment of seedlings of different tree species (savanna/non-selective and forest) in a three-year field experiment (Chapter 6). This ecosystem is characterised by light limitation (in forest patches), moisture stress in the dry season and defoliation. Survival in this extreme environment requires optimal plant resource management, trade-offs and specific adaptation to stressors. Although climatic factors were similar, soil resources, fire frequency and intensity could vary significantly. Declining tree cover may therefore not only increase grass cover but also augment air temperature and reduce fuel moisture and relative humidity (Hoffmann et al., 2012a; Little et al., 2012) leading to severe fires. Similarly, the microclimate under closing canopy influences fuel availability and perhaps also flammability and fire behaviour in the mosaic (Gomes et al., 2020; Newberry et al., 2020, this study). Tree seedling survival in this environment requires a specific adaptation to these stressors. A recent study by Boonman et al. (2020) investigated the trade-off between resource acquisition and resource conservation traits in tree seedlings along resource gradients and defoliation. The study emphasised that species from defoliation-prone environment increase resource storage in roots while those from drier areas increase rooting depth to reach deeper water resources.

Forest Tree Seedlings:_All vegetation types in the forest-savanna boundary at KSNR experience fire incursion with varied intensities. This means that all regenerating tree seedlings suffer of some 
degree of decapitation as a consequence of burning. Fire has profound but varied effects on tree seedlings of different plant functional types. Moist semi-deciduous forest seedlings did not survive in the open pyrogenic environment of the woodland where fire frequency and intensity were highest. These seedlings can be characterized by a relatively low root mass fraction and root starch content and are clearly not adapted to dry season fires and unable to re-sprout after fire (Boonman et al., 2019; Cardoso et al., 2016; Issifu et al., 2019).

Moisture stress may also be critical. Water availability is generally recognised to influence tree species distributions (Baltzer et al., 2008; Engelbrecht et al., 2007; Poorter \& Markesteijn, 2008; Veenendaal \& Swaine, 1998). Moisture stress outweighed the ameliorative environment created by closed canopy cover and its associated microclimate and richer soil resource advantages. Seedlings under tree canopy suffered from intense competition for water from surrounding trees. This was confirmed by the exploration of soil water profiles up to one meter depth in the forest-savanna boundary to assess the available amount of water at the peak of dry season. Forest patches were most strongly depleted of soil moisture because of active evapotranspiration activity of trees (chapter 3). This probably explains why moist-forest tree species were not observed in all plots in the forest-savanna transition zone in my study. These findings suggest that forest expansion in the FS transition zone is generally restricted by the availability of water and often follow the watercourses in the FS transition zone and beyond (Janssen et al., 2018).

Dry forest/non-selective species, however, survived better (this study, Cardoso et al., 2016). Survival under closed canopy requires shade and drought-tolerant traits. On one hand, these species may allocate more resources to enable rapid advantageous growth under shading, while at the same time retaining sufficient resources in their roots to survive decapitation (this study; Cardoso et al., 2016; Issifu et al., 2020). The true humid savanna tree seedlings, on the other hand, can handle the open pyrogenic environment relatively well (Gignoux et al., 2009; Hoffmann et al., 2004), because of their adaptative strategy to tolerate defoliation as a consequence of resource conservation root trait syndrome and the ability to store starch to enhance re-sprouting when defoliated (Fensham et 
Chapter 7

al., 2003; Gignoux et al., 2016; Issifu, et al., 2019; Okali \& Dodoo, 1973). As a result, savanna tree seedlings may, however, be disadvantaged in shaded conditions and will be less likely to survive under a closing canopy.

Recruitment of tree functional types into numerous vegetation types in a forest-savanna transition leads to a mixing of tree species under different degrees of canopy closure with different traits and possibly different trait plasticity. Khaya senegalensis in our study is a good example. It is often classified as savanna species (Keay, 1960; Okali \& Dodoo, 1973). In our study, it survived light limitations under closed canopy in contrast to expectations for a typical humid savanna species (REF). Its tree functional classification may however not be straightforward. Within the humid savanna, Khaya senegalensis is mostly confined to relatively moist locations with an extra water supply or along watercourses and it has therefore in the past sometimes erroneously also been classified as a forest species (Kwesiga \& Grace, 1986; Stebbing, 1935). However, based on recent examination of its root traits the species can arguably be better considered as a non-selective species, more typical of the FS ecotone (Boonman et al., 2019). I thus conclude that the effects of a closing canopy on fire, shading and water stress in the FS boundary affect moister forest, dry forest, non-selective species and savanna species differently.

\section{New insights in dynamics of the forest savanna boundary}

I set out to improve understanding of drivers of forest-savanna transitions, and human interplay shaping vegetation structure and function. There have been a variety of previous studies that have emphasised the difference between forest and savanna in terms of pyrogenic and non-pyrogenic environments. These observations have been attributed to distinct plant functional types. This study presents empirical evidence to test paradigms that are commonly associated with the forestsavanna transition and shows that the observed field situation is inconsistent with these concepts. 


\section{How fire penetrates forest patches in a forest-savanna ecotone}

The findings of this study are inconsistent with the idea that fire does not penetrate closed-canopy forest as previously reported (Cardoso et al. 2018; Hoffman et al. 2012). Canopy closure changes fire intensity and its behaviour but does not exclude fire penetrating dry forest patches. If dry leaves drop before the fire higher and hotter fires in woodlands occur it results in lower and more benign litter fires in forests while closed woodlands are intermediate. In many places, this is a natural phenomenon because there are fire-prone forest communities documented (Ratnam et al., 2011; Stott, 1986; Swaine, 1992) as a result of regular fire incursion and adaptation to frequent burning when fire intensity switches as the canopy closes. Also, occasionally, fire penetrates fire belts in the forest in ecotones. In conclusion, fire penetrates dry forest as a natural phenomenon. Trees in these habitats would have evolved with appropriate traits such as starch storage in seedlings (Boonman et al., 2019; Cardoso et al., 2016b; Issifu, Ametsitsi, et al., 2019) bark thickness (Ratnam et al., 2019) or physiological adaptations (Paine et al., 2010; Pausas, 2015; Pinard \& Huffman, 1997).

\section{Mixing of woody species in the forest-savanna transition landscape}

Previous studies emphasized that tropical savannas and forests are discrete biomes composed of distinct PFTs and VSTs (Furley et al. 1992) and the trees classified as either forest or savanna. While this is generally true, findings of this thesis suggest that in the ecotone between forests and savannas, a third group has emerged as non-selective that bridges the gap between forest and savanna. These species are found in Kogyae and elsewhere (Cuni-Sanchez et al., 2016; Goetze et al., 2006) and appear to play a special role. For instance, they seem to be able to increase cover over the last few years and may respond more rapidly to environmental change and stressors such as fire, moisture stress and light limitation with intermediate traits which confer robustness on them. The non-selective species are less adapted to intense fires on woodland but could establish in competitive closed woodland environments by developing cover which suppresses grass growth and reduces fire intensity while harbouring adequate fuel load (litter and grass) to sustain fire that 
Chapter 7

hampers forest species recruitment (this thesis). Litter fires are likely the cause of more fire-adapted forest and transition communities described in the dry forests of Africa and elsewhere (Hall \& Swaine, 1976; Ratnam et al., 2019; Stott, 1986). As mentioned earlier, unlike moister forest species, fire adapted species have thick barks to protect them. Their seedlings have intermediate rooting traits syndrome, starch allocation (Boonman et al., 2019; Issifu, Ametsitsi, et al., 2019) for successful recruitment and also moderately shade tolerant. They can attain heights up to $30 \mathrm{~m}$. and are able to compete for height in the forest-savanna ecotone (this thesis) showing a strong plasticity across the boundary. Therefore, it is justified to consider this a different intermediate functional group. Further studies of seedlings from these species appears to justify this notion (Issifu, 2020) but this group needs further investigation. In conclusion, savanna species seem to perform well in the open, the intermediate species seem to perform best in intermediate space and the forest species will survive under canopy cover although too dry for moist-forest species.

\section{Sharp versus soft edges of forest-savanna ecotones}

Many studies argue in favour of narrow thresholds which constitute sharp transitions due to the presence or absence of fire (Cardoso et al., 2019; Hoffman et al., 2012; Ibanez et al., 2013; Staal \& Flores, 2016) or sharp edges while others recognised some degree of transition due to e.g. grazing (Charles-Dominique et al., 2018b). Forest mosaics and forest islands in a forest-savanna ecotone could be influenced by distribution pattern of soil resources/available water during the dry season (this thesis). Additional groundwater supply not only increases tree cover along a border but also the timing of deciduousness as well as increasing differences in moisture level between the fuel biomass in the savanna and in the forest understorey. Fire does not penetrate these forest formations due to effects of an enhanced microclimate (Biddulph \& Kellman 1998; Cardoso et al., 2018; Marsh 1978; Justiniano \& Fredericksen 2000) and inadequate flammable fuel load, because water is not limiting. If water is limiting it will stimulate early leaf shedding in synchrony with early burning of the savannas (this thesis). In the absence of additional water supply, benign litter fires 
penetrate the forest and select for non-selective species to bridge the gap between forest and savanna species creating soft transitions (Ametsitsi et al., 2020).

Forest-savanna transition vegetation has been described as unstable, dynamic, and rapidly switching from one state to another especially in severe perturbation (Bond et al., 2005; Hoffmann et al., 2012a; Oliveras \& Malhi, 2016). However, a forest cover change detection based on NDVI for almost two decades showed that plots have been relatively stable (Cuni-Sanchez et al., 2016; Goetze et al., 2006; Mitchard et al., 2009). In Kogyae, slow canopy increases can be detected amidst regular fires while tree communities seemed to thrive in benign fire environments (Swaine 1992, this thesis). I therefore propose this to be evidence for a highly variable but still often quite stable environment.

\section{Implications for societal and resource management in Kogyae}

Kogyae Strict Nature Reserve is a forest-savanna transition barrier reserve categorized as a strict nature reserve (IUCN) that protects unique flora and fauna of enormous ecological significance. It also protects watersheds and habitats of wildlife and maintained strictly for education and scientific research use (Hagan, 1998). Soil, fire, climate and its variability and anthropogenic influences constitute drivers of vegetation function and structure in a forest savanna transition. Fire, human activities, and natural drivers created the present day Kogyae. Although edaphic factors could not be influenced in the ecotone, knowledge about soil resource distribution enhances good forestry management and rehabilitation. Our results suggest that soil factors have a major influence on potential and actual vegetation structure and function and could help explain forest patches and mosaics as well as sharpness of the boundaries of an ecotone.

Recent studies in Ghana, have described widespread deforestation and degradation especially in the 1990s (Hawthorne and Abu-Juam, 1995). Anthropogenic interference strongly influenced the occurrence and magnitude of disturbance regimes for a substantial period in KSNR (Janssen et al., 2018). Although KSNR was classified as a Strict Nature Reserve, it was degraded due to lack of 
Chapter 7

enforceable policies, logistics and trade-off between economic use and conservation values by the government. In addition, fringe communities were not adequately consulted or compensated for the land acquired and continue to intrude (Oduro-Ofori et al., 2015). To avoid frequent encroachment and poaching, there is the need to collaborate with all stake holders to observe the integrity of the designation assigned to KSNR. The government should allocate adequate funds in the budget for its management apart from providing realistic policies for management. Considering the delicate nature of the ecotone and the risk of further degradation, economic activities such as logging with its concomitant degradation should be totally avoided.

Fire is an inherent component of the forest-savanna ecotone which selects for species as described in this thesis. However, in logged dry tropical forest, the open up vegetation may initially develop into largely tree-less tall grasslands often invaded by Chromolaena odorata. In KSNR, fire is used as a management practice to stimulate grass growth for wildlife. Fringe communities routinely set fires for poaching too (Ayivor and Ntiamoa-Baidu, 2015). Logged and burned forests are more prone to seasonal fires due to availability of flammable materials (Cochrane et al., 1999; Kyereh et al., 2007). Fire may not stop vegetation recovery in the long term, but I expect a route of recovery through savanna tree species that need to attain sufficient tree cover to allow for more fire sensitive species to recruit. This is a lengthy process but feasible as long as seed resources are not a bottleneck.

Effects of environmental and anthropogenic disturbances have caused collateral damage to the ecosystem services of the forest and the need to restore some important ecosystem services like watershed function (Hagan, 1998) and habitat for large mammals (Ayivor \& Ntiamoa-Baidu, 2015b) and as a potential genetic reservoir of highly adapted tree species (this thesis). This underlines the urgent need for a restoration and protection effort for the largely disappeared dry reserve. This must include better fire protection of the original dry forest, at least in some areas with sufficient soil resources i.e., water and nutrients (in particular potassium). This could considerably facilitate dry forest regeneration. 
In addition, I propose in such locations the use of non-selective species for enrichment planting which can bridge the gap between forests and savanna due to their intermediate tolerance for shade, water stress defoliation/decapitation and above all their selective and adaptive power. These physiologically robust species may escape fire traps quickly and be able to establish (e.g. Khaya senegalensis). Remnant forest patches can be used to provide the best genetic material to enable regeneration.

\section{Concluding remarks}

Many forest-savanna boundary studies have reported a sharp pyrogenic vs. non-pyrogenic contrast. FS boundaries however appear to be far more complex and largely influenced by various local conditions. I showed that tree functional types do mix in the landscape. This revelation challenges the classic perception of a simple forest vs. savanna dichotomy of tree species controlled by fire. Most importantly, a newly identified third non-specialized species grouping capable of bridging the pyrogenic gap will contribute to understanding ecotonal responses to climate change. Further investigation and experimentation into location factors is needed.

One of the more significant findings to emerge from this study is that fire penetrates the forest in the landscape in KSNR. This study provided an empirical investigation into forest litter fires and their impact. It highlights the role of phenology and deciduousness of trees in provision of flammable fuels that complement grass fires. Litter fires are common in dry forests with intermediate behaviour in the transition type. The findings of this investigation complement those of earlier studies which suggest that there are fire adapted tree communities in an ecotone.

This thesis again has revealed the challenges of recruiting moist-forest species into the drier forest-savanna transition. Despite the ameliorative environment created by closed canopy cover and its associated microclimate and richer soil resource, adaptation to moisture stress is paramount in the dry season. Most broadly, this study contributes to the ongoing debate about the relative importance of fire and soil in determining vegetation function and structure. It is concluded that 
Chapter 7

soil, climate, and fire all interact to create boundaries and transitions in the forest savanna landscape. This finding also helps explain the underlying mechanisms of the apparent softness of forest-savanna transitions in West-Africa. 


\section{References}

Aguirre-Gutiérrez, J., Oliveras, I., Rifai, S., Fauset, S., Adu-Bredu, S., Affum-Baffoe, K., Baker, T. R., Feldpausch, T. R., Gvozdevaite, A., Hubau, W., Kraft, N. J. B., Lewis, S. L., Moore, S., Niinemets, Ü., Peprah, T., Phillips, O. L., Ziemińska, K., Enquist, B., \& Malhi, Y. (2019). Drier tropical forests are susceptible to functional changes in response to a long-term drought. Ecology Letters, 22(5), 855-865. https://doi.org/10.1111/ele.13243

Aho, K., Derryberry, D., \& Peterson, T. (2014). Model selection for ecologists: the worldviews of AIC and BIC. Ecology, 95, 631-636.

Aigbedion-Atalor, P. O., Adom, M., Day, M. D., Uyi, O., Egbon, I. N., Idemudia, I., Igbinosa, I. B., Paterson, I. D., Braimah, H., Wilson, D. D., \& Zachariades, C. (2019). Eight decades of invasion by Chromolaena odorata (Asteraceae) and its biological control in West Africa: the story so far. Biocontrol Science and Technology, 29(12), 1215-1233.

https://doi.org/10.1080/09583157.2019.1670782

Ametsitsi, G. K. ., Van Langevelde, F., Logah, V., Janssen, T., Medina-Vega, J. A., Issifu, H., Ollivier, L., den Hartogh, K., Adjei-Gyapong, T., Adu-Bredu, S., Lloyd, J., \& Veenendaal, E. M. (2020). Fixed or mixed? Variation in tree functional types and vegetation structure in a forestsavanna ecotone in West Africa. Journal of Tropical Ecology, 1-17. https://doi.org/10.1017/S0266467420000085

Andela, N., \& Van Der Werf, G. R. (2014). Recent trends in African fires driven by cropland expansion and El Niño to la Niña transition. Nature Climate Change, 4(9), 791-795. https://doi.org/10.1038/nclimate2313

Aragão, L.E.O.C., Malhi, Y., Barbier, N., Lima, A.A., Shimabukuro, Y., Anderson, L., \& Saatchi, S., (2008). Interactions between rainfall, deforestation and fires during recent years in the Brazilian Amazonia. Philos. Trans. R. Soc. Lond. Ser. B Biol. Sci. 363, 1779-1785. http://dx.doi.org/10.1098/rstb.2007.0026.

Archibald, S., \& Scholes, R. J. (2007). Leaf green-up in a semi-arid African savanna-separating tree and grass responses to environmental cues. Journal of Vegetation Science, 18(4), 583-594. 


\section{References}

Armani, M., Van Langevelde, F., Tomlinson, K. W., Adu-Bredu, S., Djagbletey, G. D. \& Veenendaal, E. M. (2018). Compositional patterns of overstorey and understorey woody communities in a forest-savanna boundary in Ghana. Plant Ecology and Diversity, 11, 451-463.

Asare, E. O. (1962). A note on the vegetation of the transition zone of the Tain Basin in Ghana. Ghana Journal of Science, 2, 60-73.

Aubréville, A. (1938). La forêt coloniale: les forêts de l'Afrique Occidentale Française. Paris: Académie des Sciences Coloniales. 244 pp.

Aubreville, A. (1959). Definitions physionomiques, structurales et ecologiques des forets claires en Afrique. In CSA Meeting of Specialists on Open Forests in Tropical Africa. Scientific Council for Africa South of the Sahara, London (pp. 81-88).

Awuku-bor, M.S., (1999). Conflicts and Harmonies in Land Use in the Kogyae Strict Nature Reserve. University of Ghana.

Ayivor, J. S., \& Ntiamoa-Baidu, Y. (2015). Assessing the socio-economic stressors of Ghana's only Strict Nature Reserve-Kogyae. Parks, 21(2), 85-100.

Ball, D. F. (1964). Loss-on-ignition as an estimate of organic matter and organic carbon in non-calcareous soils. Journal of Soil Science, 15, 84-92.

Baltzer, J. L., Davies, S. J., Bunyavejchewin, S. \& Noor, N. (2008). The role of desiccation tolerance in determining tree species distributions along the Malay-Thai Peninsula. Functional Ecology, 22, 221-231

Barlow, J., Gardner, T. a, Araujo, I.S., Avila-Pires, T.C., Bonaldo, a B., Costa, J.E., Esposito, M.C., Ferreira, L.V., Hawes, J., Hernandez, M.I.M., Hoogmoed, M.S., Leite, R.N., Lo-Man-Hung, N.F., Malcolm, J.R., Martins, M.B., Mestre, L. a M., Miranda-Santos, R., Nunes-Gutjahr, a L., Overal, W.L., Parry, L., Peters, S.L., Ribeiro-Junior, M. a, da Silva, M.N.F., da Silva Motta, C., Peres, C. a, (2007). Quantifying the biodiversity value of tropical primary, secondary, and plantation forests. Proc. Natl. Acad. Sci. U. S. A. 104, 18555-18560. http://dx.doi.org/10.1073/pnas.0703333104. 
Bartoń, K. (2013). MuMIn: multi-model inference. R package version 1.9.5. Batjes NH (1996)

Development of a world data set of soil water retention properties using pedotransfer rules. Geoderma, 71, 31-52.

Beckage, B., Platt, W. J., \& Gross, L. J. (2009). Vegetation, Fire, and Feedbacks: A Disturbance-Mediated Model of Savannas. The American Naturalist, 174(6), 805-818.

https://doi.org/10.1086/648458

Bégué, L. (1937). Contribution à l'étude de la végétation forestière de la Haute-Côte d'Ivoire. Paris, Librairie Larose, $126 \mathrm{p}$

Biddulph, J., \& Kellman, M. (1998). Fuels and fire at savanna-gallery forest boundaries in southeastern Venezuela. Journal of Tropical Ecology, 445-461.

Boko, M., Niang, I., Nyong, A., Vogel, C., Githeko, A., Medany, M., Osman-Elasha, B., Tabo, R., Yanda, P., 2007. Africa. In: Parry, M.L., Canziani, O.F., Palutikof, J.P., Van der Linden, P.J., Hanson, C.E. (Eds.), Climate Change (2007). Impacts, Adaptation and Vulnerability, Contribution of Working Group II to the Fourth Assessment Report of the Intergovernmental Panel on Climate Change. Cambridge University Press, Cambridge, pp. $433-467$.

Bonan, G. B. (2008). Forests and climate change: forcings, feedbacks, and the climate benefits of forests. Science, 320(5882), 1444-1449.

Bond, W. J. (2010). Do nutrient-poor soils inhibit development of forests? A nutrient stock analysis. Plant and Soil, 334, 47-60.

Bond, W. J., Woodward, F. I., \& Midgley, G. F. (2005). The global distribution of ecosystems in a world without fire. New Phytologist, 165(2), 525-538.

Boonman, C. C., van Langevelde, F., Oliveras, I., Couédon, J., Luijken, N., Martini, D. \& Veenendaal, E. M. (2020). On the importance of root traits in seedlings of tropical tree species. New Phytologist. 227, 156-167. doi: 10.1111/nph.16370. 
References

Borchert, R. (1994). Soil and stem water storage determine phenology and distribution of tropical dry forest trees. Ecology, 75(5), 1437-1449.

Borchert, R., Rivera, G., \& Hagnauer, W. (2002). Modification of Vegetative Phenology in a Tropical Semi-deciduous Forest by Abnormal Drought and Rain 1. Biotropica, 34(1), 27-39.

Bougma, A. B., Ouattara, K., Compaore, H., Nacro, H. B., Melenya, C., Mesele, S. A., Logah, V., Oladipupo, A. J., Veenendaal, E., \& Lloyd, J. (2020). Soil Aggregate Stability of Forest Islands and Adjacent Ecosystems in West Africa. SOIL Discussions, 1-15. https://doi.org/10.5194/soil-2019-87

Bowman, D.M.J.S. (2000). Australian Rainforests: Islands of Green in a Land of Fire. Cambridge: Cambridge University Press, 345 pp.

Bowman, D.M.J.S., Perry, G.L.W. \& Marston, J.B. (2015). Feedbacks and landscape-level vegetation dynamics. Trends in Ecology and Evolution, 30, 255-260.

Bowman, D.M.J.S., Walsh, A. and Milne, D.J. (2001). Forest expansion and grassland contraction within a eucalyptus savanna matrix between 1941 and 1994 at Litchfield national park in the Australian national park in the Australian monsoon tropics. Global Ecological Biogeography, 10, $535-548$.

Bradstock, R. A., Hammill, K. A., Collins, L., \& Price, O. (2010). Effects of weather, fuel and terrain on fire severity in topographically diverse landscapes of south-eastern Australia. Landscape Ecology, 25(4), 607-619.

Breiman, L. (2001). Random forests. Mach. Learn. 45, 5-32. http://dx.doi.org/10.1023/A:1010933404324.

Brooks, M. L., D'antonio, C. M., Richardson, D. M., Grace, J. B., Keeley, J. E., DiTomaso, J. M., ... \& Pyke, D. (2004). Effects of invasive alien plants on fire regimes. BioScience, 54(7), 677-688.

Brooks, T.M., Mittermeier, R.A., Mittermeier, C.G., Da Fonseca, G.A.B., Rylands, A.B., Konstant, W.R., Flick, P., Pilgrim, J., Oldfield, S., Magin, G., Hilton-Taylor, C. (2002). Habitat loss and 
References

extinction in the hotspots of biodiversity. Conserv. Biol. 16, 909-923.

http://dx.doi.org/10.1046/j.1523-1739.2002.00530.x.

Cardoso, A. W., Oliveras, I., Abernethy, K. A., Jeffery, K. J., Lehmann, D., Edzang Ndong, J., McGregor, I., Belcher, C. M., Bond, W. J., \& Malhi, Y. S. (2018). Grass species flammability, not biomass, drives changes in fire behavior at tropical forest-savanna transitions. Frontiers in Forests and Global Change, 1, 6.

Cardoso, A.W., Medina-Vega, J.A., Malhi, Y., Adu-Bredu, S., Ametsitsi, G.K.D., Djagbletey, G., Van Langevelde, F., Veenendaal, E. \& Oliveras, I. (2016). Winners and losers: tropical forest tree seedling survival across a West African forest-savanna transition. Ecology and Evolution, 6, 3417-3429. http://dx.doi.org/10.1002/ece3.2133.

Charles-Dominique, T., Midgley, G. F., Tomlinson, K. W., \& Bond, W. J. (2018). Steal the light: shade vs fire adapted vegetation in forest-savanna mosaics. New Phytologist, 218(4), 1419-1429. https://doi.org/10.1111/nph.15117

Charter, J.R. \& Keay, R.J. (1960). Assessment of the Olokemeji fire-control experiment (investigation 254) 28 years after institution. Nigerian Forestry Information Bulletin, 3, 1-32.

Chave, J., Andalo, C., Brown, S., Cairns, M.A., Chambers, J.Q., Eamus, D., Fölster, H., Fromard, F., Higuchi, N., Kira, T., Lescure, J.P., Nelson, B.W., Ogawa, H., Puig, H., Riéra, B., Yamakura, T., (2005). Tree allometry and improved estimation of carbon stocks and balance in tropical forests. Oecologia, 145, 87-99. http://dx.doi.org/10. 1007/s00442-005-0100-x.

Chave, J., Coomes, D.A., Jansen, S., Lewis, S.L., Swenson, N.G., Zanne, A.E., (2009).Towards a worldwide wood economies spectrum. Ecol. Letters, 12, 351-366.

Chave, J., Réjou-Méchain, M., Búrquez, A., Chidumayo, E., Colgan, M.S., Delitti, W.B., Duque, A., Eid, T., Fearnside, P.M., Goodman, R.C., Henry, M. et al. (2014). Improved allometric models to estimate the aboveground biomass of tropical trees. Global Change Biology, 20, 3177-3190.

Clayton, W.D. (1958). Secondary vegetation and the transition to savanna near Ibadan, Nigeria. Journal of Ecology, 46, 217-238. 


\section{References}

Cochrane, M. A., \& Laurance, W. F. (2002). Fire as a large-scale edge effect in Amazonian forests. Journal of Tropical Ecology, 311-325.

Cochrane, M. A., \& Schulze, M. D. (1998). Forest fires in the Brazilian Amazon. Conservation Biology, 12(5), $948-950$.

Cochrane, M. A., \& Schulze, M. D. (1999). Fire as a Recurrent Event in Tropical Forests of the Eastern Amazon: Effects on Forest Structure, Biomass, and Species Composition 1. Biotropica, 31(1), 2-16.

Cochrane, M. A., Alencar, A., Schulze, M. D., Souza, C. M., Nepstad, D. C., Lefebvre, P., \& Davidson, E. A. (1999). Positive feedbacks in the fire dynamic of closed canopy tropical forests. Science, 284(5421), 1832-1835

Coetzee, B., Meulen, F., Zwanziger, S., Gonsalves, P., and Weisser, P. (1976). A phytosociological classification of the Nylsvley Nature Reserve, Bothalia, 12, 137-160,

Cole, M. (1986). The savannas: Biogeography and geobotany. London, UK: Academic Press.

Coomes, D. A., \& Grubb, P. J. (1996). Amazonian caatinga and related communities at La Esmeralda, Venezuela: forest structure, physiognomy and floristics, and control by soil factors. Vegetatio, 122(2), 167-191.

Couteron, P., \& Kokou, K. (1997). Woody vegetation spatial patterns in a semiarid savanna of Burkina Faso, West Africa. Plant Ecology, 132, 211-227.

Cuni-Sanchez, A., White, L.J., Calders, K., Jeffery, K.J., Abernethy, K., Burt, A., Disney, M., Gilpin, M., Gomez-Dans, J.L. \& Lewis, S.L, (2016). African savanna-forest boundary dynamics: a 20year study. PLOS ONE, 11, e0156934.

Dantas, V. D. L., Batalha, M. A., França, H., \& Pausas, J. G. (2015). Resource availability shapes firefiltered savannas. Journal of Vegetation Science, 26(2), 395-403.

Dantas, V. L., Batalha, M. A., \& Pausas, J. G. (2013). Fire drives functional thresholds on the savannaforest transition, Ecology, 94, 2454-2463 
De Amorim, I.L., Sampaio, E.V.S.B., de Lima, Araújo E. (2005). Flora e estrutura da vegetação arbustivoarbórea de uma área de caatinga do Seridó, RN, Brasil. Acta Botanica Brasilica, 19:615-623.

De Bie, S., Ketner, P., Paasse, M., \& Geerling, C. (1998). Woody plant phenology in the West Africa savanna. Journal of Biogeography, 25(5), 883-900.

De Rouw, A. (1991). The invasion of Chromolaena odorata (L.) King \& Robinson (ex Eupatorium odoratum), and competition with the native flora, in a rain forest zone, south-west Cote d'Ivoire. Journal of Biogeography, 13-23.

Dexter, K. G., Pennington, R. T., Oliveira-Filho, A. T., Bueno, M. L., Silva de Miranda, P. L., \& Neves, D. M. (2018). Inserting Tropical Dry Forests into the Discussion on Biome Transitions in the Tropics. Frontiers in Ecology and Evolution, 6. https://doi.org/10.3389/fevo.2018.00104

Di Minin, E., Toivonen, T., (2015). Global protected area expansion: creating more than paper parks. Bioscience, 65, 637-638. http://dx.doi.org/10.1093/biosci/biv064.

Domingues, T.F., Meir, P., Feldpausch, T.R., Saiz, G., Veenendaal, E.M., Schrodt, F., Bird, M., Djagbletey, G., Hien, F., Compaore, H., Diallo, A., Grace, J., Lloyd, J., (2010). Colimitation of photosynthetic capacity by nitrogen and phosphorus in West Africa woodlands. Plant Cell Environ. 33, 959-980. http://dx.doi.org/10.1111/j.1365-3040.2010.02119.x.

Dowling, A.J., Webb, A.A. \& Scanlan, J.C. (1986). Surface soil chemical and physical patterns in a Brigalow-Dawson gum forest, central Queensland. Australian Journal of Ecology, 11, 155-162.

Dubois, M., Gilles, K.A., Hamilton, J.K., Rebers, P.T. \& Smith, F. (1956). Colorimetric method for determination of sugars and related substances. Analytical Chemistry, 28, 350-356.

Duranceau, M., Ghashghaie, J., Badeck, F., Deleens, E. \& Cornic, G. (1999). $813 \mathrm{C}$ of $\mathrm{CO}_{2}$ respired in the dark in relation to $\delta 13 \mathrm{C}$ of leaf carbohydrates in Phaseolus vulgaris L. under progressive drought. Plant Cell and Environment, 22, 515-523.

Eamus, D. \& Prior, L. (2001). Ecophysiology of trees of seasonally dry tropics: comparisons among phenologies. Advances in Ecological Research, 32, 113-197. 
References

Eldridge, D.J., Bowker, M.A., Maestre, F.T., Roger, E., Reynolds, J.F., Whitford, W.G., (2011). Impacts of shrub encroachment on ecosystem structure and functioning: towards a global synthesis. Ecology Letters, 14, 709-722. http://dx.doi.org/10.1111/j.1461-0248.2011.01630.x

Engelbrecht, B. M. J., Comita, L. S., Condit, R., Kursar, T. A., Tyree, M. T., Turner, B. L., \& Hubbell, S. P. (2007). Drought sensitivity shapes species distribution patterns in tropical forests. Nature, 447(7140), 80-82. https://doi.org/10.1038/nature05747

Eriksson, O., Cousins, S. A. O., \& Bruun, H. H. (2002). Land-use history and fragmentation of traditionally managed grasslands in Scandinavia. Journal of Vegetation Science, 13(5), 743-748.

Fauset, S., Baker, T. R., Lewis, S. L., Feldpausch, T. R., Affum-Baffoe, K., Foli, E. G., Hamer, K. C., \& Swaine, M. D. (2012). Drought-induced shifts in the floristic and functional composition of tropical forests in Ghana. Ecology Letters, 15(10), 1120-1129. https://doi.org/10.1111/j.14610248.2012.01834.x

Fensham, R.J., Fairfax, R.J., Butler, D.W. \& Bowman, D.M.J.S. (2003). Effects of fire and drought in a tropical eucalypt savanna colonized by rain forest. Journal of Biogeography, 30, 1405-1414.

Figueiredo, C., (2007). From Paper Parks to Real Conservation: Case Studies of National Park Management Effectiveness in Brazil. The Ohio State University, Columbus.

Finney, M. A., Cohen, J. D., McAllister, S. S., \& Jolly, W. M. (2013). On the need for a theory of wildland fire spread. International Journal of Wildland Fire, 22(1), 25. https://doi.org/10.1071/wf11117

Forman, R. T., \& Godron, M. (1986). Landscape ecology. John Wiley \& Sons. New York, 4, 22-28.

FRA, (2010). Global Forest Resources Assessment Main Report, FAO Forestry Paper 163. Food and Agriculture Organization of the United Nations, Rome, Italy.

Frazer, G.W., Canham, C., \& Lertzman, K. (1999). Gap Light Analyzer (GLA), Version 2.0: Imaging software to extract canopy structure and gap light transmission indices from true-colour fisheye photographs, users manual and program documentation. Burnaby, BC: Simon Fraser University and Millbrook, NY: The Institute of Ecosystem Studies. 
Furley, P. A. (1999). The nature and diversity of neotropical savanna vegetation with particular reference to the Brazilian cerrados. Global Ecology and Biogeography, 8(3-4), 223-241.

Furley, P. A., \& Ratter, J. A. (1988). Soil resources and plant communities of the central Brazilian cerrado and their development. Journal of Biogeography, 97-108.

Furley, P.A., Proctor, J., \& Ratter, J.A. (1992). Nature and Dynamics of Forest-Savanna Boundaries. London: Chapman \& Hall.

Gashaw, M., Michelsen, A., Friis, I., Jensen, M., Demissew, S., \& Woldu, Z. (2002). Post-fire regeneration strategies and tree bark resistance to heating in frequently burning tropical savanna woodlands and grasslands in Ethiopia. Nordic Journal of Botany, 22(1), 19-33.

Gee, G.W. \& Bauder, J.W. (1986). Particle-size analysis. In Klute A(ed.), Methods of Soil Analysis. Part 1 Physical and Mineralogical Methods. Second Edition. Agronomy No. 9, Part 1. Madison, WI: ASA-SSSA, pp. 383-411.

Gignoux, J., Konate, S., Lahoreau, G., Le Roux, X., \& Simioni, G. (2016). Allocation strategies of savanna and forest tree seedlings in response to fire and shading: outcomes of a field experiment. Scientific Reports, 6, 38838 .

Gignoux, J., Lahoreau, G., Julliard, R., \& Barot, S. (2009). Establishment and early persistence of tree seedlings in an annually burned savanna. Journal of Ecology, 97, 484-495.

Gillman, G.P. (1979). A proposed method for the measurement of exchange properties of highly weathered soils. Australian Journal of Soil Research, 17, 129-139.

Giovanni (2015). Giovanni - Interactive Visualization and Analysis (WWW Document. URL). http:// disc.sci.gsfc.nasa.gov/giovanni, Accessed date: 1 January 2015.

Goetze, D., Horsch, B. \& Porembski, S. (2006). Dynamics of forest-savanna mosaics in north-eastern Ivory Coast from 1954 to 2002. Journal of Biogeography, 33, 653-664.

Gomes, L., Miranda, H. S., Silvério, D. V, \& Bustamante, M. M. C. (2020). Effects and behaviour of experimental fires in grasslands, savannas, and forests of the Brazilian Cerrado. Forest Ecology and Management, 458, 117804. 


\section{References}

Gond, V., Fayolle, A., Pennec, A., Cornu, G., Mayaux, P., Camberlin, P., Doumenge, C., Fauvet, N., \& Gourlet-Fleury, S. (2013). Vegetation structure and greenness in Central Africa from Modis multi-temporal data. Philosophical Transactions of the Royal Society B: Biological Sciences, 368(1625). https://doi.org/10.1098/rstb.2012.0309

Gonzalez, P., (2001). Desertification and a shift of forest species in the west African Sahel. Clim. Res., 17, 217-228. http://dx.doi.org/10.3354/cr017217.

Good, S. P., \& Caylor, K. K. (2011). Climatological determinants of woody cover in Africa. Proceedings of the National Academy of Sciences, 108(12), 4902-4907.

Goodland, R., \& Pollard, R. (1973). The Brazilian cerrado vegetation: a fertility gradient. Journal of Ecology, 61, 219-224.

Grace, J., José, J. S., Meir, P., Miranda, H. S., \& Montes, R. A. (2006). Productivity and carbon fluxes of tropical savannas. Journal of Biogeography, 33(3), 387-400.

Gray EF and Bond WJ (2015). Soil nutrients in an African forest/savanna mosaic: drivers or driven? South African Journal of Botany, 101, 66-72.

Green, J.M.H., Larrosa, C., Burgess, N.D., Balmford, A., Johnston, A., Mbilinyi, B.P., Platts, P.J., Coad, L., (2013). Deforestation in an African biodiversity hotspot: extent, variation and the effectiveness of protected areas. Biol. Conserv. 164, 62-72. http://dx.doi.org/10.1016/j.biocon.2013.04.016.

Hagan, J.E., (1998). The Kogyae Strict Nature Reserve. (The World Bank/WBI's CBNRM Initiative. The World Bank/WBI's CBNRM Initiative).

Hall, J. B., \& Swaine, M. D. (1976). Classification and Ecology of Closed-Canopy Forest in Ghana. Journal of Ecology, 64(3), 913-951. https://doi.org/10.2307/2258816

Hall, J.S., Swain, M.D., (1981). Distribution and Ecology of Vascular Plants in a Tropical Rain Forest Vegetation in Ghana. Dr W. Junk. Publishershttp://dx.doi.org/10.1007/978-94-009-8650-3.

Hamilton, A. C., \& Taylor, D. (1991). History of climate and forests in tropical Africa during the last 8 million years. Climatic Change, 19(1-2), 65-78. https://doi.org/10.1007/bf00142215 
Hansen, C., Treue, T., (2008). Assessing illegal logging in Ghana. Int. For. Rev., 10, 573-590. http://dx.doi.org/10.1505/ifor.10.4.573.

Hansen, M.C., Potapov, P.V., Moore, R., Hancher, M., Turubanova, S.A., Tyukavina, A., Thau, D., Stehman, S.V., Goetz, S.J., Loveland, T.R., Kommareddy, A., Egorov, A., Chini, L., Justice, C.O., Townshend, J.R.G., (2013). High-resolution global maps of 21st-century Forest cover change. Science, 342 (80), 850-853. http://dx.doi.org/10. 1126/science.1244693.

Hartemink, A.E., \& Huting, J. (2008). Land cover, extent, and properties of Arenosols in Southern Africa. Arid Land Research and Management, 22, 134-147.

Hartter, J., Ryan, S.J., MacKenzie, C.A., Goldman, A., Dowhaniuk, N., Palace, M., Diem, J.E., Chapman, C.A., (2014). Now there is no land: a story of ethnic migration in a protected area landscape in western Uganda. Popul. Environ. 36, 452-479. http://dx.doi.org/10.1007/s11111-0140227-y.

Hawthorne, W.D. (1994). Fire Damage and Forest Regeneration in Ghana: Forestry Inventory and Management Project of the Ghana Forestry Department. ODA Forestry Series Natural Resources and Environment Department, Overseas Development Administration (ODA).

Hawthorne, W.D. (1995). Ecological Profiles of Ghanaian Forest Trees. Oxford: Oxford Forestry Institute, 345 pP.

Hawthorne, W.D., \& Jongkind, C.C. (2006). Woody Plants of Western African Forests: A Guide to the Forest Trees, Shrubs and Lianes from Senegal to Ghana. Richmond: Royal Botanic Gardens, Kew.

Hawthorne, W.D., Abu-Juam, M., (1995). State of the Reserved Forests. In: Hawthorne, W., Abu-Juam, M. (Eds.), Forest Protection in Ghana: With Particular Reference to Vegetation and Plant Species. IUCN, Cambridge, UK, pp. 16-20.

Hennenberg, K.J., Fischer, F., Kouadio, K., Goetze, D., Orthmann, B., Linsenmair, K.E., Jeltsch, F., \& Porembski, S. (2006). Phytomass and fire occurrence along forest-savanna transects in the Comoé National Park, Ivory Coast. Journal of Tropical Ecology, 22, 303-311. 


\section{References}

Hennenberg, K.J., Goetze, D., Minden, V., Traore, D., \& Porembski, S. (2005). Size-class distribution of Anogeissus leiocarpus (Combretaceae) along forest-savanna ecotones in northern Ivory Coast. Journal of Tropical Ecology, 21, 273-281.

Hiernaux, P., Diarra, L., Trichon, V., Mougin, E., Soumaguel, N., \& Baup, F. (2009). Woody plant population dynamics in response to climate changes from 1984 to 2006 in Sahel (Gourma, Mali). Journal of Hydrology, 375, 103-113.

Higgins, S.I., Bond, W.J., February, E.C., Bronn, A., Euston-Brown, D.I., Enslin, B., Govender, N., Rademan, L., Regan, S., Potgieter, A.L.F., Scheiter, S., Sowry, R., Trollope, L., \& Trollope, W.S.W. (2007). Effects of four decades of fire manipulation on woody vegetation structure in savanna. Ecology, 88,1119-1125.

Hirota, M., Holmgren, M., Van Nes, E.H., \& Scheffer, M. (2011). Global resilience of tropical forest and savanna to critical transitions. Science, 334, 232-235.

Hirota, M., Nobre, C., Oyama, M. D., \& Bustamante, M. M. C. (2010). The climatic sensitivity of the forest, savanna and forest-savanna transition in tropical South America. New Pbytologist, 187(3), 707-719. https://doi.org/10.1111/j.1469-8137.2010.03352.x

Hoare, A., Wellesley, L., (2014). Illegal Logging and Related Trade the Response in Cameroon. A Chatham House Assessment, Chatham House, London, UK.

Hoffmann, W.A., Geiger, E.L., Gotsch, S.G., Rossatto, D.R., Silva, L.C.R., Lau, O.L., Haridasan, M., \& Franco, A.C. (2012a). Ecological thresholds at the savanna-forest boundary: how plant traits, resources and fire govern the distribution of tropical biomes. Ecology Letters, 15, 759-768.

Hoffmann, W.A., Jaconis, S.Y., McKinley, K.L., Geiger. E.L., Gotsch, S.G., \& Franco, A.C. (2012b). Fuels or microclimate? Understanding the drivers of fire feedbacks at savanna-forest boundaries. Austral Ecology, 37, 634-643.

Hoffmann, W.A., Orthen, B., \& Franco, A.C. (2004). Constraints to seedling success of savanna and forest trees across the savanna-forest boundary. Oecologia, 140, 252-260. 
Honu, Y. A. K., \& Dang, Q. L. (2000). Responses of tree seedlings to the removal of Chromolaena odorata Linn. in a degraded forest in Ghana. Forest Ecology and Management, 137(1-3), 75-82. https://doi.org/10.1016/S0378-1127(99)00315-1

Hopkins, B. (1965). Forest and Savanna. London: Heinemann. 112 pp.

Hopkins, B. (1992). Ecological processes at the forest-savanna boundaries. Nature and dynamics of forest-savanna boundaries (ed. by P.A. Furley, J. Proctor and J.A. Ratter), pp. 21- 33. Chapman \& Hall, London.

Horion, S., Fensholt, R., Tagesson, T., Ehammer, A., (2014). Using earth observation-based dry season NDVI trends for assessment of changes in tree cover in the Sahel. Int. J. Remote Sens. 35, 2493-2515. http://dx.doi.org/10.1080/01431161.2014.883104.

Hosonuma, N., Herold, M., De Sy, V., De Fries, R.S., Brockhaus, M., Verchot, L., Angelsen, A., Romijn, E., (2012). An assessment of deforestation and forest degradation drivers in developing countries. Environ. Res. Lett., 7, 44009. http://dx.doi.org/10.1088/1748-9326/7/4/044009.

Hovestadt, T., Yao, P., \& Linsenmair, K.E .(1999). Seed dispersal mechanisms and the vegetation of forest islands in a West African forest-savanna mosaic (Comoé National Park, Ivory Coast). Plant Ecology, 144, 1-25.

Huttel, C.H. (1975). Récherches sur l'écosystème de la forêt subéquatoriale de basse Côte d'Ivoire. IV. Estimation du bilan hydrique. Terre Vie, 29, 192-202.

Hyndman, R.J., \& Fan, Y. (1996). Sample quantiles in statistical packages. American Statistician, 50, 361365.

Ibanez, T., Hély, C., \& Gaucherel, C. (2013). Sharp transitions in microclimatic conditions between savanna and forest in New Caledonia: Insights into the vulnerability of forest edges to fire. Austral Ecology, 38(6), 680-687.

Infield, M., (2001). Cultural Values: a forgotten strategy for building community support for protected areas in Africa. Conserv. Biol. 15, 800-802. http://dx.doi.org/10.2307/3061464. 
References

Issifu, H. (2020). Tree seedling recruitment dynamics in forest-savanna transitions. Trait responses to vegetation controls mediate differential seedling establishment success of tree functional types. PhD Thesis, Wageningen University, Wageningen, the Netherlands, 308pp.

Issifu, H., Ametsitsi, G. K. D., de Vries, L. J., Djagbletey, G. D., Adu-Bredu, S., Vergeer, P., van Langevelde, F., \& Veenendaal, E. (2019). Variation in vegetation cover and seedling performance of tree species in a forest-savanna ecotone. Journal of Tropical Ecology, 35, 74-82. https://doi.org/10.1017/S0266467418000469

IUSS (International Union of Soil Science) Working Group WRB (2006). World reference base for soil resources 2006: A framework for international classification, correlation and communication. World Soil Resources Report 103. Rome: FAO.

Janssen, T.A.J., Ametsitsi, G.K.J., Collins, M., Adu-Bredu, S., Oliveras, I., Edward, T.A., Mitchard, E.T.A., \& Veenendaal, E.M. (2018). Extending the baseline of tropical dry forest loss in Ghana (1984-2015) reveals drivers of major deforestation inside a protected area. Biological Conservation, 218, 163-172.

Jeffery, K.J., Korte, L., Palla, F., White, L.J.T., \& Abernethy, K.A. (2014). Fire management in a changing landscape: a case study from Lope National Park. Parks, 20, 35-48.

Jhariya, M. K., Bargali, S. S., Swamy, S. L., Kittur, B., Kiran, B., \& Pawar, G. V. (2014). Impact of forest fire on biomass and carbon storage pattern of tropical deciduous forests in Bhoramdeo Wildlife Sanctuary, Chhattisgarh. International Journal of Ecology and Environmental Sciences, 40(1), $57-74$.

Joppa, L.N., Loarie, S.R., Pimm, S.L., (2008). On the protection of “protected areas". Proc. Natl. Acad. Sci. 105, 6673-6678. http://dx.doi.org/10.1073/pnas.0802471105.

Justiniano, M. J., \& Fredericksen, T. S. (2000). Phenology of Tree Species in Bolivian Dry Forests. Biotropica, 32(2), 276-281. https://doi.org/10.1111/j.1744-7429.2000.tb00470.x

Kauffman, J. B., \& Uhl, C. (1990). Interactions of anthropogenic activities, fire, and rain forests in the Amazon Basin. In: Fire in the tropical biota Springer, pp. 117-134. 
Keay, R.W.J. (1960). An Example of Northern Guinea Zone Vegetation in Nigeria. Federal Department of Forest Research, Nigeria.

Keay, R.W.J. (1989). Trees of Nigeria. A revised version of Nigerian Trees $(1960,1964)$ by R.J.W. Keay, C.F.A. Onochie and D.P. Stanfield. Clarendon Press, Oxford, United Kingdom.

Kellman, M. (1985). Forest seedling establishment in Neotropical savanna: transplant experiment with Xylopia frutescens and Calophyllum brasiliense. Journal of Biogeography, 12, 373-379.

Koh, L.P., Sodhi, N.S., (2010). Conserving Southeast Asia's imperiled biodiversity: scientific, management, and policy challenges. Biodivers. Conserv., 19, 913-917. http://dx.doi.org/10.1007/s10531010-9818-9

Kwesiga, F., \& Grace, J. (1986). The role of the red/far-red ratio in the response of tropical tree seedlings to shade. Annals of Botany, 57, 283-290.

Kyereh, B., Ninnoni, R., \& Agyeman, V.K., (2007). Degraded forests are more susceptible to forest fires: some possible ecological explanations. J. Sci. Technol. 26, 40-47.

Lambin, E.F., Turner, B.L., Geist, H.J., Agbola, S.B., Angelsen, A., Bruce, J.W., Coomes, O.T., Dirzo, R., Fischer, G., Folke, C., George, P.S., Homewood, K., Imbernon, J., Leemans, R., Li, X., Moran, E.F., Mortimore, M., Ramakrishnan, P.S., Richards, J.F., Skånes, H., Steffen, W., Stone, G.D., Svedin, U., Veldkamp, T.A., Vogel, C., Xu, J., (2001). The causes of land-use and land-cover change: moving beyond the myths. Glob. Environ. Chang., 11, 261-269. http://dx.doi.org/10.1016/S0959-3780(01)00007-3.

Lasslop, G., Brovkin, V., Reick, C. H., Bathiany, S., \& Kloster, S. (2016). Multiple stable states of tree cover in a global land surface model due to a fire-vegetation feedback. Geophysical Research Letters, 43(12), 6324-6331. https://doi.org/10.1002/2016gl069365

Lasslop, G., Moeller, T., D'Onofrio, D., Hantson, S., \& Kloster, S. (2018). Tropical climate-vegetation-fire relationships: multivariate evaluation of the land surface model JSBACH. Biogeosciences, 15, 5969-5989. 


\section{References}

Lehmann, C. E. R., Archibald, S. A., Hoffmann, W. A., \& Bond, W. J. (2011). Deciphering the distribution of the savanna biome. New Phytologist, 191(1), 197-209. https://doi.org/10.1111/j.1469-8137.2011.03689.x

Lehmann, C.E.R., Anderson, T.M., Sankaran, M., Higgins, S.I., Archibald, S., Hoffmann, W.A., Hanan, N.P., Williams, R.J., Fensham, R.J., Felfili, J., Hutley, L.B., Ratnam. J., San Jose, J., Montes, R., Franklin, D., Russell-Smith, J., Ryan, C.M., Durigan, G., Hiernaux, P., Haidar, R., Bowman, D.M.J.S., \& Bond, W.J. (2014). Savanna vegetation-fire-climate relationships differ among continents. Science 343, 548-552.

Liao, Z. Y., Scheepens, J. F., Li, W. T., Wang, R. F., Zheng, Y. L., \& Feng, Y. L. (2019). Biomass reallocation and increased plasticity might contribute to successful invasion of Chromolaena odorata. Flora: Morphology, Distribution, Functional Ecology of Plants, 256(March), 79-84. https://doi.org/10.1016/j.flora.2019.05.004

Little, J. K., Prior, L. D., Williamson, G. J., Williams, S. E., \& Bowman, D. M. J. S. (2012). Fire weather risk differs across rain forest—savanna boundaries in the humid tropics of north-eastern Australia. Austral Ecology, 37(8), 915-925.

Lloyd, J., \& Veenendaal, E.M. (2016). Are fire mediated feedbacks burning out of control? Biogeosciences Discussions. https://doi.org/10.5194/bg-2015-660.

Lloyd, J., Bird, M.I., Vellen, L., Miranda, A.C., Veenendaal, E.M., Djagbletey, G., Miranda, H.S., Cook, G., \& Farquhar, G.D. (2008). Contributions of woody and herbaceous vegetation to tropical savanna ecosystem productivity: a quasi-global estimate. Tree Physiology 28, 451-468. http://dx.doi.org/10.1093/treephys/28.3.451.

Lloyd, J., Domingues, T.F., Schrodt, F., Ishida, F.Y., Feldpausch, T.R., Saiz, G., Quesada, C.A., Schwarz, M., Torello-Raventos, M., Gilpin, M., Marimon, B.S., Marimon-Junior, B.H., Ratter, J.A., Grace, J., Nardoto, G.B., Veenendaal, E., Arroyo, L., Villarroel, D., Killeen, T.J., Steininger, M., \& Phillips, O.L. (2015). Edaphic, structural and physiological contrasts across Amazon Basin forest-savanna ecotones suggest a role for potassium as a key modulator of tropical woody vegetation structure and function. Biogeosciences, 12, 6529-6571. 
Louppe, D., Oattara, N., \& Coulibaly, A. (1995). The effects of brush fires on vegetation: the Aubreville fire plots after 60 years. The Commonnealth Forestry Review, 288-292.

Lupo, K.D., Schmitt, D.N., Kiahtipes, C.A., Ndanga, J.P., Young, D.C., Simiti, B., (2015). On intensive late Holocene iron mining and production in the northern Congo Basin and the environmental consequences associated with metallurgy in central Africa. PLoS One, 10, e0132632. http://dx.doi.org/10.1371/journal.pone.0132632.

Maley, J. (1996). The African rain forest - main characteristics of changes in vegetation and climate from the Upper Cretaceous to the Quaternary. Proceedings of the Royal Society of Edinburgh. Section B. Biological Sciences, 104, 31-73. https://doi.org/10.1017/s0269727000006114

Markham, R.H., \& Babbedge, A.J. (1979). Soil and vegetation catenas on the forest-savanna boundary in Ghana. Biotropica, 11, 224-234.

Marsh, C. W. (1978). Tree Phenology in a Gallery Forest on the Tana River, Kenya. East African Agricultural and Forestry Journal, 43(4), 305-316. https://doi.org/10.1080/00128325.1978.11662915

Maurin, O., Gere, J., van der Bank, M., \& Boatwright, J.S. (2017). The inclusion of Anogeissus, Buchenavia and Pteleopsis in Terminalia (Combretaceae:Terminaliinae). Botanical Journal of the Linnean Society, 184, 312-325.

McCook, L.J. (1994). Understanding ecological community succession: causal models and theories, a review. Vegetatio, 110, 115-147.

McSweeney, C., Lizcano, G., New, M., Lu, X. (2010). NDP climate change country profiles: Ghana (WWWW Document. URL). http://ncsp.undp.org/sites/default/files/Ghana. oxford.report.pdf.

Menaut, J.C. (1977). Evolution of plot protected from fire since 13 years in a Guinea savanna of Ivory Coast. (Panama), 2, 541-558.

Mertens, B., \& Lambin, E.F. (2000). Land-cover-change trajectories in southern Cameroon. Ann. Assoc. Am. Geogr. 90, 467-494. http://dx.doi.org/10.1111/0004-5608.00205. 
References

Millar, C.I., Stephenson, N.L., Stephens, S.L., (2007). Climate change and forest of the future: managing in the face of uncertanity. Ecol. Appl., 17, 2145-2151. http://dx.doi.org/10.1890/06-1715.1.

Mitchard, E.T.A., \& Flintrop, C.M. (2013). Woody encroachment and forest degradation in sub-Saharan Africa's woodlands and savannas 1982-2006. Philos. Trans. R. Soc. B Biol. Sci. 368, 20120406. http://dx.doi.org/10.1098/rstb.2012.0406.

Mitchard, E.T.A., Saatchi, S.S., Gerard, F.F., Lewis, S.L., \& Meir, P. (2009). Measuring woody encroachment along a forest-savanna boundary in Central Africa. Earth Interactions, 13, 1-29. http://dx.doi.org/10.1175/2009EI278.1.

Mitchard, E.T.A., Saatchi, S.S., Lewis, S.L., Feldpausch, T.R., Woodhouse, I.H., Sonké, B., Rowland, C., \& Meir, P. (2011). Measuring biomass changes due to woody encroachment and deforestation/degradation in a forest-savanna boundary region of central Africa using multitemporal L-band radar backscatter. Remote Sensing of Environment, 115, 2861-2873.

Moore, A.E., \& Attwell, C.A.M. (1999). Geological controls on the distribution of woody vegetation in the central Kalahari, Botswana. South African Journal of Geology, 102, 350-362.

Moore, S., Adu-Bredu, S., Duah-Gyamfi, A., Addo-Danso, S.D., Ibrahim, F., Mbou, A.T., de Grandcourt, A., Valentini, R., Nicolini, G., Djagbletey, G., Owusu-Afriyie, K., Gvozdevaite, A., Oliveras, I., Ruiz-Jaen, M.C., \& Malhi, Y. (2017). Forest biomass, productivity and carbon cycling along a rainfall gradient in West Africa. Glob. Chang. Biol. http://dx.doi.org/10.1111/gcb.13907.

Murdoch, G., Colborne, G., Olomu, E. I., \& Odugbesan, E. M. (1976). Soils of the Western State savanna in Nigeria. Volume 1. The environment. Land Resource Study (UK). No. 23.

Murphy, B. P., \& Bowman, D. M. J. S. (2012). What controls the distribution of tropical forest and savanna? Ecology Letters, 15(7), 748-758. https://doi.org/10.1111/j.1461-0248.2012.01771.x

Murphy, P. G., \& Lugo, A. E. (1986). Ecology of Tropical Dry Forest. Annual Review of Ecology and Systematics, 17(1), 67-88. https://doi.org/10.1146/annurev.es.17.110186.000435 
Mutch, R. W. (1970). Wildland Fires and Ecosystems--A Hypothesis. Ecology, 51(6), 1046-1051.

https://doi.org/10.2307/1933631

Nangendo, G. (2005). Changing Forest-Woodland-Savanna Mosaics in Uganda: With Implication for Conservation.

Wageningen, Wageningen University, 2005. ITC Dissertation 123, Netherlands.

Nansen, C, Tchabi, A., \& Meikle, W.G. (2001). Successional sequence of forest types in a disturbed dry forest reserve in southern Benin, West Africa. Journal of Tropical Ecology, 17, 525-539.

Newberry, B. M., Power, C. R., Abreu, R. C., Durigan, G., Rossatto, D. R., \& Hoffmann, W. A. (2020). Flammability thresholds or flammability gradients? Determinants of fire across savannaforest transitions. New Phytologist.

Norris, K., Asase, A., Collen, B., Gockowski, J., Mason, J., Phalan, B., Wade, A., (2010). Biodiversity in a forest-agriculture mosaic-the changing face of west African rainforests. Biol. Conserv. 143, $2341-2350$.

Novozamsky, I., Houba, V.J.G., Van Eck, R., \& Van Vark, W. (1983). A novel digestion technique for multi-element plant analysis. Communications in Soil Science and Plant Analysis, 14, 239-248.

O’Brien, M.J., Leuzinger, S., Philipson, C.D., Tay, J., \& Hector, A. (2014). Drought survival of tropical tree seedlings enhanced by non-structural carbohydrate levels. Nature Climate Change, 4, 710_ 714.

Oduro-Ofori, E., Ocloo, K. A., Peprah, C., \& Effah, G. (2015). Assessing Natural Resource Use Conflicts in the Kogyae Strict Nature Reserve, Ghana. Environment and Natural Resources Research, 5(3). https://doi.org/10.5539/enrr.v5n3p56

Ofori, B.D., Nukpezah, D., Ayivor, J.S., Lawson, E.T., Gordon, C., (2014). Leadership, local knowledge and water management: lessons from fringe communities of the Kogyae strict nature reserve, Ghana. Int. J. Dev. Sustain. 3, 353-370.

Okali, D.U.U., \& Dodoo, G. (1973). Seedling growth and transpiration of two west African mahogany species in relation to water stress and rooting medium. Journal of Ecology, 61, 421-438. 


\section{References}

Oliveira, L.B., Ribeiro, M.R., Jacomine, P.K.T., Rodrigues, J.J.V., \& Marques, F.A. (2002). Funções de pedotransferência para predição da umidade retida a potenciais específicosem solos do estado de Pernambuco. Revista Brasiliera Ciencias do Solo, 26, 315-323.

Oliveras, I.,\& Malhi, Y. (2016). Many shades of green: the dynamic tropical forest-savannah transition zones. Philosophical Transactions of the Royal Society B, Biological Sciences, 371, 20150308.

Olsen, S.R., Cole, C.V., Watanabe, F.S., \& Dean, L.A. (1954). Estimation of available phosphorus in soils by extraction with sodium bicarbonate. Washington, DC: U.S. Department of Agriculture, Circular 939.

Owusu, K., \& Waylen, P. (2009). Trends in spatio-temporal variability in annual rainfall in Ghana (19512000). Weather, 64, 115-120.

Owusu-Afriyie, K. (2008). Forest fire incidence, damage and control measures in Ghana (Doctoral dissertation, University of Aberdeen).

Paine, C. E. T., Stahl, C., Courtois, E. A., Patiño, S., Sarmiento, C., \& Baraloto, C. (2010). Functional explanations for variation in bark thickness in tropical rain forest trees. Functional Ecology, 24(6), 1202-1210.

Paré, S., (2008). Land Use dynamics, tree diversity and local perception of dry forest decline in southern Burkina Faso, West Africa. For. Genet. Sveriges lantbruksuniv. http://pub.epsilon.slu.se/1843/1/Thesis_summary-Pare_Souleymane.pdf.

Parolin, P., Lucas, C., Piedade, M. T. F., \& Wittmann, F. (2010). Drought responses of flood-tolerant trees in Amazonian floodplains. Annals of Botany, 105(1), 129-139.

Pausas, J. G. (2015). Bark thickness and fire regime. Functional Ecology, 29(3), 315-327. https://doi.org/10.1111/1365-2435.12372

Pellegrini, A.F.A., Franco, A.C., \& Hoffmann, W.A. (2016). Shifts in functional traits elevate risk of firedriven tree dieback in tropical savanna and forest biomes. Global Change Biology, 22, 12351243. 
Pinard, M. A., \& Huffman, J. (1997). Fire resistance and bark properties of trees in a seasonally dry forest in eastern Bolivia. Journal of Tropical Ecology, 13(5), 727-740. https://doi.org/10.1017/s0266467400010890

Poorter, L., \& Markesteijn, L. (2008). Seedling traits determine drought tolerance of tropical tree species. Biotropica, 40(3), 321-331. https://doi.org/10.1111/j.1744-7429.2007.00380.x

Poulter, B., Frank, D., Ciais, P., Myneni, R., Andela, N., Bi, J., Broquet, G., Canadell, J.G., Chevallier, F., Liu, Y.Y., Running, S.W., Sitch, S., \& Van Der Werf, G.R. (2014). Contribution of semi-arid ecosystems to interannual variability of the global carbon cycle. Nature, 509, 600-603.

Promis, A., Gärtner, S., Butler-Manning, D., Durán-Rangel, C., Reif, A., Cruz, G., \& Hernández, L.

(2011). Comparison of four different programs for the analysis of hemispherical photographs using parameters of canopy structure and solar radiation transmittance.

Waldokologie online, 11, 19-33.

Quesada, C.A., Phillips, O.L., Schwarz, M., Czimczik, C.I., Baker, T.R., Patĩno, S., Fyllas, N.M., Hodnett, M.G., Herrera, R., Almeida, S., Alvarez, D. E., Arneth, A., Arroyo, L., Chao, K.J., Dezzeo, N., Erwin, T., Di Fiore, A., Higuchi, N., Honorio, C.E., Jimenez, E.M., Killeen, T., Lezama, A.T., Lloyd, G., L’opez-González, G., Luizao, F.J., Malhi, Y., Monteagudo, A., Neill, D.A., Nú nez, V.P., Paiva, R., Peacock, J., Pe nuela, M.C., Pẽna, C.A., Pitman, N., Priante, F.N, Prieto, A., Ramírez, H., Rudas, A., Salomao, R., Santos, A.J.B., Schmerler, J., Silva, N., Silveira, M., Vásquez, R., Vieira, I., Terborgh, J., \& Lloyd, J. (2012). Basin-wide variations in Amazon forest structure and function are mediated by both soils and climate. Biogeosciences, 9 , 2203-2246.

Ranwala, S. M. W., \& Thushari, P. G. I. (2012). Current status and management options for invasive plants at the Mihintale Wildlife Sanctuary. Journal of the National Science Foundation of Sri Lanka, 40(1), 67-76. https://doi.org/10.4038/jnsfsr.v40i1.4170

Ratnam, J., Bond, W.J., Fensham, R.J., Hoffmann, W.A., Archibald, S., Lehmann, C.E.R., Anderson, M.T., Higgins, S.I., \& Sankaran, M. (2011). When is a 'forest' a savanna, and why does it matter? Global Ecology and Biogeography, 20, 653-660. 
References

Ratnam, J., Chengappa, S. K., Machado, S. J., Nataraj, N., Osuri, A. M., \& Sankaran, M. (2019). Functional Traits of Trees from Dry Deciduous "Forests" of Southern India Suggest Seasonal Drought and Fire Are Important Drivers. Frontiers in Ecology and Evolution, 7(JAN), 1-6.

https://doi.org/10.3389/fevo.2019.00008

Ratter, J. A., \& Dargie, T. C. D. (1992). An analysis of the floristic composition of 26 cerrado areas in brazil. Edinburgh Journal of Botany, 49(2), 235-250. https://doi.org/10.1017/S0960428600001608

Ray, D., Nepstad, D., \& Brando, P. (2010). Predicting moisture dynamics of fine understory fuels in a moist tropical rainforest system: results of a pilot study undertaken to identify proxy variables useful for rating fire danger. New Phytologist, 187(3), 720-732. https://doi.org/10.1111/j.1469-8137.2010.03358.x

Rodríguez Casal, A., \& Pateiro L'opez, B. (2010). Generalizing the convex hull ofa sample: The R package alphahull. Journal of Statistical Software, 34, 1-28.

Roy, D.P., Boschetti, L., Justice, .CO., \& Ju, J. (2008). The collection 5 MODIS burned area product global evaluation by comparison with the MODIS active fire product. Remote Sensing of Environment, 112, 3690-3707.

Ruggiero, P.G.C., Batalha, M.A., Pivello, V.R., \& Meirelles, S.T. (2002). Soil vegetation relationships in Cerrado (Brazilian savanna) and semi deciduous forest, South-eastern Brazil. Plant Ecology, $160,1-16$

Saiz, G., Bird, M.I., Domingues, T., Schrodt, F., Schwarz, M., Feldpausch, T.R.,Veenendaal, E., Djagbletey, G., Hien, F., Compaore, H., Diallo, A., \& Lloyd, J. (2012). Variation in soil carbon stocks and their determinants across a precipitation gradient in West Africa. Global Change Biology, 18, 1670-1683.

Salzmann, U. (2000). Are modern savannas degraded forests?-A Holocene pollen record from the Sudanian vegetation zone of NE Nigeria. Vegetation History and Archaeobotany, 9(1), 1-15. 
Salzmann, U., Hoelzmann, P., \& Morczinek, I. (2002). Late Quaternary climate and vegetation of the Sudanian zone of northeast Nigeria. Quaternary Research, 58(1), 73-83.

San Jose, J. J., \& Farinas, M. R. (1983). Changes in Tree Density and Species Composition in a Protected Trachypogon Savanna, Venezuela. Ecology, 64(3), 447-453. https://doi.org/10.2307/1939963

Sankaran, M., Hanan, N.P., Scholes, R.J., Ratnam, J., Augustine, D.J. et al. (2005). Determinants of woody cover in African savannas. Nature, 438, 846- 849.

Schrodt, F., Domingues, T.F., Feldpausch, T.R., Saiz, G., Quesada, C.A., Schwarz, M., Ishida, Y.F., Compaore, H., Diallo, A., Djagbletey, G., Hien, F., Sonké, B., Toedoumg, H., Zapfack, L., Hiernaux, P., Mougin, E., Bird, M.I., Grace, J., Lewis, S.L., Veenendaal, E.M., \& Lloyd, J. (2015). Foliar trait contrasts between African forest and savanna trees: genetic versus environmental effects. Functional Plant Biology, 42, 63-83.

Schwartz, D., Floresta, H., Mariotti, A., Balesdent, J., Massimba, J.P., \& Girardin, C. (1996). Present dynamics of the savanna-forest boundary in the Congolese Mayombe: a pedological, botanical and isotopic (13C and 14C) study. Oecologia, 106, 516-524.

Schwarz, G.E. (1978). Estimating the dimension of a model. Annals of Statistics, 6, 461-464.

Singh, K. P. P., \& Kushwaha, C. P. P. (2016). Deciduousness in tropical trees and its potential as indicator of climate change: A review. Ecological Indicators, 69, 699-706. https://doi.org/10.1016/j.ecolind.2016.04.011

Singh, K. P., \& Kushwaha, C. P. (2005). Emerging paradigms of tree phenology in dry tropics. Current Science, 964-975.

Sobey, D.G. (1978). Anogeissus groves on abandoned village sites in the Mole National Park, Ghana. Biotropica, 10, 87-99.

Sokal, R.R., \& Rohlf, F.J. (1995). Biometry: The Principles and Practice of Statistics in Biological Sciences. New York: WH Freeman and Company, 859 pp.

Staal, A., \& Flores, B. M. (2015). Sharp ecotones spark sharp ideas: Comment on "Structural, physiognomic and above-ground biomass variation in savanna-forest transition zones on 
References

three continents - How different are co-occurring savanna and forest formations?” by Veenendaal et al. (2015). Biogeosciences, 12(18), 5563-5566. https://doi.org/10.5194/bg-12$5563-2015$

Staver, A. C., Botha, J., \& Hedin, L. (2017). Soils and fire jointly determine vegetation structure in an African savanna. New Phytologist, 216(4), 1151-1160. https://doi.org/10.1111/nph.14738

Staver, A.C., Archibald, S., \& Levin, S.A. (2011). The global extent and determinants of savanna and forest as alternative biome states. Science, 334, 230-232.

Stebbing, E.P. (1935). The encroaching Sahara: the threat to the West African colonies. The Geographical Journal, 85, 506-519.

Ste-Marie, C., \& Pare, D. (1999). Soil, pH and N availability effects on net nitrification in the forest floor of a range of boreal forest stands. Soil Biology and Biochemistry, 31, 1579-1589.

Stott, P. (1986). The spatial pattern of dry season fires in the savanna forests of Thailand. Journal of Biogeography, 345-358.

Stott, P. (2000). Combustion in tropical biomass fires: a critical review. Progress in Physical Geography, 24(3), 355-377. https://doi.org/10.1191/030913300701542679

Stott, P. A., Goldammer, J. G., \& Werner, W. L. (1990). The role of fire in the tropical lowland deciduous forests of Asia. In Fire in the tropical biota (pp. 32-44). Springer, Berlin, Heidelberg.

Stratton, L., Goldstein, G., \& Meinzer, F. C. (2000). Stem water storage capacity and efficiency of water transport: their functional significance in a Hawaiian dry forest. Plant, Cell \& Environment, 23(1), 99-106.

Swaine, M. D., Hawthorne, W. D., \& Orgle, T. K. (1992). The effects of fire exclusion on savanna vegetation at Kpong, Ghana. Biotropica, 166-172.

Swaine, M. D., Lieberman, D., \& Hall, J. B. (1990). Structure and dynamics of a tropical dry forest in Ghana. Vegetatio, 88(1), 31-51.

Swaine, M.D. (1996). Rainfall and soil fertility as factors limiting forest species distributions in Ghana. Journal of Ecology, 84, 419-428. 
Swaine, M.D., (1992). Characteristics of dry forest in West Africa and the influence of fire. J. Veg. Sci. 3, 365-374. http://dx.doi.org/10.2307/3235762.

Swaine, M.D., Hall, J.B., \& Lock, J.M. (1976). The forest-savanna boundary in west-central Ghana. Ghana Journal of Science, $16,35-52$.

Symes, W.S., Rao, M., Mascia, M.B., Carrasco, L.R., (2016). Why do we lose protected areas? Factors influencing protected area downgrading, downsizing and degazettement in the tropics and subtropics. Glob. Chang. Biol. 22, 656-665. http://dx.doi.org/10.1111/gcb.13089.

te Beest, M., Cromsigt, J. P. G. M., Ngobese, J., \& Olff, H. (2012). Managing invasions at the cost of native habitat? An experimental test of the impact of fire on the invasion of Chromolaena odorata in a South African savanna. Biological Invasions, 14(3), 607-618.

te Beest, M., Elschot, K., Olff, H., Etienne, R.S. (2013). Invasion Success in a Marginal Habitat: An Experimental Test of Competitive Ability and Drought Tolerance in Chromolaena odorata. PLOS ONE, 8(8): e68274. doi:10.1371/journal.pone.0068274

Thompson, J., Viana, J., Proctor, J., \& Ratter, J. A. (1992). Contrasting forest-savanna boundaries on Maraca Island, Roraima, Brazil. In: Nature and Dynamics of Forest-Savanna Boundaries, edited by: Furley, P., Proctor, J., and Ratter, J. A., Chapman and Hall, London, 367-391.

Tinley, K. L. (1982). The influence of soil moisture balance on ecosystem patterns in southern Africa. In Ecology of tropical savannas. Springer, Berlin, Heidelberg, pp. 175-192.

Tomasella, J., \& Hodnett, M. (2004). Pedotransfer functions for tropical soils. Developments in Soil Science, 30, 10.1016/S0166-2481(04)30021-8.

Tomlinson, K.W., Sterck, F.J., Bongers, F., Da Silva, D.A., Barbosa, E.R.M., Ward, D., Bakker, F.T., Van Kaauwen, M., Prins, H.T.T., De Bie, S., \& Van Langevelde, F. (2012). Biomass partitioning and root morphology of savanna trees across a water gradient. Journal of Ecology, 100, 11131121.

Torello-Raventos, M., Feldpausch, T.R., Veenendaal, E., Schrodt, F., Saiz, G., Domingues, T.F., Djagbletey, G., Ford, A., Kemp, J., Marimon, B.S., Hur Marimon Junior, B., Lenza, E., 
References

Ratter, J.a., Maracahipes, L., Sasaki, D., Sonké, B., Zapfack, L., Taedoumg, H., Villarroel, D., Schwarz, M., Quesada, C.a., Yoko Ishida, F., Nardoto, G.B., Affum-Baffoe, K., Arroyo, L.M.J.S., Bowman, D., Compaore, H., Davies, K., Diallo, A., Fyllas, N.M., Gilpin, M., Hien, F., Johnson, M., Killeen, T.J., Metcalfe, D., Miranda, H.S., Steininger, M., Thomson, J., Sykora, K., Mougin, E., Hiernaux, P., Bird, M.I., Grace, J., Lewis, S.L., Phillips, O.L., Lloyd, J., (2013). On the delineation of tropical vegetation types with an emphasis on forest/savanna transitions. Plant Ecol. Divers, 6, 101-137. http://dx.doi.org/10.1080/17550874.2012.762812.

Trapnell, C.G., Martin, J.D., \& Allan, W. (1950). Vegetation-Soil Map of Northern Rhodesia (2nd edn). Lusaka: Ministry of Agriculture.

Trollope, W. S. W. (1980). Controlling bush encroachment with fire in the savanna areas of South Africa. Proceedings of the Annual Congresses of the Grassland Society of Southern Africa, 15(1), 173-177. https://doi.org/10.1080/00725560.1980.9648907

van der Sleen, P., Groenendijk. P., Vlam, M., Anten, N.P.R., Boom, A., Bongers, P.T.L., Terburg, G., \& Zuidema, P.A. (2015). No growth stimulation of tropical trees by 150 years of $\mathrm{CO}_{2}$ fertilization but water-use efficiency increased. Nature Geoscience, 8, 24-28.

van der Werf, G.R., Dempewolf, J., Trigg, S.N., Randerson, J.T., Kasibhatla, P.S., Giglio, L., Murdiyarso, D., Peters, W., Morton, D.C., Collatz, G.J., Dolman, A.J., \& DeFries, R.S., (2008). Climate regulation of fire emissions and deforestation in equatorial Asia. Proc. Natl. Acad. Sci. U. S. A. 105, 20350-20355. http://dx.doi.org/10.1073/pnas. 0803375105.

Van Langevelde, F., Van De Vijver, C. A. D. M., Kumar, L., Van De Koppel, J., De Ridder, N., Van Andel, J., Skidmore, A. K., Hearne, J. W., Stroosnijder, L., Bond, W. J., Prins, H. H. T., \& Rietkerk, M. (2003). Effects of fire and herbivory on the stability of savanna ecosystems. Ecology, 84(2), 337-350. https://doi.org/10.1890/00129658(2003)084[0337:EOFAHO]2.0.CO;2

Van Langevelde, F., Van De Vijver, C.A.D.M., Kumar, L., van de Koppel, J., De Ridder, N., Van Andel, J., Skidmore, A.K., Hearne, J.W., Stroosnijder, L., Bond, W.J., Prins, H.H.T., \& Rietkerk, M. 
(2003). Effects of fire and herbivory on the stability of savanna ecosystems. Ecology, 84, 337350.

van Nes, E. H., Staal, A., Hantson, S., Holmgren, M., Pueyo, S., Bernardi, R. E., Flores, B. M., Xu, C., \& Scheffer, M. (2018). Fire forbids fifty-fifty forest. PloS One, 13(1), e0191027-e0191027. https://doi.org/10.1371/journal.pone.0191027

Veenendaal, E.M., \& Swaine, M.D. (1998). Limits to tree species distributions in lowland tropical rainforest. In D. M. Newbery, H. H. T. Prins and N. D. Brown (Eds.). Dynamics of Tropical Communities., pp 163-191.

Veenendaal, E.M., Swaine, M.D., Agyeman, V.K., Blay, D., Abebrese, I.K., \& Mullins, C.E. (1996a)

Differences in plant and soil water relations in and around a forest gap in West Africa during the dry season may influence seedling establishment and survival. Journal of Ecology, 84, 83-90.

Veenendaal, E.M., Swaine, M.D., Blay, D., Yelifari, N.B., \& Mullins, C.E. (1996b). Seasonal and long-term soil water regime in West African tropical forest. Journal of Vegetation Science. 7, 473-482.

Veenendaal, E.M., Swaine, M.D., Lecha, R.T., Walsh, M.F., Abebrese, I.K., \& Owusu-Afriyie, K. (1996c). Responses of West African forest tree seedlings to irradiance and soil fertility. Functional Ecology, 10, 501-511.

Veenendaal, E.M., Torello-Raventos, M., Feldpausch, T.R., Domingues, T.F., Gerard, F., Schrodt, F., Saiz, G., Quesada, C.A., Djagbletey, G., Ford, A., Kemp, J., Marimon, B.S., Marimon-Junior, B.H., Lenza, E., Ratter, J.A., Maracahipes, L., Sasaki, D., Sonk, B., Zapfack, L., Villarroel, D., Schwarz, M., Yoko Ishida, F., Gilpin, M., Nardoto, G.B., Affum-Baffoe, K., Arroyo, L., Bloomfield, K., Ceca, G., Compaore, H., Davies, K., Diallo, A., Fyllas, N.M., Gignoux, J., Hien, F., Johnson, M., Mougin, E., Hiernaux, P., Killeen, T., Metcalfe, D., Miranda, H.S., Steininger, M., Sykora, K., Bird, M.I., Grace, J., Lewis, S., Phillips, O.L., Lloyd, J., (2015). Structural, physiognomic and aboveground biomass variation in savanna-forest transition zones on three continents - how different are co-occurring savanna and forest formations? Biogeosciences, 12, 2927-2951. http://dx.doi.org/10.5194/bg-12-2927-2015. 


\section{References}

Veenendaal, E.M., Torello-Raventos, M., Miranda, H.S., Sato, N.M., Oliveras, I., Van Langevelde, F., Asner, G.P., \& Lloyd, J. (2018). On the relationship between fire regime and vegetation structure in the tropics. New Phytologist, 218, 153-166.

Vuattoux, R. (1976). Contributed to the study of the evolution of the tree and shrub strata in the Lamto savannah (Ivory Coast). Second note. Annals of the University of Abidjan, series C , 7 (1), 35-63.

Wardell, D.A., Reenberg, A., Tøttrup, C., (2003). Historical footprints in contemporary land use systems: Forest cover changes in savannah woodlands in the Sudano-Sahelian zone. Glob. Environ. Chang. 13, 235-254. http://dx.doi.org/10.1016/S0959-3780(03)00056-6.

Warman, L., \& Moles, A. T. (2009). Alternative stable states in Australia's Wet Tropics: A theoretical framework for the field data and a field-case for the theory. Landscape Ecology, 24(1), 1-13. https://doi.org/10.1007/s10980-008-9285-9

Wells, P. V. (1965). Scarp woodlands, transported grassland soils, and concept of grassland climate in the Great Plains region. Science, 148(3667), 246-249.

White, F. (1983). The vegetation of Africa: a descriptive memoir to accompany the UNESCO/AETFAT/UNSO vegetation map of Africa: Vol. null (null (ed.)).

Wildlife Department, Ghana (1994). Kogyae Strict Nature Reserve Development and Management Plan. Wildlife Department, Accra.

Williams, R. J., Gill, A. M., \& Moore, P. H. R. (1998). Seasonal Changes in Fire Behaviour in a Tropical Savanna in Northern Australia. International Journal of Wildland Fire, 8(4), 227. https://doi.org/10.1071/wf9980227

Woodgate, W., Soto-Berelov, M., Suarez, L., Jones, S.D., Hill, M.J., Wilkes, P., Axelsson, C., Haywood, A., \& Mellor, A. (2012). Searching for the optimal sampling design for measuring LAI in an upland rainforest. In Proceedings of the Geospatial Science Research Symposium GSR2, Melbourne.

Xie, X., He, B., Guo, L., Miao, C., \& Zhang, Y. (2019). Detecting hotspots of interactions between vegetation greenness and terrestrial water storage using satellite observations. Remote Sensing of Environment, 231(September 2018), 111259. https://doi.org/10.1016/j.rse.2019.111259 
Yengoh, G.T., Armah, F.A., Onumah, E.E., \& Odoi, J.O. (2010). Trends in agriculturally-relevant rainfall characteristics for small-scale agriculture in Northern Ghana. Journal of Agricultural Science. doi: 10.5539/jas.v2n3p3.

Zanne, A.E., Lopez-Gonzalez, G., Coomes, D.A.A., Ilic, J., Jansen, S., Lewis, S.L.S.L., Miller, R.B.B., Swenson, N.G.G., Wiemann, M.C.C., \& Chave, J. (2009). Global wood density database. WWW document. Dryad. http://dx.doi.org/10.5061/dryad.234.

Zhang, Y.Q., Chen, J.M., \& Miller, J.R. (2005). Determining digital hemispherical photograph exposure for leaf area index estimation. Agricultural and Forest Meteorology, 133, 166-181.

Zhu, Z., Wang, S., Woodcock, C.E., (2015). Improvement and expansion of the Fmask algorithm: cloud, cloud shadow, and snow detection for Landsats 4-7, 8, and sentinel 2images. Remote Sens. Environ. 159, 269-277. http://dx.doi.org/10.1016/j.rse.2014.12.014.

Zhu, Z., Woodcock, C.E., (2012). Object-based cloud and cloud shadow detection in Landsat imagery. Remote Sens. Environ. 118, 83-94. http://dx.doi.org/10.1016/j.rse.2011.10.028.

Zommers, Z., \& Macdonald, D.W. (2012). Protected areas as Frontiers for human migration. Conserv. Biol. 26, 547-556. http://dx.doi.org/10.1111/j.1523-1739.2012.01846.x.

Zuur, A., Ieno, E.N., Walker, N., Saveliev, A.A., \& Smith, G.M. (2009). Mixed Effects Models and Extensions in Ecology with R. New York: Springer, 574 pp. 


\section{Summary}

Forest-savanna transitions are often discussed as systems that operate next to each other with distinct woody species and separated into pyrogenic and non-pyrogenic systems with sharp transition between the two systems. It is often hypothesized that fires cannot enter closed canopy vegetation. Forest savanna-transitions have also suffered deforestation mainly through logging and agricultural expansion augmenting the effects of fire frequency and intensity. Despite these challenges, there are at present still few studies that specifically study the interplay between fire and tree cover and tree species where the savanna meets the forest. Changes in vegetation cover, soil heterogeneity and impending climate change have important consequences on tree species selection for reforestation to adapt to the derived environment.

In this thesis I presented and analysed empirical evidence to test four paradigms commonly associated with the forest-savanna transitions with field evidence supported by remote sensing. I explain the interplay by addressing the following questions: (1) How stable are the vegetation patterns in West-African forest-savanna boundaries? (2) Do tree functional types mix in the landscape? (3) How does fire penetrate the forest landscape in KSNR if forest burns? (4) How do tree functional type and stand structure affects the phenology of leaf shedding? (5) How does canopy variation selects for tree species recruitment?

In the second chapter of this thesis, remote sensing and field measurements were combined to assess the changes in woody cover that has occurred inside KSNR in the past three decades. The results reveal deforestation status of the tropical dry forest even inside a strictly protected area within the period, attributable to logging and land clearing for arable farming. In addition, suggests a trade-off between economic applications and environmental conservation. I further reveal woody encroachment in the adjacent woodland dominated mainly by non-selective species through NDVI change detection after the deforestation. Historical fire data from the MODIS burned area product indicate that the deforested area experienced a high frequency of anthropogenic burning which may have caused further degradation and essentially prevents forest regeneration. On the basis of 
Summary

the results of this research, that protection and management strategies of such areas are now being reconsidered.

In the third chapter of this thesis, I investigated the links between the vegetation composition and the vegetation structure in a forest-savanna mosaic by analysing thirty-five 400$\mathrm{m}^{2}$ plots encompassing forest, savanna and intermediate vegetation types in an ecotonal area in Ghana, West Africa. I tested the hypotheses that; (1) savanna and transitional species can co-occur in at least some closed vegetation formations. (2) many differences in vegetation structure can be simply attributed to variation in soil characteristics. The results show that forest and savanna were dominated by associated species but instead of two groups of vegetative types, a third group has emerged as non-selective that bridges the gap between forest and savanna. The average NDVI cover increase of $\sim 0.15 \%$ year observed was more prevalent on plots dominated by non-specialized species than those dominated by either forest or savanna-affiliated species. While fire frequency across all plots over a period of 15 years was relatively uniform. Data revealed that across all plots, structural parameters associated with higher soil exchangeable potassium and silt contents supporting recent suggestions of interplays between potassium and soil water storage potential as a significant influence on tropical vegetation structure. My results challenge the traditional view of a simple forest versus savanna dichotomy controlled by fire, and with my newly identified third nonspecialized species grouping also potentially important in understanding ecotonal responses to climate change.

In the fourth chapter of this thesis, I monitored natural fire behaviour across a range of vegetation types in an ecotonal area in Ghana for three years to understand the role of tree cover and tree species composition on fire intensity and expansion. Fire characteristics and behaviour in the open woodland and forest patches were analysed. The results show that open woodland and closed forest were separated by a vegetation leaf area index $\left(L_{\mathbb{W}}\right)$ threshold of 1.5 to 2.0 and two fuel load sources with inverse relationship, resulting in two distinct types of fires on the landscape scale. The more open woodland was associated with high intensity herbaceous biomass fires while 
the forest patches were associated with more benign leaf litter fires with intermediate intensity at the interface where non-selective species were located. I hypothesise a mechanism for the maintenance of non-specific species with their early deciduous nature of a critical importance. This observed duality of fire types as observed in current study leads to what we term "soft fire transitions". This in contrast to a simple savanna versus forest, fire versus no-fire dichotomy that results in a "hard fire transition", such as current prevails in the literature. I suggest that additional groundwater supply such as in gallery forests plays a role in the "sharpening" of transitions.

In the fifth chapter of this thesis, I explored if leaf phenology differences can be attributed to specific tree species, tree functional type or stand structural types and to what extent this phenological behaviour may influence the tree phenology and as a consequence the production of tree leaf litter at the start of the dry season. I showed seasonal leaf retention and shedding patterns and overall deciduousness of tree species in synchrony with wildfires. I found strong evidence that particularly species and tree functional type effects are important for leaf retention in the first half of a dry season with transition and savanna type similar but transition vegetation as a result of greater leaf cover the strongest contribution to leaf litter at the start of the dry season. Overall, the phenology patterns observed seem to support the possibility of litter fires across a closing cover of trees and help to explain the existence of litter fires under these conditions.

In the sixth chapter of this thesis, I report on a three-year-long field transplant experiment we conducted in the forest-savanna ecotone of Ghana to investigate influences of vegetation type/canopy cover and its associated factors on seedling survival, growth and traits. The results suggest a limitation of the possibilities of moist semi-deciduous forest species to establish predominantly in the forest-savanna ecotone possibly due to dry season and its associated pyrogenic environment.

I further demonstrate that albeit savanna species survived better, they differ in their tolerance to canopy cover and open pyrogenic environments specifically related to root storage functions, thus contributing to a better understanding of differences in tree seedling recruitment 
Summary

between species across the forest-savanna ecotones. The results reveal that tree cover variation has species-specific effects on tree seedling recruitment which is related to root storage functions.

In the synthesis, I highlight the significance of the main findings, conclusions, or contribution of the study to the ongoing discussion about the relative importance of fire and soil in determining vegetation function and structure. These findings have significant implications for the understanding of how soil, climate, and fire interact to create boundaries and transitions in the forest savanna landscape. Most importantly, a newly identified third non-specialized species grouping capable of bridging the pyrogenic gap will contribute to understanding ecotonal responses to climate change. Another significant finding to emerge from this study is that fire penetrates the forest in the landscape in KSNR, that forest-savanna transitions burn regularly. 


\section{Samenvatting}

Overgangen tussen bos en savanne worden vaak gezien als systemen die naast elkaar bestaan, gekarakteriseerd worden door verschillende boomsoorten, gescheiden in pyrogene en nietpyrogene vegetatie, en met een scherpe overgang tussen de twee systemen. Vaak wordt verondersteld dat branden niet in een gesloten vegetatie doordringen. In overgangen tussen bos en savanne heeft veel ontbossing plaatsgevonden, voornamelijk door houtkap en uitbreiding van de landbouw, waardoor de effecten van brandfrequentie en -intensiteit werden vergroot. Ondanks deze uitdagingen zijn er momenteel nog weinig studies die specifiek de interactie tussen vuur, boombedekking en de samenstelling van boomsoorten in detail bestuderen in streken waar de savanne en bos in elkaar overgaan. Veranderingen in vegetatiebedekking, bodemheterogeniteit en dreigende klimaatverandering hebben belangrijke gevolgen voor de selectie van boomsoorten en kunnen mogelijk een nieuw licht werpen op de rol van vuur bij bos-savanne - transities. Kennis van de boomsoorten en hun aanpassingen is ook van waarde voor herbebossing in dit soort systemen.

In dit proefschrift presenteer en analyseer ik veldgegevens verzameld in de bos-savanne overgang in het Strict Nature Reserve in Kogyae (KSNR) in Ghana met het doel om ideeën te testen die vaak worden geassocieerd met de overgangen tussen bos en savanne. Ik baseer mij op veldstudies, soms ondersteund door remote sensing. Ik bestudeerde de interactie tussen vuur, bodem en vegetatie met het doel de volgende vragen te beantwoorden: (1) Hoe stabiel zijn de vegetatiepatronen in de FS-grens in de KSNR? (2) Hoe zijn de verschillende functionele boomtypen verdeelt over het landschap? (3) Dringt vuur door in het boslandschap in KSNR en hoe verhoudt dit zich tot de mate van boombedekking? (4) Hoe beïnvloeden het functionele boomtype en de vegetatiestructuur het bladverlies in de droge tijd? En (5) Hoe beïnvloedt de variatie in de boombedekking de vestiging van boomsoorten? 
Samenvatting

In het tweede hoofdstuk van dit proefschrift werden veldmetingen en remote sensing gecombineerd om de veranderingen in de boombedekking te analyseren. Ik heb me hierbij gericht op de veranderingen die zich in de KSNR in de afgelopen drie decennia hebben voorgedaan.

De resultaten onthullen een dramatische ontbossing van het tropische droge bos, zelfs binnen een strikt beschermd gebied zoals Kogyae Strict Nature Reserve. Dit is te wijten aan houtkap en (illegale) akkerbouw, zoals bleek uit lokale interviews. De geschiedenis van KNSR laat in die zin een vaak geziene wisselwerking tussen de economische ontwikkeling en het natuurbehoud zien. De NDVI-veranderingen na de ontbossing laten een langzame verbetering van de houtige bedekking zien (met hierin mogelijk een bijzondere bijdrage van voornamelijk niet-selectieve boom soorten; zie voor meer informatie hoofdstuk 3). Historische brandgegevens van het MODISproduct voor verbrande gebieden wijzen ook op een hoge frequentie van branden met een antropogene oorsprong (stroperij, landbouw, maar ook natuurbeheer). Deze hebben mogelijk hebben geleid tot een verdere vermindering van de bosbedekking en zij remmen de snelheid van bosherstel mogelijk af. Op basis van de resultaten van dit onderzoek wordt het beheer van de KSNR nu heroverwogen.

In het derde hoofdstuk van dit proefschrift heb ik de verbanden tussen de vegetatiesamenstelling en de vegetatiestructuur in een bos-savanne mozaïek in detail onderzocht door de vijfendertig percelen van $400 \mathrm{~m}^{2}$ te analyseren die bos, savanne en overgangsvegetatie omvatten. Ik heb de hypotheses getest dat (1) bos- savanne en overgangs-soorten samen kunnen voorkomen afhankelijk van de mate van boombedekking van vegetatie structuur, en (2) Verschillen in vegetatiestructuur kunnen grotendeels worden toegeschreven aan variatie in bodemeigenschappen. De resultaten laten zien dat bos en savanne worden gedomineerd door specifieke soorten, en dat in plaats van de vegetatiegroepen karakteristiek voor bos of savanne, er ook er een derde niet-selectieve groep voorkomt (d.w.z. die zowel voorkomt in bos- als savanne formaties) die de kloof overbrugt tussen bos en savanne. Er is een gemiddelde NDVI-toename van 
$\sim 0,15 \%$ per jaar waargenomen, waarbij juist de grootste toename wordt waargenomen op plekken die worden gedomineerd door 'niet-gespecialiseerde' soorten in vergelijking tot plekken die worden gedomineerd door bos- of savanne gerelateerde soorten. Tevens bleek dat de brandfrequentie over alle percelen over een periode van 15 jaar relatief uniform was. Tevens bleek dat structurele parameters geassocieerd waren met hogere uitwisselbare kalium- en slibgehaltes in de bodem, en daarmee de "CWAK" (gecombineerde water en beschikbare kalium) hypothese ondersteunen. Dit werd waargenomen in alle percelen. Deze recente hypothese suggereert dat de wisselwerking tussen kalium en bodemwateropslag potentieel de structuur van tropische vegetatie significant sterk kan beïnvloeden. Mijn resultaten stellen de traditionele opvatting van een simpele dichotomie tussen bos en savanne, veroorzaakt door vuur, ter discussie. De nieuwe 'niet-gespecialiseerde' soortgroepering helpt het meer genuanceerde beeld te verklaren en kan ons mogelijk helpen de reacties op klimaatverandering in bos-savanne overgangen beter te begrijpen.

In het vierde hoofdstuk van dit proefschrift heb ik drie jaar lang het natuurlijke brandgedrag onderzocht. Ik heb met hierbij gericht op de verschillende vegetatietypen in de bos-savanne overgang in KSNR met als doel de rol van boombedekking en samenstelling van boomsoorten op brandintensiteit en brandverspreiding beter te begrijpen. Ik heb hierbij de eigenschappen en het gedrag van brand in open bossen en bosgebieden geanalyseerd. De resultaten laten zien dat open bos en gesloten bos worden gescheiden door een bladoppervlakte-index (LW) drempel van 1,5 tot 2,0. Als gevolg hiervan ontstaan er twee soorten van brandstof welke respectievelijk leiden tot twee verschillende soorten branden in het landschap. In het meer open bos worden branden met hoge intensiteit voornamelijk gevoed door droog gras en kruiden, terwijl de gesloten bosgebieden vooral te maken hebben met relatief milde, 'goedaardige' branden gevoed door afgevallen bladstrooisel. In de overgangszones, waar vaak de 'niet-selectieve' soorten voorkomen, hebben branden een tussenliggende intensiteit. De 'niet-specifieke' soorten verliezen hun blad eerder dan bos soorten en beïnvloeden daarmee de intensiteit van de branden in de overgangszones. Dit leidt potentieel tot een hogere stabiliteit in de overgangsvegetatie. De waargenomen dualiteit van brand types zoals 
Samenvatting

waargenomen in de huidige studie kan leiden tot "zachte brand overgangen". Dit in tegenstelling tot de veelal gehanteerde "scherpe brand overgangen" welke worden aangestuurd door een simpele savanne versus bos en brand versus geen-vuur dichotomie.

In hoofdstuk 5 heb ik gekeken of verschillen in bladfenologie kunnen worden gerelateerd aan boomsoort en type en tot in hoeverre boomsoort en boomtype het blad-houdend vermogen en daarmee de hoeveelheid bladval kunnen verklaren. In eerste instantie lijkt het patroon van bladval aan het begin van het droge seizoen vergelijkbaar in de savanne en overgangszone. Maar bomen in de overgangsvegetatie hebben doorgaans vanwege een dichter bladerdak meer bladoppervlak, en daarmee dus ook aanzienlijke hoeveelheid bladval aan het begin van het droogteseizoen. Over het algemeen is het voorkomen en de intensiteit van branden in dichtere vegetaties gerelateerd aan de hoeveelheden en waargenomen patronen van bladval. De aanwezigheid van bomen in deze vegetaties is mogelijk dan ook een belangrijke stimulerende factor bij het ontstaan van branden van verschillende intensiteit. Bladval verklaart het algemene voorkomen van dit type branden in bosgebieden, in KSNR maar ook in tropische bos-savanne en droge bos systemen elders in de tropen.

In het zesde hoofdstuk van dit proefschrift rapporteer ik over een drie jaar lang veldtransplantatie-experiment dat we hebben uitgevoerd in de bos-savanne overgangszone van Ghana met als doel de invloeden van vegetatietype en bladerdak en de bijbehorende factoren op de overleving, groei en eigenschappen van zaailingen te onderzoeken. Bossoorten uit de meer vochtige bossen bleken minder goed te zijn aangepast aan de bos-savanne overgangszone dan de savanne soorten. Deze mindere aanpassing aan waarschijnlijk het lange droge seizoen en pyrogene omgeving uitte zich vooral in een verminderde groei en overleving. Verder bleek dat savanne soorten onderling ook sterk verschillen in hun tolerantie voor zowel brand als de mate van beschaduwing. Dit verschil in tolerantie lijkt direct bepaald door het vermogen om ondergronds (in de wortels) reserves op te slaan. Bij typische bossoorten is de ondergrondse opslag van reserves 
over het algemeen zeer beperkt. Savanne soorten worden over het algemeen gekarakteriseerd door het vermogens ondergronds reserves op te slaan, als belangrijke aanpassing aan een pyrogene omgeving. De mate van ondergrondse opslag blijkt echter tussen sterk sterk te verschillen, wat, naast beschaduwing door het bladerdak, mede het voorkomen in de overgangszone verklaart. Deze resultaten hebben geleidt tot een beter inzicht in voorkomen van verschillende soorten in savanneen bosvegetaties. Tevens blijkt de variatie in boomdichtheid een grote rol te spelen bij de vestiging van soorten, onder andere door verschil in beschaduwing maar ook microklimaat en bodemcondities. Deze resultaten hebben geleid tot nieuwe inzichten in de verspreiding van boomsoorten in savanne en bosvegetatie en verklaren waarom boomsoorten met verschillende functies verspreid over verschillende vegetatietypes kunnen voorkomen.

In de synthese vat ik mijn belangrijkste bevindingen en conclusies samen. Daarbij ga ik in op de bijdrage van mijn onderzoek aan de discussie over het relatieve belang van brand en bodemcondities bij het bepalen van de functie en structuur van vegetatie in Bos-savanne overgangen. Mijn bevindingen hebben belangrijke implicaties voor het begrip van hoe bodem, klimaat en vuur op elkaar inwerken om grenzen en overgangen in het bos-savanne landschap te creëren. Het laat zien dat vuur een veel voorkomend verschijnsel is in droge bosgebieden, ook in vegetaties die als bos worden gekwalificeerd. Misschien wel het belangrijkste gegeven, een derde is de realisatie dat er een derde niet-gespecialiseerde soortgroep (die mogelijk wel heterogeen van aard is bestaat die tot nu toe niet goed in beeld was. Deze is in staat is om de kloof tussen open sterk pyrogene en gesloten minder-pyrogene tropische bosformaties te overbruggen. Mijn bevindingen zullen bijdragen tot een beter begrip van de dynamiek in bos-savanne overgangen door veranderingen, vooral wanneer er veranderingen in in brand patronen plaatsvinden en bij aanhoudende klimaatverandering.

Samenvattend toont deze studie dus aan dat (1) bos-savanne-overgangen regelmatig branden (2) vegetatiestructuur sterk afhankelijk is van bodemeigenschappen, (3) vuur doordringt in de droge 
Samenvatting

bossen en (4) dat een variëteit aan functionele boom-typen helpen om de variatie van bos formaties verklaren. Daarbij speelt aanvullende grondwatervoorziening zoals in galerijbossen waarschijnlijk een rol bij het 'aanscherpen' van bos-savanne overgangen die zo vaak worden gerapporteerd. 


\section{Acknowledgments}

$\mathrm{PhD}$ study is a tortuous journey that may test your resilience to the extremes and therefore requires support, collaboration, sacrifices, passion, leadership and sponsorship to be accomplished. Christopher Columbus could not have "discovered" America without his dedicated sailors, cooks and medics etc. I would therefore like to acknowledge all the individuals, agencies and institutions that contributed directly or indirectly towards successful completion of my $\mathrm{PhD}$.

I thank the Wageningen University Sandwich Fellowship Programme for the opportunity and the EU KP7 GEOCARBON project (contract number 283080) for financial support. I also wish to express my profound gratitude to my promoters; Prof. David Kleijn, Dr. Elmar Veenendaal and Dr. Philippine Vergeer for their guidance and support throughout my studies.

I am extremely thankful and pay my gratitude to Dr. Elmar Veenendaal my supervisor, for his patience, guidance, support and understanding throughout my $\mathrm{PhD}$ tenure. Elmar, without your assistance and dedicated involvement in every step throughout the process, this thesis would not have been accomplished. You were so committed to support me to complete my $\mathrm{PhD}$ against all odds. I appreciate your support as a friend to pick me at the airport, for your rich hospitality together with your wife and for helping me to settle down. I am extremely grateful for the numerous dinners organised for me. I appreciate the opportunity to be connected to a network of esteemed scientists and collaborated with them as co-authors, building my capacity as an independent scientist. I look forward to continuing working with your research team.

David, I consider myself lucky to have you as my promotor. Your commitment to your students and the Group is clearly evident and very much appreciated. Thank you for your critical review of my flagship manuscript which sought to challenge widely accepted views of the forestsavanna transition. Your thought-provoking comments guided me in the thesis writing. I am grateful to you for your invaluable support. 
Acknowledgements

Philippine, I am intrigued by your enthusiasm in tropical forest studies and your commitment to my work. Thank you and Frank for the thoughtful comments and recommendations on this study and critical reviews that enhanced the work. Your support and guidance are highly appreciated. Frank I will always remember you for the innovative ways in which you presented statistical analysis for my appreciation in class.

I would also like to say special thank you to Dr. Stephen Adu-Bredu my local supervisor who enrolled me on the GEOCARBON project which granted me the opportunity to do my $\mathrm{PhD}$. Dr. Adu-Bredu was kind and supportive. I must also thank Prof. Victor Agyeman, the DirectorGeneral of the Council for Scientific and Industrial Research (CSIR) for his mentorship and support. Similarly, I extend sincere appreciation to Prof. Daniel Ofori, Director of FORIG for his support, granting me a friendly working conditions and for monitoring my progress.

This study received overwhelming support from some prominent Wageningen University and Research Alumni in Ghana. I appreciate their support and guidance particularly Dr (Mrs). Amissah, Dr. Kwame Oduro, Dr. Emmanuel Marfo and Dr. Hamza Issifu of UDS. Lucy, I am flabbergasted at your enormous and innumerable contributions. You volunteered to help me more as a supervisor and shared personal experiences with me and encouraged me when I was almost losing hope. In fact, you were the valve of "no retreat no surrender". Hamza, I appreciate your willingness to help, reading through my work and sharing documents and compiling documents. Thanks for everything. I cannot thank you enough.

Gratitude goes to all RSA members CSIR-FORIG, who directly or indirectly helped me to complete this research especially Prof. Emmanuel Opuni-Frimpong who on many occasions offered me his vehicle and driver to collect data in emergency situations, Prof. Paul Bosu, Dr. Kennedy-Owusu-Afriyie, Dr(Mrs). Gloria Djabletey who bolstered the initial process, Dr. Ernest Foli, Dr. Akwasi Duah-Gyamfi, Dr. Emmanuel Ebanyenle, Mr. Samar Sparkler, Dr Luke Anglaaere, Dr. Reginald Guuroh, Mrs. Sarah Pentsil, Dr. (Mrs) Beatrice Darko Obiri, Dr. Shalom 
Addo-Danso, Dr. Bright Kankam, Dr (Mrs). Elizabeth Obeng for your encouragement and support. Sometimes all that I needed was moral support.

I am extremely grateful to Plant Ecology and Nature Conservation (PEN) Group of WUR for providing a perfect atmosphere for my studies, the state of the arts facilities and for their warm hospitality and support. Particularly thankful to Liesje Mommer, Monique Heijmans, Joop Schaminee, Juul Limpens, Jasper van Ruijven and Frank Berendse. I appreciate your invaluable contributions especially during coffee breaks and presentations. Special thanks also to Petra Kloppenburg and Gerda Martin-Westphal for your wonderful administrative support that provided for my academic and logistics support and also financial transactions, Jan van Walsem for the impeccable soil analysis. There were many post-graduate students of WUR who worked with me in the field, as coauthors or study mates. Special thanks to Mohammed Armani, Thomas Janssen, José Medina-Vega, Laurianne Ollivier and Koos den Hartogh. I am thankful to José van Paassen for the beautiful thesis cover design.

I am also greatly indebted to Prof. Jon Lloyd for his many critical but always supportive remarks on a number of manuscripts and his assistance with advanced statistical analyses particularly in chapter 3. I must also thank Imma Oliveras for her guidance and support especially in the fire observation studies and field training. Lourens Poorter, for his encouragements. Thank you, Dr. Vincent Logah and your KNUST soil science team. All the technical and logistic support provided by your team and comments during the development of articles is highly appreciated. I am very grateful to Thomas Janssen, Edward Mitchard and Murray Collins for the remote sensing analyses which formed an important contribution to the understanding of Kogyae's past.

I also wish to expressy my profound gratitude to the Ghanaian community and their families in Wageningen (Sikaman) for their love and support. Uncle Sampson and auntie Monica, your hospitality and support will be forever remembered.

My heartfelt thanks also go to the Wildlife Division of the Forestry Commission, Ghana for granting me permission to conduct field studies in Kogyae Strict Nature Reserve. My fieldwork 
would not have been possible without the support of the staff and employees who on many occasions supported me as volunteers. I thank former KSNR Managers for granting me extensive interviews about the Park. I particularly thank Isaac Sarpong, Kwaku Yinye, Yaw Agyeman and colleagues who developed personal relationships with the trees to understand how they function to quantify their phenology in a creative way. Thank your Mr. Sarpong for your technical skills which enabled me installed equipment on the flux tower several meters above the tree canopy and Mr. Constant Ezuame of CSIR-FORIG for your unique technical skills. I am particularly indebted to the late Mr. Ntim Gyakari with love and fond memories, for the tree identification and tagging, the pivot upon which this classification was built.

I also acknowledge with deep sense of reverence, my gratitude towards my parents and members of my family. I am extremely grateful to my larger family for their love and care; you always give me a reason to live. I thank my father George Bediako Ametsitsi (late) and my aged mother, Janet for their steadfast love and guidance. I also thank my siblings and their families especially my elder brother Fred Ametsitsi, who motivated me so much during the tenure of the studies and my loving sisters who supported me emotionally for peaceful state of mind to study.

Most importantly, I wish to thank my loving and supportive wife, Gifty, and my three wonderful children, Julius, Jane and Johnson who provide unending inspiration. Thanks for all your extreme sacrifices, without which I would have abandoned these studies. I look forward to compensating you for your "loss" or investments as I seemed to be so uncaring. 


\section{Short Biography}

George Kwaku Duku Ametsitsi was born on April 1, 1972 in Ghana. George attended Bishop Herman College in Kpando where he obtained his G.C.E. O' and A' levels in 1991 and 1993, respectively. In 1994, he got enrolled at Kwame Nkrumah University of Science and Technology (KNUST) where he obtained a BSc

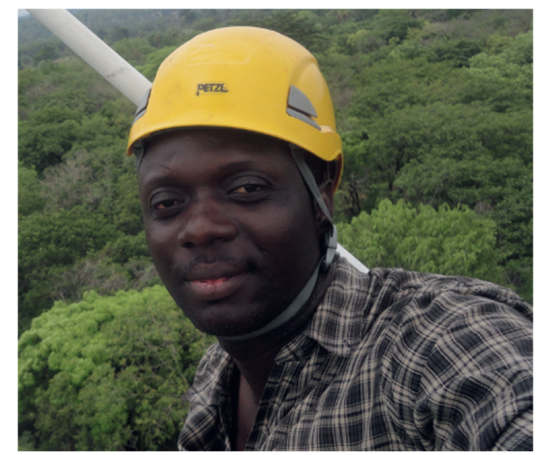
Natural Resources Management Honours degree. After graduation, he was retained as a Teaching Assistant and later as a Demonstrator in the University. In 2001, he was admitted to KNUST to do his master's in Environmental Resources Management at the Institute of Mining and Mineral Engineering. For his research, he examined timber defect patterns in different ecological zones of Ghana. In 2002, he joined Friends of Rivers \& Water Bodies, an NGO as a project officer coordinating environmental education and restoration programmes, organizing workshops and press conferences.

In 2005, he was appointed as a Project Officer on the International Tropical Timber Organisation (ITTO) project, ITTO PD 318/4 Rev. 2 (I). In 2008 he was trained at Forest Product Research \& Development Institute (FPRDI), the Philippines to develop and promote quality control guidelines for wood products in Ghana. Between 2006 and 2010, he was a member of the Technical Committee for Wood \& Wood Products of Ghana Standards Authority (GSA) and was instrumental in the review and publication of quality standards published for wood products in Ghana.

In July 2009, he was employed as a Research Scientist by the Council for Scientific and Industrial Research -Forestry Research Institute of Ghana (CSIR-FORIG) and assigned to the Forest and Climate Change Division (FCCD). During this period, he was among other things involved with the evaluation of forestry programmes in Ghana. 
Short Biography

In December 2011, he joined the GEOCARBON project and simultaneously started his $\mathrm{PhD}$ program as a sandwich student at Wageningen University and joined the Plant Ecology and Nature Conservation Group. He set up a research facility in the Kogyae Strict Nature Reserve in Central Ghana. As part of his $\mathrm{PhD}$, he supervised several master students from Wageningen University. He also had the opportunity to attend international conferences and workshops and presented posters and papers. In August 2019, he won the Runner-Up Poster Prize at the $44^{\text {th }}$ New Phytologist Symposium in Accra, Ghana for his research that sought to challenge the classical perception of forest and savanna as distinct biomes, separated by sharp ecotones. This research has already resulted in a number of publications in international journals.

His research interest is broad though much in plant and system ecology, the tropical forest and savanna, and climate change issues. He is married to Gifty and has three children: Julius, Jane and Johnson. George can be reached at jarhmano@gmail.com and on +233245669665. 


\section{Selected Publications}

1. Ametsitsi, G. K. ., Van Langevelde, F., Logah, V., Janssen, T., Medina-Vega, J. A., Issifu, H., Ollivier, L., den Hartogh, K., Adjei-Gyapong, T., Adu-Bredu, S., Lloyd, J., \& Veenendaal, E. M. (2020). Fixed or mixed? Variation in tree functional types and vegetation structure in a forest-savanna ecotone in West Africa. Journal of Tropical Ecology, 1-17. https://doi.org/10.1017/S0266467420000085

2. Issifu, H., Ametsitsi, G. K. D., de Vries, L. J., Djagbletey, G. D., Adu-Bredu, S., Vergeer, P., van Langevelde, F. and Veenendaal, E. (2019). Variation in vegetation cover and seedling performance of tree species in a forest savanna ecotone. Journal of Tropical Ecology, 35:74-82.

3. Janssen, T. A. J., Ametsitsi, G. K. D., Collins, M., Adu-Bredu, S., Oliveras, I., Mitchard, E. T. A., \& Veenendaal, E. M. (2018). Extending the baseline of tropical dry forest loss in Ghana (1984-2015) reveals drivers of major deforestation inside a protected area. Biological Conservation, 218. https://doi.org/10.1016/i.biocon.2017.12.004

4. Cardoso, A. W., Medina-Vega, J. A., Malhi, Y., Adu-Bredu, S., Ametsitsi, G. K. D., Djagbletey, G., van Langevelde, F., Veenendaal, E., \& Oliveras, I. (2016). Winners and losers: Tropical forest tree seedling survival across a West African forest-savanna transition. Ecology and Evolution, 6(10), 3417-3429. https://doi.org/10.1002/ece3.2133

5. Bonsi, R., Hammett. A.L. and Ametsitsi, G. 2011. Assessing the current situation of Ghana's forest products industry. Ghana Journal of Forestry 27(3): 1-14.

6. Djagbletey, G. D., Adu-Bredu, S., Duah-Gyamfi, A., Abeney, E. A., Asante, W. A., Akyeampong, E., Addo-Danso, S., Ametsitsi, G. K., Amponsah-Manu, E., \& Dabo, J. (2018). Floristic composition and carbon stocks of tree species of different conservation 
Selected publications

status following selective logging in a moist semi-deciduous forest in Ghana. Ghana J. Forestry, 34(1), 15-34.

\section{Submitted}

Issifu, H., Vergeer, P., Ametsitsi, G. K. D., Klijn, J., Sartorelli, P., Tanson, M., Bayor, H., Logah., van Langevelde, F. and Veenendaal, E. Responses of tropical tree seedlings in the forest-savanna boundary to combined effects of grass competition and fire. Biotropica (Under revision)

\section{Other scientific publications}

1. Ametsitsi, G.K.D. (2007). Photo-monitoring and assessment of the livelihood enterprises in beneficiary communities of AfDB Community Forestry Management Project in Ghana. Forest Plantation Development Centre, MLN, Ghana.

2. Ametsitsi, G.K.D. (2008). Photo-monitoring and assessment of forest plantations in degraded forest reserves in Ghana. Forest Plantation Development Centre, MLNR, Ghana.

3. Agyeman, V.K., Owusu-Afriyie, K., Foli, E.G., Ametsitsi G.K.D., Darko-Obiri, B., DuahGyamfi, A., Nutakor, E. and Addo-Danso, S. (2012). Independent technical assessment of the National Forest Plantation Development Programme. Ministry of Lands and Natural Resources (MLNR), Ghana.

4. Ametsitsi, G.K.D., Kyereh, B., Duah-Gyamfi, A. (2009). Some Reasons for Poor Application of Wood Products Standards and Strengthening the Process of Standards Development. ITTO.

https://www.itto.int/files/itto_project_db_input/2554/Technical/Act \%201.1\%20Streng thening $\% 20$ the $\% 20$ Process $\% 20$ of $\% 20$ Standards $\% 20$ Development.pdf 
5. Ametsitsi, G.K.D., Kyereh, B., Duah-Gyamfi, A. (2009). Identify Local Market Requirements for Timber and Wood Products and Priority Areas For Standards And Grading Rules Development. ITTO.

https://www.itto.int/files/itto project db input/2554/Technical/Act $\% 202.2 \% 20$ Identi fy $\% 20$ Local $\% 20$ Market $\% 20$ Requirements $\% 20$ for $\% 20$ Timber $\% 20 \& \% 20$ Wood $\% 20$ Produ cts.pdf

6. Ametsitsi, G.K.D., Kyereh, B., Duah-Gyamfi, A. and Agyeman, V.K. (2008). Factors Influencing Criteria and Indicators of Quality Control of Timber and Timber products in Ghana. IT'TO.

https://www.itto.int/files/itto_project_db_input/2554/Technical/Act $\% 202.3 \% 20$ Facto rs $\% 20$ Influencing $\% 20$ Criteria $\% 20 \& \% 20$ Indicators $\% 20$ of $\% 20$ Quality $\% 20$ Control.pdf

7. Ametsitsi, G.K.D., Agyeman, V.K. and Kuma, M.T. (2008). Some Strategies for Wood Standards Development for the Timber Industry and Selection of Wood Product for Standardisation. ITTO.

https://www.itto.int/files/itto_project_db_input/2554/Technical/Act\%203.1\%20Some $\% 20$ Strategies $\% 20$ for $\% 20$ Sustainable $\% 20$ Standards $\% 20$ Development.pdf

\section{Standards}

1. Agyeman, V.K., Kyereh, B., Ametsitsi, G.K.D. and Duah-Gyamfi, A. (2009). Furniture Specifications for TABLES. Ghana Standard GS 980:2009, ICS 97.140. 26 pp. Standards Document produced by CSIR-FORIG and Adopted by Ghana Standards Board. ITTO http://www.itto.int/files/itto_project_db_input/2554/Technical/GHANA\%20STAND ARD\%20\%20GS\%20980_Furniture_Tables.pdf 
Selected publications

2. Agyeman, V.K., Kyereh, B., Ametsitsi, G.K.D. and Duah-Gyamfi, A. (2009). Furniture Specifications for SEATING. Ghana Standard GS 981:2009, ICS 97.140. 26 pp. Standards Document produced by CSIR-FORIG and Adopted by Ghana Standards Board. ITTO. http://www.itto.int/files/itto_project_db_input/2554/Technical/GHANA\%20STAND ARD \%20\%20GS\%20981_Furniture_\%20Specification\%20for\%20Seating.pdf

3. Agyeman, V.K., Kyereh, B., Ametsitsi, G.K.D. and Duah-Gyamfi, A. (2009). Furniture Specifications for BEDSTEADS. Ghana Standard GS 982:2009, ICS 97.140. 22 pp. Standards Document produced by CSIR-FORIG and Adopted by Ghana Standards Board. ITTO. http://www.itto.int/files/itto_project_db_input/2554/Technical/GHANA\%20STAND ARD\%20\%20GS\%20982_Furniture_\%20Specification\%20for\%20Bedsteads.pdf

4. Agyeman, V.K., Kyereh, B., Ametsitsi, G.K.D. and Duah-Gyamfi, A. (2009). Furniture Specifications for FURNITURE COMPONENTS. Ghana Standard GS 983:2009, ICS 97.140. 26 pp. Standards Document produced by CSIR-FORIG and Adopted by Ghana Standards Board.

http://www.itto.int/files/itto_project_db_input/2554/Technical/GHANA\%20STAND ARD \%20\%20GS\%20983_Furniture_\%20Specification\%20for\%20Furniture\%20Compo nents.pdf

5. Agyeman, V.K., Kyereh, B., Ametsitsi, G.K.D. and Duah-Gyamfi, A. (2009). SemiFurniture - Specification for PLANED TIMBER AND MOULDINGS. Ghana Standard GS 984:2009, ICS 97.140. 21 pp. Standards Document produced by CSIR- FORIG and Adopted by Ghana Standards Board.

http://www.itto.int/files/itto_project_db_input/2554/Technical/GHANA\%20STAND ARD \%20\%20GS\%20984_Furniture_\%20Specification\%20for $\% 20$ Planed $\% 20$ Timber $\% 2$ 0\&\%20Mouldings.pdf 


\section{Affiliations of co-authors}

\section{Thomas Adjei-Gyapong}

Department of Crop and Soil Sciences, Kwame Nkrumah University of Science and Technology, Kumasi, Ghana

\section{Stephen Adu-Bredu}

CSIR-Forestry Research Institute of Ghana, Kumasi, Ghana

\section{Murray Collins}

School of GeoSciences, University of Edinburgh, Edinburgh, United Kingdom

\section{Gloria D. Djagbletey}

CSIR-Forestry Research Institute of Ghana, Kumasi, Ghana

\section{Koos den Hartogh}

Plant Ecology and Nature Conservation group, Wageningen University, The Netherlands

\section{Jon Lloyd}

Department of Life Sciences, Imperial College London, United Kingdom

\section{Hamza Issifu}

Department of Forestry and Forest Resources Management, University for Development Studies, Tamale, Ghana

Thomas A.J. Janssen Department of Earth Sciences, Vrije Universiteit, Amsterdam, The Netherlands

\section{Frank van Langevelde}

Wildlife Ecology and Conservation group, Wageningen University, The Netherlands

Vincent Logah, Department of Crop and Soil Sciences, Kwame Nkrumah University of Science and Technology, Kumasi, Ghana 
Affiliations of co-authors

\section{Jose A. Medina-Vega}

Forest Ecology and Forest Management group, Wageningen University, The Netherlands

\section{Edward T.A. Mitchard}

School of GeoSciences, University of Edinburgh, Edinburgh, United Kingdom

\section{Imma Oliveras}

School of Geography and the Environment, University of Oxford. United Kingdom

\section{Laurianne Ollivier}

Plant Ecology and Nature Conservation group, Wageningen University, The Netherlands

\section{Elmar M. Veenendaal}

Plant Ecology and Nature Conservation group, Wageningen University, The Netherlands

\section{Philippine Vergeer}

Plant Ecology and Nature Conservation group, Wageningen University, The Netherlands

\section{Lana J. de Vries}

Plant Ecology and Nature Conservation group, Wageningen University, The Netherlands 


\section{Colophon:}

This PhD was funded by the EU KP7 GEOCARBON project (contract number 283080) and Wageningen University \& Research. Wageningen University \& Research financed the printing of this thesis.

\section{Thesis cover designed by}

José van Paassen, Plant Ecology and Nature Conservation Group, Wageningen University \& Research

\section{Thesis printed by}

ProefschriftMaken, the Netherlands 
